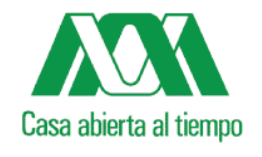

\begin{tabular}{c} 
Universidad Autónoma Metropolitana \\
Unidad Iztapalapa \\
\hline
\end{tabular}

División de Ciencias Sociales y Humanidades

Departamento de Sociología

Posgrado en Estudios Sociales

Línea de Estudios Laborales

\title{
LA DINÁMICA LABORAL Y FAMILIAR DE LAS TRABAJADORAS SUBCONTRATADAS A DOMICILIO EN TEHUACÁN, PUEBLA.
}

Tesis que presenta:

Lourdes Nancy Martínez Márquez

206381406

\begin{abstract}
Para obtener el grado de Maestra en Estudios Sociales en
\end{abstract} la línea de Estudios Laborales

Directora de Tesis

Dra. Rocío Guadarrama Olivera

10 de diciembre de 2009

nancydriver19@yahoo.com.mx

nan31.nmm@gmail.com 


\section{INDICE}

INTRODUCCIÓN

\section{CAPÍTULO 1 \\ SUBCONTRATACIÓN, TRABAJO A DOMICILIO Y VIDA FAMILIAR}

Introducción

1. Aspectos que impulsaron la subcontratación actual $\quad 13$

1.1 La subcontratación. Un concepto en construcción.

1.2 El proceso de subcontratación en la industria de la confección de ropa. 25

2. Los estudios sobre el trabajo a domicilio en México. $\quad 27$

2. 1 El trabajo a domicilio subcontratado. $\quad 36$

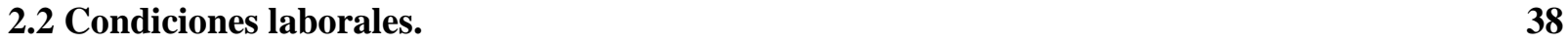

3. La simultaneidad del trabajo femenino: tiempos-espacios reproductivo y productivo. 41

3.1 Las relaciones entre producción-reproducción. 44

3.2 Los estudios más recientes en España. Finales de los 90 y principios del 2000.

3.3 Los debates en México y América Latina $\quad 53$

$\begin{array}{lr}\text { Conclusiones } & 57\end{array}$

Introducción $\quad 59$

1.1 El proceso de instalación de las maquilas en territorio mexicano. $\quad 60$

$\begin{array}{ll}\text { 1.2 Posturas y debates en torno a las maquilas } & 64\end{array}$

2. Encadenamiento global en el sector de la industria de la confección 66

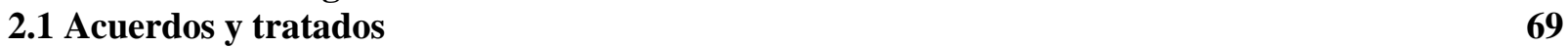

2.2 La relocalización de la industria de confección de ropa en México.

3. La industria de la confección en Puebla. $\quad 74$

3.1Aspectos Generales $\quad \mathbf{7 4}$

3.2 Desarrollo económico de la industria de confección en Puebla. $\quad 75$

4. Tehuacán: Aspectos generales. $\quad 83$

4.1 La maquila de confección de ropa en Tehuacán, Puebla. $\quad 85$

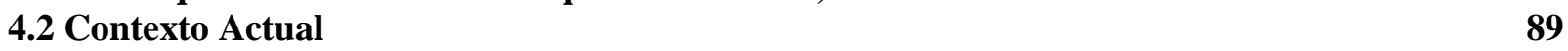

$\begin{array}{lr}\text { Conclusiones } & 93\end{array}$

\section{CAPÍTULO III \\ LAS TRAYECTORIAS LABORALES DE LAS DESHEBRADORAS SUBCONTRATADAS A DOMICILIO EN TEHUACÁN, PUEBLA.}

Introducción

1. Consideraciones metodológicas. $\quad 96$

$\begin{array}{lr}1.1 \text { Instrumentos de investigación } & 98\end{array}$

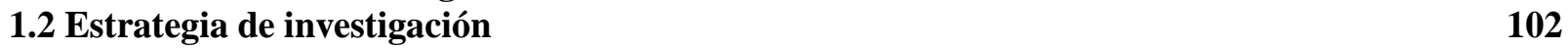

$\begin{array}{ll}1.3 \text { Construyendo la muestra } & 105\end{array}$

2. Breve recorrido por el desarrollo de la industria maquiladora en México $\quad 107$

2.1 Recorrido por el desarrollo de la industria de la confección en Tehuacán, Puebla. $\quad 109$ 
3. El trabajo subcontratado a domicilio en Tehuacán, Puebla.

\section{CAPÍTULO 4}

LA DINÁMICA LABORAL Y FAMILIAR EN LOS TALLERES DE DESHEBRADO

Introducción

1. El Relato Biográfico.

2. Las mujeres del deshebrado a Domicilio

3. Analizando los relatos

4. La formación del taller subcontratado a domicilio: El Autoempleo Precario.

5. El mundo de lo productivo en el espacio doméstico

6. La volatidad y vulnerabilidad del trabajo a domicilio

7. Simultaneidad del trabajo: el mundo de la familia y del trabajo en un mismo espacio.

\section{ANEXOS}

Anexo 1

Instrumentos para la recolección de la información

Encuesta

Guía de entrevista

Anexo 2

Cuadros de análisis del capítulo 3 


\section{INTRODUCCIÓN}

Las sucesivas crisis económicas de finales de los setenta y principios de los ochenta derivaron en cambios importantes en el sistema económico, lo que caracterizó las transformaciones en el mundo del trabajo. Los programas de ajuste estructural se plantearon como salida para afrontar dicha crisis, mientras que la reestructuración económica en México y América Latina eran una realidad. Estas modificaciones tuvieron su efecto en la lógica de las empresas y en los procesos productivos. Temas como la globalización se hicieron recurrentes, al igual que las cadenas globales de producción, dejando atrás al modelo económico proteccionista y dando paso al modelo exportador.

La conformación de un mercado internacional con fluctuaciones constantes y la fuerte rivalidad empresarial para la conquista de nuevos nichos, hizo imperiosa dentro de las estrategias empresariales, la disminución de los costos de producción y la relocalización productiva. Los empresarios se apoyaron en la flexibilidad laboral para externalizar hacia otras empresas o personas parte de los procesos productivos. Esta práctica propició una desprotección constante de los derechos laborales, es decir, entre la empresa y los trabajadores aparece la figura del "intermediario", quien no asumía responsabilidades laborales con el trabajador. Esto deterioró las condiciones de trabajo por las que se había luchado décadas atrás.

El Estado ha sostenido una política de desregulación macroeconómica y del mercado de trabajo, junto con políticas antisindicales que, en conjunto, generaron condiciones favorables para las más diversas formas de subcontratación laboral, desprovistas todas de regulación básica que brinde protección a los trabajadores y las trabajadoras. (Iranzo y De Paula, 2006).

Es bajo este marco social y económico, que ocurre un giro en los patrones culturales, específicamente el del modelo de hombre proveedor exclusivo. A consecuencia del deterioro de su salario y condiciones laborales, los hombres ya no podían solventar solos el gasto familiar, lo que originó dos fenómenos importantes. Por un lado, las mujeres se integraron de manera masiva al mercado de trabajo en actividades estereotipadas como femeninas, entre las que se encontraban el trabajo doméstico remunerado, educación, salud, etc., casi siempre 
en posiciones de menor prestigio y con menores remuneraciones en relación con los hombres. Estos cambios no implicaron una redefinición de los roles tradicionalmente femeninos, sino que el trabajo productivo se sumaba a las labores domésticas.

Por otro lado, en el país tras haber concluido el Programa de Braceros, las maquiladoras se instalaron en la frontera norte como parte de la nueva política económica para disminuir el desempleo y aminorar los efectos de la crisis. Se instrumentaron programas de impulso a la industria, como el Programa de Fomento a la Industria Maquiladora de Exportación 19831988 y el Programa Nacional de Fomento a la Industria y el Comercio Exterior. (De la O, 2001).

Estos aspectos convergen en un contexto en el que la crisis empuja a un conjunto de mujeres a ingresar al trabajo remunerado, donde las maquilas son vistas como un paliativo al creciente desempleo. De estas mujeres, un número importante eran pobres y con bajos niveles de educación, muchas de ellas sólo buscaban contribuir al gasto familiar a través de su incorporación al mercado laboral, predominando el autoempleo o en diversas ramas del sector terciario y secundario, como las industrias ensambladoras de manufacturas nacionales y de exportación, en nuestro caso la maquila de confección de ropa.

En 1994 con la firma del TLCAN entre EE.UU, Canadá y México, las maquilas se extienden al Centro y Sureste del país, aprovechando la mano de obra disponible desplazada de ocupaciones como la agricultura y donde la presencia de indígenas es muy importante. A partir de la firma de este nuevo tratado, la industria de la confección de ropa recibe el impulso más importante de su historia. La inserción de esta industria a la economía global, a través de un proceso de subcontratación internacional, generó un importante dinamismo en el empleo, los productos y las exportaciones del sector en la economía, llegando a representar la cuarta actividad manufacturera en importancia y la primera por su participación en la generación de empleos. En 1994 se convirtió en una fuente de divisas de gran valor al convertirse en la segunda rama industrial con mayor exportación.

México se colocó como el principal productor de prendas de vestir hacia nuestro vecino del norte, hasta que en el 2001 en los Estados Unidos comienza una desaceleración económica 
que obligó a realizar procesos de ajuste y recomposición. Una consecuencia será la pérdida de su posición como primer exportador, debido en gran medida a que México no responde ante la contracción del mercado norteamericano. Para el año 2002, la República Popular China se convierte en el primer productor de prendas de vestir ya que lograron desarrollar el "paquete completo", alcanzando mayor competitividad.

Hoy día, la industria de confección en México vive una verdadera crisis, ya que las firmas estadounidenses buscaron otros países como los centroamericanos que les ofrecieran mano de obra más barata. Aunado a esto, México no fue capaz de desarrollar áreas de suma importancia como el diseño y la comercialización. En este contexto económico, normativo y social se enmarca la subcontratación laboral en México, particularmente bajo la forma de trabajo subcontratado a domicilio. Esta antigua forma de producción fue revitalizada por los empresarios, a costa de la producción intensiva de los trabajadores, en su mayoría mujeres. (Alonso, 1988). Aprovechando su carácter informal se disminuían aún más los costos de producción, por lo que hoy más que nunca se recurre a su uso.

Paralelamente surgen nuevas formas de trabajo a domicilio, nuevos fenómenos que deben ser estudiados para comprender cabalmente los efectos de la crisis y la recomposición del mercado mundial en este sector exportador. Sobre todo, en regiones donde se acude a este tipo de trabajo de manera extensiva bajo nuevas modalidades como las del Valle de Tehuacán. En esta región en las que han proliferado talleres insertos en el espacio doméstico, que son jefaturados por mujeres, las que a su vez subcontratan a otras mujeres para que realicen distintas tareas dentro del taller o desde su propia casa. Son los cambios en el proceso mismo de subcontratación, que se subdivide aún más en el espacio doméstico, lo que hace que su estudio sea relevante en la actualidad.

Este es el marco bajo el cual se desarrolló la presente investigación, la cual buscó indagar el trabajo femenino subcontratado a domicilio en la industria de la confección de ropa en Tehuacán, Puebla, en el nuevo contexto de mundialización de los mercados y de las cadenas globales de producción. Asimismo, se consideró que el caso de la industria de confección de ropa es un claro ejemplo de este proceso, en el que el trabajo femenino juega un papel de primera importancia, principalmente en el último eslabón de esta cadena productiva. 
Son dos las razones principales para estudiar a las mujeres del trabajo subcontratado a domicilio en Tehuacán, Puebla:

La primera, relacionada con que estas mujeres son su principal fuerza de trabajo. Se trata de un trabajo que se desarrolla desde el ámbito privado de sus casas, en donde se empalman las actividades productivas y reproductivas en el tiempo y espacio. Estos talleres, que aparentemente funcionan de manera independiente de la maquila formal, en realidad son parte integral de ésta, como un brazo productor de la misma, en condiciones de asalariamiento encubierto en el espacio doméstico. A su vez, este espacio se transforma radicalmente, con la integración de prácticamente todos los miembros de la familia, desde los hijos e hijas de las trabajadoras, hasta los abuelos, pero de manera no remunerada. Se trata de una cadena de explotación poco explorada.

La segunda, tiene que ver con la escasez de investigaciones que analicen de manera meticulosa las redes de subcontratación laboral, tejidas desde estos talleres domiciliarios. Organizados en su mayoría por mujeres, que cuentan con experiencia previa en la maquila formal, y que encontraron este trabajo como un nicho disponible para emplearse y resolver aspectos que tienen que ver, sobre todo, con su mundo familiar.

Hasta la fecha, gran parte de las investigaciones que refieren al trabajo a domicilio se concentran, en su mayoría, en la descripción del funcionamiento de los talleres (Alonso: 1988a; 1988b; 1991; 1991b), el impacto del trabajo a domicilio en zonas rurales y en su población indígena (Arias, 1998); también se toman en cuenta, algunos aspectos de la vida familiar de las trabajadoras (Treviño, 1988), y algunos estudios, retoman el enfoque de género y ciertos aspectos de su trabajo productivo y reproductivo. (Benería y Roldan, 1992).

Consideramos, por lo tanto, que los estudios sobre el tema han dejado huecos importantes que esta investigación, en parte, se propone llenar. Por esta razón asumimos los siguientes puntos como propósitos de la presente investigación, pues consideramos que han sido poco explorados: 
Incorporar y enfatizar, el proceso de subcontratación laboral dentro de los talleres domiciliarios, ya que toma formas variadas $\mathrm{y}$ arreglos diferenciados entre las trabajadoras, aspecto poco explorado en estudios anteriores.

Acercarnos al trabajo domiciliario desde la experiencia de las personas que laboran en estos lugares, así como destacar los efectos globales del trabajo maquilador en una localidad como la de Tehuacán, conociendo, desde este caso, la dialéctica entre lo global y lo local, y la dinámica de este proceso.

Explorar quiénes son las mujeres que trabajan a domicilio, con qué tipo de trayectoria laboral cuentan y cómo construyen sus relaciones laborales actuales, a partir de las redes de subcontratación. Estas redes que se tejen en torno a un trabajo informal como es el domiciliario, sin límites claros entre lo público y lo privado, entre lo productivo y lo reproductivo, entre relaciones familiares, vecinales y de amistad. Estas relaciones se encuentran encimadas, a pesar de esto los talleres se sostienen y hacen posible su existencia.

\section{Ejes teóricos de análisis}

Vistos estos propósitos de investigación, se distinguen tres ejes teóricos principales que giran, en torno a la idea de analizar el trabajo femenino subcontratado a domicilio y su dinámica familiar y laboral, los cuales se señalan a continuación:

1. Revisar los principales planteamientos sobre la subcontratación, que darán luz sobre las implicaciones sociales, laborales y legales para las trabajadoras domiciliaras, subcontratadas por empresas maquiladoras que forman parte de la cadena global de confección de ropa, con el objetivo primordial de reducir los costos de producción.

En esta revisión se discuten las dificultades en la construcción de este concepto derivadas de la diversidad de aspectos positivos (traslado de tecnología, por ejemplo), negativos (ilegalidad, precarización del trabajo) y formas (que se desarrollan dentro y fuera de las empresas) vinculadas a la subcontratación. De esta manera, se considera que existen puntos medulares que definen la subcontratación del trabajo domiciliario como un trabajo dependiente y subordinado a los procesos productivos de la fábrica, constituyéndose en una 
forma de asalariamiento encubierto. Esta idea es central en este eje de análisis.

\section{Discusión sobre el concepto de trabajo a domicilio y sus principales características.}

Esto con el objetivo de resaltar las líneas de investigación que no se ha profundizado, y que son de interés en esta investigación. Entre otras, se hallan los estudios sobre las redes de subcontratación que se tejen en torno a los talleres domiciliarios, aspecto que se hace más relevante cuando este tipo de trabajo está vinculado con las cadenas globales de producción, sello que le brinda un carácter particular. Además de indagar en cómo se construyen las capacidades de liderazgo en un contexto donde las mujeres son las principales organizadoras del trabajo productivo en los talleres. Estos aspectos imprimen un carácter original a la investigación.

\section{Discusión sobre la simultaneidad laboral del trabajo productivo y reproductivo en el} tiempo y espacio. Debido a que el trabajo a domicilio subcontratado se desenvuelve dentro del ámbito privado de su casa, es que sus efectos más importantes remiten al espacio doméstico y al tiempo familiar de las trabajadoras, cambiando y reestructurando su espacio y dinámica familiar. De esta manera se produce un empalme de actividades productivas y reproductivas, donde no existe una definición clara de los límites de lo reproductivo/productivo y de lo público/privado. Las fronteras se diluyen, los tiempos y espacios se mezclan en una clara contradicción de dos lógicas diferentes. Es precisamente este fenómeno uno de los ejes centrales en la investigación. Para desarrollarlo, se retomaron los enfoques de la doble presencia propuestos por teóricos de la vida cotidiana, geografía feminista y "conciliación". Estos planteamientos dotaron de elementos suficientes para explicar el fenómeno de la simultaneidad, problematizados desde un nivel micro social. Al poner el acento en este nivel, se retoma la experiencia de las trabajadoras, interés central de esta investigación.

En consecuencia, la subcontratación, el trabajo a domicilio y la simultaneidad del trabajo productivo y reproductivo, son planteados como ejes teóricos de análisis para la investigación.

El enfoque teórico de la subcontratación, desde los ángulos antes expuestos, puso en 
evidencia la dificultad metodológica de construir mediaciones entre los niveles de análisis macro y micro. En el nivel macro, se analizaron las cadenas globales de producción y la subcontratación laboral; entre este nivel y el micro, se distinguió un nivel meso, en el que la familia juega el papel de mediador entre las grandes estructuras y el individuo; y finalmente, en el nivel micro se recuperó la experiencia del sujeto para reconstruir las redes de subcontratación a domicilio, su dinámica laboral y familiar en un mismo espacio.

\section{Contexto de la investigación}

La investigación tuvo lugar en la ciudad de Tehuacán, Puebla, debido a su contexto e historia significativas, primero en relación con la instalación de la industria textil y más recientemente de la industria de la confección vinculada a la exportación. Sus antecedentes apuntan a 1971 y 1973, cuando se instalaron las primeras maquiladoras enfocadas al mercado interno y a la elaboración de marcas propias.

El desarrollo de la maquila de confección se vio favorecida por la abundante mano de obra desocupada por la agricultura y la industria refresquera, después de entrar en crisis años atrás. Con ello, la mano de obra se refugió en la maquila de confección, tomando un lugar fundamental en la región. Más tarde, en 1989 se promovió el Decreto sobre Maquiladoras, asentándose un complejo industrial de 80, empleando a 8,000 trabajadores con el apoyo de programas de exportación. En 1995, la maquila se expande al resto del estado de Puebla, llegando hasta la Sierra Negra. (Juárez, 2004).

De manera particular, Tehuacán se ha constituido como una región importante en la producción de prendas de vestir, llegando a ser considerada como la capital de los "blue jeans" propiciando la migración del campo a la ciudad. A mediados de los noventa se desarrolló el esquema de subcontratación, eje de nuestro estudio, en el que se contrataron establecimientos independientes administrativamente, de los grandes grupos y flexibles para desarrollar cualquier subproceso. Esta fragmentación de la producción posibilitó el desarrollo de toda una red de subcontratación, paralela a las filiales de las transnacionales, en una triangulación entre empresas productoras y exportadoras. La abundante mano de obra, en su mayoría mujeres, favoreció este tipo de industria, las cuales buscaban trabajar para contribuir 
al raquítico salario de sus esposos, mermados por la crisis económica. Insertándose a la cadena de producción global de ropa vía el trabajo a domicilio subcontratado.

Actualmente, la industria de la confección en Tehuacán atraviesa por una crisis que ha originado serios problemas económicos y sociales debido al cierre de empresas que va en aumento, a la par que el desempleo. Esta situación ha traído consigo, tal como señala Morales (2009), que el 80\% de las maquiladoras de prendas de vestir de la región subcontrate talleres de costura con el fin de ahorrarse costos de producción. Por ello, el trabajo a domicilio toma un papel relevante y significativo, ya que hoy, más que nunca, se recurre a su uso como una forma de solventar la crisis.

Con el fin de explorar este contexto se elaboraron algunas preguntas guía, éstas fueron transformándose en la medida en que se conoció de cerca el fenómeno.

1. ¿Cómo se construyen y en qué consisten las redes de subcontratación que vinculan las fábricas y los talleres a domicilio a lo largo de la cadena global de confección de ropa en un contexto local como el de Tehuacán, Puebla?

2. ¿Cómo se organiza el trabajo en estos talleres y qué papel juegan las mujeres en este proceso de intermediación entre la fábrica y el espacio doméstico?

3. ¿Qué efectos produce el empalme de la vida laboral y familiar en la vida cotidiana de las mujeres trabajadoras y en su construcción como sujetos sociales?

El trabajo se llevó a cabo con mujeres que ejercen un liderazgo en su comunidad como organizadoras principales de un trabajo informal y precario como es el domiciliario. Para esta investigación se partió del supuesto de que su trayectoria laboral, en su mayoría en la maquila formal y de exportación, las dotó de los conocimientos necesarios para desempeñar estas tareas. Esta experiencia y las relaciones que se desprenden de su trayectoria laboral, podrían ser la base para la creación de sus propios talleres, al mismo tiempo que estos surgen impulsados por las circunstancias del mercado y de la crisis de las empresas maquiladoras. Es decir, se trata de una convergencia de situaciones y es precisamente en este contexto, que el interés estuvo centrado en cómo se construyen ciertas capacidades de liderazgo en las jefas de los talleres. 
Esto condujo a indagar sobre los factores que las llevaron a trabajar a domicilio. También se consideró importante retomar los relatos sobre la historia de su trabajo y dar voz a estas mujeres, para que narraran desde su experiencia, la manera en que enfrentan los altibajos de una industria en crisis, que tiene como sello particular la inestabilidad.

\section{Estrategia metodológica}

Con el propósito de dar cuenta del trabajo femenino subcontratado a domicilio desde la experiencia de vida y de trabajo, se puso especial énfasis en el enfoque cualitativo del problema, utilizando el relato biográfico como método de investigación. A través de esta metodología se pretendió conocer los aspectos fundamentales de su vida laboral y familiar, a su vez reconstruir los hilos más finos de las cadenas globales de este sector.

La fuente de información principal ha sido el testimonio de las mujeres, donde resaltaron los aspectos significativos sobre su trabajo y su vida cotidiana. A partir de estos testimonios se dio cuenta del modo en que enfrentan una situación contradictoria de vulnerabilidad, pues están sujetas a los altibajos del mercado maquilador, y por el otro, el cambio que significa, para algunas mujeres, este espacio en términos de la construcción de su propia subjetividad como mujeres y trabajadoras.

Es importante no dejar de considerar que el trabajo subcontratado a domicilio se caracteriza por su clandestinidad e informalidad que se desarrolla en el espacio privado y familiar de las trabajadoras, por lo que el acceso a los talleres es difícil. Esta investigación pudo desarrollarse por medio de la intermediación de la Comisión de Derechos Humanos y Laborales del Valle de Tehuacán (CDHyLVT), organización que ha jugado un papel fundamental en la defensa de los derechos laborales de las y los trabajadores de la maquila. Gracias a ellos el acercamiento con las trabajadoras pudo ser posible, aunque no sin complicaciones. En el proceso de construcción de esta relación se dio el cierre de algunas fábricas y talleres producido por la crisis y la búsqueda incesante de mujeres que quisieran compartir su experiencia, pero que debido a la naturaleza informal las trabajadoras se mostraban renuentes a ser entrevistadas. 
Esta situación de mayor vulnerabilidad en el trabajo de las mujeres y sus familias obligó a readecuar la estrategia de investigación y optar por una observación del proceso menos intrusiva. Lo que significó que cuando no se encontraron las posibilidades para realizar entrevistas, se siguió el procedimiento de observar y participar en el trabajo de los talleres, hasta donde fue posible, con el objetivo de ganar la confianza de las trabajadoras y compartir su vida cotidiana. En ese proceso, limitado por el tiempo para realizar el trabajo de tesis, se conocieron de primera mano las implicaciones de este trabajo, desde las duras jornadas, las presiones de los intermediarios y familiares, así como las vivencias, sentimientos y formas en que día a día las mujeres tratan de "conciliar" su vida familiar y laboral en la práctica, algunas veces en conflicto y otras en armonía. Aspectos que sólo son posibles de conocer desde el papel discreto de observadora.

Son estos factores los que fueron enriqueciendo el estudio, al mismo tiempo que se fue generando un ambiente de confianza por parte de las trabajadoras para que accedieran a compartir su experiencia y relatar su historia de vida laboral y familiar.

En esta investigación, también fue de interés conocer las características sociodemográficas de las mujeres que trabajan en los talleres, de las que se sabe poco debido al carácter clandestino de su actividad, así como indagar en sus trayectorias laborales para poder explicar cómo es que llegan a convertirse en jefas o trabajadoras de los talleres. Para ello, se elaboró un cuestionario que fue aplicado, cuando fue posible, a algunas trabajadoras.

A partir de la observación participante, la entrevista en profundidad y el cuestionario fue posible dar cuenta de mi objeto de investigación, de tal manera que pudiera cubrir cada uno de los objetivos propuestos. A lo largo de este texto profundizamos en la estrategia metodológica y en las técnicas empleadas. 
La estructura del trabajo fue ordenada en cuatro capítulos y conclusiones. En el primero, se exponen las categorías teóricas que guían esta investigación, se definen las dimensiones más importantes de análisis y se exponen los debates que abordan la subcontratación laboral, el trabajo a domicilio y la simultaneidad del trabajo productivo y reproductivo.

En el segundo capítulo se detalla el contexto en relación con las maquilas, se presentan los debates que abordan las diversas discusiones sobre el papel de ésta en el desarrollo económico y social de los países en donde se asientan. A través de esto buscamos dar cuenta de la dinámica general de la industria maquiladora y especialmente de sus efectos en los espacios locales como Tehuacán. En ese sentido se presentan los rasgos más importantes de la maquila en el municipio y algunas características generales del Estado de Puebla.

En el tercer capítulo se presenta la estrategia metodológica y la forma como se elaboró la investigación empírica, se exponen las particularidades del trabajo de campo y los resultados encontrados a partir de la información recabada por el cuestionario sobre características sociodemográficas y trayectorias laborales de las mujeres trabajadoras a domicilio en Tehuacán.

En el último capítulo se expone la forma en que se realizaron las entrevistas en profundidad, además de los principales hallazgos encontrados en esta investigación. Finalmente, se exponen las conclusiones generales. 


\section{CAPÍTULO I}

\section{SUBCONTRATACIÓN, TRABAJO A DOMICILIO Y VIDA FAMILIAR}

\section{Introducción}

El objetivo de la presente investigación es abordar la problemática del trabajo a domicilio subcontratado. Con dicho propósito, se expone a lo largo de este capítulo una revisión de las principales líneas teóricas para este estudio, mismas que han quedado divididas de la siguiente manera: 1) la subcontratación laboral; 2) el trabajo a domicilio; y 3) la simultaneidad del trabajo productivo y reproductivo. Este tercer apartado, ha quedado dividido en tres subapartados.

En el primer apartado, doy cuenta del fenómeno de la subcontratación laboral, en particular, la forma como se expresa en la industria de la confección. Es decir, las múltiples redes y variadas formas de la industria, según el ciclo económico, definidas por el mercado en términos de su amplitud, diversificación, entre otros. Me interesa indagar, específicamente, en el último eslabón de la cadena productiva: la subcontratación femenina a domicilio. Desde la perspectiva del encadenamiento de empresas con mujeres subcontratadas para trabajar desde sus hogares, cosa que permite observar la relación del contexto global, local y doméstico. Para ello, expondré los principales planteamientos teóricos sobre la subcontratación.

A lo largo del segundo apartado, reviso las ideas planteadas por los principales estudiosos del tema de trabajo a domicilio en nuestro país. Me intereso principalmente, en las condiciones laborales que se viven en este tipo de trabajo, en las relaciones sociales, los procesos, las contradicciones y la organización laboral. Sin perder de vista el hecho de que este tipo de relación laboral se encuentra inserto dentro del mundo reproductivo, donde las mujeres se enfrentan a fenómenos que no experimentarían en la fábrica.

Finalmente, en el último apartado, se presenta la discusión sobre las consecuencias del trabajo a domicilio subcontratado en el espacio doméstico. Me intereso, sobre todo, en el 
tema de la "conciliación" entre las actividades productivas y las reproductivas, y en su simultaneidad.

Con el propósito de alcanzar los objetivos anteriormente expuestos, se resumieron los debates teóricos que a lo largo del siglo XX ocuparon a estudiosas y estudiosos del trabajo femenino de las principales escuelas de Europa ${ }^{1}$ y Latinoamérica. Pretendo sintetizar el amplio debate sobre la relación entre trabajo productivo y reproductivo, para luego entonces analizar los nuevos planteamientos, sobre la "conciliación" del trabajo productivo y vida cotidiana, desarrollados en Europa. Es sobre todo esta última, la discusión que me interesa abordar, para analizar los problemas del trabajo a domicilio subcontratado en contextos globalizados.

\section{Aspectos que impulsaron la subcontratación actual}

Los aspectos que impulsaron el fenómeno de la subcontratación tienen que ver con cambios normativos, económicos y sociales que se dieron a partir de la reestructuración económica en la década de los ochenta. La normatividad es un primer aspecto, de suma relevancia debido a que, ha incidido en la masificación de la subcontratación en la actualidad, pues según Díaz y Yáñez (1998) han existido: “...cambios estructurales precedentes que implicaron tanto modificaciones del cuerpo normativo legal como la drástica apertura comercial y sus consecuencias sobre el sector [del vestuario]” (Díaz y Yáñez, 1998: 6). Estos cambios estructurales precedentes, dieron como resultado un vacío en la normatividad, cosa que en gran medida permite que las empresas recurran a la subcontratación de talleres y trabajadoras a domicilio, imponiendo sus propias normas y obligando a las trabajadoras a emplearse en condiciones de total desprotección.

Estas alteraciones de la normativa legal se caracterizaron por ser funcionales al modelo económico implementado, vale decir, se expresaron en la forma de incentivos para que las

\footnotetext{
${ }^{1}$ Entre las que se destacan: a) Escuela de Cambridge, b) Escuela Italiana, c) Escuela Francesa y d) Escuela Española.
} 
empresas pudieran mantenerse y consolidarse en mercados cada vez más abiertos sobre la base de la limitación de los derechos laborales y la precarización del empleo.

Un ejemplo del efecto de estas alteraciones ocurre en la industria de la confección, que hoy día está caracterizada por la presencia de firmas dominantes, que para reducir costos concentran sus actividades crecientemente, en la esfera de la comercialización, el diseño y modelaje, externalizando gran parte o el total de la fabricación de las prendas de vestir. Sustituyendo así, la producción interna por la producción subcontratada hacia talleres, hacia el exterior del país o por la compra y reventa. (Díaz y Yánez, 1998: 6)

La flexibilidad laboral también sirve como promotora de la subcontratación, pues subyace y enmarca la reciente intensificación del trabajo a domicilio. Concretamente, se relaciona con una de las distinciones clásicas de la flexibilidad del trabajo, vale decir la flexibilidad externa o numérica, que remite “...al ajuste flexible de la cantidad de fuerza de trabajo según las necesidades de la producción y del mercado." (De la Garza, 1998:203, en Iranzo y Leite, 2006: 268). En la actualidad, se busca el ajuste de la fuerza de trabajo a través de la subcontratación.

Por otro lado, Consuelo Iranzo y Paula Leite (2006) plantean que la subcontratación laboral no tiene un carácter pasajero, debido a que responde a las condiciones impuestas por el nuevo momento de la acumulación. En este sentido, los factores que mueven la implantación de la subcontratación como una estrategia inherente a ésta pueden sintetizarse en los siguientes aspectos:

- La conformación de un mercado internacional con fluctuaciones constantes y la fuerte rivalidad empresarial para conquistar nuevos nichos, hizo imperativo dentro de las estrategias empresariales la disminución de los costos.

- La relocalización productiva en la búsqueda de los más bajos costos. "Hay así una asociación que no debe dejarse de lado entre globalización y esquemas de externalización-descentralización de procesos productivos."

- La acción del Estado a través de la desregulación macroeconómica y del mercado de trabajo, junto con sus políticas antisindicales, ha jugado un papel impulsor en el uso de las más diferentes formas de subcontratación laboral. (Iranzo y De Paula, 2006: 269-270) 
En este contexto económico, normativo y social es que se enmarca la subcontratación laboral en la actualidad, particularmente el trabajo subcontratado a domicilio, que bajo estos términos no sólo representa un remanente del pasado, sino que forma parte del trabajo que promueve la acumulación capitalista de grandes empresas, pero que guarda un rasgo muy importante, el de la "invisibilidad".

\subsection{La subcontratación. Un concepto en construcción.}

Autores como José A. Alonso (2004), señalan que la subcontratación laboral ha formado parte del sistema capitalista casi desde los inicios europeos en el siglo XVI. Sin embargo, igual que el capitalismo el fenómeno de la subcontratación también ha evolucionado, volviéndose cada vez más complejo. Actualmente, su estudio corresponde a las condiciones impuestas por el capitalismo global y en América Latina a los procesos de reestructuración y flexibilidad productiva, que guarda rasgos particulares, y en algunos casos, formas que no habían estado presentes en el pasado.

En realidad, se puede observar que coexisten formas tradicionales y formas nuevas de subcontratación laboral (Bronstein, 1999). En la década de los 90, varios estudiosos trabajaron arduamente por ampliar el estudio de sus diversas manifestaciones, al mismo tiempo que intentaban llegar a un consenso sobre el concepto de subcontratación. Esta variedad de planteamientos es lo que presento a continuación.

Arturo Bronstein (1999), señala que la subcontratación laboral no es un fenómeno nuevo, sus primeras formas se observaron en los procesos de intermediación en el suministro de mano de obra en industrias tales como: construcción, trabajos públicos, minería, agricultura, plantaciones y maderera. Bajo formas más recientes, la subcontratación de producción tiene una tradición no menos larga en industrias como la confección o el calzado, a través de la contrata a domicilio. En contraste, la subcontratación de servicios y labores, se han desarrollado más recientemente. (Bronstein, 1999: 9-10). 


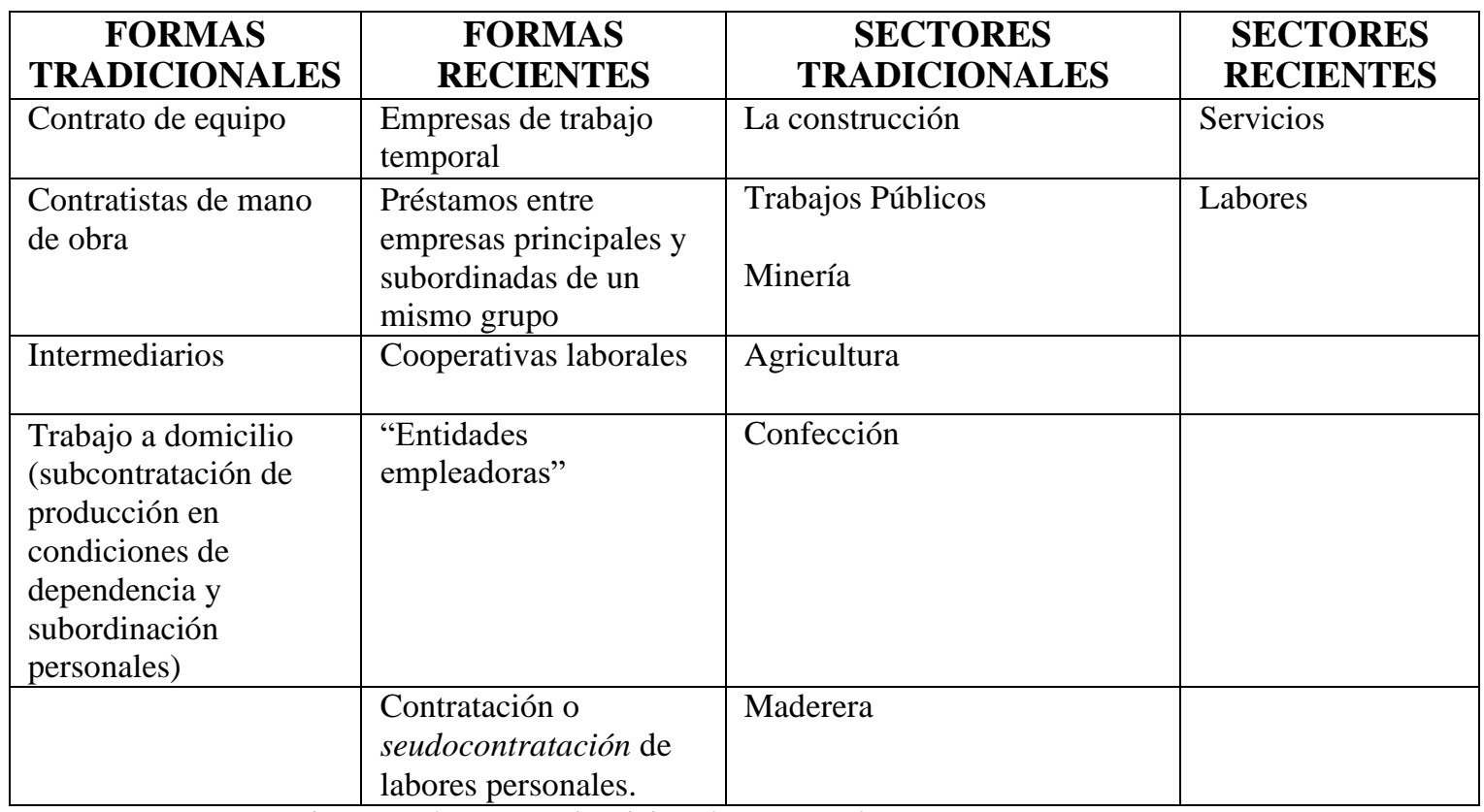

Fuente: Arturo Bronstein “La subcontratación laboral”, Costa Rica, OIT, 1999:24.

En este estudio voy a concentrarme en un sector tradicional, como es el de la industria de la confección, con el objetivo de hacer visibles las distintas formas de subcontratación que subyacen en él, tradicionales y recientes, que conviven al mismo tiempo y que responden a procesos distintos de un mismo sector. Para ello es importante primero desentrañar los principales planteamientos sobre el tema.

Aún no existe un consenso para nombrar este fenómeno, algunos autores lo definen con el nombre de outsourcing, otros externalización o terciarización, mientras que la OIT lo llama trabajo en régimen de subcontratación. Independientemente de cuál sea la manera más adecuada de llamarlo, todos estos términos tienen en común que “...apuntan a actividades que antes se desarrollaban internamente, dentro de la estructura de las empresas y que se externalizan, o sea, pasan a ser realizadas fuera de la empresa, quedando en manos de <<terceros〉>." (Racciatti, 1997 y Watanabe, 1974 en Echeverría y Uribe, 1998: 5)

En 1998 la OIT se reunió en una conferencia para impulsar el reconocimiento internacional de esta modalidad de trabajo, intentando llegar a un consenso con el término de subcontratación. Sin embargo, debido a que se le considera una manifestación de la flexibilización de la producción y del empleo, las opiniones sobre el fenómeno se han dividido. Por una parte, se aprecian sus efectos positivos, la promoción de nuevas unidades 
económicas acompañadas de nuevas especialidades y calificaciones; por otra, se hacen ver los efectos negativos: la precarización de las condiciones de trabajo y el empleo. (Bronstein, 1999)

Una de las razones relevantes por las que la OIT no llegó a ningún acuerdo, es la dificultad que implica la diversidad de formas que adopta la subcontratación en cada país y las variaciones en los respectivos marcos institucionales. La otra razón deriva, de la situación económico-laboral por la que atraviesan las distintas regiones y países, especialmente en el empleo y el desempleo. (Echeverría y Uribe, 1998)

Aún con todas estas dificultades, existen algunos aspectos generales que la mayoría de los investigadores toman en cuenta para estudiar la subcontratación laboral, mismos que son resumidos por las sociólogas chilenas Magdalena Echeverría y Verónica Uribe (1998). En su opinión, se destacan:

1. El objeto de subcontratación.

2. La duración: permanente o transitoria.

3. Cercanía y distancia del centro del negocio.

4. Niveles de especialización.

5. El lugar físico: interno o externo.

6. La intermediación.

7. Legalidad e ilegalidad.

8. Sus efectos sobre las relaciones colectivas y las condiciones de trabajo.

Para el primer aspecto, las autoras señalan que existen distintos tipos de subcontratación y que la diferenciación resulta clave en dos sentidos, es necesario distinguir si se trata de subcontratar la “...producción de bienes o la prestación de servicios, por un lado, o si se trata de subcontratar trabajo, específicamente trabajadores, por otro." (Echeverría y Uribe, 1998: 7) 
Asimismo, desde el derecho laboral, Arturo Bronstein añade que, además de estas formas de subcontratación, “...podríamos agregar un número no menos importante de formas mixtas de subcontratación, con dosis variables de las anteriores, siendo evidente que la naturaleza jurídica de cada una de ellas puede llegar a diferir mucho de las otras.” (Bronstein, 1999: 6)

Así, por ejemplo, la subcontratación de la producción de bienes y/o de la prestación de servicios se destaca por tener las siguientes características:

- Se refiere al ámbito de las relaciones que se establecen entre partes o de partidas completas de la producción de bienes o la prestación de determinados servicios que la segunda empresa se compromete a llevar a cabo por su cuenta y riesgo, con sus propios recursos financieros, materiales y humanos.

- Se establece una relación comercial, donde una compra y la otra vende sus servicios.

- Debe cumplir determinadas especificaciones, modalidades, plazos de entrega y por último, definiendo un precio.

- El contratista no se involucra ni en la forma ni en las condiciones en que el vendedor lo realizará. Este último asume autónomamente la tarea. Esta es una característica muy importante para diferenciar el tipo de subcontratación.

- La relación laboral es clara. Se establece entre la empresa "contratista" y sus trabajadores, es decir, la compañía mandante o contratante no forma parte de la relación. La figura del empleador es una e inequívoca: aquél con el cual el trabajador suscribe contrato y de quién pasa a estar bajo subordinación y dependencia. (Echeverría y Uribe, 1998: 7-8)

Por otro lado, la subcontratación de trabajo consiste en que:

- El objeto no es un producto, sino trabajo. Es decir, lo que una empresa contrata con otra, no es la compra de determinados bienes o servicios sino el suministro de trabajo, específicamente, de trabajadores.

- El usuario compra además de la oportunidad del encuentro con el contratado la administración, por parte del contratista, de la relación laboral.

- El colocador se ubica en el medio de la relación, haciendo de suministrador de mano de obra frente al contratante y de empleador frente al trabajador.

- El colocador fija y paga las remuneraciones; paga las horas extraordinarias, las cotizaciones previsionales, las indemnizaciones por fin de contrato y el seguro contra riesgos de accidentes y enfermedades laborales.

- Los trabajadores así contratados pasan a estar bajo dependencia y subordinación del contratante, quien se concentra en el contenido y en la dirección del trabajo, quedando los aspectos formales de la relación a cargo del contratista. (Echeverría y Uribe, 1998: 9) 
A partir, en primera instancia, del objeto que esta guarda podemos distinguir el tipo de subcontratación que nos interesa estudiar. Pero no es ésta la única forma, enumero otras más a continuación:

\section{Según la duración: Permanente o transitoria.}

El factor tiempo determina muchos aspectos de las relaciones y condiciones de trabajo. Es distinto si se trata de una relación de subcontratación de carácter permanente o si se trata de una relación transitoria o esporádica.

\section{La cercanía y distancia del centro del negocio.}

Esta distinción hay que hacerla desde la empresa usuaria o contratante y se refiere a la cercanía o distancia que tengan la producción, el servicio externalizado o la actividad que ejecutan los trabajadores subcontratados, respecto de la actividad central o el giro del negocio de la empresa desde donde se hace el análisis y se define el contrato base o la parte "comitente".

\section{A partir de los niveles de especialización.}

En esta materia las alternativas reales se mueven entre el trabajo simple sin ningún nivel de calificación y los altamente especializados y calificados. (Echeverría y Uribe, 1998)

\section{El lugar físico: Interno o externo.}

Desde el punto de vista de la empresa contratante, la externalización de las actividades puede ser sólo jurídica y realizarse físicamente en los recintos de la empresa, o externalizarse geográficamente. "Sólo se han encontrado formas de subcontratación de la producción o de los servicios que se realicen fuera de los recintos de la empresa contratante, la subcontratación de trabajo tiene hasta el momento sólo una expresión interna." (Echeverría y Uribe, 1998: 13)

En los procesos de montaje de partes o en los que se realizan en etapas autónomas, cada una de las partes o las etapas pueden fabricarse en distintos lugares, como en la industria metalmecánica o en la confección de ropa. En esta última la situación es más compleja, 
debido a que la externalización geográfica va desde la empresa central a los talleres y trabajo a domicilio (Reinecke, 1997).

\section{La intermediación.}

Tanto la subcontratación de la producción como la subcontratación de trabajo realmente existentes pueden funcionar con o sin intermediarios frente a la realización de sus tareas. (Echeverría y Uribe, 1998: 14)

A este respecto, Arturo Bronstein (1999) agrega que la subcontratación laboral comprende la situación particular de que el suministro de mano de obra es posible “...a través de un intermediario, siendo sus formas más tradicionales el contrato de equipo y el enganche por medio de un reclutador [...] el rasgo común es el mantenimiento de un contrato de trabajo formal (y yo agregaría no formal) con el suministrador de mano de obra, al tiempo que se establece una relación de subordinación laboral con la empresa usuaria" (Bronstein, 1999: 6-7) Este rasgo de subordinación es lo que existe detrás de este tipo de relaciones laborales.

Actualmente existen formas sofisticadas de intermediación, un ejemplo de ello son las Agencias de Colocación (AC) que, como señalan autores como Albizu (1997) y Partida (2001), deben de ser entendidas como las negociadoras, encaminadas a proporcionar una colocación dentro del mercado laboral. Es decir, las empresas que buscan un trabajador acuden a las AC para aportar el perfil de la persona que desean contratar y las agencias recogen la petición, dándose a la tarea de conseguir los candidatos idóneos del cliente.

Estas AC juegan un importante papel, al prestar el servicio en otro negocio, pero sus trabajadores permanecen formalmente como empleados de la primera. Por lo tanto, en esta figura la relación habitual directa entre empleador y trabajador se ve intermediada por un tercero, “...Este nuevo invitado en la relación laboral puede ser desde una persona física cualquiera hasta una empresa con alta formalidad. El suministrador vende un servicio que consiste, por un lado, en vincular al trabajador con una empresa que requiere de su quehacer y, por otro, retener para sí la calidad formal de empleador." (Echeverría y Uribe, 1998: 28 en Partida, 2001: 106-107) 


\section{Legalidad e ilegalidad.}

Como se ha señalado, el trabajo en régimen de subcontratación, en cualquiera de sus formas, a pesar de estar tan extendido en el país, prácticamente no está normado. Es más, apenas es mencionado en el Código del Trabajo o en el resto de las leyes laborales.

Por ejemplo, la subcontratación laboral presenta la particularidad de que

“...reviste una apariencia jurídica alejada del Derecho del Trabajo, en la medida en que tiene por objeto la prestación de servicios personales o la realización de labores en beneficio de una empresa usuaria, dentro del marco formal de un contrato civil o comercial. Ciertos contratos también pueden asumir la forma de una subcontratación de producción; el más conocido es el contrato de trabajo a domicilio, que quizás es la única forma de subcontratación de producción a la que numerosos países reconocen naturaleza laboral." (Bronstein, 1999: 7)

La más problemática de las relaciones de subcontratación estudiadas es, la existencia del vínculo de subordinación y dependencia respecto de la persona a la que se le prestan los servicios personales, condición central del contrato de trabajo: "La existencia del vínculo de subordinación y dependencia se infiere de a lo menos los siguientes indicadores: continuidad de los servicios prestados en el lugar de la faena, cumplimiento de un horario de trabajo, supervigilancia en el desempeño de las funciones, obligación de ceñirse a instrucciones impartidas por el empleador, entre otras." (Echeverría y Uribe, 1998: 15)

En la realidad, la nitidez entre lo legal e ilegal se va opacando en la medida en que las relaciones se complejizan, tal como sucede en las relaciones reales de trabajo. Pero, si en la colocación de trabajadores la empresa suministradora pone una cadena de supervisión y control, su figura de mero enganchador y de papel comienza a tomar mayor cuerpo jurídico.

Finalmente, desde el punto de vista de la localización espacial de la subcontratación puede establecerse que, en su versión más alejada del recinto del contratante del trabajo principal como es el trabajo a domicilio, los niveles de legalidad son muy escasos. Lo que allí ocurre, ocurre más bien en el ámbito del mundo doméstico, con bajo cumplimiento real de la normativa laboral, aun cuando muchas cadenas de subcontratación terminen y se realicen en parte importante allí, como el trabajo de confección en la industria textil. (Echeverría y Uribe, 1998) 
8. Efectos de la subcontratación sobre las relaciones colectivas y las condiciones de trabajo.

En primera instancia, la fragmentación de los procesos de trabajo y la atomización de las relaciones laborales fragmenta también, las condiciones básicas de la asociatividad en el trabajo: compartir un espacio, condiciones de trabajo y relaciones laborales entre y con figuras sociales claramente identificables. Todas estas premisas se diluyen en el trabajo bajo régimen de subcontratación. (Echeverría y Uribe, 1998)

En términos de sus condiciones laborales el trabajo subcontratado, como señala Neffa (1985), cuenta con algunas características esenciales como es: la precariedad y la inestabilidad, ya que "El empleador es disociado entre el empleador real y el empleador legal, combinado con la noción de descentralización con la atribución de poder dejar sin efecto el contrato de trabajo." (Neffa, 1985: 101, en Partida, 2001: 109)

Es de destacar el aspecto social y el deterioro del trabajo debido a la precarización del empleo subcontratado, “...el cual se encuentra sujeto al comportamiento del mercado nacional e internacional." (Partida, 2001: 110)

Echeverría y Uribe (1998) señalan que:

"Como tendencia puede establecerse que el nivel de las condiciones de trabajo en los encadenamientos de subcontratación depende de la naturaleza técnica de los procesos productivos o servicios, del nivel de desarrollo económico del sector, del sistema de responsabilidades a lo largo de la cadena que obligue la legislación nacional y del grado efectivo de cumplimiento de estas obligaciones de parte de las empresas. (Echeverría y Uribe 1998: 19)

De hecho, como ya ha sido constatado por numerosos estudios, son las empresas y los trabajadores ubicados en los eslabones más bajos de las cadenas de subcontratación los que suelen tener vínculos laborales débiles y condiciones precarias de trabajo. De esta manera:

"En el caso de la subcontratación de trabajo, en particular del empleo suministrado de carácter permanente, el interés central de la empresa usuaria es reducir los costos laborales y de administración del trabajo, lo que tiende a precarizar el empleo; se hace altamente inestable, el nivel de las remuneraciones tiende a ser menor que el de los trabajadores contratados, así como la protección frente a la seguridad social y laboral." (Echeverría y Uribe, 1998: 19) 
Estos son los rasgos generales y más importantes, desde la perspectiva de este estudio, sobre la subcontratación de trabajo y, aunque en estos aspectos muchas veces no es tan claro poder detectar fácilmente estas características, sí nos sirven de referente para su estudio. Existen varías definiciones sobre subcontratación y esto responde a la diversidad de la que hemos dado cuenta, a continuación, presentaré las más importantes.

Con el propósito de cubrir, tanto la subcontratación de mano de obra como la de tareas o servicios personales, la OIT propone la siguiente definición en donde aspectos como la dependencia y subordinación son centrales:

“... la expresión «trabajo en régimen de subcontratación» designa todo trabajo realizado para una persona física o jurídica (designada como «empresa usuaria») por una persona (designada como «trabajador en régimen de subcontratación»), cuando el trabajo lo realiza el trabajador en régimen de subcontratación personalmente, en condiciones de dependencia o de subordinación efectivas respecto a la empresa usuaria, análogas a las que caracterizan una relación laboral de conformidad con la legislación y la práctica nacionales siempre que el trabajador en régimen de subcontratación no sea empleado de la empresa usuaria. (Bronstein, 1999: 8-9).

Para Echeverría y Uribe (1998), que visualizan la subcontratación más como una relación comercial, el trabajo subcontratado es:

“...aquél en el que se establecen relaciones entre dos empresas (una usuaria u otra de colocación) donde una encarga a otra la producción de etapas, de partes o de partidas completas de la producción de bienes o prestación de determinados servicios, que la segunda empresa se compromete a llevar a cabo por cuenta y riesgo, con recursos financieros propios. En este caso, se establece una relación comercial entre dos unidades económicas, en donde una compra y la otra vende servicios". (Echeverria y Uribe, 1998: 73).

Mientras que para Raquel Partida (2001) la característica principal de la subcontratación está determinada por el hecho de que no son empresa de bienes sino de suministro de trabajo, específicamente de obreros. 
Para fines de este estudio, retomo el planteamiento de Ximena Díaz y Sonia Yáñez (1998) porque, desde mi punto de vista, da cuenta de manera más fiel de la problemática que viven las trabajadoras a domicilio, en la industria de confección de ropa. Dichas autoras señalan que:

"La subcontratación es posible visualizarla como un recorte dentro de un continuo de relaciones entre las empresas y sus proveedores que parten, en principio, todas de la situación en que una empresa solicita a otro productor o prestador de servicios formalmente independiente la realización de una fracción del proceso necesario para la fabricación del bien, de acuerdo a determinadas especificaciones provistos por la primera (la contratista)." (Díaz y Sonia Yáñez 1998: 15).

Resalta del planteamiento anterior, que la subcontratación constituye un "recorte" dentro de un continuo de relaciones que se fijan y trabajan de manera formalmente independiente en la fabricación de un producto, que en la industria de la confección es una característica particular. Cabe agregar, que bajo este contexto no solo se delegan a un intermediario las responsabilidades, en el mejor de los casos, sino que, en el caso de las trabajadoras a domicilio ellas son las que absorben esa responsabilidad y es ahí donde la desprotección se manifiesta ampliamente.

Es debido a la subcontratación que los empresarios y dueños de las empresas pueden desentenderse y delegar responsabilidades, al mismo tiempo que se encubre una forma de asalariamiento, debido a que estas trabajadoras realizan el mismo trabajo que las que se encuentran en la nómina de la empresa, sólo que, de manera externa, sin protección social y en condiciones de precariedad.

Entre los tipos de subcontratación existe uno en particular que promueve el trabajo a domicilio, me refiero a la subcontratación externa, la cual consiste en externalizar parte de la producción de las empresas a talleres establecidos de manera independiente o a las trabajadoras domiciliarias de manera individual. Cuando las empresas se ven sobrepasadas, o en otros casos, se desea reducir los costos de producción y seguridad social, es que deciden "La subcontratación externa [que] incluye: i) los trabajadores a domicilio que no son autónomos y ii) los trabajadores de empresas que trabajan para otra de manera que una de ellas (contratista) encarga a otra (subcontratista) la fabricación de partes o piezas 
o el desarrollo de una operación, siguiendo planos, especificaciones o normas técnicas fijadas por la primera." (Iranzo y De Paula, 2006: 268). Por lo que este tipo de subcontratación busca el ahorro, la reducción de costos y/o, en su caso, de conflictos sindicales.

\subsection{El proceso de subcontratación en la industria de la confección de ropa.}

En este punto me propongo profundizar en el proceso de subcontratación en la industria de confección de ropa y en el trabajo a domicilio que es el objeto de mi investigación.

El proceso de subcontratación varía en algunos aspectos, dependiendo del sector de la economía que se trate y aun dentro de éste, tal como lo señalan Díaz y Yáñez: “Las modalidades que puede adoptar el proceso de subcontratación y la distribución de los beneficios resultantes de la misma no parecen ser igual en todos los casos. De hecho, las cadenas de subcontratación, siendo un fenómeno complejo y multiforme, no son las mismas en los diferentes sectores de la economía ni aún al interior de un mismo sector o subsector." (1998: 15). De la misma manera varía la situación de las trabajadoras ocupadas bajo este régimen de subcontratación.

Las autoras citadas, plantean que “...existe evidencia empírica de una estrecha relación entre las modalidades que asume la fragmentación del proceso productivo, por un lado, y la calidad del empleo que se genera a lo largo de las cadenas de subcontratación, por el otro." (Díaz y Yáñez, 1998: 15). Por lo que estudiar el caso particular del proceso de subcontratación de la industria de la confección, nos lleva a destacar algunos aspectos del proceso para desentrañar no sólo el tipo de fragmentación, sino también la calidad de empleos que se originan para las trabajadoras que se subcontratan.

En términos generales, las cadenas de subcontratación de la industria de confección se destacan por: 
“...la presencia de firmas dominantes que, a fines principalmente de reducir los costos, concentran sus actividades crecientemente en la esfera de la comercialización, el diseño y modelaje, externalizando gran parte o el total de la fabricación de las prendas de vestir, sustituyendo la producción interna por la producción subcontratada hacia talleres, hacia el exterior o por la compra y reventa" (Díaz y Yánez, 1998: 6).

Así entonces, el último eslabón de la cadena estaría formado por el trabajo a domicilio subcontratado. Es en este último eslabón, donde se observa una red aún más fina de subcontratación entre las trabajadoras domiciliarias. Es en este mismo eslabón y, en las redes que genera, en donde me propongo profundizar.

Acorde a lo anterior, conviene definir a los talleres de confección como un eslabón intermedio en las cadenas de producción y comercialización en la industria del vestuario, tal como lo señalan Díaz y Yánez (1998). En este nivel se encuentra un abanico, heterogéneo y multifacético, de talleres que transitan desde pequeños talleres de tipo familiar que funcionan en el hogar de las trabajadoras, hasta fábricas de ropa de mayor tamaño que combinan la producción y comercialización de sus productos con la prestación de servicios a empresas mandantes. (Díaz y Yánez, 1998: 34).

Todos estos aspectos hacen hincapié, en lo complejo que puede llegar a ser el proceso de subcontratación de las cadenas globales de confección, por lo que se requiere de una descripción muy fina, la cual nos proponemos hacer para el caso de Tehuacán, Puebla.

En el caso de este último eslabón, es decir del trabajo a domicilio, los intermediarios juegan un papel de enganchadores, lo que les confiere de manera paradójica un papel central, debido a que intervienen en fases estratégicas del proceso tales como la distribución del trabajo. De esta manera lo apunta Sandra Treviño:

"En lo que respecta a la intermediación, resulta sorprendente la gran cantidad de pasos que se llevan a cabo a lo largo del proceso "gracias" a la acción del intermediario, lo cual lo coloca en una posición estratégica en el desarrollo de la actividad: es el contacto con el exterior, el que conoce el mercado de la materia prima, el que tiene capacidad de traslado, de compra y de pago en efectivo, el enlace entre la trabajadora a domicilio y el taller, el que realiza el control de calidad y, por si fuera poco, el enlace con los comerciantes que venderán el producto final.”. (1988: 592) 
Por lo señalado, será de gran relevancia indagar qué tipo de intermediario existe en el trabajo a domicilio en Tehuacán, con qué características cuenta, qué tan central es su papel en esa localidad, en cuántas fases del proceso interviene, con qué medios realiza su trabajo, en qué condiciones subcontrata, etc.

\section{Los estudios sobre el trabajo a domicilio en México.}

La selección de autores tiene que ver con los temas que cada uno de ellos ha dado cuenta a lo largo de sus análisis. En primer término, José Antonio Alonso, trata aspectos que tienen que ver con el funcionamiento de los talleres a domicilio en un contexto urbanomarginal y periférico. En segundo término, reviso los planteamientos de Patricia Arias quien desde la antropología estudia el impacto del trabajo a domicilio en zonas rurales y en su población indígena. En tercer término, hago un acercamiento a los trabajos de Sandra Treviño Siller, quien se destaca por analizar aspectos de vida cotidiana a mayor profundidad y con un análisis micro. Por último, Lourdes Benería y Martha Roldán con uno de los trabajos pioneros que toma en consideración el enfoque de género y a quienes les interesa destacar la heterogeneidad de actividades que se desarrollan a domicilio.

José Antonio Alonso, en los años 80, desarrolla dos muy interesantes estudios con respecto a la microindustria doméstica y la industria domiciliaria, entendida como el trabajo a domicilio (Alonso, 1988a; 1988b; 1991; 1991b). Su investigación toma como base un estudio del municipio de Nezahualcóyotl, Estado de México, que se publicó en una serie de artículos, entre los que destacan "La maquila industrial domiciliaria en la metrópoli mexicana" (1988b) y "Crisis, sismos e industria doméstica” (1988a), para alcanzar su máximo desarrollo en su libro "Mujeres maquiladoras y microindustria doméstica" publicado en el año de 1991, el cual después compara, en otro momento, con el desarrollado en el Estado de Tlaxcala titulado "La industria domiciliaria del vestido en Tlaxcala. Una investigación exploratoria" (1991a). En estos dos estudios hace un interesante recorrido que da cuenta, con una visión histórica, del trabajo a domicilio, tratando de responder por qué, aún en el actual contexto globalizado, sigue presente. 
El estudio desarrollado en Nezahualcóyotl se publica en 1988 y 1991, destaca por tener un contexto urbano-marginal, con un objetivo central: “...precisar el tipo de relación que existe entre la emancipación de la mujer en las sociedades modernas y el empleo femenino económicamente remunerado. ¿Cómo influye este tipo de actividad laboral específicamente en la situación social de las mujeres mexicanas?" (Alonso, 1991b: 19). Debido a este interés, se concentra primero en saber cómo desempeñan este tipo de trabajo, cómo se organizan, cómo es su proceso de trabajo, en qué condiciones laborales y familiares, así como poner al descubierto su relación con la producción local de prendas de vestir y los efectos que produce en su vida diaria.

De esta manera, Alonso encuentra que se trata de mujeres costureras menores de 30 años y casadas, sin embargo, no indaga más en las características sociodemográficas, por lo que no se puede hablar a profundidad de una relación entre estas características su dinámica familiar y el ciclo de vida. Sin embargo, describe la vida laboral, por ejemplo, las describe como dueñas de las máquinas de coser, que cuentan con trabajadoras a su cargo, a la que se les provee de materia prima que deben ensamblar, encargadas de recoger esa materia prima en la empresa que la subcontrata y regresarla a la misma, con sus propios recursos, no cuentan con ningún contrato, se le paga a destajo y tampoco cuentan con seguridad social.

El autor observa también, que los hombres que participan en este tipo de microempresas son los esposos que al ver consolidado el negocio se adhieren a él, pero manteniendo puestos de dirección, es decir se constituyen en "capataces o patrones" (Alonso, 1988b).

La subcontratación es un tema de relevancia, ya que es a través de esta que los empresarios reducen "...costos mediante la desintegración del proceso productivo, subcontratando la parte que requiere más mano de obra, es decir, la costura." (Alonso, 1988b:525). Por lo que su interés se centra en entender y explicar las redes que tejen estas trabajadoras con los empresarios de la Ciudad de México, a lo que él llama subcontratación local. Por otro lado, comienza a vincularse la producción local y el trabajo a domicilio con la producción internacional, sobre todo a los EE. UU., a través de redes de intermediación. Estas 
reflexiones abren la discusión, que se desarrollaría más tarde, sobre las cadenas globales de producción.

Alonso señala, una vez que se adquieren más máquinas cuando la empresa de la trabajadora va creciendo, esta contrata otras mujeres para que trabajen en sus casas, sin embargo, son consideradas aprendices por lo que no reciben el salario mínimo, sino un salario a destajo. (Alonso, 1988b). El autor realiza un minucioso estudio de cómo las mujeres organizan este negocio y destaca que la condición de clandestinidad, bajo la que operan estas empresas informales, dificulta una investigación de tipo cuantitativo por lo que utiliza el recurso metodológico de las entrevistas a profundidad.

Aunque se mencionan algunos aspectos de subordinación en el ámbito familiar y la sobrecarga de trabajo, no se profundiza en estas características. Sin embargo, se deja abierta, como una línea de investigación la no redefinición de los roles femeninos, planteándolo de la siguiente forma: "La plena integración de la mujer a la actividad industrial no implica ninguna redefinición de los roles tradicionalmente femeninos" (Alonso, 1988b: 520). Podemos agregar que esto se debe a que el trabajo industrial se añadía a las labores hogareñas.

En su segundo estudio, ahora en el estado de Tlaxcala, el autor compara algunos de los resultados con los que obtuvo en el primero, en el Estado de México. Así encuentra que, el fenómeno analizado, es la expresión de los desplazamientos de los empresarios de la industria del vestido y la confección de la periferia de la Ciudad de México hacia otros estados del centro del país (Alonso, 1991a) por lo que en palabras del autor: “...el trabajo industrial domiciliario constituye una de las formas privilegiadas -aunque clandestina- que permite sobrevivir a los campesinos y a los pobladores urbano [del Estado de Tlaxcala]." (Alonso, 1991a: 54). En este estudio Alonso pone al descubierto un nuevo fenómeno rural-urbano: el desplazamiento espacial de la industria de la confección de la Ciudad de México a otros estados del centro del país, observación que representa un valioso aporte a los estudios del trabajo a domicilio. (Arias, 1998). 
Su estudio no se centra en la ciudad, pues toma en cuenta tanto el área urbana como la rural. En este caso, se consideran algunas características sociodemográficas y se encuentra con que son mujeres que han nacido y vivido en Tlaxcala, su edad oscila entre 30 y 60 años, el nivel de escolaridad es muy bajo, es decir, cuentan sólo con primaria, son casadas y viven en familias grandes de por lo menos siete miembros. (Alonso, 1991a: 56) Las mujeres, también dueñas de las máquinas de coser y se encargan de todos los gastos de transporte, hilo y pago de luz, recibiendo un salario a destajo (Alonso, 1991a).

Otro rasgo que se resalta es el desarrollo de redes de intermediación muy interesantes, por ejemplo, las que no tienen muchas máquinas (menos de 5) trabajan para intermediarios locales, mientras que las que tienen por lo menos 8 trabajan directamente con empresarios del Distrito Federal. La clandestinidad es un rasgo presente para la mayoría de los casos, pero que se acentúa en el municipio de Nezahualcóyotl. En este caso tanto hombres como mujeres se emplean en los talleres. Cabe señalar que este estudio fue exploratorio por lo que la forma en cómo se profundizo en los datos fue diferente.

Otro aspecto de los estudios que ha realizado Alonso tiene que ver con su visión histórica del fenómeno, toma tintes teóricos muy interesantes en su libro publicado en el 2002 titulado "Maquila domiciliaria y subcontratación en México en la era de la globalización liberal”. En este plantea que "El trabajo a domicilio ha sido una constante organizativa-aunque con diversos rasgos- en todas las fases del desarrollo capitalista" (Alonso, 2002:

14) y que es debido al trabajo a domicilio que se posibilitó el tránsito de la organización económica feudal y gremial a la economía capitalista (Alonso, 2002).

No profundizaré en el tema, pero basta decir que, tal como lo señala Alonso "El aporte decisivo de Lenin es que, según él, la maquila domiciliaria <〈no>> es un simple remanente del pasado. Es una vieja forma de producción, pero <<revitalizada〉> por los mayoristas (los empresarios-comerciantes, en nuestra terminología) a costa de la producción intensiva de los trabajadores, en su mayoría mujeres." (Alonso, 1988: 523). Por esto resulta interesante contextualizar el fenómeno y más aún señalar sus diferencias históricas, algo que hace muy bien Alonso. 
Por último, me gustaría añadir, que el autor realizó un avance valioso en el estudio del trabajo a domicilio, ya que es de los primeros en describir el proceso de trabajo, sus conexiones con las empresas formales en un contexto urbano-marginal, sumándole un componente histórico. Sin embargo, no va más allá en los aspectos estructurales y organizativos.

Otra estudiosa del tema, la antropóloga Patricia Arias, realiza en los años 80 un interesante estudio titulado: "La aguja y el surco: cambio regional, consumo y relaciones de género en la industria de la ropa en México” junto con Fiona Wilson, publicado en 1997. También pública un artículo en 1998 llamado "El trabajo femenino a domicilio ayer y hoy" donde destaca un aspecto no considerado antes, que tiene que ver con el desarrollo de "...formas de maquila y de trabajo a domicilio en comunidades indígenas." (Arias, 1998: 79) Plantea que cada vez más localidades y mujeres de “...los estados de Michoacán, Oaxaca, Puebla y Yucatán se habían integrado a una nueva geografía del trabajo a domicilio." (Arias, 1998: 79).

En su hipótesis general Arias plantea, que el trabajo a domicilio habría pasado de ser un lastre para el desarrollo que algún día iba a ser finalmente superada, a convertirse en parte integrante del mismo, por lo menos en ciertas actividades y procesos de trabajo. (Arias, 1998). Asegura que las mujeres del campo y de la ciudad, han encontrado en el trabajo a domicilio la manera de enfrentar el impacto doméstico del modelo que vivió el país en la década de los ochenta, debido a que "El trabajo a domicilio persiste como modalidad de trabajo y permanece como una posibilidad de ingresos para las familias rurales." (Arias, 1998: 90)

La autora describe el proceso, muy importante, de los problemas que atravesaron las industrias desde la apertura comercial iniciada en 1989, relacionado con “...el surgimiento de actividades productivas en el medio rural, en ciudades pequeñas, fenómeno de tal magnitud e intensidad que, como se ha visto, ha logrado competir con la producción de las grandes ciudades y ha modificado la distribución espacial del empleo en ciertas ramas industriales." (Arias, 1998: 88). Por lo que el estudio de las zonas rurales del país resulta muy importante para estudiar la evolución espacial de este trabajo y su impacto en la localidad. 
Plantea una nueva característica de esta actividad que tiene que ver con que "...las diversas opciones de empleo en las actividades rurales han convertido en trabajadoras a las mujeres de todas las edades y estados civiles, en cualquier etapa del ciclo doméstico, en casi todas las situaciones familiares" (Arias, 1998: 93). Un aspecto interesante de estudiar en otros contextos. Por último, es relevante que la autora integre en su estudio a otro tipo de trabajadoras como las indígenas y que analice nuevos aspectos como el espacial en un nivel de análisis macro.

En el trabajo de Sandra Treviño Siller titulado "Reflexiones sobre el trabajo a domicilio en la zona noreste de Guanajuato" y publicado en 1988 se estudia la idea de que el trabajo a domicilio representa “... una de las formas más comunes que asume el capitalismo para la elaboración de ciertos productos o etapas específicas del proceso de los mismos." (Treviño, 1988: 583) La autora considera que los trabajos en torno al trabajo a domicilio se han enfocado a exponer la problemática en forma economicista, sin detallar las condiciones de vida cotidiana de los trabajadores, o bien por analizar el fenómeno solamente a nivel macro. (Treviño, 1988)

Sandra Treviño se destaca por estudiar aspectos que antes no habían sido tomados en cuenta como “... analizar la situación cotidiana de los principales actores sociales involucrados: tejedoras e intermediarios (trabajo y capital), y reflexionar sobre las posibles tendencias y la posición que ocupa el trabajo a domicilio en la actual lógica de recomposición de capital y de la <<nueva〉> división internacional del trabajo.” (Treviño, 1988: 584.) En la región estudiada, se encontró que el tejido a domicilio era “...la principal actividad [...] más importante aún que las actividades primarias, básicamente por la cantidad de capital que se mueve diariamente, la generación masiva de empleos para las dimensiones regionales y el aumento cualitativo de la capacidad de consumo que esto significa." (Treviño, 1988: 588) Esto para la zona noreste de Guanajuato, lo cual habla de la importancia que tenía para la región el trabajo a domicilio. 
Incluye el estudio del ámbito tanto productivo como reproductivo de las mujeres trabajadoras a domicilio, al igual que las ventajas que representa el trabajar en su casa, ya que "...no se ven obligadas a romper con su papel tradicional y porque consideran que ellas mismas controlan, de alguna manera, sus tiempos de trabajo.” (Treviño, 1988: 591). Es interesante la inclusión de la dinámica familiar en el estudio y del enfoque de género. La autora identifica las ventajas que las trabajadoras le confieren a este trabajo, entre ellas se encuentran las siguientes: “...a) permite a la mujer trabajar mientras atiende su casa, razón por la cual las variables de estado civil y maternidad resultan fundamentales; b) se "controla" el ritmo de trabajo, y c) se percibe semanalmente el salario en efectivo." (Treviño, 1988: 591-592). Pero la autora sólo indica las ventajas sin problematizarlas ni analizar su impacto real.

Esta autora también toma en cuenta el espacio laboral, aunque no profundiza en el tema, lo deja como una línea indagatoria importante de posible análisis.

"Otro aspecto fundamental de la cotidianidad se sitúa en el espacio laboral tan particular. Es decir, que el trabajo a domicilio se realiza en la vivienda del trabajador, en un espacio específico -doméstico y laboral- en donde se conjugan todos los vicios del hogar con las dificultades del propio proceso de trabajo. No hay una separación estricta de tiempos ni de actividades: el tejido y el quehacer se trasladan continuamente. Así se teje (se produce) mientras se <<echa un ojo〉> a la comida, se cuida a los niños o se espanta a los pollos; incluso, se $<<$ descansa del tejido $>>$, lavando los trastes." (Treviño, 1988: 592)

Se estudia con más profundidad la dinámica laboral y concluye que:

"La jornada laboral se extiende de manera indefinida a lo largo del día y/o la noche, se retrasa o se suspende algunos días, se acelera en otros, según la urgencia del pedido o de la necesidad económica de la tejedora. No existe, por tanto, un control directo/continuo del capital sobre el trabajo; ello hace creer a la tejedora que controla su ritmo de trabajo; lo cual constituye, de hecho, una de las principales ventajas para las tejedoras casadas y/o con hijos que han trabajado en talleres y fábricas que cuentan con un cuerpo administrativo en forma." (Treviño, 1988: 593)

Lo anterior habla, de las dificultades a las que se enfrentan estas trabajadoras para poder hacer compatible su trabajo productivo y reproductivo. 
Por último, en el caso de Lourdes Benería y Martha Roldán, su estudio es pionero en el interés por estudiar la maquila domiciliaria en la Ciudad de México, desarrollado en un interesante documento, publicado en inglés en el año de 1987 y traducido al español en 1992, titulado "Las encrucijadas de clase y género. Trabajo a domicilio, subcontratación y dinámica de la unidad doméstica en la ciudad de México”. Mostrando su interés por el estudio de aquellos ámbitos en los no se dedicará a producir prendas de vestir, ya que consideraban que abundaba la información sobre la maquila doméstica del vestido (Benería y Roldán, 1992). Este trabajo bajo, muy importante, es de los primeros en asumir un enfoque de género, debido a que ponen el acento en el mundo familiar y en temas como la doble jornada.

Un aspecto que se constató en su estudio, con una muestra significativa de 140 mujeres, es la ampliación del espectro de actividades productivas que recurren al trabajo domiciliar, entre las que se encontraban, por ejemplo, la confección y acabado textil, armado de flores de plástico, de juguete, de bolsas de plástico; además de otros como, el empacado de dulces de fibra metálica, envasado de pepitas de girasol y el armado de cajas de cartón. Otras labores que se apuntan en el estudio son: pulimento plástico de diversos productos, ensamble de grapas y bolígrafos, control de calidad de diversos productos, embobinado electrónico, remachado de metal laminado y fabricación de partes para antena, ensamble de cerrojos, etc. (Benería y Roldán, 1992)

Gracias a su estudio, el perfil de la trabajadora a domicilio urbana de principios de los ochentas fue documentado, dando cuenta, del origen predominantemente rural, de baja escolaridad, entre los 21 y 40 años de edad, casadas o con pareja, que consideraban sus ingresos como complementarios, en la muestra estudiada había una mínima proporción de mujeres que eran jefas de hogar.

Un interés primordial de las autoras fue, en sus propias palabras “...estudiar cómo se articulan la clase y el género con una situación concreta de trabajo y de vida." (Benería y Roldán, 1992: 13). Lo que hace que el estudio tenga características muy interesantes, ya que se pone el acento en aspectos que no se habían tomado en cuenta antes o que no habían sido estudiados en profundidad. Esto tiene que ver con analizar la posición ocupada por el trabajo industrial en el seno de la economía, con aspectos estructurales y económicos, pero a su vez 
también se pone el acento en el género, la dinámica familiar y su relación con procesos socioeconómicos más amplios. Los conflictos que acarrea el trabajo a domicilio para las mujeres y la posibilidad de hablar de sus relaciones de género y de cómo el dominio, sobre su propio ingreso, la faculta para renegociar las relaciones de género dentro del hogar. (Benería y Roldán, 1992)

Por interés metodológico se incluye un cuestionario cuyo propósito fue recolectar información acerca de "...datos generales sobre el trabajo a domicilio, las condiciones en que se realiza, datos sobre la unidad doméstica, trayectorias de ocupación de las mujeres entrevistadas, trabajo doméstico no remunerado y la percepción de las mujeres sobre su propio trabajo y situación familiar." (Benería y Roldán, 1992: 42)

Por otra parte, las entrevistas en profundidad trataron de dar cuenta de los “...presupuestos domésticos, asignación de recursos en el seno del hogar, mecanismos para sobrevivir, poder de decisión, relaciones conyugales y normas y valores relativos a la situación de la mujer como esposa que trabaja y como madre." (Benería y Roldán, 1992: 42) Este es un avance en los estudios sobre el tema, ya que es posible generar un perfil sociodemográfico más amplio que permita conocer el tipo de mujeres que laboran en esta actividad y, al mismo tiempo, lo relacionan con su ámbito familiar y la dinámica que en él se genera.

Se resaltan aspectos sobre las relaciones de género en el ámbito familiar, debido a que las autoras hablan de que estas mujeres “...llevan a cabo estrategias para crear espacios mínimos de control sobre su vida." (Benería y Roldán, 1992: 137), se les comienza a dar espacios de acción más amplios y no se les ve solamente como mujeres subordinadas, sino como actoras sociales. Analizan los casos en qué esto es posible y en los que no. Uno de sus resultados, indica que los circuitos de asignación y los puntos de control, sus tensiones y conflictos, pueden considerarse no sólo como desenlace sino también como condición de renegociación del poder entre marido y esposa. Se marca el inicio de los estudios del 
trabajo a domicilio con un enfoque de género, sin olvidarse de los factores económicos y estructurales. (Benería y Roldán, 1992)

Por último, a manera de conclusión de este recuento, considero que existen aportes valiosos en los trabajos presentados anteriormente, sobre todo en los aspectos descriptivos y estructurales del fenómeno, la heterogeneidad de actividades que se desempeñan a domicilio, las redes de subcontratación, los conflictos subjetivos y objetivos a los que se enfrentan las trabajadoras. También es de destacar los instrumentos metodológicos que se han utilizado, tales como la entrevista a profundidad y el cuestionario, cabe decir que los autores hacen referencia a sus dificultades, ventajas y desventajas de utilizar uno u otro. Sobre todo, en lo que tiene que ver con el problema que implica cuantificar un trabajo clandestino como este, pero también con los objetivos de la investigación.

\section{1 El trabajo a domicilio subcontratado.}

Para hablar sobre el trabajo a domicilio es importante primero aclarar la diferencia entre "trabajo a domicilio" y "trabajo en el domicilio". Para hacer esta distinción, nos basamos en la idea que expone Giovanna Rossignotti (2001) cuando dice que el argumento principal tiene que ver con que el "trabajo a domicilio" es aquél que se encuentra subordinado y dependiente como es el que se encuentra en la maquila de confección; mientras que, el denominado "trabajo en el domicilio" es el que incluye al trabajo independiente y a las personas clasificadas como inactivas en las mediciones habituales. (Rossignotti: 2001:2). Por lo que se optó en llamar a este trabajo "a" domicilio y no "en" domicilio, debido a que resalta las condiciones de dependencia, subordinación, pero sobre todo de subcontratación que nos interesa abordar.

Cabe aclarar que en los hechos el trabajo a domicilio muchas veces se encuentra encubierto con el supuesto de ser un trabajo independiente, es decir, de ser un trabajo en el domicilio, pero tal como lo señala Henríquez, et al (2005) "Аunque externo, este trabajo a domicilio perdió todo el carácter autónomo del antiguo artesanado y se subordinó hasta ser un empleo dependiente, sujeto a la disciplina de la fábrica e integrándose a la potente 
dinámica de constitución del asalariado.” (Henríquez, et al, 2005: 5) En este sentido, Mercedes Pedrero (2000) agrega y aclara que “... si no hay un arreglo formal o garantía de suministro de materias primas a condición de devolver el producto procesado a cambio de un pago, se trata de un trabajador independiente; ellos son los que tradicionalmente se han identificado como trabajadores por cuenta propia." (Pedrero, 2000: 569).

La subcontratación y, por ende, el suministro de materias primas es lo que hace la diferencia entre un trabajador a domicilio y uno por cuenta propia. El trabajo a domicilio, al que me voy a referir en esta investigación, lo denominaré "trabajo a domicilio subcontratado", para distinguirlo de aquél que es desarrollado de manera independiente y para dar cuenta del proceso de subcontratación que se da en las cadenas globales de producción de ropa, sobre todo en el último eslabón de esa cadena a la cual pertenece.

El aspecto fundamental, que define al trabajo a domicilio subcontratado, consiste en que "Los trabajadores dependientes o maquiladores generalmente trabajan en su casa, pero tienen un acuerdo con alguna fábrica, empresario o empleador para que les provea materia prima que ellos, desempeñando un monto específico de trabajo, transformarán en un periodo de tiempo determinado y por un pago que se acuerda en función de la cantidad de trabajo realizado." (Pedrero, 2000: 596). Características que cumplen las trabajadoras a domicilio subcontratadas en Tehuacán, Puebla.

Las nuevas modalidades del trabajo a domicilio subcontratado se destacan porque se desarrollan en un contexto de globalización y flexibilidad laboral, en las que el mercado es uno de los factores que determinan su existencia, amplitud y diversificación. Debido a esto se desarrollaron, diversas formas de subcontratación a domicilio, que no se habían encontrado antes de manera tan extendida. Es decir, no solamente se encuentran encadenados a un proceso de producción global, sino que aún en este último eslabón se desarrollan redes menos visibles de subcontratación familiares, vecinales y de amistad que no se han estudiado suficientemente. 
El trabajo a domicilio es una práctica muy antigua, que cumple funciones particulares dentro de las relaciones capitalistas, en particular, en la última fase de globalización de las relaciones de producción, durante la cual ha tenido momentos de auge y en otros en casi ha desaparecido. Importante, para fines de este estudio, es destacar aquellos aspectos que han propiciado su práctica, enmarcándola en un nuevo contexto de permanencias y transformaciones. Entre los diversos factores que sirven de intensificadores del trabajo a domicilio subcontratado destacan los siguientes: la flexibilidad laboral, modificaciones en la normatividad laboral, el neoliberalismo, la subcontratación, la globalización y sus efectos en la economía, etc.

Es de suma importancia subrayar, que el trabajo a domicilio que estudio durante la presente investigación es un "trabajo a domicilio subcontratado" en un contexto de globalización. Es decir, este trabajo es posible debido a que es subcontratado por empresas transnacionales, empresas medianas o talleres familiares encabezados por grandes firmas, a partir de un proceso de encadenamiento. El revisar el proceso de subcontratación permite comprender el eje principal de este trabajo, la subcontratación de mujeres que forman parte de la cadena de confección de ropa, quienes están sujetas a los vaivenes del mercado, encontrándose en condiciones de precariedad y de asalariamiento disfrazado.

\subsection{Condiciones laborales.}

Daremos cuenta de algunos aspectos encontrados en estudios previos sobre las condiciones laborales en que estas mujeres trabajan, tales como, el tipo de jornada laboral y el control de sus tiempos de trabajo, el cual se percibe como una de las mayores ventajas del trabajo a domicilio subcontratado. También indagaré en el tipo de relaciones que tienen con los intermediarios que les proporcionan el trabajo, cómo es el pago, el asalariamiento que existe dentro de la fábrica disfrazado de trabajo independiente a ella, por lo que no se tiene la obligación de cumplir con ningún tipo de prestación social.

Las condiciones objetivas y materiales de las trabajadoras no son nada favorables, esto debido a que su situación laboral es muy precaria. En primera instancia, el tipo de jornada 
laboral se extiende de manera indefinida, pues su trabajo está sujeto a los requerimientos del mercado. Tal como se encontró Sandra Treviño: "La jornada laboral se extiende de manera indefinida a lo largo del día y/o la noche, se retrasa o se suspende algunos días, se acelera en otros, según la urgencia del pedido o de la necesidad económica de la tejedora." (1988: 593)

El que la jornada de trabajo se extienda o intensifique, provoca agotamiento y cansancio, debido a que, aunque "deciden" cuando trabajar y en qué momentos deben estar disponibles y terminar el trabajo para el día y hora que el empleador o subcontratista estime, si les interesa que las sigan proveyendo de materia prima. De esta manera el "control" con el que las trabajadoras cuentan es muy relativo, casi imaginario, ya que en la práctica los empresarios ejercen control a distancia sobre su vida de trabajo y familiar.

Las relaciones que mantienen con los intermediarios que las provén son diversas, debido al tipo de relación que pueden ser: "...relaciones de amistad, parentesco o compadrazgo." (Treviño, 1988: 593), El reconocimiento del capital se diluye, es decir, no se sabe para quién realmente se trabaja, por lo que, si el intermediario no cumpliera con el pago o dejara de proveerle el trabajo, no se sabría a quién reclamarle.

Sobre esta relación ambigua entre trabajo y vida familiar, algunas autoras, como Patricia Arias (1998), resaltan la complementariedad como un componente que contribuye a mantener “...el bajo costo de esa forma de empleo y ese tipo de ingreso.” (1998: 87). Según ella: “El argumento de la complementariedad [salarial] coincide muy bien con una imagen que los empresarios quieren mantener a toda costa. Los patrones gustan de hacer hincapié en que para las mujeres el salario es un complemento: Ellas $<<\ldots$ trabajan para sus uñas... >>, para darse ciertos gustos, no para mantener a una familia. Aunque las mujeres que día a día acuden a entre gar y recibir trabajo a domicilio desmientan esa afirmación." (1998: 87). Esta idea de complementariedad no solo afecta el ingreso, sino también el reconocimiento de su trabajo. 
El tipo de pago es a destajo, es decir, por pieza elaborada (Díaz y Yáñez, 1998) y al tratarse de un trabajador semi o no calificado resulta más económico que si trabajara dentro de la fábrica. Como lo plantean Consuelo Iranzo y Marcia De Paula Leite (2006), quienes señalan que:

"El trabajador subcontratado en condición de interino o a través de un contrato civil o mercantil, cuando es semi o no calificado, resulta más económico para la empresa porque percibe remuneraciones inferiores a las de los trabajadores fijos, estableciendo una desigualdad de trato "en materia de: derechos colectivos, seguridad social, salarios y condiciones de trabajo, seguridad en el empleo, protección en caso de insolvencia, seguridad industrial y protección a la maternidad.” (Bronstein, 1999: 12 en Iranzo y De Paula, 2006: 274).

Aun cuando los trabajadores son dependientes de la empresa y realizan las mismas tareas que las empleadas en la fábrica, la subcontratación elude las responsabilidades laborales y de seguridad social. Se plantea que:

"Entre las trabajadoras a domicilio y los talleres o empresas que les entregan trabajo, parece haber relaciones de dependencia muy fuertes que ilustran las semejanzas de esta forma de trabajo con el trabajo asalariado que se realiza al interior de las fábricas. [...] Una expresión de ello es el hecho que sobre el $80 \%$ de las mujeres trabajan sólo para una empresa o taller. De estas, ellas reciben órdenes de trabajo claramente definidas y especificadas. [....] Si no se cumplen los plazos o las cuotas de producción, no se imponen multas, pero la consecuencia puede ser la disminución del trabajo en el futuro." (Díaz y Yáñez, 1998: 54)

Por este motivo “...existe una sobreexplotación de los trabajadores a nivel de talleres y de trabajo a domicilio, hecho que se refleja en extremadamente bajos costos laborales de la producción externalizada. La situación de desprotección total se expresa principalmente en el trabajo a domicilio y en talleres muy pequeños que funcionan en el domicilio o anexos a un domicilio." (Díaz y Yáñez, 1998:20). Son entonces los talleres y el trabajo a domicilio subcontratado los que más condiciones de precariedad. En el caso del trabajo a domicilio es aún peor debido a la clandestinidad en la que se desenvuelven. 


\section{La simultaneidad del trabajo femenino: tiempos-espacios reproductivo y productivo.}

El trabajo a domicilio subcontratado, como ya se explicó, es un trabajo flexibilizado, que se desenvuelve en un contexto de globalización. Sus efectos más importantes remiten al espacio doméstico, el tiempo familiar de las trabajadoras, cambiando y reestructurándolos.

El enfoque de género analiza la situación de las mujeres que lo desempeñan, pues este trabajo se desarrolla en el domicilio entremezclando su mundo familiar y laboral en el tiempo y en el espacio doméstico. No existe una situación clara en cuanto a los límites de lo reproductivo/productivo y de lo público/privado. Las fronteras se diluyen, los tiempos y espacios se mezclan, formando una clara contradicción de dos lógicas diferentes.

Con este propósito se resumieron los debates teóricos que a lo largo del siglo XX ocuparon a estudiosas y estudiosos del trabajo femenino de las principales escuelas europeas ${ }^{2} \mathrm{y}$ latinoamericanas. Me acerco al amplio debate sobre la relación entre trabajo productivo y reproductivo, para analizar los nuevos planteamientos sobre la "conciliación" del trabajo productivo y vida cotidiana desarrollados en Europa, sobre todo la discusión que aborda el análisis de los problemas del trabajo a domicilio subcontratado en contextos globalizados.

\subsection{Las relaciones entre producción-reproducción.}

a) Los estudios de la doble presencia

A finales de los años 70 comenzaron los estudios que intentaban introducir análisis conjunto del trabajo productivo y reproductivo de las mujeres, llamado desde entonces de la doble presencia. Este enfoque cuestionaba la dicotomía historia de la familia e historia del trabajo, pues eran consideradas poco aptas para dar cuenta de las complejas experiencias de trabajo de las mujeres, que “...han tenido tradicionalmente que desarrollar estrategias de

\footnotetext{
${ }^{2}$ Entre las que se destacan: a) Escuela de Cambridge, b) Escuela Italiana, c) Escuela Francesa y d) Escuela Española
} 
<<conciliación〉> del trabajo familiar y mercantil y de su identidad como esposas, madres y trabajadoras." (Borderías, 2003: 90). Esto significó un paso adelante en la manera en que se abordaba el trabajo femenino remunerado y no remunerado.

La doble presencia se presenta como una categoría analítica de las experiencias de trabajo de las mujeres pues “...plantearon así mismo no sólo la necesidad de abordar los análisis del trabajo femenino desde las relaciones entre familia y trabajo, sino también la necesidad de nuevas relaciones disciplinares." (Borderías, 2003: 90-91)

Las dimensiones desde las que se abordó la relación producción y reproducción fueron dos: el análisis de las relaciones sociales de sexo y clase y el análisis de las relaciones de las mujeres con la producción, a nivel de prácticas y representaciones.

Pionera en el abordaje del trabajo femenino desde esta perspectiva fue Laura Balbo (1978), quien planteó la idea del "doble trabajo", señalando que “...los resultados que para las mujeres había supuesto el proceso de creciente incorporación al mercado de trabajo, ante la persistencia de la división sexual del trabajo tradicional: la acumulación de dos trabajos y la realización de una doble jornada." (Balbo, 1978 en Borderías, 2003: 91). Este concepto señalaba también los límites de la incorporación de las mujeres al mercado de trabajo al constatar "...cómo el crecimiento de la actividad femenina se concretaba en una doble explotación y en una doble jornada de trabajo: en el mercado y en la familia." (Borderías, 2003: 92) Debido a que su incorporación a la actividad productiva remunerada no modifico que la mujer fuera la principal encargada del trabajo de la reproducción, ocasionó la "jornada interminable" o "doble trabajo" concepto definidor de la condición femenina en la época contemporánea.

Poco después de haber sido planteada la idea del "doble trabajo", la reflexión avanzo y nació la idea de un nuevo concepto, señalando una nueva etapa y perspectiva en los estudios sobre el trabajo femenino: "la doble presencia". Cristina Borderías (2003) plantea la diferencia entre un concepto y otro, afirmando que el concepto de doble trabajo “...ponía el énfasis en la persistencia de la discriminación y en la doble explotación que 
sufrían las mujeres", mientras que el concepto de doble presencia cambiaba sustancialmente la óptica de análisis, dando a la experiencia del doble trabajo una dimensión de mayor complejidad pues “...el trabajo de las mujeres no constituía sólo la acumulación de dos jornadas, implicaba la necesidad de asegurar una presencia -material y simbólicasimultánea en ambas esferas porque en esta nueva etapa de la condición femenina -y frente a la anterior prioridad de lo doméstico- la nueva condición femenina aparecía definida por la equiparación de las exigencias y valores de lo profesional y lo familiar." (Borderías, 2003: 92)

En el caso de las trabajadoras a domicilio subcontratadas en Tehuacán, no sólo se trata de la acumulación de dos jornadas y de la necesidad de asegurar una presencia simultánea en las esferas material y simbólica, sino que también se agrega la superposición espacial y la multiactividad.

Para estudiar la doble presencia de las mujeres surgieron nuevos conceptos tales como gestión mental, "charge mental”, doble invisibilidad, trabajo generalizado o tiempo diferentemente trabajado, ambivalencia y ambigüedad, analizando las exigencias de esta simultaneidad en la nueva experiencia y las respuestas de las mujeres. Éstas se reflejadas en “...estrategias y formas de organización del trabajo, en la forma de organización de los tiempos, en la forma de interrelación entre trayectoria laboral y trayectoria familiar o en las formas en que las mujeres vivían su relación con el trabajo productivo y reproductivo" (Borderías, 2003: 92). Al igual que los conflictos o compatibilidad que derivaban de estas mismas estrategias.

Lo anterior plateó la imposibilidad de separar prácticas y representaciones del trabajo remunerado y no remunerado, al igual que sus mediaciones. La transversalidad de esta experiencia comenzaba a verse como la “...capacidad de gestionar la presencia simultánea en ambas esferas, de articular dos sistemas de trabajo y dos culturas de trabajo antagónicas, de pensar y actuar de forma transversal." (Borderías, 2003: 92) 
Los estudios de la doble presencia abarcaron diversos contextos sociales, económicos, familiares y profesionales; además de los proyectos, prioridades y valores femeninos, que introducen una gran variabilidad en las estrategias femeninas de doble presencia. (Borderías, 2003: 92-93). Esta idea es sumamente importante pues en el centro de nuestra investigación se encuentra el trabajo a domicilio subcontratado, como una estrategia de "conciliación" de lo productivo y de lo reproductivo, mismos que conllevan aspectos como el de la simultaneidad del trabajo, pero en un mismo espacio, el de la casa.

Por último, estos estudios contribuyeron a poner de relieve la enorme capacidad de las mujeres para crear, a partir de una construcción social, modalidades de trabajo, cultura e identidades no reductibles en modo alguno al modelo masculino. (Borderías, 2003). Como lo muestra el trabajo a domicilio subcontratado, caracterizado por el ciclo de vida, el matrimonio y el tener o no hijos, por las que recurren a este tipo de trabajo que concilia los aspectos productivo y reproductivo.

b) Culturas de trabajo, identidad femenina y reorganización social.

Algunas perspectivas tradicionales en psicología profundizaron aspectos como el de la ambivalencia y la ambigüedad que sufren las mujeres por la necesidad de desenvolverse en los ámbitos productivo y reproductivo, así como los conflictos, la indecisión e insatisfacciones que producen a lo largo de sus vidas. Estas perspectivas les otorgan un sentido negativo, al considerar que estos efectos son propios de la personalidad de las mujeres.

No es sino hasta principios de los años 80 y desde una perspectiva feminista, que comienza a ser abordado el tema de la ambivalencia de su doble presencia rompiendo así “...la negatividad de su sentido tradicional para atribuirle una nueva dimensión significativa." (Borderías, 2003: 94)

Ulrike Prokop habla de ambivalencia y se refiere a ella como: 
“...un sentimiento femenino que no es sólo muestra de la insatisfacción por la sobrecarga del trabajo, sino por el encadenamiento de lo que ella llama las fuerzas productivas femeninas que caracterizarían el trabajo doméstico de las mujeres (orientación a las necesidades, comportamiento expresivo y no instrumental, flujo de tensión afectiva, alejamiento de las amenazas inmediatas, imaginación y fantasía, espontaneidad, orientación al arreglo de la casa, al cuerpo, al consumo, a la satisfacción del deseo y que aun siendo gestadas en el modo de producción femenino difícilmente se adaptan al aislamiento de la casa." (Borderías, 2003: 94)

Prokop concluye que la ambivalencia en las mujeres era

“... analizada como respuesta al <<malestar>> producido por este conflicto que se manifiesta en angustia, rechazo del éxito, trastornos vegetativos y sus <<compensaciones>>: orientación al consumo, ritualización de lo cotidiano. Recurriendo a evidencias acumuladas por numerosos y muy diversos estudios sociológicos sobre las resistencias de mujeres con $<$ doble carrera >> a identificarse con el trabajo doméstico o asalariado, Prokop interpretó esta ambivalencia como conciencia de que el trabajo extradoméstico no resolvía la sensación de insatisfacción y como expresión de la <<aspiración de vivir de otro modo>>, enlazando con las reflexiones sobre <<el malestar de la emancipación”, planteadas por las feministas italianas." (Borderías, 2003: 95)

Cristina Borderías (2003) plantea que “...son precisamente los pasajes continuos de una esfera a otra, de una lógica a otra, de una cultura a otra, lo que paradójicamente coloca a las mujeres como sujetos capaces de concebir la globalidad de una vida social." (Borderías, 2003: 108). El estudio de las estrategias del trabajo productivo y reproductivo brinda ejemplos de la manera en que construyen esa globalidad, algunas veces con conflicto y otras con armonía.

c) Crisis de los modelos tradicionales de empleo. La reorganización del mercado y la flexibilización del empleo.

Con la reestructuración productiva de los años 80, la globalización y la creciente flexibilización del trabajo, han comenzado a surgir cambios muy importantes en el mundo del trabajo. Sin embargo, hay ideas que perduran, como la consideración de que la mujer es la principal responsable de lo doméstico. La flexibilización se presenta entonces como 
“...[1a] flexibilización del tiempo de las personas a un trabajo que siguen conservando su centralidad en la organización social y que en algunas de sus formas llamadas <<flexibles>> se manifiesta incluso más rígido.” (Borderías, 2003: 97)

Borderías plantea también que “...las mujeres están más frecuentemente representadas en el trabajo a tiempo parcial, que presenta un índice de irregularidad mayor, lo que en lugar de constituirse un sistema de mejor articulación entre familia y trabajo puede suponer nuevas dificultades." (Borderías, 2003: 97). Quiero abordar este aspecto en mi investigación, pues las mujeres que trabajan a domicilio subcontratado tienen la percepción de que este trabajo es la fórmula para permanecer en ambos espacios, es decir, trabajan desde la casa para poder ocuparse de los hijos y del mundo doméstico. Sin embargo, más que aceptar esta idea, partimos de este hecho como aspecto a indagar, conociendo de los problemas que se resuelven y los que aparecen de esta nueva configuración de lo productivo y lo reproductivo, para desentrañar qué conflictos se enfrentan al tratar de conciliar en un mismo espacio ambas actividades.

\subsection{Los estudios más recientes en España. Finales de los 90 y principios del 2000.}

Los enfoques abordados en este apartado se rescatan sobre de estudios desarrollados en España a finales de los años 90 y principios del 2000. Entre estos se encuentran los estudios sobre el reparto del tiempo, los usos sociales del tiempo, la conciliación del trabajo productivo/familiar; destacándose los estudios de vida cotidiana; como valioso aporte para el estudio de la conciliación del trabajo productivo y reproductivo, pues plantean un escenario de análisis más amplio. Otro enfoque estudiado es el de la geografía feminista para el estudio del espacio, transformado por la llegada del trabajo productivo al mundo doméstico.

a) Estudios sobre el reparto del tiempo, los usos sociales del tiempo, la conciliación del trabajo productivo/familiar y la vida cotidiana.

M. Ángeles Durán (1986; 1991), Teresa Torns (1994; 2001) y M. Jesús Izquierdo (1988) cuestionan las dicotomías entre la sociología del trabajo y la sociología del tiempo 
sugiriendo la necesidad de construir una sociología de la vida argumentando que "La atención a la vida cotidiana se ha planteado como un escenario de análisis más amplio que el del mercado laboral y la familia. Un escenario que se hace visible al incluir la dimensión temporal y que permite un mejor conocimiento de la organización social y de las desigualdades de género: el uso desigual del tiempo de vida." (Borderías, 2003:100) Tanto en el mundo productivo como reproductivo.

Teresa Torns plantea que el uso desigual del tiempo devela la existencia de lógicas distintas que rigen el tiempo laboral y el tiempo de trabajo reproductivo. Lo que conduce a la reflexión sobre la “...subjetividad y las lógicas diferenciadas de las experiencias de trabajo masculinas y femeninas." (Torns, 2001, Citada por Borderías 2003: 100)

En estudios más recientes Torns (2005), hace una crítica al concepto de “conciliación”, pues históricamente la conciliación surge de la acción de mediar entre contrarios u opuestos (Loiseau y Tobler, 1999), idea que se ha prolongado hasta nuestros tiempos, donde “...puede verse como la actual idea de conciliación de la vida laboral y familiar pretende seguir esa misma lógica mediando entre dos ámbitos que no son, de partida, ni equitativos ni democráticos." (Torns, 2005: 18)

En un estudio presentado en el área de «Género y Empleo» de la Comisión Europea Torns enumera los principales inconvenientes de la conciliación:

- "El principal obstáculo para la plena participación de las mujeres en el mercado de trabajo, así como para su promoción profesional, es la responsabilidad de los trabajos de cuidado y atención a las personas dependientes (trabajo doméstico-familiar)

- Esa responsabilidad y esos trabajos suponen una gran desigualdad entre mujeres y hombres, porque las mujeres siempre son las principales responsables y las cuidadoras efectivas. Esta situación se plantea tanto en los trabajos de cuidado formales (trabajadoras en los servicios correspondientes) como informales (trabajadoras en economía sumergida y trabajo de las mujeres en sus familias)." (Torns, 2005: 21-22) 
Tras debates y reflexiones se ha llegado a la conclusión de que los problemas ligados a la relación del trabajo y el tiempo deben pensarse en el entorno de la vida cotidiana. Y desarrollarse a través de políticas públicas orientadas, principalmente, en torno a tres ejes:

- "Lograr la redistribución de la carga total de trabajo (empleo y trabajo doméstico-familiar y también trabajo cívico) entre todas las personas no dependientes.

- Promover el cambio de la organización temporal socialmente vigente, en el ámbito laboral (jornada laboral), en la ciudad (políticas de tiempo y ciudad) y en el conjunto de la sociedad.

- Impulsar el cambio de las pautas socio-culturales que amparan el modelo «male breadwinner»." (Torns, 2003: 26)

Por último, Teresa Torns nos habla de políticas de conciliación que se han implementado en empresas de la Unión Europea, donde la conciliación muestra claras limitaciones pues considera únicamente permisos laborales para tiempos excepcionales. Por lo que "...la relación de tiempo y trabajo es algo que requiere no menospreciar la cotidianidad y la lógica de sincronía o simultaneidad con la que operan todas las combinaciones posibles en esa relación." (Torns, 2003: 27-28)

Por otra parte, Ana María Rivas (2006), agrega un aspecto más a la problemática de la "conciliación" engarzando la organización del trabajo asalariado y la flexibilidad laboral en la que se vive hoy día. Su argumento principal gira en torno a “...la conciliación real entre la vida laboral y la personal-familiar no es posible en un sistema económico capitalista de producción y consumo y mucho menos en un contexto de capitalismo flexible como el actual." (Rivas, 2006: 368). Debido a que la “conciliación”, tal y como ha sido planteada, se adhiere al orden capitalista, sin oponerse a los principios económicos que fundamentan dicho orden. Por lo que las diversas formas de flexibilidad laboral no reducen ni facilitan la jornada de trabajo, sino que “...la redistribuye de acuerdo con las necesidades de la empresa, lo que normalmente significa una organización del tiempo que repercute negativamente en la vida de las personas, especialmente de las mujeres. Las políticas de flexibilidad laboral lejos de facilitar la conciliación entre vida familiar y laboral, entre géneros, lo que hace es 
acentuar las diferencias y utilizar la conciliación como una coartada para legitimar estas políticas." (Rivas, 2006: 368).

De esta manera, en el caso de las mujeres que trabajan a domicilio en la modalidad de subcontratación, sujetas a las necesidades del mercado, se encuentran con una jornada impredecible, en el sentido de que no saben cuándo tendrán trabajo y cuando no, por lo que en algunas ocasiones puede ser muy intensificada y otras en las que sus ingresos se disminuyan a casi nada por la falta de trabajo.

Por último, para Rivas es imposible conciliar “...lógicas, de contextos, actividades tan opuestas como son las derivadas de la búsqueda del beneficio, el lucro, la ganancia y la acumulación como fin en sí mismo, y las derivadas del cuidado, el bienestar, y la sostenibilidad de la vida humana, que implican un fuerte contenido emocional y afectivo difícilmente sustituibles por el mercado, porque no pueden ser valoradas a precio de mercado." (Rivas, 2006: 368). Asimismo, en la conciliación se afecta más en el lado familiar que en el laboral, como si éste pareciese intocable y las medidas que se proponen son paliativas, que no cuestionan el sistema capitalista de producción que está en el origen de la organización actual del trabajo. (Rivas, 2006)

Para concluir debo decir que la "conciliación" del trabajo productivo y reproductivo es relevante sobre todo cuando se toman en cuenta aspectos económicos, sociales y empresariales. En el caso del trabajo a domicilio subcontratado por tener un carácter clandestino e informal, le son aplicadas estas políticas de conciliación de manera informal, pues en el discurso de los empresarios, las mujeres trabajan desde sus casas por necesidad, por lo que se les ofrece este tipo de trabajo para su comodidad, pero lo cierto, es que en el fondo están ocultas las razones económicas de la empresa. 
b) Desde la Geografía Feminista

Nos interesa retomar este enfoque en tanto que aborda aspectos tales como el desarrollo del trabajo productivo y reproductivo en un mismo espacio, característica central del trabajo a domicilio subcontratado.

Las mujeres que trabajan en su casa reconfiguran su hogar como lugar de trabajo, además de que ajustan de manera creativa sus horarios cotidianos. (López, 2006). Por lo que es de suma importancia examinar lo que Silvia López llama los arreglos tempo-espaciales que las mujeres que trabajan en casa llevan a cabo para acomodar el trabajo productivo dentro del hogar, enfatizando sus consecuencias en los roles y las relaciones socio-espaciales de género. (López, 2006: 77). Es importante hacer hincapié en la diversidad de arreglos que se pueden dar -tanto los armoniosos como los conflictivos-, dependientes de varios factores, como el tipo de trabajo que desempeñan, las características de la familia, la clase, la ocupación, la educación, la etapa de vida en el que se encuentran y las circunstancias más amplias que rodean a estas mujeres.

Es necesario ver el hogar como un espacio económico y social. Asimismo, integrar la discusión desarrollada en apartados anteriores sobre la "conciliación" de tiempos y espacios productivos y reproductivos. Por lo que el estudio de la integración en los hogares que funcionan también como lugares de trabajo, es importante para analizar si es posible la conciliación y cómo ésta afecta la dinámica familiar.

Betty Beach (1989) encuentra en su estudio que el conflicto y la integración como estrategia ideal dependen de factores específicos, “...tales como el control sobre el proceso laboral, horarios flexibles, acceso de los miembros de la familia al lugar de trabajo- [que] pueden facilitar un balance entre trabajo y vida familiar." (Beach, 1989: 92). Por el contrario, las interrupciones mutuas entre familia y trabajo, largas jornadas y la intrusión de los niños pueden exacerbar tensiones entre la vida familiar y el trabajo remunerado. (López, 2006). 
Ver a las trabajadoras a domicilio subcontratado como actoras sociales, permite verlas con la capacidad de crear estrategias y resolver los conflictos que se les presentan de manera creativa, pues en la vida cotidiana tienen que enfrentar las contradicciones de sus papeles dobles, “...los cuales con frecuencia se manifiestan espacial y temporalmente en la reorganización de sus hogares para acomodar el trabajo pagado.” (López, 2006: 106)

Es de resaltar el hogar "...es un lugar continuamente renegociado - en ocasiones como un espacio privado, otras veces, como un sitio socioeconómico público y dinámico. En el hogar, entonces, las mujeres experimentan una diversidad de relaciones cuya naturaleza puede variar de conflicto a solidaridad." (López, 2006: 107) En el caso de las trabajadoras domiciliarias en Tehuacán que concentran un número considerable de mujeres dentro de sus casas, experimentan, tal como lo señala la autora, su espacio de manera pública y dinámica, por lo que las fronteras entre el espacio privado y público se diluyen, entre un ir y venir constante.

Linda McDowell (1989) plantea como propósito de las teóricas feministas la superación de la definición del hogar como un espacio doméstico y privado, debido a que debe ser considerado “...como un espacio dinámico donde la reproducción y la producción tienen lugar, y la distinción entre lo público y lo privado resulta poco clara (McDowell, 1989, Citada por López, 2006: 81). En esta visión, el hogar es un ambiente productivo y social significativo para las mujeres.

También se plantea la necesidad de poner atención en cómo influye el ambiente físico del hogar, y cómo a su vez es afectado por las prácticas productivas y reproductivas que las mujeres llevan a cabo en su interior. (López, 2006). En el caso de las trabajadoras a domicilio subcontratadas, se ha observado que modifican su espacio para integrar el material que utilizan para deshebrar, o en otras ocasiones acondicionan un espacio específico para que se desarrolle el trabajo, o estar totalmente superpuesto sobre el espacio reproductivo. 
Uno de los aspectos más importantes a destacar desde esta perspectiva es “...el género y la cambiante naturaleza de la relación entre producción y reproducción como parte de un mismo proceso que varía en tiempo y espacio." (McDowell, 1989: 59; Pratt y Hanson, 1991; Mackenzie, 1986). Este planteamiento se complementa con el planteado por Silvia López, donde señala que este tipo de análisis se centra en "...relaciones de género y el uso y construcción de espacio a nivel del hogar, teniendo como focus las prácticas sociales de las mujeres en su vida cotidiana." (López, 2006: 82)

Como ya he mencionado existen algunos autores que resaltan que esta estrategia de trabajo en casa puede llevar a la integración o a la oposición y al conflicto. Algunos como Betty Beach (1989) sugieren que la integración entre hogar y trabajo es una estrategia ideal que promueve la armonía, mientras que para otros como Kathleen Christensen (1993) el trabajo en casa puede conducir a la oposición y al conflicto. Silvia López rescata otra idea planteado por Minna Salmi (1996), que a mi parecer es más completa, señalando que “...estas distintas experiencias no constituyen polos opuestos; sino que forman parte de un continum." (Salmi, 1996: 82). Es decir, entre un ir y venir del conflicto a la armonía, lo que depende del tipo desde mi punto de vista de las estrategias que las mujeres desarrollen, del tipo de trabajo y del ciclo de vida, tal como lo había señalado antes.

De acuerdo con Minna Salmi (1996) la estrategia del trabajo remunerado en casa no está claramente definida, ya que tiene motivaciones complejas que pueden cambiar a lo largo del tiempo. Al igual que cambian sus circunstancias y contextos. (Salmi, 1996: 150 en López, 2006: 82).

En el caso de las trabajadoras a domicilio subcontratadas en contextos globalizados nos interesa analizar la diversidad formas y condiciones del trabajo productivo dentro de casa, sus consecuencias y significados para las mujeres involucradas en esta estrategia.

Por último, las mujeres que trabajan a domicilio buscan formas alternativas de organizar sus actividades remuneradas en la microgeografía de sus hogares por lo que crean nuevos usos de los espacios al remodelarlos y usarlos como lugares de trabajo temporales o 
permanentes (Mackenzie, 1986). Los arreglos del espacio están vinculados con el tipo de actividades que las mujeres desempeñan, el espacio disponible en el hogar, dependiendo del mercado y de las empresas subcontratistas. Los estudios desarrollados desde la Geografía Feminista han sido incorporados a la discusión general pues brindan pistas claras para el estudio del trabajo empalmado y superpuesto que desarrollan las trabajadoras domiciliarias subcontratadas.

\subsection{Los debates en México y América Latina}

En México han desarrollado estudios sobre el trabajo femenino productivo y reproductivo, autoras como Orlandina de Oliveira, Brígida García, Mercedes Blanco, Edith Pacheco, Marcela Eternod, María de la Paz López y en América Latina como Marcela Cerrutti y Elizabeth Jelin, entre otras que, dieron cuenta de la problemática a la que se enfrentaban las mujeres en los países de Latinoamérica, principalmente México.

Es importante rescatar los estudios sobre familia, mujer y trabajo porque aportan elementos de manera indirecta para el estudio del trabajo a domicilio subcontratado que afecta la vida familiar al recuperarlos completamos el estudio del trabajo a domicilio subcontratado, visto en su expresión más micro social.

En los años 80, desde el enfoque sociodemográfico, tiene lugar el estudio de la familia en México, con conceptos tales como el de familia, unidad doméstica y hogar para hacer referencia a "...las unidades residenciales conformadas por un conjunto de personas ligadas o no por lazos de parentesco- que comparten una vivienda y un gasto, principalmente destinado a la alimentación." (De Oliveira, 1999: 211), debido a que se le otorga un papel central en la reproducción cotidiana y generacional de los individuos. Se adopta un enfoque de género donde se introducen cuestionamientos importantes en los estudios de la familia, importantes para explicar lo que sucede en el trabajo a domicilio subcontratado, estos cuestionamientos se resumen a continuación. 
a) Se busca redefinir la visión del ámbito doméstico como espacio privado y propio de las mujeres y opuesto a la esfera de lo público, espacio masculino por excelencia.

b) Se subraya la diversidad de arreglos familiares existentes y se cuestiona a la familia nuclear con jefe varón como el único modelo que debe ser aceptado socialmente.

c) Se critica la visión de la familia como unidad con un interés común, cuyos integrantes comparten en forma armónica y solidaria derechos y responsabilidades.

d) Se intenta dar visibilidad al trabajo doméstico femenino, a la vez que se pone en duda el supuesto de que la división sexual del trabajo es algo natural, derivado de la capacidad reproductora de las mujeres. (De Oliveira, et al., 1999: 212-213)

Es en estos análisis se revisan de los procesos de formación y disolución de las familias, además de que se incursiona en el terreno de la estructura de los hogares, de acuerdo con el tamaño, la composición de parentesco y el ciclo de vida. Asimismo, se aborda el tema de las familias con jefatura femenina, arreglo familiar que ha recibido especial atención en los últimos años. (De Oliveira, et al., 1999)

Brígida García y Orlandina De Oliveira (2006), hacen un recorrido teórico por los estudios que se han llevado a cabo en México y América Latina en las dos últimas décadas del siglo XX y principios del XXI, donde destacan, los planteamientos que aluden a la división del trabajo y las formas de convivencia familiar.

Desde el punto de vista metodológico, destacan aquellos acercamientos que ponen especial interés en los individuos, tanto hombres como mujeres de distintas generaciones, y también en las familias, debido a que su estudio remite a la relación de los individuos con las instituciones. (García y De Oliveira, 2006)

Revisan las posturas funcionalistas de los años 70, que pretendían establecer las conexiones entre la familia, el trabajo y las transformaciones sociales más amplias. Su principal postulado tiene que ver con la idea de roles femeninos y masculinos, en las esferas de actividad, dentro de la familia y en la sociedad. 
Ubican otro enfoque, como el de las estrategias familiares de sobrevivencia o reproducción que tuvo un gran auge en México y América Latina en los años 70, pero sobre todo en los 80. Este enfoque nació en un contexto de crisis económica. Su contribución tiene que ver con “...la reflexión más amplia en torno de la producción y la reproducción social que hace énfasis en los nexos del sistema económico y las relaciones familiares en diferentes clases sociales." La familia es vista como mediación y como unidad de análisis, así como la importancia que le otorgaron al conjunto de "...comportamientos económicos y familiares en la búsqueda de la sobrevivencia común.” (García y De Oliveira, 2006: 28).

Las autoras plantean que la perspectiva de género ha llevado a profundizar en la naturaleza asimétrica de las relaciones familiares y también a redefinir el concepto de trabajo, para no incluir únicamente a las actividades productivas, sino también a las reproductivas.

Por último, para García y Oliveira la confluencia de diferentes enfoques teóricos ha llevado a retomar críticamente conceptos como riesgo, vulnerabilidad social y desinstitucionalización, que permiten entender los cambios laborales y familiares que acompañan al nuevo modelo de desarrollo.

En otro acercamiento, Brígida García, Mercedes Blanco y Edith Pacheco (1999) bajo una perspectiva de género estudian la incorporación de la mujer al mercado de trabajo, abordando las transformaciones sectoriales, ocupacionales, del autoempleo y el sector informal, haciendo hincapié en la segregación entre géneros y en los estudios acerca de este fenómeno. También dan cuenta de las diferencias entre los sexos y la discriminación de las mujeres en el mercado de trabajo. (García, et al., 1999)

Para abordar la participación económica desde una perspectiva de género se deben tener en cuenta aspectos tales como:

1. Abordar el problema de la insuficiente visibilidad de la actividad económica de las mujeres, ya que se tiende a subestimar su contribución a la esfera productiva.

2. La importancia de establecer las diferencias entre la actividad masculina y la femenina, y señalar en qué medida dichas diferencias se convierten en desigualdades.

3. Es crucial relacionar el trabajo extradoméstico con el doméstico. 
Por su parte Elizabeth Jelin (1994), hace un estudio de la familia en América Latina, donde aborda la organización doméstica como tema de análisis, ligando los procesos sociales de producción y de reproducción. Plantea el aumento en la proporción de mujeres en la fuerza de trabajo que tiene efectos directos sobre la organización familiar. Estas tendencias apuntan a transformaciones en la organización doméstica y a reestructuraciones de los lazos de convivencia y de las obligaciones basadas en el parentesco. Por lo que son estos aspectos los que contribuyen, a su parecer, a la renovación de los estudios de la familia.

Por último. Marcela Cerrutti (2002) hace un estudio en Argentina, en la década de los 90 donde lo que pretende es dar cuenta de las intersecciones entre género, trabajo y familia. Con un grupo de 19 mujeres no profesionales y de clase económicamente baja, sus compañeros e hijos. Con lo que se propone examinar “...cómo la situación de clase establece diferencias en las experiencias y percepciones de las entrevistadas, y además, busca ilustrar el modo en que las relaciones entre género, familia y trabajo se encuentran atravesadas por la situación de clase de dichas mujeres." (Cerrutti, 2002: 108).

Para ello, su principal objetivo es explorar tres campos de investigación que se resumen a continuación:

1. Teniendo en cuenta el tipo de empleo que en la actualidad desempeñan, se observarán las relaciones que existen entre la participación de las mujeres casadas (o unidas) en actividades económicas y sus trayectorias laborales pasadas;

2. Las relaciones entre los géneros, particularmente en lo relativo a los arreglos laborales establecidos entre las parejas y la división familiar del trabajo doméstico, y

3. La dinámica general de las familias.

La intención es dar respuesta a las siguientes interrogantes: ¿Cómo se deciden las mujeres a trabajar o no trabajar?, ¿Cuáles han sido los principales obstáculos en la búsqueda de empleo? y ¿Cómo se organiza la vida familiar de mujeres que trabajan o han trabajado? Este estudio es un claro ejemplo de la importancia que tiene el abordar tanto el trabajo productivo como el reproductivo, para dar cuenta de su complejidad. 
Estos estudios nos brindan un panorama general metodológico del tema de la vida familiar para el caso del trabajo a domicilio subcontratado. Es importante retomar el enfoque de género al estudiar una actividad desarrollada principalmente por mujeres. Estos estudios nos brindan ejemplos claros de cómo ha sido estudiado el mundo productivo y reproductivo.

\section{Conclusiones}

En este capítulo abordamos de manera detallada las líneas teóricas más importantes, a nuestro parecer, del trabajo a domicilio subcontratado. Este tipo de trabajo se diferencia del estudiado hasta ahora al desarrollarse en un contexto de globalización y flexibilización, a través de encadenamientos que son posibles por la subcontratación en la industria de confección de ropa.

El estudio del trabajo a domicilio subcontratado guarda aspectos laborales importantes, como el de la precariedad de sus condiciones laborales, el asalariamiento disfrazado que invisibiliza su importancia para el desarrollo de la industria de confección de ropa. Estos aspectos son desarrollados durante todo el capítulo, por los principales estudiosos del trabajo a domicilio y serán analizados en el estudio empírico.

La triada analítica entre subcontratación, trabajo a domicilio y simultaneidad del trabajo productivo y reproductivo, nos brinda los elementos teóricos necesarios para comprender la complejidad que implica el estudio del trabajo a domicilio subcontratado y sus consecuencias en el mundo doméstico.

Existen distintos niveles en el que puede ser abordado el estudio del trabajo a domicilio subcontratado, por un lado, el nivel macro donde el tema de la subcontratación es central para entender cómo es que el trabajo a domicilio es posible y, a partir del cual es revitalizado. El otro nivel es donde los estudios micro como el de la vida cotidiana son importantes, ya que nos ayudan a escudriñar cómo es que el trabajo productivo y reproductivo se desarrolla en el mundo de lo doméstico, con todas las contradicciones que 
de ello se derivan. A su vez los estudios de la vida cotidiana proponen la manera de estudiar lo productivo y lo reproductivo de manera conjunta, asimismo cuestiona y pone en el debate el tema de la conciliación del trabajo productivo y reproductivo, aspecto relevante y central, que va a ser estudiado y analizado en mi estudio empírico.

Finalmente es importante rescatar los estudios sobre la geografía feminista, los que nos brindan los planteamientos teóricos para el análisis de los cambios espaciales en el ámbito doméstico, el cual deja de ser privado, para convertirse en un espacio público y productivo. 


\section{CAPÍTULO II}

\section{LA MAQUILA DE CONFECCIÓN DE ROPA}

\section{Introducción}

En este capítulo se hace un balance general de la situación actual de la industria de confección de ropa en México y en Tehuacán, Puebla. Se indaga en el trabajo a domicilio subcontratado que forma parte de la cadena de producción global de ropa. Es necesario entonces dar cuenta del contexto que envuelve al trabajo domiciliario. La discusión parte del señalamiento de los aspectos más importantes en el surgimiento de la maquila, así como también presenta las distintas posturas teóricas que se ocupan de su estudio.

Debido a que la industria de confección se caracteriza por un proceso de encadenamiento a través de la subcontratación, es que resulta de relevancia desentrañar el contexto global y local en el cual se desenvuelve, por lo que explicaré las distintas formas que toman las cadenas globales de producción, al igual que sus características, las cuales tienen que ver con el proceso de diseño, producción y comercialización de las prendas de vestir hoy en día. Para ilustrar este contexto, también se hace referencia a la normatividad internacional, es decir, tratados y acuerdos que se firmaron para regir a la industria de confección, entre los que destaca el TLCAN firmado en 1994. Por último, se describirá el contexto específico del municipio de Tehuacán, Puebla, analizando el proceso de encadenamiento local e internacional, sus consecuencias y presencia actual.

Todos estos aspectos, forman parte del contexto en el que tiene lugar el trabajo a domicilio femenino subcontratado. A partir de ellos se busca demostrar que las mujeres de los talleres de deshebrado en Tehuacán, Puebla, se encuentran encadenadas a un proceso económico mayor. Son mujeres que realizan una tarea desde sus casas, inmersas en un contexto 
económico más amplio, que las condiciona a sus necesidades de producción y que repercute en su vida laboral y familiar de manera directa.

\subsection{El proceso de instalación de las maquilas en territorio mexicano.}

El trabajo a domicilio subcontratado, como se ha mencionado, se encuentra enmarcado por un contexto mundial de globalización, reestructuración económica, flexibilidad del trabajo, crisis económica, desempleo, originando la apertura externa del mercado nacional y la atracción de capitales extranjeros. En ese contexto las maquilas fueron presentadas desde los años setenta, como la panacea para combatir el desempleo, obtener divisas y propiciar la transferencia de tecnología.

Tal como lo señala Morales (2002) “...la dinámica de las maquiladoras está articulada con el proceso complejo que ha envuelto a la reestructuración productiva, que ha impulsado la empresa trasnacional para enfrentar la crisis de largo plazo del capitalismo. La maquila, surge como un eslabón de la cadena productiva industrial y una estrategia económica de la empresa global." (Morales, 2002: 10).

Después de muchos estudios es indiscutible que una de las principales ventajas que México, de manera particular, les proporciona a las grandes transnacionales es la mano de obra barata y la reducción de los costos de producción a través de exenciones fiscales. Estos aspectos son clave y se encuentran presentes desde el inicio, cuando la primera maquila comenzó a operar en territorio mexicano. (De la O y Quintero, 2001; De la Garza, 2005)

María Eugenia de la O (2001) en su artículo "Ciudad Juárez: un polo de crecimiento maquilador" propone varias etapas de crecimiento de la maquila, desde el punto de vista de su estructura de empleo, expansión, localización y definición productiva. El siguiente cuadro presenta sus ideas, las cuales son actualizadas al día de hoy. 
ETAPAS DE LA INDUSTRIA MAQUILADORA EN MÉXICO

\begin{tabular}{|c|c|c|c|}
\hline $\begin{array}{c}\text { PRIMERA ETAPA } \\
(1966-1975)\end{array}$ & $\begin{array}{c}\text { SEGUNDA } \\
\text { ETAPA } \\
(\mathbf{1 9 7 6 - 1 9 9 5 )}\end{array}$ & $\begin{array}{l}\text { TERCERA ETAPA } \\
\text { (Década de los 90) }\end{array}$ & $\begin{array}{c}\text { CUARTA ETAPA } \\
(2000-2009)\end{array}$ \\
\hline $\begin{array}{c}1966 \\
\text { Integración de la } \\
\text { industria maquiladora en } \\
\text { las "zonas libres" y que } \\
\text { forma parte de una } \\
\text { estrategia de corto } \\
\text { alcance para generar } \\
\text { empleos y conformar } \\
\text { espacial y } \\
\text { productivamente las } \\
\text { ciudades y los mercados } \\
\text { locales de trabajo. } \\
1975 \\
\text { Cierre de maquiladoras- } \\
\text { capital golondrino }\end{array}$ & $\begin{array}{c}\text { Caracterizada por la } \\
\text { consolidación y } \\
\text { diversificación } \\
\text { tecnológica de la } \\
\text { industria que estuvo } \\
\text { favorecida por la crisis } \\
\text { económica de } 1982 . \\
\\
\text { 1980-1990 } \\
\text { Fase de } \\
\text { especialización } \\
\text { industrial: automotriz, } \\
\text { electrónica y } \\
\text { confección }\end{array}$ & $\begin{array}{c}\text {-Marcada por los } \\
\text { efectos del TLCAN en } \\
\text { los patrones de } \\
\text { subcontratación, el } \\
\text { declive del sindicalismo } \\
\text { maquilador y la } \\
\text { unilateralidad } \\
\text { empresarial en la } \\
\text { regulación de las } \\
\text { condiciones de trabajo. } \\
\text {-Crecimiento constante } \\
\text { y consolidación de los } \\
\text { patrones de localización } \\
\text { industrial a través de } \\
\text { parques y áreas } \\
\text { industriales }\end{array}$ & $\begin{array}{c}\text {-Crisis de la maquila. } \\
\text { El personal ocupado } \\
\text { disminuyo. } \\
\text { El número de } \\
\text { establecimientos } \\
\text { maquiladores se } \\
\text { redujo. } \\
\text { China desplaza a } \\
\text { México como } \\
\text { principal exportador } \\
\text { hacia los EE.UU. }\end{array}$ \\
\hline
\end{tabular}

Fuente: De la O, 2001

La primera etapa (1966-1975) se refiere a la integración de las maquiladoras en las "zonas libres", este proceso se describe a continuación:

La maquila en México tuvo un origen común tal como lo señalan De la O y Quintero (2001), después de la cancelación del Programa de Braceros en 1964 y al desempleo que de ello se originó: “...derivado, en gran medida, de las políticas de crecimiento y fomento a la inversión extranjera en la frontera norte en los años sesenta." (De la O y Quintero 2001: 14). En 1965 se puso en marcha el Programa de Industrialización Fronteriza, donde se busca la localización de segmentos productivos de multinacionales en la zona libre del país, como una estrategia de corto alcance para generar empleos en estas regiones, fomentar la localización de fábricas -en su mayoría extranjeras-, así como un nuevo esquema de desarrollo económico en la región. (De la O, 2001)

Las empresas extranjeras, principalmente provenientes de Estados Unidos, encontraron facilidades y concesiones para su ubicación en México. La cercanía geográfica, la utilización de insumos como el agua y la electricidad, además de concesiones fiscales y facilidades aduanales para el establecimiento de plantas maquiladoras como 
“...un decreto de fomento para la operación de la industria maquiladora que la autorizaba a vender en el país hasta el $20 \%$ de su producción; la autorización del impuesto al valor agregado con tasa cero; la aplicación de la Ley de Inversión Extranjera, que agilizaba los procedimientos de autorización de permisos automáticos para las nuevas industrias o para la relocalización de éstas, y la autorización del pedimento consolidado, que derogaba los trámites y fianzas por cada importación o exportación, lo que permitió que cada cierto tiempo (seis meses) se realizaran las declaraciones." (De la O, 2001: 31)

En un inicio sus actividades se orientaron a la fabricación de productos de madera, para la década de los setenta se instalaron maquiladoras de la industria textil y de la confección, así también se especializaron en el ensamble de productos del ramo electrónico y automotriz. Un aspecto relevante es que las maquiladoras utilizan insumos producidos en Estados Unidos, lo que originó que en la mayoría de los casos la producción funcionará sin eslabonamientos con el resto de la economía nacional. Las fábricas se caracterizaron por el “....uso intensivo de la fuerza de trabajo en actividades de ensamble, atendiendo al esquema de ventajas comparativas en cuanto a la abundancia y bajo costo de la fuerza laboral. Empleaban especialmente a mujeres jóvenes." (De la $\mathrm{O}, 2006: 85$ )

A partir de 1976 hasta 1982 comenzó la segunda etapa de consolidación de la industria maquiladora, la cual se caracterizó por “...el incremento de su peso relativo en relación con variables como la ocupación, el número de establecimientos y el valor de la exportación.” (De la O, 2001: 32) La década de los setenta está marcada por el cierre de algunas plantas debido a la recesión económica de Estados Unidos. A esta etapa se le denominó "golondrina", al ponerse al descubierto la volatilidad de este tipo de industria.

Al concluir la recesión, empezó una segunda etapa de lenta consolidación de la industria con índices de crecimiento constantes. Este proceso se benefició con la crisis mexicana de 1982 y la devaluación del peso.

De acuerdo con Ruiz y Velazco (1995) y De la O (2001), las maquiladoras se enfocaron en atraer fuerza laboral masculina. Pero, para principios de la década de los ochenta a partir de 
numerosos estudios se constató la participación predominante de mujeres en las maquilas, sobre todo, de la confección de ropa, ya que el salario de los hombres se empobreció, principalmente por la crisis económica, provocando que las mujeres se incorporaran al mercado laboral.

El tercer periodo de crecimiento corresponde a los años posteriores a la crisis de 1982, hasta la recesión económica estadounidense al inicio de los noventa. Este lapso se caracterizó por un rápido aumento de las contrataciones en las maquiladoras, especialmente entre 1983 y 1984. (De la O, 2001: 33)

Se instrumentaron programas que impulsaron la industria como el Programa de Fomento a la Industria Maquiladora de Exportación 1983-1988 y el Programa Nacional de Fomento a la Industria y el Comercio Exterior. Aunque no fue sino con el TLCAN firmado entre Estados Unidos, Canadá y México que las maquiladoras tomaron empuje, extendiéndose por todo México.

También se caracteriza por una clara consolidación de patrones de localización industrial en la ciudad a través de parques y áreas industriales; así como una mayor complejidad en las formas de subcontratación bajo el régimen maquilador. (De la O, 2001: 36)

La cuarta etapa va a estar marcada por la recesión económica de EE.UU. del 2001, lo que originó que la maquila dejara de crecer y que tres años después siguiera estancada. Para el 2003 había expulsado alrededor de 236000 trabajadores.

De la Garza (2005b) atribuye las causas de esta crisis a tres factores principales:

1. "La caída en la demanda de productos de las Maquilas, debido a la recesión en la economía de los Estados Unidos.

2. La competencia de otros países de salarios más bajos que México, tales como China y los países de América Central, provocando el cierre de maquilas en México y su traslado hacia alguno de aquellos países.

3.El crecimiento de los salarios de la maquila en México en los últimos años, lo que habría reducido el margen de ganancia de este sector." (De la Garza, 2005: 3). 
En la actualidad estudios como el desarrollado por María Eugenia de la O (2007), han dado cuenta de la reciente desfeminización de la fuerza de trabajo en la industria maquiladora de exportación (IME), debido a que se ha registrado una paulatina paridad de participación por sexo y, en algunos casos una contratación de hombres más dinámica con respecto a la de las mujeres. Asimismo, la expansión del empleo femenino en las nuevas regiones maquiladoras al Occidente, Centro y Península de Yucatán. Por lo que es necesario hacer una revisión tanto del momento por el que atraviesa la industria en general, así como del sector que se trate, ya que no ocurre lo mismo en el sector de autopartes que en el sector de la confección o en el de la electrónica.

\subsection{Posturas y debates en torno a las maquilas}

Tal como lo señala De la Garza (2005b) la idea central del programa de maquilas de exportación ha sido la de atraer capital productivo exportador con la finalidad de incrementar la inversión productiva, de crear empleo, lograr transferencia de tecnología, elevar la calificación de la mano de obra y equilibrar las balanzas de capitales y mercancías por la inversión directa y las exportaciones de la maquila. (De la Garza, 2005b: 1)

En este apartado voy a desarrollar las diferentes posturas que existen en torno a la maquila, aquellas que la presentan como una vía aceptable de desarrollo industrial, a través, de una transición (upgrading) del ensamble sencillo a la manufactura compleja y aquellos que consideran que no es una vía aceptable de crecimiento de la economía y de empleos dignos.

En primer lugar, destacan las posturas críticas como la de De la Garza (2005a, 2005b) quien señala que la maquila es una empresa que hace tareas productivas para otra, y su principal desventaja es la limitación en la toma de las decisiones principales, ya que estas se llevan a cabo en el extranjero. También señala que existen múltiples explicaciones que aceptan que “...la maquila es un sector basado en bajos salarios, y por tanto que cuando esta ventaja nacional se agota, la Maquia tiende a salir del país o a cerrar simplemente sus plantas." Señala también que "La maquila es un eslabón de la cadena industrial transnacional, no de la industria mexicana, por lo que no se ha podido convertir en un motor de la industrialización del país, ni en un eslabón interno de la producción nacional (De la Garza, 
et al., 2005: 2, 34)

Existen otras posturas más optimistas que aceptan que la maquila empezó como un trabajo de ensamble fordista, con trabajo no calificado, mayoría de mujeres, bajos salarios, tecnología basada en herramientas o en máquinas no automatizadas; con organización taylorista del trabajo y con muy escasos encadenamientos productivos y de servicios en el territorio nacional.

Sin embargo, añaden los partidarios de esta posición, que la maquila ha tendido a transformarse, a partir de la década del ochenta, en una actividad que no se reduce al ensamble sino que incorpora procesos propiamente de manufactura, con tecnología automatizada, con nuevas formas de organización del trabajo, con obreros más calificados o un incremento en el porcentaje de técnicos de producción, que ha implicado mayor aprendizaje tecnológico y la formación de clusters y otros encadenamientos productivos y de servicios (Carrillo y Hualde, 1997; 2002; Lara, 1998; Gereffi, et. al, 2002). En resumen, esta propuesta presenta a la maquila como una vía de desarrollo industrial a través de una transición (upgrading) del ensamble sencillo a la manufactura compleja.

Por otro lado, las posturas críticas como la de De la Garza (2005), considera que los que mantienen posiciones optimistas han declinado debatir en torno a si la maquila es realmente un modelo de producción e industrialización.

Por último, al hacer un balance de los distintos estudios relacionados con la maquila, podemos advertir de la necesidad de profundizar en las diferencias regionales y sectoriales del sector maquilador. Que llevarían a localizar procesos de upgrading en la frontera norte, en ciertos sectores industriales, como el automotriz, y procesos precarios en el centro y sureste del país, en sectores como el de la confección. 
La importancia de este recorrido radica en enmarcar el contexto de las trabajadoras a domicilio en la industria de confección, por lo que, a continuación, presentaremos cómo se desenvuelve este tipo de industria, con la finalidad de amarrar la discusión.

\section{Encadenamiento global en el sector de la industria de la confección}

Las cadenas globales de producción forman parte del fenómeno más amplio de globalización teniendo que ver con aspectos, tales como el desplazamiento de parte de la producción de los países industrializados a países del tercer mundo, que se encuentran fuertemente vinculados y en la mayoría de los casos bajo las necesidades y objetivos de producción de estos países. Incentivados por acuerdos, tratados y leyes que regulan la manera en que se debe de producir, los costos que se deben de pagar y su tiempo de duración. Este último aspecto se profundizará más adelante.

A continuación, trataré de explicar las distintas formas que toman las cadenas globales de producción, al igual que sus características, las cuales tienen que ver con el diseño, producción y comercialización de productos como computadoras, automóviles y ropa.

Me parece importante comenzar diciendo, tal como lo plantea Gereffi (2000), que una cadena productiva desarrolla “...toda la gama de actividades que suponen el diseño, la fabricación y la comercialización de un producto" y son básicamente de dos tipos: a) Las cadenas dirigidas por los fabricantes y b) Las cadenas dirigidas por los intermediarios. (Gereffi, 2000: 11)

Las primeras son aquellas “...en que los grandes productores, generalmente transnacionales, cumplen el papel fundamental de coordinar la producción. Este tipo es característico de las ramas de actividad que hacen un uso intensivo del capital y la tecnología, como la automovilística, la aeronáutica y la fabricación de computadoras, semiconductores y maquinaria pesada." (Gereffi, 2000: 11-12). Este es uno de los tipos más extendidos en nuestro país, pero desde el punto de vista de la fuerza de trabajo contratada no es el más importante, por lo que no es el que nos interesa estudiar. 
Mientras que las segundas se caracterizan porque

"...se vinculan a industrias en que las grandes tiendas de menudeo, las comercializadoras y los fabricantes de marcas desempeñan el papel primordial en el establecimiento de sistemas de producción descentralizados en diversos países exportadores, generalmente ubicados en el tercer mundo. Esta modalidad de industrialización impulsada por el comercio se ha vuelto común en las industrias de bienes de consumo que hacen un uso intensivo de la mano de obra, como el vestido, el calzado, los juguetes, los enseres domésticos, los artículos electrónicos de consumo y una variedad de artesanías." (Gereffi, 2000: 11-12).

Habitualmente "la producción está a cargo de redes escalonadas de contratistas de países del tercer mundo que fabrican los productos finales para compradores extranjeros. Las grandes tiendas de menudeo o las comercializadoras que piden los productos definen las especificaciones correspondientes." (Gereffi, 2000: 12). Es decir, que estas empresas diseñan o comercializan, pero no fabrican los productos, por lo que son los llamados "fabricantes sin fábricas" que separan la producción física de los bienes de las etapas del diseño y la comercialización del proceso productivo. (Gereffi, 2000: 12).

Asimismo, esta cadena corresponde a la vía de baja intensidad de capital y alta intensidad de mano de obra, que Enrique De la Garza llama "toyotismo precario" y que es la más extendida en países como México, sobre todo en la maquila, debido a que las empresas en su necesidad por reestructurar el proceso productivo han optado por modificar la organización del trabajo y han apostado por la flexibilidad del mismo, sobre todo de sus relaciones laborales. Son pocas las empresas que invierten en tecnología dura. (De la Garza, 2005).

Esto supone formas de organización del trabajo donde se mezcla taylorismo con toyotismo, lo que “...implica baja calificación de la mano de obra, bajo salario, alta rotación externa; segmentación entre concepción y ejecución, culturas laborales presumiblemente de poco apego a la empresa; poca delegación de las decisiones productivas hacía los obreros por parte de la gerencia. [...] Es posible que la expansión de la producción moderna y el 
crecimiento de la productividad en los noventa hayan descansado en las potencialidades de este toyotismo precario." (De la Garza, 2005: 84)

Debido a que nuestro interés se centra en la cadena de producción de la industria de confección de ropa, es que nos abocaremos a la cadena dirigida por los intermediarios, la cual tiene, como ya se mencionó, el rasgo distintivo de estar dirigida por tiendas de menudeo, diseñadores y comercializadores. Estos tres “...ejercen un control considerable sobre la forma, el momento y el lugar en que se realizará la fabricación, y qué utilidades se obtendrán en cada etapa del proceso." (Gereffi, 2000: 13). Aspecto de importancia para los fabricantes, debido a que tienen que responder a las necesidades que les fijan las grandes firmas. En este sentido, existen tres tipos de "empresas principales" o "firmas" en la cadena de productos del vestido y estos se explican a continuación:

Por un lado, se encuentran los comercializadores detallistas-minoristas de ropa-Wal Mart, por ejemplo-. Estos establecen contratos sobre volúmenes determinados de prendas con maquiladores de terceros países y son los que se responsabilizan por los materiales y la manufactura, incluyendo en ocasiones el diseño y los procedimientos de ensamblaje. Por tanto, su cualidad reside en que se trata de la producción de grandes lotes estandarizados.

Por otro lado, están los comercializadores de marca (como Gap, Levis, Wrangler, Old Navy, Tommy, Guess, Nike) que son los llamados "fabricantes sin fábricas". Debido a que contratan con productores de terceros países, de acuerdo a volúmenes y especificaciones que están pensados para obtener sus ofertas de mezclas. Una cualidad más es el ensamble de prendas ajeno a los criterios del productor que se guía por los diseños exclusivos de las marcas. Este es el caso más generalizado en la industria de la confección.

Por último, están los productores de marca (como Sara Lee), son los comercializadores que aún tienen fábricas fuera de sus países sede y también han aprovechado las regulaciones del Régimen 807 para trasladarse a otras regiones donde realizan la fabricación utilizando sus redes propias de proveeduría, aprovisionando esos lugares de producción con telas y accesorios. (Juárez, 2004; Gereffi, 2000) 
En los tres casos son las grandes firmas las que dictan cómo se producirá, bajo qué lineamientos, en qué cantidades y bajo qué diseños. A partir de la subdivisión del trabajo, vía la subcontratación, a empresas medianas y pequeñas ubicadas regularmente en países del tercer mundo, encargadas sobre todo de ensamblar las partes de la prenda, el deslavado (en algunos casos), planchado, acabado final y empaquetado.

\subsection{Acuerdos y tratados}

La historia de la regulación en la industria de confección comienza en la década de los 50, cuando se firma el acuerdo llamado de restricción voluntaria entre Estados Unidos y Japón, que consistía en un régimen arancelario que “...permite un tratamiento especial a ciertos productos norteamericanos que salen y vuelven a entrar. De acuerdo con el tratamiento aduanero para este programa sólo se pagan derechos sobre el valor agregado y no sobre la fracción norteamericana que retorna." (Juárez, 2004: 29). A esto también se le llamó "producción compartida" y su regulación va a darse por una ley que se denominó 807.00 e inició en el año de 1963. Éste fue uno de los primeros acuerdos que marcó la pauta de producción no solamente entre EU y Japón, sino entre EU y el resto de los países, sobre todo del tercer mundo.

A estos acuerdos le siguieron otros como el de sistemas preferenciales, que consistía en un conjunto de políticas arancelarias cuyas expresiones más conocidas son el esquema de la Nación Más Favorecida (NMF), el esquema del Sistema Generalizado de Preferencias (SGP) y el Esquema de Maquiladoras (EZP). (Juárez, 2004)

Estos acuerdos tienen que ver con un fenómeno más amplio ocurrido en EE.UU. con la reestructuración textil norteamericana. Ésta ingreso en una nueva fase de modernización de equipo y maquinaria, además de un naciente uso de nuevas fibras textiles. Esto fomentó la utilización de mano de obra extranjera, pero con la exigencia de utilizar telas estadounidenses. Para ello se firman acuerdos donde se asienta que la tela sea fabricada y cortada por los EE.UU., lo que llevo en el largo plazo a que la industria textil de países 
como México entrara en crisis, pues no se utilizaba tela nacional y se veía fragmentada la cadena de producción nacional.

Otro acuerdo importante durante esta transformación es el Acuerdo Multifibras (AMF) que se firma en 1974, el cual trata de una "...regulación que permite a los países con alto desarrollo $<<$ negociar o imponer unilateralmente restricciones cuantitativas (cuotas) contra las importaciones de productos textiles y de la confección provenientes de los países en vías de desarrollo>>." (Chacón, 2000 en Juárez, 2004: 31) Este acuerdo se complementa con la ley 807 donde se plantea que “...la regla general es que los componentes que forman parte del producto ensamblado deben ser producidos en EU y como ingredientes adicionales tenemos que los derechos de importación se establecen a partir del valor agregado en otros lugares.” (Juárez, 2004: 33)

Por último, se firman dos acuerdos importantes previos al TLCAN. El Sistema Armonizado (SA) y el Acuerdo sobre los Textiles y el Vestido (ATV). El primero

“...está dirigido especialmente a promover la relocalización de la industria del vestido a las regiones del sur de América del Norte y, por otra parte, se transforma en una barrera para contener las exportaciones de las regiones asiáticas, quienes, irónicamente, impulsadas por el proteccionismo norteamericano, pasaron a niveles mayores de integración de su industria (paquete completo) y con ello amenazaban nuevamente a la producción norteamericana con sus grandes volúmenes y sus bajos costos." (Juárez, 2004: 33).

El segundo (ATV) consiste en “....un programa de liberalización de restricciones existentes, especialmente las devenidas del AMF, que deberán actualizarse en función de las normas del GATT y ahora de la OMC." (Juárez, 2004: 39) Es sobre este acuerdo que tienen que discutirse las características que asume la producción textil y de bienes del vestido en nuestras regiones.

Bajo este contexto, México fue durante varios años el principal productor de prendas de vestir para los EE.UU., papel que se consolidó después de la firma del TLCAN en 1994. La segunda mitad de la década de los noventa fue la época de auge de la maquila de exportación de ropa a los EE.UU. Sin embargo, al inicio de la década siguiente, en 2001 la 
desaceleración económica de EU obligó a realizar procesos de ajuste y recomposición. La consecuencia más importante para México fue poder su posición de primer exportador, por lo que, al no tener respuesta a la contracción del mercado norteamericano, en el 2002 fue desplazado como primer productor, por los exportadores de la República Popular China quienes lograron desarrollar el "paquete completo", logrando un carácter más competitivo.

Hoy día, la industria de confección en México vive una verdadera crisis, ya que las firmas estadounidenses buscaron otros países que les ofrecieran mano de obra más barata y donde México no fue capaz de desarrollar una industria más competitiva que tratará de desarrollar áreas como el diseño y la comercialización.

\subsection{La relocalización de la industria de confección de ropa en México.}

María Eugenia de la O y Cirila Quintero (2001) señalan que el fenómeno maquilador se caracteriza por su complejidad, debido a la diversidad productiva, laboral y espacial que ha logrado desde la instalación de la primera planta en la frontera norte, y que si bien las maquiladoras en México tuvieron un origen común derivado de las políticas de crecimiento y fomento a la inversión extranjera en la frontera norte en los años sesenta, su crecimiento, distribución geográfica, especialización productiva y tipo de relaciones laborales variaron con el tiempo.

Actualmente, es posible distinguir “...asentamientos industriales de viejo cuño que se han tornado en los núcleos tradicionales y más consolidados de la maquila de exportación en la frontera norte, como Ciudad Juárez, Matamoros y Tijuana. En este sentido podrían considerarse como < <las fronteras tradicionales de la industria maquiladora >>." (De la $\mathrm{O}$ y Quintero, 2001: 14).

A su vez, describen los asentamientos asociados con un esquema característico de las ventajas comparativas de los años setenta, es decir, las fronteras en transición atrofiada, debido a que compiten con espacios económicos regionales más ventajosos en la frontera norte. Otro aspecto relevante es que tienen la presencia de sindicatos activos y empresarios 
tradicionales con escasa iniciativa. Ejemplo de ello son las ciudades de Nogales y Piedras Negras. (De la O y Quintero, 2001)

Con la firma del TLCAN se propicia el crecimiento y despegue de la maquila en Mexicali y Hermosillo, zonas que no iniciaron tempranamente sus actividades sino hasta entrada la década de los ochenta y son denominadas en transición expansiva. Para 1997, México se convirtió en el principal productor de prendas de vestir para el mercado norteamericano, desplazando a los productores del lejano oriente como la República Popular China, Hong Kong, Corea, Taiwan, etc. (Juárez, 2004)

Fue durante ese periodo que diversas regiones mexicanas se integraron dentro de las cadenas productivas y comerciales, entre otras: La Comarca Lagunera, El Bajío, el Centro Sur, la Península de Yucatán y Puebla, a los pedidos. Estas ciudades se destacan por contar con trayectorias histórico-regionales emergentes. Las cuales responden a un proceso de localización de estas actividades en ciudades medias y localidades rurales no fronterizas, sobre todo a fines de los sesenta y profundizándose en los noventa, son las llamadas nuevas fronteras de la industria maquiladora. (De la O y Quintero, 2001; Juárez, 2004). Es en este último caso me enfocaré más adelante.

Con este desplazamiento geográfico hacia el centro y sureste del país, México se convirtió en un lugar favorable para las empresas de la industria de la confección de ropa, debido, sobre todo, a las ventajas que produce la cercanía y el bajo costo de producción. 


\section{RELOCALIZACIÓN DE LA MAQUILA DE CONFECCIÓN DE ROPA EN MÉXICO}

\begin{tabular}{|c|c|c|c|}
\hline $\begin{array}{c}\text { FRONTERAS } \\
\text { TRADICIONALES }\end{array}$ & $\begin{array}{l}\text { FRONTERAS EN } \\
\text { TRANSICIÓN } \\
\text { ATROFIADA }\end{array}$ & $\begin{array}{c}\text { EN TRANSICIÓN } \\
\text { EXPANSIVA }\end{array}$ & $\begin{array}{c}\text { LAS NUEVAS } \\
\text { FRONTERAS DE LA } \\
\text { INDUSTRIA } \\
\text { MAQUILADORA }\end{array}$ \\
\hline $\begin{array}{l}\text {-Asentamientos } \\
\text { industriales de viejo } \\
\text { cuño que se han } \\
\text { tornado en los núcleos } \\
\text { tradicionales y más } \\
\text { consolidados de la } \\
\text { maquila de } \\
\text { exportación en la } \\
\text { frontera norte, como } \\
\text { Ciudad Juárez, } \\
\text { Matamoros y Tijuana }\end{array}$ & $\begin{array}{c}\text {-Asociados con el } \\
\text { esquema característico } \\
\text { de las ventajas } \\
\text { comparativas de los años } \\
\text { setenta. } \\
\text {-Compite con espacios } \\
\text { económicos regionales } \\
\text { más ventajosos en la } \\
\text { frontera norte. } \\
\text {-Presencia de sindicatos } \\
\text { activos y empresarios } \\
\text { tradicionales con escasa } \\
\text { iniciativa. } \\
\text {-En ciudades como } \\
\text { Nogales y Piedras } \\
\text { Negras. }\end{array}$ & $\begin{array}{c}\text {-No iniciaron } \\
\text { tempranamente. } \\
\text {-En los } 80 \text { presentan } \\
\text { una relativa expansión } \\
\text { en este tipo de } \\
\text { industrias. } \\
\text {-En este caso es } \\
\text { importante el TLCAN } \\
\text { en el crecimiento de la } \\
\text { maquila al propiciar su } \\
\text { despegue. } \\
\text {-Ejemplos son los } \\
\text { casos de Mexicali y } \\
\text { Hermosillo. }\end{array}$ & $\begin{array}{l}\text {-Ciudades con } \\
\text { trayectorias histórico- } \\
\text { regionales emergentes. } \\
\text {-Responden a un proceso } \\
\text { de localización de estas } \\
\text { actividades en ciudades } \\
\text { medias y localidades } \\
\text { rurales no fronterizas. } \\
\text { - A fines de los sesenta y } \\
\text { profundizándose en los } \\
\text { noventa. } \\
\text {-Ejemplos son } \\
\text { Guadalajara y Mérida } \\
\text { Yucatán. }\end{array}$ \\
\hline
\end{tabular}

Fuete: De la O 2001, 2006

Las maquilas fueron presentadas como una estrategia de creación de empleos frente a la imposibilidad de generar un proyecto local. De esta forma, la especialización productiva junto al declive económico de las principales actividades en algunas ciudades tuvo como resultado la conformación de regiones maquileras. En el caso de la frontera norte del país, predominan las actividades de procesamiento de productos electrónicos y de autopartes, mientras que las regiones interiores del centro, occidente y sur se han especializado en la confección y el vestido con bajas remuneraciones y malas condiciones laborales. (De la O, 2006: 86)

Por último, es de destacar que la expansión de las maquiladoras ha propiciado la internacionalización de la base económica de varias ciudades del país, ocasionando la reorganización del trabajo y del capital local. Tal como lo señala De la O (2006), un elemento indicativo de dicho proceso es la polarización de las ocupaciones y de los salarios de la fuerza de trabajo, en un contexto de ajuste de los mercados laborales. Lo que ha favorecido la expansión de un sector fabril precarizado vinculado con las cadenas de subcontratación internacional de manera formal o informal. 


\section{La industria de la confección en Puebla.}

En este apartado lo que se busca es destacar los efectos globales de la maquila en nuestra localidad de estudio: Tehuacán, Puebla. Para ello, es necesario dar cuenta de las características principales del Estado, para entender la importancia del municipio en este sector.

Nos parece relevante hacer un recorrido de sus características socioeconómicas y por la periodización de su desarrollo industrial. Partimos con la perspectiva de Tehuacán como un espacio globalizado, por lo que articularemos la información particular del municipio con la general del Estado, destacando su importancia para el mismo.

\subsection{Aspectos Generales}

El Estado de Puebla se encuentra situado al sureste del altiplano central de la República, entre la Sierra Nevada y el oeste de la Sierra Madre Oriental. Limita con siete estados de la República Mexicana: al norte y al este con Veracruz, al sur con Oaxaca, al suroeste con Guerrero y al oeste con Hidalgo, Tlaxcala, Morelos y el Estado de México. Cuenta con 3,437 localidades, políticamente se encuentra dividido en 217 municipios, y para fines de planeación se subdivide en siete regiones socioeconómicas que son: I Huachinango, II Teziutlan, III Ciudad Serdán, IV Cholula, V Puebla, VI Matamoros y VII Tehuacán. (Hernández, 2007: 83)

Los municipios con mayor desarrollo industrial, excluyendo al de Puebla son: Tehuacán, en el que destacan las ramas refresquera, alimenticia y del vestido; San Martín Texmelucan en petroquímica, textil, autopartes, farmacéutica y de materiales de construcción; Teziutlán en la metal-mecánica y del vestido; y por último, San Pedro Cholula en el textil, bebidas y manufacturas varias. (Hernández, 2007: 83).

Tehuacán se destaca como la segunda ciudad más grande del Estado, se encuentra ubicada a 120 kilómetros de la ciudad de Puebla que es su capital política. Tehuacán cuenta con una 
superficie de $390.4 \mathrm{~km}^{2}$ y, limita con los municipios de Santiago Miahuatlán, Ajalpan, Chilac, San Martín Atexcal, Altepexi, San Antonio Cañada, Zapotitlán Salinas, Nicolás Bravo, Vicente Guerrero y Tepanco de López.

El Valle de Tehuacán cuenta con una de las cuencas hidrográficas más importantes del centro del país, lo valoriza económicamente a las actividades productivas que se desarrollan. Esta cuenca es parte de la Cuenca del Papaloapan, los afluentes que la alimentan provienen de la Sierra de Zongolica, Zapotitlán y el Norte de Tehuacán. (Juárez, 2004)

Para el año 2005 el Estado de Puebla contaba con una población total de 5 millones 595 mil 760 habitantes, de los cuales 2 millones 699 mil 408 son hombres y 2 millones 896 mil 352 son mujeres, lo que la hace la quinta entidad más poblada, después del Estado de México, el Distrito Federal, Veracruz y Jalisco. A su vez la ciudad de Puebla cuenta con 1 millón 566 mil 145 habitantes y el municipio de Tehuacán con 260, 923, lo que lo hace el segundo municipio más poblado del Estado. (INEGI, 2005)

Según el gobierno del Estado, la población indígena de Puebla representa el 10.1\% del total de la población y las principales lenguas indígenas que se hablan son el náhuatl, totonaca, popoloca y mazateco.

\subsection{Desarrollo económico de la industria de confección en Puebla.}

A continuación, presentaré los periodos más importantes por los que atravesó la industria textil y de la confección de ropa en Puebla: 


\begin{tabular}{|c|c|c|c|}
\hline $\begin{array}{c}\text { Antecedentes de la } \\
\text { industria }\end{array}$ & $\begin{array}{c}\text { Industrialización } \\
\text { hacia dentro (1930- } \\
\text { 1976) }\end{array}$ & $\begin{array}{c}\text { Modelo Exportador } \\
\text { (1980-1999) }\end{array}$ & Crisis Actual \\
\hline 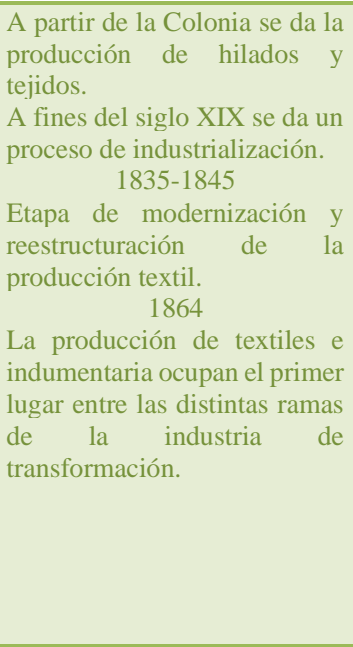 & $\begin{array}{l}\text { La industria textil era una de } \\
\text { las más importantes junto con } \\
\text { la de alimentos y bebidas. } \\
1940 \\
\text { La mano de obra aumenta su } \\
\text { oferta. La industria textil se } \\
\text { convirtió en el pilar más } \\
\text { importante del desarrollo } \\
\text { económico en Puebla. } \\
\text { Entra en crisis y en un proceso } \\
\text { de reestructuración. Las } \\
\text { empresas enfrentan graves } \\
\text { problemas debido a lo } \\
\text { obsoleta de su maquinaria. } \\
\text { Termina el periodo de las } \\
\text { estructuras industriales } \\
\text { tradicionales }\end{array}$ & $\begin{array}{l}\text { Mediados de } 1980 \\
\text { Se da la apertura comercial, } \\
\text { los establecimientos } \\
\text { nacionales entran en crisis } \\
\text { debido a que no estaban en } \\
\text { condiciones de enfrentar la } \\
\text { competencia de productos } \\
\text { extranjeros. } \\
\text { Las empresas nacionales } \\
\text { buscan modernizarse o aliarse } \\
\text { con empresas extranjeras. } \\
\text { Crecen las micro y pequeñas } \\
\text { empresas. } \\
\text { La maquila de confección ya } \\
\text { no se encuentra asociada a la } \\
\text { industria textil estatal, sino a } \\
\text { un encadenamiento de } \\
\text { producción global. }\end{array}$ & $\begin{array}{l}\text { La industria es afectada por la } \\
\text { recesión económica de los } \\
\text { EEUU. } \\
\text { Para el } 2009 \text { los empleos } \\
\text { pasan de } 5625 \text {, cuando en el } \\
2005 \text { eran } 9245 \text {. } \\
\text { Se da el cierre de importantes } \\
\text { empresas en el estado como } \\
\text { Vaqueros Navarra. } \\
\text { Crece el número de empresas } \\
\text { y talleres clandestinos e } \\
\text { informales a un } 50 \% \text {. }\end{array}$ \\
\hline
\end{tabular}

\section{a) Antecedentes de la industria}

La ciudad de Puebla fue fundada con el propósito de crear un asentamiento sólido para los colonizadores donde se aprovechará la mano de obra y los recursos disponibles para la producción de hilados y tejidos. Por lo que el obraje en la ciudad de Puebla toma relevancia.

Para fines del siglo XIX, bajo el régimen de Porfirio Díaz, se impulsa un proceso de industrialización, lo cual se reflejó en una rápida mecanización en la producción. Entre 1835 y 1845 , se presenta la primera etapa del proceso de modernización y reestructuración de la producción textil. Para 1864, la producción de textiles e indumentaria ocupaban el primer lugar, entre las distintas ramas de la industria de transformación localizadas en la ciudad. Durante un largo período el número de establecimientos y el monto de su producción aumentaron y se mantuvieron constantes. (Grosso, 1995; Flores, 2005; Gamboa, 1985 en Hernández, 2007: 84) 


\section{b) Industrialización hacia dentro (1930-1976)}

Durante el período post revolucionario, la industria textilera en Puebla era una de las más importantes junto con la de alimentos y bebidas. Con el crecimiento de la población urbana que se dispara a partir de 1940, la mano de obra de la ciudad y de las regiones agrícolas aledañas, aumentan su oferta y el sector terciario y secundario crece. La industria textil se convirtió en el pilar más importante del desarrollo económico en Puebla. Para la década de los cincuenta, entra en crisis y en un proceso de reestructuración, las empresas que producen hilos y tejidos de algodón enfrentan graves problemas debido a que su maquinaria es obsoleta y en el mercado los productos de algodón son desplazados por los de fibras artificiales. (Martínez de Ita, 1993: 193)

Para 1965, Puebla aún tenía una estructura tradicional basada en el sector primario y en las industrias de alimentos y textiles. Es entre 1963 y 1967, que se vivieron momentos determinantes en la configuración de la nueva estructura económica del estado, en particular en el desarrollo del sector industrial. (Hernández, 2007)

En este período la economía poblana sufrió cambios fundamentales, parecidos a los que se dan en el resto del país. Esta etapa corresponde a un momento histórico en el que se transitó desde la consolidación del modelo sustitutivo de importaciones, hasta la manifestación de la crisis de dicho modelo y el advenimiento de un estancamiento productivo.

En el periodo de 1965 a 1976, termina una larga etapa de predominio de estructuras industriales tradicionales. En el país desde los años cuarenta, la industria de transformación se ajusta a un ritmo de acumulación del capital que había surgido, marcando la pérdida de la hegemonía de la rama textil y el desarrollo de un nuevo tipo de empresas como Hojalata y Lamina SA (HYLSA) y Volkswagen.

c) Modelo Exportador (1980-1999) 
Para mediados de la década de los ochenta, la apertura comercial provocó que la industria textil pasara de ser una de las manufacturas más protegidas a una de las más competidas. Lo que significó que las fábricas nacionales tuvieran que competir con productos importados a precios menores, como resultado de este escenario, fue la crisis de los establecimientos que no estaban en condiciones de enfrentar la competencia de los productos extranjeros, lo que acarreó el despido de trabajadores, el endeudamiento y el cierre de un gran número de fábricas.

Por otro lado, otras empresas se modernizaron o buscaron aliarse con empresas extranjeras a través, de esquemas de subcontratación como la maquila; otras más, optaron por competir en el mercado vía bajos salarios y precarización del trabajo. (Martínez de Ita, 2004: 134)

Otro elemento característico de la estructura industrial poblana es que muestra un gran crecimiento de la micro y pequeña empresa. En este contexto la maquila en Puebla se convierte en una de las formas más dinámicas de empleo.

Entre 1993 y 1999, las principales ramas industriales son las textiles de fibras blandas, la maquila de confección y la automotriz. Durante esta etapa, la maquila de confección ya no se encuentra asociada a la industria textil estatal, sino que está asociada a un encadenamiento de producción global, la maquila de exportación a los EE.UU predomina durante toda esta etapa de manera sumamente dinámica.

\section{d) Crisis actual (2000-2009) $)^{3}$}

La importancia de la industria de confección de ropa en Puebla, ubicada en la década de los noventa, se vio frenada en el año 2001, debido a la recesión económica de los Estados Unidos.

\footnotetext{
${ }^{3}$ Para tener un panorama actualizado de la situación de la industria de confección en Puebla, se realizó una revisión hemerográfica desde enero del 2009 hasta junio del mismo año, en el diario La Jornada de Oriente en su página electrónica www.lajornadadeoriente.com.mx. La mayoría de los datos que se presentan a continuación, son fruto de esa revisión.
} 
María Eugenia Martínez de Ita declaró que después de la crisis de 2001 quebraron casi la mitad de las empresas textiles y maquiladoras quebraron debido a la baja en el consumo de los estadounidenses, principales compradores, además China superó al país en la exportación de estos productos. (La Jornada de Oriente, 16 de marzo del 2009).

Por otra parte, en los últimos ocho años, el estado de Puebla registró un descenso del $41.5 \%$ en el número de empresas registradas en el Sistema de Información Empresarial Mexicano (SIEM), lo que ubica a la entidad en el lugar 21 de los estados con más empresas registradas. Actualmente el $78 \%$ de los negocios en la entidad son microempresas, y sólo el 2.2 exporta sus productos.

Los datos estadísticos del SIEM indican una disminución entre 1,000 a 1,200 empresas menos por año desde el 2001, hasta llegar a las actuales 9,318. De las cuales 2,016 están en el sector industrial; 5,217 en el sector comercial y 2,085 en el de comercio.

Esta crisis no solamente afectó a la industria de la confección, para el 2008 se perdieron 17 y 20 mil empleos en la entidad poblana debido a recortes de personal, quiebra de comercios pequeños y medianos, así como el cierre de unas 12 empresas, entre éstas La Perla, Telas Finas, Industria Modela, Vaqueros Navarra, Hiladuras Pegaso, de la industria de la confección, entre otras. Con el cierre de Alcoa Fujikura se quedaron sin trabajo 1,700 trabajadores, mientras que Vaqueros Navarra despidió a 300 empleados, y entre Untromex, Whirlpool, Hiladuras Pegaso, Industria Modela y otras empresas textiles se perdieron casi mil fuentes laborales más.

El personal ocupado en la fabricación de prendas de vestir en Puebla paso de 9,245 personas en el 2005 a 5,625 para marzo del 2009. Este es un indicador del paulatino aumento del desempleo que se ha vivido en este sector, se ha acentuado con de la actual crisis económica mundial sufrida a partir desde fines del 2008. 


\section{Cuadro 1.}

\begin{tabular}{cc}
\hline PERIODO & $\begin{array}{c}\text { PERSONAL } \\
\text { OCUPADO }\end{array}$ \\
\hline $\mathbf{2 0 0 5}$ & 9245 \\
$\mathbf{2 0 0 6}$ & 7838 \\
$\mathbf{2 0 0 7}$ & 6982 \\
$\mathbf{2 0 0 8}$ & 6173 \\
$\mathbf{2 0 0 9}$ & 5625 \\
\hline
\end{tabular}

(Fuente: INEGI)

Solamente en enero del 2009, 2 mil personas fueron despedidas del sector automotriz, autopartes y textil. Mientras que el 2008 cerró con 7 mil personas despedidas del sector de la transformación. ${ }^{4}$

De acuerdo con Miguel Reyes Hernández investigador de la Universidad Iberoamericana, unas 25 mil personas durante el 2008 se incorporaron a la economía informal, debido a que no encontraron empleo en las empresas establecidas. Reyes explicó que se calcula que por cada empleo formal que se creó, se generaron dos fuentes de trabajo informales.

De acuerdo con el INEGI, 12 millones 861 mil personas, es decir $29.4 \%$-quienes se encuentran en el rubro de trabajadores por cuenta propia y no remunerados-, las que se mantienen de la informalidad, mientras que, de acuerdo con los cálculos de Reyes Hernández, con base en fuentes laborales, se debieron crear cada año más del doble las que se encuentran en la economía informal, es decir, casi 26 millones de personas.

En un artículo publicado en la Jornada de Oriente el jueves 5 de febrero del 2009 se plantea que las condiciones laborales del estado de Puebla son peores que las del país, esto de acuerdo con los últimos indicadores de ocupación y empleo del INEGI, que se refieren al tercer trimestre de 2008, donde se describe que sólo el 41.6\% de los trabajadores tiene prestaciones, mientras que en el país la cifra aumenta al 61\%. Así como, el 63.2\% delos

\footnotetext{
${ }^{4}$ Esto fue señalado por Leobardo Soto Martínez de la CTM.
} 
empleados poblanos no tiene contrato de trabajo escrito, y a nivel nacional esta cifra se reduce al 46.2.

\begin{tabular}{|l|c|c|c|c|}
\hline \multicolumn{4}{|c|}{ Trabajadores subordinados y su acceso a prestaciones laborales } \\
\hline \multicolumn{1}{|c|}{ INDICADORES } & \multicolumn{2}{c|}{ PUEBLA } & \multicolumn{2}{c|}{ MEXICO } \\
\cline { 2 - 5 } & HABITANTES & $\%$ & HABITANTES & $\%$ \\
\hline $\begin{array}{l}\text { Condiciones de acceso a las } \\
\text { instituciones de salud }\end{array}$ & $1,270,045$ & 100 & $28,654,347$ & 100 \\
\hline Con acceso & 459,251 & 36.2 & $15,831,578$ & 55.3 \\
\hline Sin acceso & 809,288 & 63.7 & $12,570,771$ & 43.9 \\
\hline $\begin{array}{l}\text { Prestaciones laborales } \\
\text { (sin considerar el acceso a las } \\
\text { instituciones de salud) }\end{array}$ & $1,270,045$ & 100 & $28,654,347$ & 100 \\
\hline Con prestaciones & & & & \\
\hline Sin prestaciones & 528,154 & 41.6 & $17,467,133$ & 61.0 \\
\hline
\end{tabular}

(Fuente: INEGI, Tercer trimestre del 2008)

Según los últimos datos, el 62.9\% de las personas ocupadas en México no tiene acceso a las instituciones de salud a través de su trabajo, pero esa cifra aumenta al $79.1 \%$ para el caso de Puebla.

Los trabajadores no remunerados en Puebla alcanzan el 12.7\%, mientras que a nivel nacional se reducen a 6.9\%. Un 5.8\% más en Puebla no recibe ninguna percepción monetaria, aunque trabaje.

En cuanto a prestaciones laborales los empleados poblanos tienen menos -aguinaldo, vacaciones, reparto de utilidades y fondo para la vivienda- que, a nivel nacional, ya que sólo el $41.6 \%$ tiene prestaciones, mientras que en el país la cifra aumenta a 61\%. Casi $20 \%$ menos de trabajadores poblanos en comparación con el país cuenta con prestaciones como lo marca la ley laboral.

El 52.8\% de las personas que laboran en alguna empresa o institución a nivel nacional cuenta con su contrato de trabajo escrito, pero en Puebla la cifra se reduce al 36.5\%. En otro rubro, en la entidad también las personas trabajan más horas, ya que el $32.8 \%$ de los 
empleados poblanos labora más de 48 horas, y a nivel nacional la cifra disminuye al 28.8\%, es decir $4 \%$ menos.

El 56.9\% del total de la población ocupada en la entidad es personal subordinado, mientras que en el país representa el $65.7 \%$.

\begin{tabular}{|lcc|}
\multicolumn{3}{|c}{$\begin{array}{c}\text { Indicadores estratégicos de ocupación y empleo, INEGI, } \\
\text { tercer trimestre }\end{array}$} \\
\hline \multicolumn{1}{|c}{ 2008 } \\
\hline INDICADORES & PUEBLA & MABITANICO \\
& $\mathbf{5 , 6 0 2 , 9 0 8}$ & HABITANTES \\
\hline Posición en la ocupación & $\mathbf{1 0} 6,794,362$ \\
\hline Trabajadores subordinados y remunerados & $3,950,908$ & $77,396,311$ \\
\hline Asalariados & $2,317,559$ & $45,535,466$ \\
\hline Con percepciones no salariales & $2,230,330$ & $43,625,738$ \\
\hline Empleadores & 87,229 & $1,909,728$ \\
\hline Trabajadores por cuenta propia & $1,633,349$ & $31,860,845$ \\
\hline Trabajadores no remunerados & 420,333 & $5,132,479$ \\
\hline No especificado & $1,213,016$ & $26,728,366$ \\
\hline
\end{tabular}

Los trabajadores poblanos por cuenta propia significan el $25.6 \%$, aunque a nivel nacional son el 22.5\%. La población ocupada en Puebla tiene ocho años de escolaridad, mientras que a nivel nacional tiene nueve años.

Aunque la tasa de desocupación en el tercer trimestre del año pasado es menor $3.8 \%$ que la del país de $4.2 \%$, las condiciones laborales están muy por debajo del promedio nacional. El 24.7\% de la población ocupada de la entidad trabaja en las actividades de agricultura, ganadería, silvicultura, caza y pesca, es decir 550,160 personas de las 2,230,330 ocupadas, mientras que a nivel nacional en este sector labora sólo el 13.6\% del total.

En el sector industrial trabajan 569,222 personas en la entidad, es decir el $25.2 \%$, casi el mismo porcentaje que a nivel nacional. En los servicios y comercios se emplea el $49.5 \%$ de la población ocupada total, es decir un millón 103 mil 491 personas, aunque a nivel nacional la cifra aumenta al $60.7 \%$. 
Los trabajadores poblanos por cuenta propia significan el $25.6 \%$, aunque a nivel nacional son el $22.5 \%$. Aunque la tasa de desocupación en el tercer trimestre del año pasado es menor 3.8\%- que la del país -4.2\%-, las condiciones laborales están muy por debajo del promedio nacional.

Una vez revisada la información estadística resulta evidente la crisis que vive la industria de confección de ropa en Puebla. Ahora revisaremos los datos correspondientes a nuestra zona de estudio, Tehuacán, Puebla, en el contexto de esta industria.

\section{Tehuacán: Aspectos generales.}

Como se ha descrito en apartados anteriores, Tehuacán se destaca por ser la segunda ciudad más grande del Estado, encontrándose ubicada a 120 kilómetros de la ciudad de Puebla que es su capital política. Cuenta con una superficie de $390.4 \mathrm{~km}^{2}$, limita con los municipios de Santiago Miahuatlán, Ajalpan, Chilac, San Martín Atexcal, Altepexi, San Antonio Cañada, Zapotitlán Salinas, Nicolás Bravo, Vicente Guerrero y Tepanco de López. La población en todos estos municipios es mayoritariamente indígena.

El municipio de Tehuacán está conformado por 99 colonias y 72 fraccionamientos que se encuentran ubicados en la cabecera municipal y sus 12 juntas auxiliares. De acuerdo con los datos reportados por el Censo de Población del 2000, la población total del municipio era de 226, 258 habitantes, de los cuales 89,307 habitantes están ocupados/as y, 62,275 son empleados u obreros siendo 37,813 hombres y 24,462 mujeres.

En el municipio, todavía se cultiva maíz, frijol, chile, calabaza, trigo, avena, alfalfa y jitomate. Sin embargo, las actividades agrícolas han venido desapareciendo aceleradamente como consecuencia de la industrialización.

De acuerdo con Barrios y Hernández (2004) las industrias más importantes de Tehuacán son las siguientes:

- Del vestido, en especial la maquiladora de exportación,

- Las embotelladoras de refresco, 
- La producción de vacunas,

- La producción de alimento para animales,

- La producción de ónix y jarcia,

- La producción ganadera que consta de los sectores: avícola (huevo y pollo de engorda), bovina, caprina, equina, piscícola y porcícola, además del reciente crecimiento de la industria del calzado. (Barrios y Hernández, 2004)

El gobierno municipal señala que la actividad económica por sector, de acuerdo a la población ocupada señalada por INEGI, se distribuye de la siguiente forma.

\begin{tabular}{lc}
\hline \multicolumn{2}{c}{ POBLACIÓN OCUPADA POR SECTOR DE ACTIVIDAD (2000) } \\
\hline PRIMARIO & $6.4 \%$ \\
SECUNDARIO & $46.4 \%$ \\
TERCIARIO & $45.8 \%$ \\
NO ESPECIFICADO & $1.4 \%$ \\
\hline
\end{tabular}

En el sector primario (agricultura, ganadería, caza y pesca) existe un 6.4\% de participación. Mientras que en el sector secundario (Minería, extracción de petróleo y gas, industria manufacturera, electricidad, agua y construcción) se concentra la mayoría con $46.4 \%$. Finalmente, el sector terciario (Comercio, transporte y comunicaciones, servicios financieros, de administración pública y defensa, comunales y sociales, profesionales y técnicos, restaurantes, hoteles, personales, de mantenimiento entre otros) en segundo lugar con $45.8 \%$. Prácticamente la población ocupada se divide entre estos dos sectores. Otro dato importante para nuestro estudio es que existían 17,663 trabajadores que lo hacen por su cuenta, donde podría entrar el trabajo a domicilio.

\begin{tabular}{cccccccc}
\hline \multicolumn{7}{c}{ POBLACIÓN OCUPADA EN EL MUNICIPIO DE TEHUACÁN POR SEXO (INEGI,2000) } \\
\hline $\begin{array}{c}\text { MUNICIPIO } \\
\text { SEXO }\end{array}$ & TOTAL & EMPLEADOS & JORNALEROS & PATRONES & TRABAJADORES & TRABAJADORES & NO \\
& & Y OBREROS & Y PEONES & & POR SU & FAMILIARES & ESPECIFICADA \\
& & & & & CUENTA & SIN PAGO & \\
\hline TEHUACÁN & 89307 & 62275 & 2914 & 1647 & 17663 & 2721 & 2087 \\
\hline
\end{tabular}




\begin{tabular}{cccccccc} 
HOMBRES & 55592 & 37813 & 2753 & 1247 & 11370 & 1228 & 1181 \\
MUJERES & 33715 & 24462 & 161 & 400 & 6293 & 1493 & 906 \\
\hline
\end{tabular}

Mientras que las principales actividades en las que se emplean los habitantes de Tehuacán son las siguientes:

\begin{tabular}{|c|c|c|c|c|c|c|c|}
\hline \multicolumn{8}{|c|}{ POBLACIÓN OCUPADA POR SECTOR DE ACTIVIDAD SEGÚN SITUACIÓN EN EL TRABAJO (INEGI, 2000) } \\
\hline $\begin{array}{l}\text { SECTOR DE } \\
\text { ACTIVIDAD }\end{array}$ & TOTAL & $\begin{array}{r}\text { EMPLEADOS } \\
\text { Y OBREROS }\end{array}$ & $\begin{array}{l}\text { JORNALEROS } \\
\text { Y PEONES }\end{array}$ & PATRONES & $\begin{array}{l}\text { TRABAJADORES } \\
\text { POR SU } \\
\text { CUENTA }\end{array}$ & $\begin{array}{l}\text { TRABAJADORES } \\
\text { FAMILIARES } \\
\text { SIN PAGO }\end{array}$ & $\begin{array}{c}\text { NO } \\
\text { ESPECIFICADA }\end{array}$ \\
\hline TOTAL & 89307 & 62275 & 2914 & 1647 & 17663 & 2721 & 1087 \\
\hline \multicolumn{8}{|l|}{$\begin{array}{l}\text { AGRICULTURA, } \\
\text { GANADERÍA, }\end{array}$} \\
\hline $\begin{array}{c}\text { FORESTAL, PESCA Y } \\
\text { CASA }\end{array}$ & 5744 & 2288 & 1147 & 92 & 1606 & 502 & 109 \\
\hline CONSTRUCCIÓN & 5902 & 2582 & 1394 & 109 & 1681 & 40 & 96 \\
\hline $\begin{array}{c}\text { INDUSTRIAS } \\
\text { MANUFACTURERAS }\end{array}$ & 35287 & 31021 & 137 & 349 & 2795 & 340 & 645 \\
\hline COMERCIO & 14745 & 6739 & 61 & 535 & 5757 & 1305 & 348 \\
\hline $\begin{array}{c}\text { TRANSPORTES, } \\
\text { CORREOS Y } \\
\text { ALMACENAMIENTO }\end{array}$ & 3364 & 2534 & 22 & 55 & 687 & 12 & 54 \\
\hline SERVICIOS & 1475 & 718 & 3 & 82 & 624 & 26 & 22 \\
\hline $\begin{array}{c}\text { SERVICIOS } \\
\text { EDUCATIVOS }\end{array}$ & 4387 & 4146 & 7 & 22 & 129 & 15 & 68 \\
\hline $\begin{array}{l}\text { SERVICIOS DE SALU } \\
\text { U DE ASISTENCIA } \\
\text { SOCIAL }\end{array}$ & 2058 & 1683 & 1 & 36 & 288 & 11 & 39 \\
\hline $\begin{array}{c}\text { SERVICIOS DE } \\
\text { HOTELES Y } \\
\text { RESTAURANTES }\end{array}$ & 3130 & 1340 & 9 & 111 & 1319 & 274 & 77 \\
\hline \multicolumn{8}{|l|}{ OTROS SERVICIOS } \\
\hline GOBIERNO & 7540 & 4717 & 95 & 155 & 2295 & 128 & 150 \\
\hline GOBIERNO & 1976 & 1874 & 8 & 12 & 26 & 1 & 55 \\
\hline NO ESPECIFICADO & 1234 & 748 & 8 & 20 & 54 & 32 & 372 \\
\hline
\end{tabular}

La mayoría está concentrada en el sector de las industrias manufactureras con 35,297 personas empleadas, de esas 31,021 son considerados empleados y obreros. Por otra parte, los trabajadores por su cuenta del mismo sector son 2,795 y 340 los trabajadores reportados como trabajadores familiares sin pago. En segundo lugar, se encuentra el comercio con 14,745. Este cuadro muestra lo amplio de las ramas de actividad en Tehuacán y la importancia del municipio para el Estado.

\subsection{La maquila de confección de ropa en Tehuacán, Puebla.}

Hasta hace poco Tehuacán era considerada la segunda capital del pantalón de mezclilla, solamente por debajo de Torreón, Coahuila. Su ingreso a la industria globalizada de 
confección de ropa se debió a la relocalización, de la frontera norte del país hacia el sur del territorio mexicano que se vivió durante la década de los noventa.

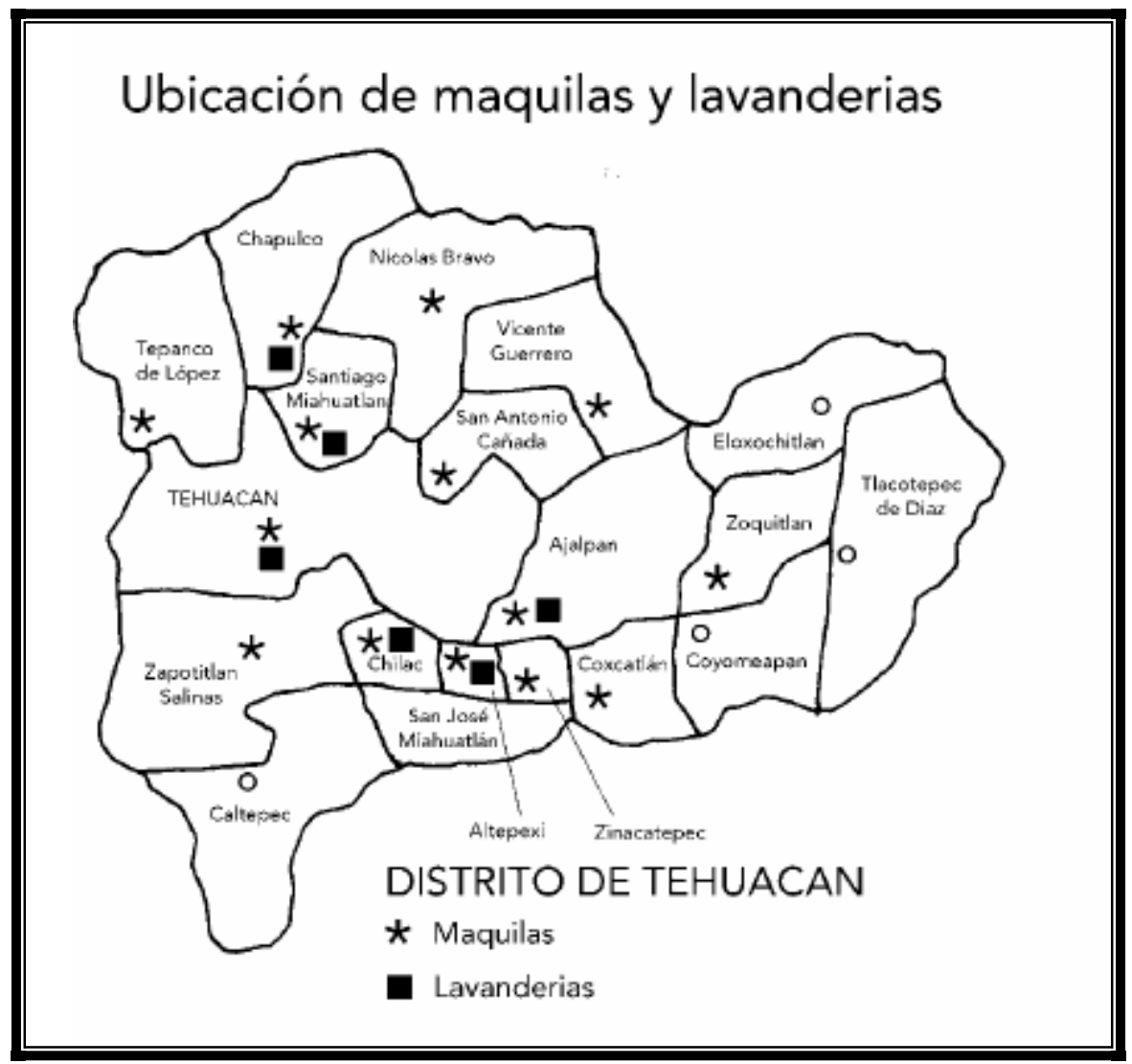

(Mapa tomado de Barrios y Hernández, 2004)

En las faldas de las sierras Madre Oriental, Zongolica, Mazateca y Negra en colindancia con el Estado de Veracruz, se levantan las fábricas en las que de manera frecuente indígenas hacen el trabajo más duro, convertir el hilo en los pantalones de las marcas más caras del mundo. (Hernández, 2007: 94)

La instalación de las primeras maquiladoras comienza entre los años de 1971 y $1973^{5}$, en un inicio se dedicaron al mercado interno y a la elaboración de sus propias marcas, que eran vendidas en los tianguis de ropa del Estado de Puebla.

\footnotetext{
${ }^{5}$ La información fue obtenida de las pláticas sostenidas con Martín Barrios miembro de la CDHyLVT. Muchas de estas notas fueron retomadas de la tesis de maestría de Luis Hernández, "La vida detrás de la fibra. Las Mujeres de la Maquila de confección del Valle de Tehuacán, Puebla. Hilvanando identidades" 2007.
} 
En 1978 existían 28 maquilas que daban empleo a 2,000 trabajadores se fabricaban para el mercado nacional, haciendo exportaciones de manera indirecta. En 1989, se contaba con 80 maquiladoras que daban empleo a 8000 trabajadores y desarrollaban producción en programas de exportación directas. (Juárez, 2004: 110)

Los primeros empresarios en incursionar en el sector fueron principalmente de origen español como la familia Fernández, que era dueña del Grupo Navarra; y de origen libanés como el núcleo de Haddad, propietarios de Grupo Famián anteriormente llamado Tarrant Apparel Group. Con los años se constituyen otras empresas, entre las cuales se encuentran Troncos, San Mat, Élite que para 1999 se fusionaría para conformar el Grupo Tarrant. El socio mayoritario era Kamel Nacif, el "Rey de la Mezclilla". La familia Fernández fundó el conglomerado de Vaqueros Navarra que con el paso del tiempo se constituiría como Grupo Navarra. Las plantas maquiladoras se instalan primero en las ciudades de Tehuacán, Ajalpan y Miahuatlan, principalmente. (Hernández, 2007)

Hernández señala que, a principios de la década de 1990, las plantas que fabrican prendas de vestir ya tienen un lugar importante en la estructura regional junto a la producción de refrescos y producción de huevo y pollo.

En 1991, el presidente municipal de Tehuacán fue el empresario maquilero José Méndez Gómez, quien a la postre sería presidente de la delegación local de la Cámara Nacional de la Industria del Vestido (Canacives) durante el 2001. Como autoridad municipal Méndez Gómez, viajó constantemente a Estados Unidos, especialmente a California, para tocar puertas en los consorcios estadounidenses de la confección con el propósito de atraer sus líneas de producción e inversiones a Tehuacán.

Estos viajes empezaron a rendir resultados para los empresarios locales a partir de la entrada en vigor del TLCAN en 1994, logrando consolidar el "boom" maquilero local a partir de 1995 y hasta el 2000. Antes del TLCAN, algunas empresas tehuacaneras ya exportaban, pero el mencionado período de cinco años fue el lapso de mayor crecimiento de la maquila local en el desarrollo de infraestructura, índices económicos de exportación, 
expansión industrial, automatización, producción y en la creación de empleos. (Barrios y Hernández, 2004: 23-24)

A mediados de la década de los 90 y con la cobertura del Acuerdo Multifibras (AMF), las plantas adquirieron mayor consistencia en tanto los contratos con las redes comercializadoras se consolidan y amplían sobre lo que podríamos llamar dos pilares: la formación desde la década de los 80 de grupos maquiladores en expansión como Navarra, Famián, Yamil y Mazara y la especialización productiva sustentada en el crecimiento del consumo en Estados Unidos de una nueva línea de productos: pantalones de mezclilla para hombre y mujer. Junto a esta línea se encuentran productos de mezclilla como chamarras y prendas de mujer y niño con telas de gabardina. (Juárez, 2004: 111)

Estos dos grupos se destacan por el número de empleos que generan para la industria de la confección y porque se encuentran vinculados a cadenas globales de producción a partir de redes escalonadas de contratistas, encabezadas por grandes firmas de marca como:

- Gap: Gap chinos, Banana Republic, Old Navy

- Limited: Express, Venecia, Limited

- Vf Corporation: Lee, Wrangler, Brittania

- Anchor Blue: Paris Blues, Mudd

- Levi's: Jc Penny, Dockers

- American eagle Outfitters: American Eagle

- Polo Ralph Laurent: Polo Jeans Co., Polo Sport, Polo Ralph Laurent, Chaps

- Tommy Hilfiger

- Calvin Klein

- Guess

- Savane

- Liz Claiborne (Juárez, 2004: 192-193)

Estas firmas son las que diseñan y especifican de qué manera se debe de producir, cuánto y para cuándo. Estas especificaciones son transmitidas a lo largo de la cadena, de arriba hacia abajo, y marcan las formas de encadenamiento de las grandes firmas, los intermediarios nacionales, las medianas y pequeñas empresas y los talleres a domicilio. 
Esto por varias razones, entre las que destacan la reducción de los costos y porque se ve rebasada la capacidad de la empresa. Por lo que la reconstrucción de esta cadena es muy importante para entender la lógica bajo la cual las mujeres trabajan.

\subsection{Contexto actual ${ }^{6}$}

En la actualidad, Tehuacán atraviesa por una crisis económica que ha mermado a la industria de la confección, de tal manera, que de ser uno de los municipios más importantes en términos de exportación y empleo, actualmente enfrenta serios problemas económicos y sociales, debido a que el cierre de empresas va en aumento a la par que el desempleo.

Debido a ello, el desarrollo de la maquila en Tehuacán se ha orientado hacia su precarización. En este camino, cada vez más recurre a la maquila clandestina para poder sobrevivir a la crisis de la industria ${ }^{7}$. Actualmente la industria textil y del vestido en el estado de Puebla se encuentra en Tehuacán, Teziutlán y el municipio de Puebla, principalmente. Se calcula que un $50 \%$ de las empresas que se dedican al sector textil y maquilador son clandestinas, por lo que las condiciones de trabajo son deplorables y precarias. "Más de la mitad del personal ocupado en el sector carece de prestaciones sociales como el seguro social y el Infonavit” señala Martínez de Ita.

Según esta investigadora, es debido a la ambición empresarial, la industria textil actual es "fierro inservible por la falta de modernización tecnológica"; en tanto, la maquila sólo ha beneficiado a las trasnacionales porque "el país o el estado no tiene control sobre las empresas, sino sólo las comercializadoras".

\footnotetext{
${ }^{6}$ Los datos presentados en este apartado se basan en la búsqueda de notas periodísticas, realizada entre enero y junio del 2009 en el diario: La Jornada de Oriente, www.lajonadadeoriente.com.mx

${ }^{7}$ Esta hipótesis se encuentra apoyada con algunos datos que se encontraron a través de notas periodísticas apoyadas en investigadores de la localidad e indicadores presentados por instituciones como la STPS, CNIV, etc.
} 
Por su parte, José Manuel Monroy Romero, consultor y quien ha trabajado en diferentes empresas textiles, apoya la misma idea y agrega que son los gobiernos federal y estatal quienes no han sabido impulsar el sector.

El presidente de la Cámara Nacional de la Industria del Vestido (CNIV), Antonio Bassil Alam, indicó que actualmente el $70 \%$ de la ropa que se comercializa en el estado de Puebla es importada, de la cual el $50 \%$ entra al país de forma ilegal.

En este sentido, agregó que unos 40 mil trabajadores del sector en el país perdieron sus empleos el año pasado; sin embargo, en el estado de Puebla la cifra fue de mil personas, porque, el $80 \%$ de la producción poblana va para el mercado nacional; en tanto, las entidades más perjudicadas fueron las del norte.

El director de la Cámara Nacional de la Industria de la Transformación (Canacintra) de Tehuacán, Javier López Pineda, señaló que más de la mitad de las 400 empresas, incluidos talleres pequeños, dedicadas a la industria del vestido en la región -tanto las que se dedican a la costura como a otros procesos de acabados de ropa-, opera en la clandestinidad y no paga impuestos ni prestaciones laborales. En este caso se encuentra también el trabajo a domicilio.

Por lo anterior, unas 20 mil personas del sector carecen de estabilidad y seguridad social, quienes trabajan en las empresas que no están dadas de alta ante la Secretaría de Hacienda y Crédito Público (SHCP), las cuales se pueden ir de una localidad a otra fácilmente, dejando desprotegidos a los trabajadores de éstas con relación a sus pagos de liquidación y prestaciones.

Agregó que la industria del vestido en la región de Tehuacán ha ido en picada en los últimos años, pues actualmente sólo quedan unas 150 empresas registradas formalmente, cuando en 1998 se llegaron a contabilizar mil 200 compañías de este sector. Con respecto al número de trabajadores hubo una reducción del 50 por ciento, pues a finales de la década pasada unas 120 mil personas laboraban en esta industria y actualmente son menos de 60 mil. 
Señaló que la exportación de prendas de vestir, principalmente a EU, se redujo en un 70 por ciento en comparación a hace unos ocho años, debido a la crisis internacional que inició en 2001 y ello provocó que cerraran decenas de maquilas pequeñas que le trabajaban a empresas exportadoras.

Sin embargo, pese a esta caída del sector, la economía de Tehuacán aún está basada en un 50 por ciento en la actividad de las empresas maquiladoras que quedan en la región.

Para la delegación de la Canacintra, las causas del desplome de la industria del vestido en la región fueron el alto costo de la mano de obra, la competencia desleal de las empresas clandestinas, la crisis internacional de 2001 de la que nunca se han recuperado y la falta de apoyo por parte de las autoridades de los tres niveles de gobierno.

El caso del Grupo Navarra - que comprendía varias empresas- es un ejemplo de la baja en la industria de la confección, ya que a principios de esta década llegó a tener más de 10 mil trabajadores que realizaban los diferentes procesos de la fabricación de prendas de vestir, desde costura, lijado, planchado hasta el lavado, pero la falta de pedidos de exportación provocó la separación de sus socios.

El representante empresarial indicó que, debido a la falta de pedidos del extranjero, las maquiladoras que aún funcionan tuvieron que centrar su producción y comercialización en el mercado nacional. Los municipios que tienen más empresas de la industria del vestido en la región son Ajalpan, Santiago Miahuatlán, San Gabriel Chilac, Tepanco de López, Magdalena Cuayucatepec y Tehuacán.

Las prendas de vestir que se producen para el mercado nacional se venden como marcas piratas o propias en los diferentes tianguis del estado y en otras entidades del país. Los procesos de la maquila de prendas de vestir son el corte, la costura, el planchado, el lavado y los diferentes acabados. Las maquiladoras que funcionan en la actualidad tienen en promedio 250 trabajadores, aunque existen unas 20 que tienen más de 500 empleados. 
El propietario de la empresa Camisa y Diseño de Tehuacán, Guillermo Hernández González, aseguró que hasta el año 2001 la industria maquiladora de Tehuacán confeccionaba 6 millones de prendas por semana. Hoy, en 2009, no son más de 800 mil; es decir, hubo una reducción del 86 por ciento en ocho años en la producción.

Por ello, consideró que la apuesta es el mercado nacional, a la producción de ropa para consumo interno desde su diseño hasta su acabado final. Empresas como la suya en los próximos días lanzarán su propia marca de ropa, pues es lo que garantizará que las fuentes de empleo se conserven y se abran otras más.

Es en este sentido que nos pareció necesario dar cuenta del contexto de la industria de la confección en México y particularmente en Tehuacán, ya que es por medio de este contexto que podemos ubicar la posición que ocupan las trabajadoras a domicilio en este proceso.

Hoy más que nunca, el trabajo a domicilio representa en la localidad un nicho importante para el trabajo femenino en la región, por su carácter doméstico y porque las empresas recurren a éste de manera considerable. No se cuentan con datos específicos sobre el número de personas que participan en él, debido a que es un trabajo informal y clandestino, pero es bien sabido que su uso es extensivo y que forma parte importante en el proceso de producción de ropa.

El trabajo a domicilio se ubica en el último eslabón de la cadena de producción, donde sobre todo mujeres son subcontratadas por empresas nacionales, las cuales aún maquilan para grandes firmas extranjeras.

También se pueden encontrar niños, ancianos y en menor medida hombres trabajando desde sus casas. Son fuerza de trabajo que representa menores costos para las empresas y nulas obligaciones en seguridad social. Por lo que el trabajo a domicilio es considerado como trabajo precario.

En una entrevista con Martín Barrios dirigente de la CDHyLVT señaló el incremento del trabajo a domicilio subcontratado debido a la crisis económica por la que atraviesa 
actualmente Tehuacán, ya que facilita reducir aún más los costos de producción, lo que permite a las empresas seguir operando.

Por lo que, en este contexto resulta particularmente relevante su estudio. También será relevante indagar las consecuencias que ha acarreado en este último eslabón de la cadena de producción de ropa, así como para las mujeres que trabajan en él.

\section{Conclusiones}

Tal como se detalló a lo largo de este capítulo, el estudio del proceso de desarrollo de las maquilas en México permite entender mejor el contexto actual de crisis que se vive a nivel global y local en la industria de confección de ropa.

En sus orígenes, las maquilas se instalaron con el objeto inicial de brindar empleo en regiones como la frontera norte del país, al menos ese era el propósito esperado por las políticas nacionales. Pero después de cuarenta años podemos decir que no solamente trajo empleo, en muchos casos precarios, sino también desempleo, problemas ambientales y una industria nacional fragmentada y con fuertes problemas de articulación.

En ese sentido, el estudio de las cadenas globales de producción resulta necesario, ya que es a través de él que es posible comprender la lógica en que se produce, diseña y comercializan los productos como los que desarrolla esta industria.

Al mismo tiempo se plasmaron las leyes y acuerdos que facilitaron la posición de las grandes firmas con respecto a los países del tercer mundo y sus consecuencias desfavorables para los mismos. También puedo concluir que el encadenamiento global de producción nos lleva a entender otros procesos como la subcontratación de empresas medianas, talleres familiares y la industria domiciliaria en un proceso global. 
Desde el inicio, la presencia predominante de las mujeres en las empresas maquiladoras marcó su papel protagónico, esta presencia se da a lo largo de la cadena de producción, en condiciones distintas, lo cual responde no solamente a aspectos económicos, sino también sociales, regionales y culturales.

Un fenómeno para destacar es la relocalización de la industria de confección de ropa al sur del país, lo que permitió el desarrollo de otras regiones maquiladoras, las cuales se caracterizaron por no tener gran experiencia fabril, en comunidades rurales y con importante presencia indígena, donde se contaba con una importante presencia de mano de obra disponible.

La industria maquiladora en Tehuacán tiene una larga trayectoria, donde su orientación pasó de una orientación exclusiva al mercado nacional a formar parte del encadenamiento global en la década de los 90 .

Tehuacán es una localidad que ha atravesado varias fases de expansión y de crisis en esta industria, trayendo como consecuencia no solamente el empleo, sino también la explotación de sus trabajadores. Sobre todo, porque es un caso típico de el encadenamiento de empresas basado en el uso intensivo de mano de obra.

Actualmente las maquiladoras de confección en Tehuacán han dado un giro de la producción hacia fuera a una producción nacional, pero en condiciones de informalidad, clandestinidad y mayor precariedad. Donde el trabajo a domicilio toma un papel relevante en el contexto actual de crisis. 


\section{CAPÍTULO III}

\section{LAS TRAYECTORIAS LABORALES DE LAS DESHEBRADORAS SUBCONTRATADAS A DOMICILIO EN TEHUACÁN, PUEBLA.}

\section{Introducción}

El trabajo a domicilio es considerado por muchos estudiosos como un remanente del pasado. Sin embargo, su estudio adquirió relevancia cuando fue incorporado a la cadena global de producción de ropa como último eslabón, a través del proceso de subcontratación.

Este trabajo se caracteriza por la presencia mayoritaria de mujeres trabajadoras a destajo para empresas ligadas a grandes firmas extranjeras, además de su carácter informal y muchas veces clandestino, con nulas prestaciones laborales y pagos raquíticos, lo que disminuye considerablemente los costos de producción.

La crisis económica actual, que ha afectado de manera considerable a la maquila en México, por la salida y cierre de plantas. Existe evidencia de que parte de la mano de obra despedida se relocaliza en este tipo de trabajo, encareciendo sus condiciones laborales, así como revitalizando su uso y extendiéndose con más fuerza.

En este capítulo describiremos las trayectorias laborales de las mujeres que trabajan a domicilio, pues consideramos que son un fiel reflejo de la convergencia de los procesos macro-productivos y sociales, dentro de los cuales se insertaron a la actividad económica y de los procesos micro, que forman el tejido fino de sus historias personales.

El capítulo está estructurado de la siguiente manera, se presentan los principios metodológicos de las técnicas utilizadas y las particularidades del trabajo de campo. Un breve contexto del lugar y de la situación actual de la maquila en la región y finalmente el análisis de sus antecedentes familiares, perfil sociodemográfico y propiamente el de sus trayectorias. 


\section{Consideraciones metodológicas.}

La metodología que conduce esta investigación es la historia de vida, a partir de ella podemos conocer las trayectorias laborales de las mujeres. A través de su reconstrucción observamos el modo en que estas mujeres presentan los aspectos del pasado relevantes para su situación presente.

A partir de su testimonio las mujeres reconstruyen sus experiencias, señalando los elementos que consideraron como más relevantes, dando cuenta de los hechos trascendentes que las han transformado. Con el estudio de las trayectorias laborales, analizamos el interjuego de factores que, en distintos ámbitos sociales, principalmente el de mercado de trabajo y familiar, condicionan sus trayectorias. Permite observar también de manera dinámica, cómo han ido sucediendo sus experiencias laborales y las características de éstas, datos fundamentales para poder caracterizar las trayectorias de este tipo de trabajadoras, aspecto escasamente estudiado.

Tal como lo precisan Guzmán, et al (1999) la participación de las mujeres en el mercado de trabajo es el producto de procesos de índole diferente que discurren a nivel cultural y simbólico, social y económico, y de la vida privada. En este proceso los factores económicos, políticos y sociales, los demográficos y culturales se conjugan con las etapas de transición crítica de vida, como la conclusión de estudios, la entrada a la vida adulta, la unión, formación de la familia, la crianza de los hijos, el divorcio o viudez. (Guzmán, et al, 1999: 10)

Entendemos por trayectoria laboral:

“...los itinerarios visibles, los cursos y orientaciones que toman las vidas de los individuos en el campo del trabajo, y que son el resultado de acciones y prácticas desplegadas por las personas en situaciones específicas a través del tiempo. Estas acciones y prácticas son a su vez obra de intervenciones subjetivas por parte de los sujetos, de naturaleza consciente o inconsciente. En este sentido, los itinerarios están constituidos por acciones y prácticas animadas desde las representaciones y significaciones del sujeto." (Guzmán, et al, 1999: 12) 
El concepto de trayectoria conjuga en consecuencia, aspectos que tradicionalmente han sido ubicados en la polaridad externo e interno al considerar simultáneamente las dimensiones prácticas y acciones concretas y las significaciones y representaciones que las respaldan. De esta manera, se esclarece la permanente interacción y el mutuo condicionamiento entre ambos tipos de componentes. (Guzmán, et al, 1999)

Las trayectorias se van construyendo, definiendo y redefiniendo de manera no lineal, a través del tiempo de acuerdo con la experiencia de las personas, los distintos momentos de su ciclo de vida, las condiciones y oportunidades ofrecidas por el mercado de trabajo, la percepción de los límites y de las potencialidades personales. En este proceso, el papel del sujeto como instancia de mediación y construcción entre los condicionantes externos y los discursos y representaciones sociales, resulta fundamental para entender el curso que adoptan los itinerarios. (Guzmán, et al, 1999: 12).

Bajo estas consideraciones es que planteamos los objetivos del estudio de las trayectorias laborales de las mujeres que trabajan a domicilio:

- Describir las características sociodemográficas de las trabajadoras, así como dar cuenta de los aspectos relacionados con su familia de origen, la socialización de sus padres y la migración. Para responder a la pregunta de quiénes son las mujeres que trabajan a domicilio en Tehuacán, Puebla.

- Conocer su entrada al mercado laboral.

- Conocer sus trayectorias laborales

- Describir el contexto familiar y laboral que enmarcó sus entradas y salidas del mercado laboral a lo largo de sus trayectorias. Partiendo de la consideración de que el contexto de la maquila y sus trayectorias se encuentran íntimamente relacionados.

En estos objetivos se profundizará a partir de las entrevistas en profundidad. 
Para llevar a cabo el estudio de los objetivos planteados, para esta primera parte del análisis, nos plantemos los instrumentos de investigación que enumeramos y desarrollamos enseguida. $^{8}$

\subsection{Instrumentos de investigación ${ }^{9}$}

Se plantea como principal método de investigación la entrevista en profundidad, la cual se encuentra combinada con un ejercicio de observación y un cuestionario para conocer a las mujeres del trabajo a domicilio, sus trayectorias laborales, las redes de subcontratación laboral, el tipo de relaciones laborales que se dan dentro del taller y la dinámica laboral y familiar en el espacio doméstico. En este capítulo nos concentraremos en analizar el tipo de mujeres que trabajan a domicilio y sus trayectorias laborales. Los demás aspectos de estudio serán analizados en el capítulo subsecuente.

\section{El cuestionario}

Con éste buscamos explorar datos descriptivos sobre algunas características sociodemográficas y de la trayectoria laboral. El cuestionario nos permitió organizar los datos de manera sistematizada para facilitar su análisis considerando, que solamente tienen significado en el contexto del análisis de los datos cualitativos, sustento básico y fundamental de la investigación.

Elaboramos una imagen del perfil de trabajadora domiciliaria, que nos sirviera como un marco del cual partir. El cuestionario fue diseñado para obtener información de siete dimensiones, relevantes para el tipo de investigación que queríamos desarrollar y para nuestros objetivos de investigación. El cuadro siguiente resume la información que nos interesa recabar:

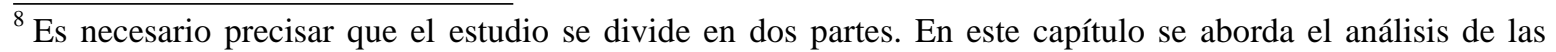
trayectorias laborales de las mujeres que trabajan a domicilio y la segunda parte se refiere a la dinámica laboral y familiar, así como las redes de subcontratación que se tejen en este último eslabón, que se analizará en el siguiente capítulo.

${ }^{9}$ Los instrumentos fueron diseñados tanto para los jefes y jefas de taller como para las trabajadoras subcontratadas.
} 


\section{CUADRO 1}

DIMENSIONES

INDICADORES

\begin{tabular}{|c|c|}
\hline DATOS GENERALES & $\begin{array}{ll}\text { - } & \text { Nombre } \\
\text { - } & \text { Domicilio Completo } \\
\text { - } & \text { Fecha de la entrevista }\end{array}$ \\
\hline $\begin{array}{c}\text { ANTECEDENTES } \\
\text { FAMILIARES }\end{array}$ & $\begin{array}{ll}\text { - } & \text { Grado de estudios de la madre } \\
\text { - } & \text { Grado de estudios del padre } \\
\text { - } & \text { Trabajo de la madre } \\
\text { - Trabajo del padre }\end{array}$ \\
\hline $\begin{array}{c}\text { DATOS } \\
\text { SOCIODEMOGRÁFICOS }\end{array}$ & $\begin{array}{ll}\text { - } & \text { Fecha de nacimiento } \\
\text { - } & \text { Lugar de nacimiento } \\
\text { - } & \text { Estadoridad Civil } \\
\text { - } & \text { Escolaridad de la pareja } \\
\text { - } & \text { Número de hijos } \\
\text { - } & \text { Edades de los hijos } \\
\text { - } & \text { Púmero de hijos que viven con ella } \\
\text { - } & \text { Cómo se considera: Esposa, madre, hija de familia, etc. }\end{array}$ \\
\hline DATOS ECONÓMICOS & $\begin{array}{ll}\text { - } & \text { Ingresos Mensuales } \\
\text { - } & \text { Quiénes aportan al ingreso familiar } \\
\text { - } \quad \text { Ocupación de las personas que aportan al ingreso familiar }\end{array}$ \\
\hline HISTORIA LABORAL & $\begin{array}{l}\text { - Tipos de trabajo que ha realizado a lo largo de su vida } \\
\text { - } \quad \text { Actividad que realizaba en cada uno de sus trabajos. } \\
\text { - } \quad \text { Registro de los trabajos simultáneos } \\
\text { - } \quad \text { Registro de las salidas o interrupciones en el trabajo y las } \\
\text { razones de esas salidas (en una tarjeta adjunta al } \\
\text { cuestionario) } \\
\text { Nombre de las tres últimas empresas en las que ha trabajado } \\
\text { - } \quad \text { Cómo logro entrar a esas tres empresas o cuál fue el contacto } \\
\text { que le ayudo a entrar o por el cual se enteró. } \\
\text { Razones de elegir ese tipo de trabajo (aplica para las tres } \\
\text { empresas) } \\
\text { Razones por las que se cambió de trabajo en esas tres últimas } \\
\text { empresas. }\end{array}$ \\
\hline $\begin{array}{c}\text { REDES DE } \\
\text { SUBCONTRATACIÓN }\end{array}$ & $\begin{array}{ll}\text { - } & \text { Número de personas que trabajan en el taller } \\
\text { - } & \text { Cuántos son parientes y de qué tipo es ese parentesco } \\
\text { - } & \text { Nuímes de ellos viven en su casa } \\
\text { - } & \text { Número de personas que trabajan dentro del taller } \\
\text { - } & \text { Los nombres de las empresas que la han subcontratado en } \\
& \text { los últimos tres años } \\
\text { - } & \text { Tipo de productos con los que trabaja } \\
\text { - } & \text { Actividades que realiza }\end{array}$ \\
\hline HISTORIA MIGRATORIA & $\begin{array}{ll}- & \text { Lugar de nacimiento } \\
- & \text { Lugares en los que ha vivido } \\
\text { - } & \text { Periodo en el que vivió en cada uno de los lugares } \\
\text { - } & \text { Los motivos o razones para cambiarse de localidad }\end{array}$ \\
\hline
\end{tabular}

Este cuestionario fue diseñado para las jefas y jefes de los talleres, así como para las trabajadoras subcontratadas. El único apartado que sale de esta lógica tiene que ver con las redes de subcontratación de las trabajadoras, apartado que se expone en el cuadro siguiente: 


\begin{tabular}{|c|c|}
\hline DIMENSIONES & INDICADORES \\
\hline REDES DE SUBCONTRATACIÓN & $\begin{array}{ll}\text { - } & \text { Si tiene alguna relación de parentesco con la } \\
& \text { dueña del taller } \\
\text { - } & \text { Qué tipo de relación } \\
\text { - } & \text { Quién la contacto o recomendó con la dueña del } \\
\text { - } & \text { taller } \\
\text { - } & \text { Cuántas horas trabaja en el taller } \\
\text { - } & \text { Qué otros tros trabajos } \\
\text { - } & \text { La actividad que realiza en esos otros trabajos } \\
- & \text { El promedio de cuánto gana en ese otro trabajo } \\
\text { - } & \text { Horas promedio que trabaja al día } \\
-\quad & \text { La cantidad que le pagan por prenda } \\
\text { deshebrada. }\end{array}$ \\
\hline
\end{tabular}

(Para mayor detalle véase el anexo 1)

El cuestionario debe ser visto como la puerta de entrada a la problemática que nos interesa investigar, el centro de nuestra investigación entonces, se encuentra en la entrevista.

\section{La entrevista}

Como señalamos anteriormente es el método principal de nuestra investigación. Se elaboró una guía de entrevista que tuvo como objetivo construir un instrumento con dos características: un carácter biográfico que permitiera reconstruir las historias de vida y en particular las trayectorias laborales, y además que diera cuenta de las redes sociales que sirven de base al trabajo de los talleres y su dinámica laboral y familiar. Esta guía de entrevista contiene preguntas disparadoras que dieran pie a respuestas espontáneas y a un relato fluido.

Se planteó que la guía de entrevista tuviera como principales ejes temáticos y líneas indagatorias los siguientes aspectos que se resumen en el cuadro 3: 
E.JES TEMATICOS

HISTORIA LABORAL

HISTORIA DEL TALLER
LÍNEAS INDAGATORIAS

Entradas y salidas del mercado de trabajo

- Otras actividades remuneradas actualmente

- Razones para trabajar o dejar de trabajar

- Motivaciones para la creación del taller domiciliario

- Trabajadoras Subcontratadas

- Características del trabajo productivo

- Los intermediarios

- Relación con los supervisores de la maquila

- Hacinamiento y distribución doméstica

DISTRIBUCIÓN DE LOS INGRESOS • D Distribución de los Ingresos

- Gastos del taller

Y GASTOS DEL TALLER

LA RELACIÓN TRABAJO Y

FAMILIA
- Dinámica familiar y laboral

- Negociación con los familiares

- Impacto del trabajo en la dinámica familiar

- Conflictos en la dinámica

- Ejercicio de autoridad en la familia

- Valoración del trabajo productivo

- $\quad$ Significado del trabajo en el deshebrado

(Para mayor detalle, véase anexo 1)

También se diseñó una guía de entrevista para las trabajadoras subcontratadas, en este caso, no tiene el apartado sobre la historia del taller, pero se le agregó un apartado con el título de "El trabajo dentro del taller" que se presenta en el cuadro 4.

\section{CUADRO 4}

\begin{tabular}{cll}
\hline EJES TEMATICOS & \multicolumn{1}{l}{ LÍNEAS INDAGATORIAS } \\
\hline EL TRABAJO DENTRO DEL TALLER & $\bullet$ & Características del trabajo productivo \\
& $\bullet$ & Relación con la jefa del taller \\
& $\bullet$ & Distribución de sus ingresos \\
\hline
\end{tabular}

\section{La observación}

La observación fue fundamental durante todo el proceso de investigación. Debido al carácter clandestino del trabajo a domicilio, las trabajadoras se rehusaban a ser entrevistadas por el miedo a perder su trabajo. Es por ello la observación que pudimos realizar dentro de los talleres fue fundamental para recabar información y conformar nuestra muestra. 
Para esta parte se realizó un diario de campo donde se registraron los aspectos que se observaron o experimentaron en el desarrollo del trabajo de campo. El diario es un complemento significativo a los instrumentos que describí antes y será posteriormente analizado a la luz de éstos mismos.

\subsection{Estrategia de investigación.}

La investigación se realizó en la ciudad de Tehuacán, Puebla, segunda en importancia económica para el Estado. Forma parte del fenómeno de relocalización de la maquila del norte al centro del país, nos parecía interesante estudiar un Estado que formará parte de las nuevas fronteras de la industria y que, como tal, no había sido suficientemente estudiado.

Asimismo, el Estado de Puebla, y en particular Tehuacán, cuentan con una historia rica en cuanto a maquila se refiere y de una fuerte presencia de empresas que forman parte de la cadena de producción global de ropa. Estos son factores hacen de esta región una importante zona de estudio.

El trabajo de campo se realizó con la ayuda de la Comisión de Derechos Humanos y Laborales del Valle de Tehuacán (CDHyLVT), que actúan en el terreno maquilador del municipio y que nos facilitaron la entrada al terreno de investigación. Su apoyo consistió en el acercamiento a las trabajadoras de los talleres y en el acompañamiento durante todo el proceso.

\section{Etapas del trabajo de campo}

El trabajo de campo está conformado por tres etapas. La primera se refiere a la exploración de los posibles talleres para el estudio. La segunda tiene que ver con la prueba piloto del cuestionario y de la guía de entrevista. Y la tercera el levantamiento de información mediante el cuestionario, guía de entrevista final y el diario de campo elaborado a partir de la observación. A continuación, explicaré de manera detallada cada una de estas etapas. 


\begin{tabular}{l|l|l}
\multicolumn{1}{c}{ PRIMERA ETAPA } & CEGUNDAO 5 \\
\hline $\begin{array}{l}\text { Exploración inicial: Dónde se } \\
\text { encuentran los talleres, desde } \\
\text { cuándo, qué tipo de trabajo } \\
\text { realizan, qué actividades etc. }\end{array}$ & $\begin{array}{l}\text { Prueba piloto del cuestionario y } \\
\text { de la guía de entrevista }\end{array}$ & $\begin{array}{l}\text { Levantamiento de } \\
\text { cuestionarios. }\end{array}$ \\
\hline $\begin{array}{l}\text { Entrevista abierta con } \\
\text { informantes calificados. }\end{array}$ & $\begin{array}{l}\text { Realización de correcciones al } \\
\text { cuestionario y a la guía de } \\
\text { entrevista. }\end{array}$ & $\begin{array}{l}\text { Realización de } \\
\text { entrevistas. }\end{array}$ \\
\hline $\begin{array}{l}\text { Búsqueda de los talleres } \\
\text { domiciliarios }\end{array}$ & Trabajo de observación. & $\begin{array}{l}\text { Elaboración del diario de } \\
\text { campo. }\end{array}$ \\
\hline $\begin{array}{l}\text { Primer acercamiento a los } \\
\text { talleres. }\end{array}$ & $\begin{array}{l}\text { Acuerdos con las trabajadoras en } \\
\text { las fechas en que se realizaría el } \\
\text { trabajo de campo. }\end{array}$ & Análisis del cuestionario. \\
\hline $\begin{array}{l}\text { Búsqueda de los talleres para el } \\
\text { estudio y afianzamiento de los } \\
\text { contactos. }\end{array}$ & & $\begin{array}{l}\text { Primera transcripción de } \\
\text { entrevistas. }\end{array}$ \\
\hline Trabajo de observación & & Trabajo de observación.
\end{tabular}

\section{a) Primera etapa}

Esta etapa se realizó entre el 17 y 18 de junio del 2008, el principal objetivo fue el de obtener información general del trabajo a domicilio y buscar los contactos necesarios para llevar a cabo el trabajo de investigación futuro. Para lo cual se realizaron las siguientes actividades:

- Una exploración inicial que consistió en indagar: Dónde se encuentran los talleres, desde cuándo, qué tipo de trabajo realizan, qué actividades, etc.

- También se realizaron entrevistas abiertas con informantes calificados que nos brindaron un panorama general de la maquila en Tehuacán y de los talleres domiciliarios.

- Se realizó una búsqueda de los talleres domiciliarios, la cual consistió en hacer recorridos a diferentes zonas de Tehuacán y algunos pueblos cercanos como Patzingo, Altepexi y Ajalpan.

- Se tuvo un primer acercamiento con las trabajadoras(res) de los talleres y al trabajo que realizan.

- Se platicó con las trabajadoras con el fin de afianzar los contactos.

- En general se realizó un trabajo de observación a lo largo de esta primera etapa, el cual se registró en el diario de campo.

En conclusión, esta primera etapa tuvo como resultado el contacto con dos talleres de deshebrado a domicilio, uno jefaturado por una mujer y el segundo por un matrimonio, cada uno cuenta con aproximadamente entre 20 y 30 trabajadoras. 


\section{b) Segunda etapa}

El objetivo principal de esta etapa fue realizar la prueba piloto de los instrumentos, para ello, se llevaron a cabo las siguientes actividades:

a) Una visita a Tehuacán el 11 de julio del 2008, donde se realizó la prueba piloto del cuestionario diseñado para las jefas de taller, los jefes de taller y las trabajadoras subcontratadas, se aplicaron dos a cada tipo de trabajadora y una con el trabajador.

b) El 7 de agosto del 2008 regresé a Tehuacán para llevar a cabo la prueba piloto de la guía de entrevista dirigida a las jefas de los talleres a domicilio.

c) Se hicieron las correcciones necesarias tanto al cuestionario como a la guía de entrevista.

d) Se acordaron las fechas tentativas con las trabajadoras en que se llevaría a cabo la aplicación de los cuestionarios y la realización de las entrevistas.

e) El trabajo de observación fue algo que se realizó en todas las etapas y que se registró en el diario de campo.

\section{c) Tercera etapa}

El objetivo principal de esta última etapa fue la realización del trabajo de campo, para ello, se llevaron a cabo las siguientes actividades:

- Se aplicaron once cuestionarios.

- Se realizaron cuatro entrevistas en profundidad con mujeres y una con un hombre.

- La elaboración del diario de campo.

- El análisis de los datos obtenidos del cuestionario

- La transcripción de entrevistas

- La transcripción de las notas del diario de campo

- El análisis de los datos cualitativos en su conjunto.

Es importante decir que no se les pudo aplicar el cuestionario a todas las trabajadoras de los talleres, debido a que como éstos tienen un carácter clandestino fue difícil ganarme la confianza de la gente. Aunque convivimos de manera cotidiana durante dos semanas, no aceptaron que se les aplicará el cuestionario o que se grabaran las entrevistas. Por lo que el ejercicio de observación tomó mayor importancia, así como las conversaciones informales de las cuales existen notas en el diario de campo. 


\subsection{Construyendo la muestra.}

La conformación de la muestra se realizó a partir del procedimiento de bola de nieve, donde unas trabajadoras nos llevaban a otras, esta era la única manera de acceder a ellas, debido a la desconfianza que ya apuntamos.

Aunque ya se había realizado un acercamiento con las trabajadoras de los talleres, a mi llegada me encontré con que uno de los talleres que había contactado en el mes de julio y al cual le había aplicado el cuestionario piloto, cerró debido a problemas con los intermediarios de la maquila para la cual trabajaban de manera exclusiva. En un principio esto fue inquietante porque creí que había perdido uno de los talleres, después me di cuenta de que era la oportunidad para dar cuenta de la inestabilidad del trabajo domiciliario y de los problemas que existen en torno a ellos. Decidí buscar a las personas encargadas de este taller, que no solamente se habían quedado sin trabajo, sino que también habían tenido que vender su casa para pagar sus deudas.

El jueves 16 de octubre las hermanas de Antonio ${ }^{10}$, uno de los jefes del taller, y quienes le compraron la casa, me brindaron el teléfono de su nuevo trabajo en una de las maquiladoras, de nombre YARA, instalada a las afueras de Tehuacán. Mi acompañante de la CDHyLVT y yo, nos dimos a la tarea de tratar de localizarlo por teléfono en la maquila para concertar una cita con Antonio, para que nos platicará su historia de lo que había pasado. Aunque fue difícil localizarlo, una de nuestras tantas llamadas a la maquila tuvo éxito y concertamos una cita para el 21 de octubre a las 6:30 pm. Hora en que saliera de trabajar.

Mientras encontraba a y Antonio y su esposa Ana, me dedique a otro taller, jefaturado por la Sra. Flora donde aplique 6 cuestionarios y 2 entrevistas grabadas. En este taller no todas las trabajadoras aceptaron que les aplicará el cuestionario o que grabará las entrevistas, por lo que opté por realizar observación participante y entrevistas informales, las cuales registré en mi diario de campo, con ellas estuve dos semanas, del 13 al 24 de octubre.

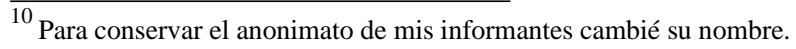


El 21 de octubre tuvimos nuestra cita con Antonio, nos explicó cuales habían sido las causas por las que tuvieron que cerrar su taller y la situación actual en que se encontraban. Me proporcionó una entrevista de 43 minutos en la que narraba todas las peripecias y problemas por los que había pasado y, que ahora se encontraban viviendo en casa de sus suegros, en donde la familia de su esposa también tenía un taller de deshebrado. Ese día pactamos volver a reunirnos el viernes 24 de octubre a las 11 de la mañana para aplicarle el cuestionario a Ana, su esposa, y a una mujer de nombre Yolanda que había trabajado con ellos en el anterior taller y que ahora se mantenía trabajando en el actual.

El 24 de octubre acudí a la cita, en el transcurso del día realicé 2 entrevistas y aplique 2 cuestionarios. También tuve la oportunidad de platicar con las encargadas del actual taller en el que se encuentra trabajando Ana, las dos encargadas eran su hermana y cuñada. En este último caso solamente su cuñada aceptó que se le aplicara el cuestionario, al igual que una de sus tías. Lo que sí pude realizar fue trabajo de observación y entrevistas con la condición de que no fueran grabadas. Este fue el proceso por el que atravesó el trabajo de campo durante dos semanas.

En general se realizaron las entrevistas y cuestionarios necesarios para el análisis, tanto con jefas(es) como con trabajadoras subcontratadas, buscando realizar por lo menos dos por cada taller. Aunque existieron contratiempos, éstos se pudieron resolver en la marcha del trabajo de campo. Al final, aunque se perdió tiempo valioso en encontrar a las personas del taller que cerró, también se ganó en otros aspectos, como el de dar cuenta de la vulnerabilidad en la que viven las personas que trabajan a domicilio.

Para esta parte del estudio seguimos la trayectoria de diez mujeres y un hombre, que por distintos caminos llegaron a ser jefas/fes de los talleres o sus trabajadoras subcontratadas, tejiéndose las redes necesarias para realizar este tipo de trabajo. En general este fue el camino que se tuvo que recorrer para conformar nuestra muestra. 
Es necesario ahora, hacer un breve recorrido por la industria de la confección en México, pero sobre todo en Tehuacán, ${ }^{11}$ para hacer un análisis de las trayectorias laborales a la luz del contexto maquilador.

\section{Breve recorrido por el desarrollo de la industria maquiladora en México.}

En este apartado se intenta mostrar las etapas de desarrollo de la industria maquiladora en México, para explicar la dinámica de las trayectorias laborales y el sentido atribuido a las mismas por las propias mujeres. Para fines de este análisis y con el objetivo de aclarar mejor la dinámica de las trayectorias laborales, se retomarán también las principales etapas de la industria de confección de ropa en Tehuacán, Puebla. Esto con el objetivo de precisar el contexto en el que se sitúan las trayectorias. Las maquiladoras son, en términos generales, plantas ensambladoras que compañías extranjeras, principalmente de EE.UU, instauraron en los países en desarrollo con el objeto de aprovechar su abundante mano de obra.

Entre 1960 y 1970, se inició el traslado de plantas de ensamblaje hacia México y América Latina. Para 1990 esta práctica se había generalizado gracias al impulso del comercio internacional. Las maquiladoras en México tuvieron un origen común, derivado en gran medida de las políticas de crecimiento y fomento a la inversión extranjera. En 1965, tras la cancelación del convenio de trabajadores temporales (braceros) entre México y los Estados Unidos, el gobierno inició un programa temporal, que popularmente se denominó programa maquilador. (De la O, 2001).

\footnotetext{
${ }^{11}$ Para mayores detalles consultar el capítulo 2.
} 
A finales de los años sesenta, este proceso de relocalización industrial se inició en la frontera norte y más tarde extendería en el resto del territorio nacional. Se comenzó con la instalación de empresas de capital extranjero, fundamentalmente estadounidense, que trasladaron una parte de proceso productivo hacia México. Se trataba de procesos de ensamble que requerían del uso intensivo de mano de obra.

En términos generales se pueden distinguir cuatro grandes periodos en el desarrollo de las maquiladoras en México. El primero (1966-1982) es un largo periodo en el que se definen las características esenciales del modelo maquilador mexicano. Este periodo de instauración estuvo atravesado, entre 1975 y 1982, por la recesión de la economía estadounidense y la devaluación del peso mexicano, fenómenos ambos que afectaron particularmente la frontera norte. (De la O, 2001: 29).

El segundo periodo (1983-1990), se caracterizó por la puesta en marcha de programas como: el Programa de Fomento a la Industria Maquiladora de Exportación 1983-1988 y el Programa Nacional de Fomento a la Industria y el Comercio Exterior. Como una salida a la crisis, sostenidos en el fomento de la industria maquiladora de exportación. Con estos programas se inició una fase de consolidación y crecimiento, de mayor flexibilización del trabajo y especialización industrial, en la que destacarían las ramas ligadas a la industria automotriz, la electrónica y la confección.

El tercer periodo abarcó la década de los noventa, se puede dividir en dos: el primero corresponde a la merma del sector maquilador entre 1987 y 1991, asociada al impacto del ciclo recesivo de la economía estadounidense; el segundo fue de recuperación previo a la firma del TLCAN. En esta segunda mitad de la década se observa el crecimiento constante de las empresas maquiladoras y la consolidación de patrones de localización industrial a través de parques y áreas industriales, así como una mayor complejidad en las formas de subcontratación.

Este nuevo arreglo comercial, resultó en la conformación de una nueva geografía maquiladora constituida por regiones tradicionalmente maquiladoras, que comprenden a los 
estados de la frontera y norte del país; y en nuevas fronteras en las regiones interiores como el centro, occidente y sur del país, en clara desventaja. Las regiones tradicionales, se especializan en el procesamiento de productos electrónicos y de autopartes; en tanto que las nuevas fronteras lo hacen en la confección. (De la O, 2006)

Finalmente, un último periodo comenzaría a finales del año 2000, relacionado nuevamente con la economía en recesión de los Estados Unidos. Otro factor adyacente está relacionado con la competencia representada por China. Esta crisis se manifestaría en la salida o cierre de plantas y despido de personal.

\subsection{Recorrido por el desarrollo de la industria de confección en Tehuacán, Puebla.}

La instalación de las primeras empresas que se dedicaron a la producción de ropa tuvo lugar entre 1971 y 1973. Estas empresas vendían su producción (camisas y pantalones de vestir, pantalones de mezclilla, uniformes escolares e industriales, ropa interior y ropa para mujeres y niños) con sus propias marcas en los tianguis regionales. En 1978 ya existían 28 empresas de confección, que daban empleo a 2,000 trabajadores, fabricando para el mercado nacional y exportaciones indirectas. Diez años después, bajo la influencia de los programas de fomento a las maquiladoras y dentro de programas de exportación directa creció el número de empresas hasta 80, con 8,000 trabajadores, (Juárez, 2004).

Desde principios de la década de 1990, las plantas maquiladoras se empezaron a extender de la ciudad de Tehuacán y a otras comunidades cercanas, destacando ya en la estructura regional junto con la producción de refrescos, huevo y pollo. Sin embargo, fue con la entrada en vigor del TLCAN, en 1994, cuando se produjo el auge maquilero local (Barrios y Santiago, 2004: 24).

Este crecimiento se detuvo en marzo de 2001. El proceso de desaceleración de la economía norteamericana impactó en las exportaciones y en el empleo de las maquiladoras mexicanas, afectando también en Tehuacán. Muchos gerentes comenzaron a “descansar” gente, lo que sumado con los paros técnicos generalizó los recortes al salario y prestaciones 
(Juárez, 2004). Paralelamente, emigraron empresas estadounidenses hacia el sureste del país y Centroamérica. Un promedio de 25 plantas desapareció en la región de Tehuacán, originando con ello que más de mil trabajadores se quedaran sin empleo. En 2005, cerraron las cinco plantas del corporativo Tarrant Apparel Group, que tuvo como efecto inmediato el despido de más de cinco mil trabajadores.

En la actualidad, Tehuacán atraviesa por una crisis económica que ha mermado a la industria de la confección, de tal manera, que de ser uno de los municipios más importantes en términos de exportación y empleo, actualmente enfrenta serios problemas económicos y sociales, debido a que el cierre de empresas va en aumento a la par que el desempleo.

Debido a ello, el desarrollo de la maquila en Tehuacán se ha orientado hacia su precarización. La industria, cada vez más recurre a la maquila clandestina para poder sobrevivir a la crisis. Actualmente se calcula que un $50 \%$ de las empresas que se dedican al sector textil y maquilador son clandestinas, por lo que las condiciones de trabajo son deplorables y precarias.

\section{El trabajo subcontratado a domicilio en Tehuacán, Puebla.}

El trabajo subcontratado a domicilio, hoy más que nunca, representa en la localidad un nicho importante para el trabajo femenino en la región, no solamente por su carácter doméstico, sino porque debido a la crisis económica las empresas recurren a éste con más frecuencia. No se cuentan con datos específicos sobre el número de personas que participan en él, debido a que es un trabajo informal y clandestino, pero es bien sabido que su uso es extensivo y que forma parte importante en el proceso de producción de ropa, tal como se pudo constatar a través de entrevistas abiertas con informantes calificados de la localidad y de mi propia observación.

El trabajo subcontratado a domicilio se ubica en el último eslabón de la cadena de producción de ropa, donde sobre todo mujeres, niñas/ños, ancianas/nos y en menor medida hombres quienes son subcontratados desde sus casas por empresas nacionales que maquilan 
para grandes firmas extranjeras. Son fuerza de trabajo que representa menores costos para las empresas y nulas obligaciones en seguridad social.

El deshebrado o deshilado de las prendas es una de las actividades que se llevan a cabo con más frecuencia en estos talleres, pues no se requiere ningún tipo de capacitación previa para realizarla. Es uno de los últimos pasos que se realizan después de terminar de ensamblar las partes de la prenda y consiste en cortar los hilos que quedan de las uniones del ensamble por el derecho y el revés de ésta. Lo único que se necesita son unas tijeras especiales que se compran en cualquier tienda.

Son los talleres que se dedican al deshebrado los que nos interesa estudiar, debido a que consideramos que esta actividad implica una acentuación en la precarización, ya que se trabaja por prenda deshebrada, es decir, a destajo. Asimismo, el deshebrado facilita la integración de las mujeres, sus hijos e hijas y adultos mayores, no solamente en los talleres sino también desde sus casas. Creándose una red de subcontratación en el nivel de este eslabón que no se había estudiado antes. Otro aspecto que lo hace interesante es que se desarrolla en el espacio de la casa, donde la simultaneidad, el empalme de actividades y la invasión del espacio doméstico es su sello distintivo.

Este tipo de talleres, sobre todo en periodos de crisis económica, juegan un papel de reserva de mano de obra, en algunos casos cuando la maquila cierra, existe una tendencia a recurrir a los talleres domiciliarios y cuando vuelve a darse la estabilidad económica las personas regresan a trabajar a la maquila.

En gran medida los talleres se nutren también de personas que no tienen experiencia laboral, como de las mujeres jóvenes o de edad avanzada que se quedan viudas y que se vuelven jefas de hogar que en momentos de crisis económica recurren a un trabajo en el que pueden ingresar sin ningún requisito y que no les implica más que presentarse o pedir que le den prendas para deshebrar. 
Los talleres también pueden implicar una reserva de mano de obra infantil. En un contexto difícil se recurre al trabajo de los hijos pequeños en este tipo de espacios, sobre todo si se trata de talleres de deshebrado, donde las actividades que se realizan son sencillas y fáciles de aprender.

En conclusión, los talleres de deshebrado subcontratados a domicilio son importantes en tanto que forman parte de una cadena de producción global de la industria de confección en Tehuacán, cumplen con el papel de dotar de empleo a un número significativo no solamente de mujeres, sino también de niños, ancianos y cada vez más de hombres desempleados. Su existencia se torna más relevante sobre todo en momentos de crisis económica, donde se recurre en mayor medida a ellos, por el ahorro que implican para las maquiladoras formales en términos de gastos de producción y organización interna de la misma maquila, por lo que prefieren transferir esta responsabilidad a una tercera persona que los absorbe.

\subsection{Dos talleres subcontratados a domicilio.}

El estudio se realizó en dos talleres, el taller 1 es jefaturado por una mujer, tiene la característica de que sus trabajadoras no tienen relación de parentesco con ella. El segundo taller es jefaturado por una pareja y cerró sus puertas debido a un problema con los intermediarios, en este caso, los jefes y parte de las trabajadoras se relocalizaron en un tercer taller. Lo que habla de cómo el trabajo a domicilio subcontratado constantemente se está multiplicando y resituando con relación a las condiciones de la maquila. Por ejemplo, si se acaban los contratos con las empresas que tiene pactada la producción, simplemente se acaba el taller a domicilio, por la falta de trabajo y la dependencia que existe entre el taller y las maquilas. En este caso las redes familiares permiten que se relocalicen en otros talleres como mano de obra subcontratada o como organizadores de los mismos.

La investigación se realizó con dos talleres, uno que mantiene actividades hasta ahora y otro que cerró, pero donde se llevó a cabo su reconstrucción. A continuación, realizaré una 
descripción general de cada uno de ellos, es decir, de cómo están integrados y cuáles son sus características generales.

El Taller 1, se encuentra en la colonia 3 de mayo, en el patio de la casa de la Sra. Flora (1) ${ }^{12}$ jefa y organizadora del taller. Está compuesto por su suegra y aproximadamente veinticinco trabajadoras no familiares. Algunas de ellas trabajan desde ese espacio y otras lo hacen desde sus casas. En este taller se le aplicó el cuestionario a Eugenia (02), Carmen (03), Asunción (04), Felipa (05) y Aquilina (06). Aunque este taller se caracteriza porque las trabajadoras subcontratadas no tienen una relación familiar con la jefa del taller, en la observación se constató que los hijos y el esposo de la Sra. Flora trabajan activamente en las labores de deshebrado.

El taller 2 es jefaturado por una pareja Ana (7) y Antonio (11), contaba con diecisiete mujeres trabajadoras no familiares. En este taller también se pudo contactar a Yolanda (9) a quien se le aplicó el cuestionario, al igual que a los dueños, también a los tres se les entrevisto. Este es el taller que cerró, pero del cual se pudo reconstruir como estaba conformado a partir del cuestionario piloto que se aplicó a Ana jefa del taller el 11 de julio del 2008 cuando aún se encontraba en funcionamiento.

El taller 3 es jefaturado por Fátima (12), Agustina (10), hermana y cuñada de Ana (7). En el laboran cinco trabajadoras familiares que realizan sus actividades desde el taller y tres trabajadoras no familiares que realizan el trabajo desde sus casas. En este último taller se le aplicó el cuestionario a Petra (8), una de las tías de Ana.

Hay un gran número de talleres y una gran diversidad en la localización del trabajo que realizan, nuestra muestra es ejemplo de ello, en el caso del cierre del taller 2, algunas trabajadoras se reagruparon en el taller 3.

\footnotetext{
${ }^{12}$ Para conservar el anonimato de mis informantes cambié su nombre y les asigné un número para facilitar su identificación en las tablas y el mapa que resumen sus trayectorias y sus datos sociodemográficos.
} 

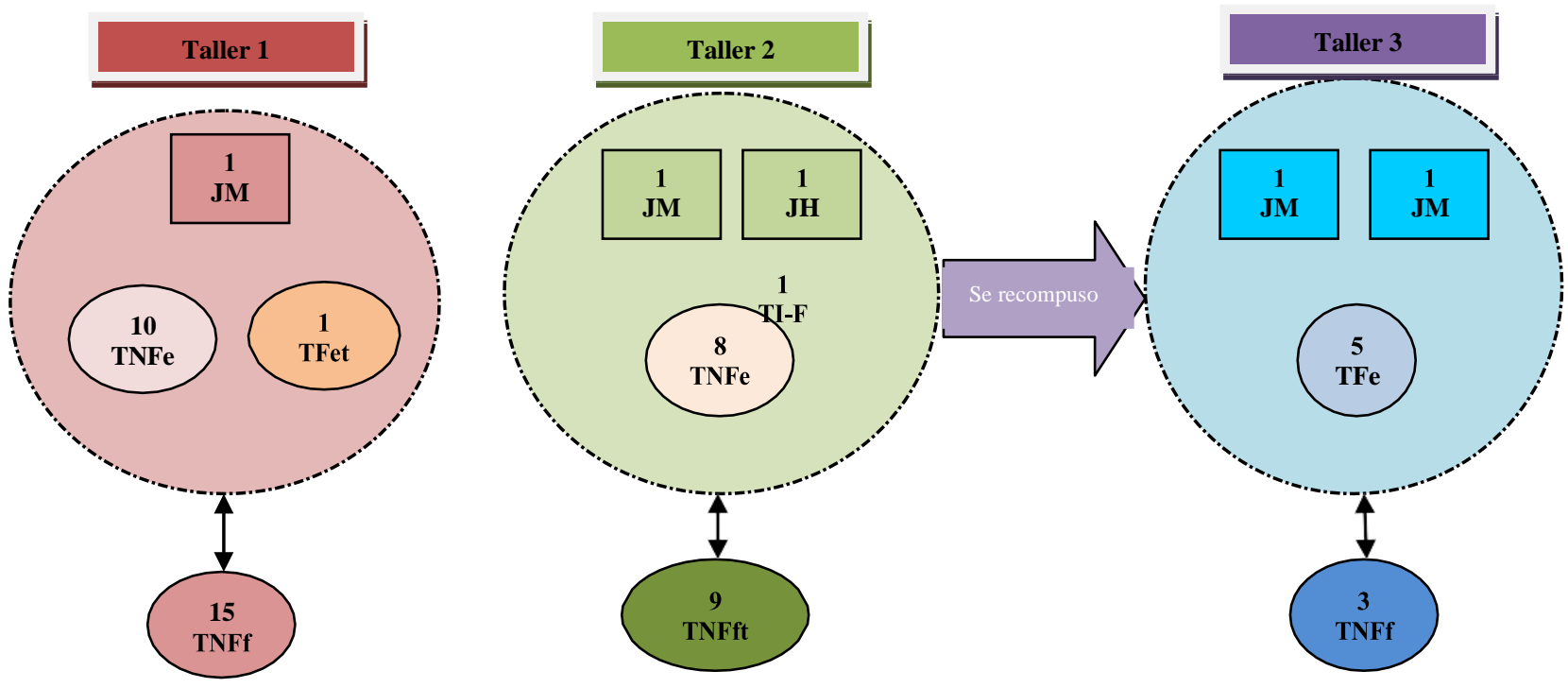

JM: Jefa de Taller

JH: Jefe de Taller

TFet: Trabajadora Familiar en el taller

TNFet: Trabajadora No Familiar en el taller

TFft: Trabajadora Familiar fuera del taller

TNFft: Trabajadora No Familiar fuera del taller

Las redes que se generan a partir de las trabajadoras subcontratadas poseen cierta fluidez y movilidad. Estas redes tienen las siguientes características generales:

- Las trabajadoras subcontratadas pueden decidir entre hacer el deshebrado desde sus casas, dentro del taller o en qué momento quieren hacerlo. No existen horarios, depende de sus condiciones familiares y de cuánto necesite ganar a la semana, ya que es importante recordar que éste es un trabajo a destajo.

- Pueden trabajar simultáneamente en varios talleres, dependiendo de la cercanía en que se ubican éstos de su domicilio.

- Se observó que las mujeres que trabajan en el taller o desde sus casas, viven cerca del mismo.

- Las que trabajan desde sus casas integran a las hermanas, los hijos, etc. Por lo que el trabajo se extiende de tal manera que se hace imposible saber realmente cuántas personas trabajan para el taller, en este caso las redes de subcontratación se vuelven 
borrosas, ni siquiera la jefa tiene pleno conocimiento del número de personas que trabajan para ella.

- Pueden a su vez trabajar en otro tipo de actividades como la venta de cosméticos, utensilios de cocina, ropa, lavar ajeno, etc. trabajos que se pueden combinar con el deshebrado de manera simultánea.

Estos talleres ejemplifican la flexibilización llevada al extremo, donde las mujeres salen de la planta maquiladora o llegan sin experiencia a subcontratarse allí, adecuando el espacio de la casa para poder trabajar, en condiciones laborales se precarias por la pérdida de sus prestaciones laborales y la reducción de sus pagos, sujetos a lo que lleguen a deshebrar durante una semana.

Al mismo tiempo subcontratarse es una iniciativa que toman las mujeres con hijos pequeños sin las redes sociales necesarias con las cuales apoyarse para seguir trabajando. El trabajo subcontratado a domicilio representa un recurso de las trabajadoras para no abandonar el mercado laboral y hacerse de un ingreso. También existen casos de mujeres con más de sesenta años, que toda su vida se dedicaron a las labores de la casa o al servicio doméstico, que al quedar viudas necesitan trabajar en actividades sencillas accesibles a su edad. En este caso, el trabajo domiciliario representa un nicho importante de empleo.

Los talleres son una extensión de la maquila formal, el trabajo a domicilio en realidad constituye una forma de trabajo encubierto, en la medida en que se acrecienta en épocas de crisis. Las jefas y los jefes de los talleres de alguna manera fungen el papel de gerentes de producción de las empresas, desempeñando el papel intermediarios entre los talleres y las fábricas. Muchos de ellos, según sus trayectorias, trabajaron en la maquila en algún momento de sus vidas.

A continuación, presentaremos el análisis de los datos obtenidos a través de nuestros instrumentos de investigación. 


\subsection{Las mujeres del trabajo subcontratado a domicilio en Tehuacán. ${ }^{13}$}

\section{Antecedentes Familiares}

En este apartado pretendo construir un marco general que nos permita entender quiénes son las mujeres que trabajan a domicilio en Tehuacán. Con este propósito abordaré primero los elementos que tienen que ver con su familia de origen, su situación migratoria, sus obligaciones familiares y algunas características sociodemográficas. Consideramos que, al dar cuenta de sus antecedentes familiares, podremos comprender mejor su transición a la edad adulta y su condición de madres trabajadoras.

\section{Escolaridad}

En cuanto a su escolaridad, nos encontramos con que estas mujeres apenas alcanzan los cinco y seis años de estudios (ver cuadro 1), mientras que la mayoría de sus madres no cuentan con estudio alguno y sus padres apenas alcanzan en promedio los seis años (Ver cuadro 2).

Si tenemos en cuenta estos datos junto con las condiciones de pobreza rural y urbana en las que crecieron estas mujeres, podríamos hablar de una cierta movilidad social, que aunque sigue siendo poca, sí representa un esfuerzo importante sostenido casi por ellas mismas.

\section{El trabajo de los padres}

Por otro lado, en cuanto al trabajo que realizan sus madres, nos encontramos que el abanico de oportunidades se concentra en el trabajo doméstico remunerado, la agricultura, en la maquila o en los talleres de deshebrado. (Ver cuadro 2)

Si analizamos la trayectoria laboral de las trabajadoras a domicilio (ver cuadro 4), podremos observar que algunas de ellas siguen trabajando o trabajaron en las mismas actividades que

\footnotetext{
${ }^{13}$ Los cuadros del análisis que se presenta a continuación se puede ver en el Anexo 2 de este documento.
} 
desempeñaban sus madres como el trabajo doméstico y las artesanías, aunque comienzan también a dedicarse a otras actividades como el comercio, los servicios y la maquila.

En el caso de los padres de las trabajadoras, pareciera que su abanico de posibilidades para insertarse al mercado laboral es más diverso. Algunas de estas posibilidades son: la agricultura, ganadería, los servicios y en algunos casos en la industria de la construcción o en la maquila. (Ver cuadro 2) Por lo que pareciera que los papás tienen opciones de trabajo más amplias que las madres.

\section{Migración}

Aunque no se pudo profundizar demasiado en este aspecto, debido a la dimensión de la muestra, sí encontramos algunos indicios importantes de que existe cierta migración dentro del mismo Estado de Puebla, es decir, de poblados aledaños hacia nuestra zona de estudio, como es que caso de los municipios de Tlacotepec, Atolotitlán y Zoquitlán. También encontramos algunos casos en los que ellas migraron de muy pequeñas junto con sus padres en la búsqueda de mejores oportunidades, desde el Estado de Oaxaca hacia Tehuacán (Ver cuadro 3). Esta es una línea de investigación abierta para futuros estudios.

\section{Trabajo y vida familiar}

Los estudios especializados en el tema del trabajo a domicilio realizados en los años ochenta y noventa describían a las mujeres como casadas, en plena etapa reproductiva, con hijos y con poco nivel de instrucción, (Alonso, 1988 ; 1988b; 1991ª ; 2002). A partir de los datos de nuestra muestra, que como es evidente no tiene un carácter representativo sino indicativo, podríamos plantear que debido al creciente desempleo en la región, causado por el cierre masivo de plantas maquiladoras sumado al hecho de que las actividades que se practican en este trabajo son básicamente de deshebrado, una mujer de cualquier edad o condición puede emplearse a domicilio pues no se requiere ningún tipo de capacitación y prácticamente cualquiera puede deshebrar. 
Encontramos en nuestro estudio, que si bien la mayoría de las trabajadoras entrevistadas, han estado unidas o casadas y que han tenido entre dos y seis hijos, también existen algunas (2 casos) que son solteras y sin hijos. (Ver cuadro 1) Lo que nos dice que las mujeres que buscan trabajo en los talleres podrían ser las que están tratando de conciliar su carga doméstica y familiar con el trabajo productivo. También representa una opción para aquellas mujeres jóvenes o ancianas sin experiencia laboral que no encuentran otra forma de emplearse.

En el caso de las mujeres con obligaciones familiares, el trabajo en los talleres ofrece la oportunidad de intentar la anhelada conciliación entre trabajo doméstico y extradoméstico, como lo señala una de ellas a continuación:

"El tiempo se presta, no tengo que estar a una hora determinada, y termino de hacer mi quehacer, mi comida y me vengo a deshebrar. A la hora que tengo hambre me voy a comer, luego vengo y ya sigo trabajando, así puedo atender a mis hijos, por eso me gusta este trabajo." (Flora)

Es de destacar que en el trabajo de observación que se realizó en los talleres se pudo constatar la presencia de niños y niñas. En una de las entrevistas nos fue narrado por una de ellas como fue que desde niña comenzó a trabajar en un taller, como lo describe a continuación:

"Trabajaba en una maquiladora chica; creo que ni nombre tenía porque era como en una casa, como aquí. Tenía unas cuantas maquinas, nada más, pero sacaban unas chamarrotas, pero bien tremendas y entonces a mí me pusieron a repartir el trabajo como aquí reparten el trabajo para deshebrar. Pues a mí me puso la señora a repartir trabajo casa por casa y en el diablito, jalando el diablito, no en coche ni nada, jalando el diablito. A mí tampoco me gustó, porque estaba pesadísimo, luego era un diablote, pues grandote y las chamarras, no me gustó y que me salgo. (Flora)

También se observó la presencia de mujeres muy jóvenes y otras que rebasan los setenta años. Esto se explica en gran medida, a partir de su trayectoria laboral en la que por mucho tiempo se movieron en un mercado limitado de trabajo doméstico o artesanal y que al final de sus vidas encuentran en el trabajo subcontratado a domicilio un nicho de oportunidad para ellas. En este aspecto se profundizará más adelante. 


\section{Edad}

El estudio reveló (ver cuadro 1), que la edad media de este grupo es de 38 años siendo el rango de edades entre los 26 y 46 años. El cual puede considerarse como un periodo de edad reproductiva, es decir que no solamente es el periodo en que se tienen hijos, si no en el que todavía se encuentran encargadas de los hijos más jóvenes.

Es importante apuntar que la más joven cuenta con 16 años y la más grande con 74 . Esto marca diferencias muy grandes en cuanto, no solamente, a la variabilidad de rangos, sino también en que el trabajo se experimenta de manera distinta. También apuntan a un fenómeno de inclusión de mujeres muy jóvenes, de niñas y niños que están trabajando en los talleres a edades muy tempranas, entre los 7 y 9 años, se insertan por primera vez en los talleres domiciliarios, para ayudar a sus madres.

La diferencia de edades indica que estas formas de trabajo precario, sumergido, no especializado absorben a todos aquellos excluidos del trabajo formal, incluidas sus familias.

\section{Primeras obligaciones familiares}

Durante su infancia es común que las mujeres realicen actividades domésticas y familiares, indispensables para la sobrevivencia de sus familias, eventualmente desempeñan trabajos remunerados para contribuir al ingreso familiar. Estos tienden a ser trabajos "impuestos" por las necesidades familiares. Son actividades como el trabajo doméstico, ayudante en algún comercio o de niñera como señala Ana en su relato: "Trabajé de niñera con una maestra, nada más dos años. Tenía como 12, era en quinto y en sexto de primaria."

Su incorporación al mercado de trabajo es una continuación inequívoca de su historia anterior. Este primer acercamiento al trabajo y a una "paga" fue lo que las preparó y dotó de experiencia para el ingreso a su primer trabajo remunerado y generó en ellas un sentido de responsabilidad, tal como señala Ana a continuación: 
“A mí me urgía trabajar porque mi mamá estaba sola. Mi papá casi no estaba y a veces mandaba [dinero] y a veces no. A mí me urgía trabajar por mis hermanos que estaban más chicos que yo. Veía que sí había necesidad en mi casa."

\section{Trayectorias Laborales}

Ingreso al mercado de trabajo

Cuando hablamos del primer empleo nos referimos específicamente al primer empleo remunerado. En los casos estudiados, observamos que prácticamente la mitad de las mujeres entraron directamente a trabajar en las empresas maquiladoras mientras que la otra mitad lo hizo en el trabajo doméstico y las artesanías. (Ver cuadro 4)

También encontramos que las que se incorporan a la maquila lo hicieron en las décadas de los ochenta y noventa, a edades tempranas entre los 11 y los 14 años. Mientras la mayoría de quienes ingresan al trabajo doméstico lo hicieron en las décadas del cuarenta al setenta, en edades que iban de los 7 hasta los 13 años; en este caso se encuentran las mujeres de más de 70 años, donde su abanico de oportunidades de ingreso al mercado laboral era mucho más reducido.

De acuerdo con las entrevistadas que ingresaron a su primer empleo remunerado en el sector maquilador, lo hicieron a través de una amiga o vecina. Esto nos habla de la importancia de las redes sociales para ingresar al mercado de trabajo de manera más ágil. Como lo relata Felipa “...cuando entré a la maquila por primera vez, una amiga me llevó, bueno una vecina. Me dijo -cuando salgas de la primaria nos vamos a trabajar en la maquila y voy a decir que eres mi prima-, y ya salí de la primaria y ella me llevo a la maquila, y le dijo al encargado y él dijo que si era su prima que pasara."

En su primer trabajo en la maquila era común que la primera actividad que realizaran fuera el planchado, debido a que iniciaban como manuales antes de pasar a tareas más complicadas como la costura, ese fue el caso de Flora: 
"Yo... primero empecé a planchar. Cuando apenas inicie, planchaba talla y etiqueta, eso era lo que yo planchaba." Y también el de Felipa, aunque ella duró poco tiempo haciendo esa actividad porque revolvía el trabajo, después de eso la pusieron a marcar botón."

Resultó interesante que Ana una de las jefas de los talleres, desde el principio de su carrera laboral deshebró. Ana narra cómo en toda su trayectoria realizó esta actividad porque le resultaba fácil y lo hacía muy rápido, no es de extrañar que se encuentre sumamente familiarizada con este paso en particular: “...como siempre he deshebrado, lo hago rápido, siempre lo hice rápido."

Aprendizaje

El aprendizaje en su primer empleo suele ser decisivo para el resto de su trayectoria laboral. Muchas veces la primera actividad que aprenden a realizar es la que desarrollan durante su paso por la maquila, como lo narraba Ana, cuando aprendió a deshebrar hace 13 años, actividad que sigue realizando actualmente.

En otros casos van aprendiendo tareas cada vez más complejas como le paso a Flora cuando ingreso se dedicaba al planchado, para después aprender a coser, tal como ella lo relata: " $\mathrm{Ya}$ después poco a poco, ya me ponían en la sencilla, aprendí a coser cuando tenía como 17 años. Me enseño el encargado a coser, y ya después empecé a agarrar poco a poco la Yamato."

La manera en que experimentan este proceso y la forma en la que van aprendiendo a realizar sus actividades es significativa, en tanto, les permite ir acumulando conocimiento para moverse en el mundo de la maquila, no solamente en ese momento sino en el resto de su trayectoria.

El aprendizaje es un factor importante, en la medida que es a través de él que encuentran el gusto por las actividades de la maquila: "A mí me gustaba aprender pasos difíciles" nos cuenta Felipa. Así como el apoyo de algunos personajes clave en el proceso de aprendizaje, por ejemplo, los encargados o las trabajadoras de más experiencia, tal como lo señala Flora: 
"El encargado de la línea, le dijo a otra [trabajadora] que estaba planchando, -Enséñale a hacer tu paso a ella- y ya que me enseña la muchacha que estaba ahí, y me decía, -No pues vas a hacer esto así y así-, - Nada más te tienes que apurar bastante porque si no te van a corretear-."

\section{Continuidad y Heterogeneidad ${ }^{14}$}

Ahora analizaremos las diferentes rutas que siguen estas trabajadoras a lo largo de su vida laboral, su permanencia en el sector maquilador de la costura, sus entradas y salidas, así como la multiactividad y la simultaneidad del trabajo.

En términos generales observamos dos tipos de trayectorias: una que muestra cierta continuidad en la maquila y otra que indica cierta dispersión, es decir, que entran y salen de distintos empleos no maquiladores, realizando trabajos simultáneos y que por lo regular no se mantienen en la maquila.

Las trayectorias continuas se caracterizan por el trabajo en plantas maquiladoras terminando finalmente en los talleres. Veamos algunos ejemplos:

Como se puede observar en el cuadro 4, existen las trayectorias que se caracterizan por entrar y salir de una planta a otra, pero que se mantienen en el sector maquilador, como Ana (07) que tiene una trayectoria de 10 años de trabajo, cinco años entrando y saliendo de una planta a otra y el resto trabajando en su propio taller de deshebrado. Felipa (05) que tiene una trayectoria de 29 años, 17 de ellos en la maquila formal y 12 años combinando distintos talleres de deshebrado. Entre el periodo de fines de los noventa y principios del año 2000 ingresan al trabajo a domicilio, ya sea como dueñas del taller o subcontratándose en los talleres de sus vecinas. Este periodo coincide con el inicio de la crisis en la maquila de la industria de la confección en Tehuacán.

\footnotetext{
${ }^{14}$ Se reconstruyeron las trayectorias laborales de diez trabajadoras y un trabajador, a partir del cuestionario y las entrevistas en profundidad. Para fines de esta investigación, solamente se tomó en cuenta la trayectoria de las diez mujeres.
} 
Flora (01) permaneció 8 años en una sola planta maquiladora y cuando salió puso su propio taller de deshebrado. La razón principal que ella señaló para dejar la maquila formal de manera definitiva fue el nacimiento y cuidado de sus hijos.

Por último, en el caso de Eugenia (02), ella entra a trabajar en la maquila un año, tiene una interrupción de cuatro años y reingresa al trabajo maquilador, pero esta vez a través del deshebrado.

En estos casos existen distintos motivos para abandonar la maquila formal e insertarse al trabajo domiciliario, entre los más importantes están el desempleo, el nacimiento y cuidado de los hijos y los problemas de salud, como en el caso de Felipa, que, tras 17 años de haber trabajado en la maquila, comenzó a sufrir de fuertes dolores de espalda a causa de permanecer tanto tiempo sentada, lo que la obligó a dejar definitivamente la maquila formal. Todas estas trayectorias se caracterizan por mantenerse siempre en la maquila de confección, más adelante profundizaremos en estos casos.

Por otra parte, existe otra ruta muy clara, caracterizada por su itinerancia, ya que entran y salen de distintos empleos no maquiladores o nunca trabajaron en la maquila formal insertándose por distintas razones a los talleres de deshebrado. En este caso se encuentran sobre todo las mujeres de mayor edad de la muestra, como son Carmen (03), Petra (08), Asunción (04) y Aquilina (06). Ellas pasan periodos muy largos en el trabajo doméstico remunerado o en las artesanías y al final de su trayectoria a finales de la década de los noventa y principios del actual siglo, ingresan a un taller domiciliario.

Por último, se encuentra la más joven, que combina el trabajo doméstico remunerado con los servicios y el comercio, a su vez entra y sale del trabajo a domicilio.

Son las mujeres adultas entre los 30 y 40 años quienes cuentan con una trayectoria laboral consolidada en la maquila. Mientras que las más jóvenes y las de mayor edad se caracterizan por ser las que tienen una trayectoria laboral dispersa. 


\section{Trayectorias continuas}

Ahora vamos a profundizar en las trayectorias continuas, para ello vamos a retomar las entrevistas hechas a Flora (01) y Ana (07), retomamos estos casos porque corresponden a las jefas de los talleres y para los fines de nuestra investigación es muy importante dar cuenta de estos casos.

Flora (01) suma 20 años de trayectoria laboral, de los cuales 12 ha trabajado en su taller domiciliario. Su primer trabajo fue en la fábrica Dember, donde ingresó a los 13 años en 1988. Allí permaneció 7 años, el tiempo necesario para adquirir la experiencia que requería para instalar su propio taller. Su paso por la maquila formal fue muy satisfactorio para ella, debido a que fue en ella donde recibió buenas prestaciones e incentivos, tal como lo señala:

"Allí sí me gusto la verdad, en diciembre hacían convivíos, nosotros cooperábamos y le hacíamos misa a la virgencita. El patrón ponía la mitad y nosotros la otra mitad, y él daba premios, nos daba unos boletitos que decían $<<$ premio estufa $>>$ o $<<$ feliz navidad $>>$ si es que no te ganabas nada, o de premio decía $<<$ Feliz Navidad, un cobertor $>>$ " (Flora).

Fue cuando trabajaba en Dember que conoció a su esposo, se casó y tuvo a sus tres hijos. Este aspecto fue decisivo, debido a que se vio obligada a dejar la maquila, ya que no contaba con las redes sociales o familiares que la apoyaran en el cuidado de sus hijos. Como estrategia recurrió a la guardería, aspecto que no le ayudó y termino por abandonar su trabajo en la maquila. Ella narra lo difícil de la decisión, pero también la ambigüedad que sentía al trabajar y no poder estar con sus hijos.

"Dije no para qué voy a trabajar si mis hijos lloran. Luego yo también pensaba en ellos y digo no pues no tiene caso. Mis hijos quién sabe cómo quedan allá, pensaba en ellos y no ya no estaba tranquila, ya mejor me salí definitivamente. Aunque la extrañe bastante [a la maquila]." (Flora)

$\mathrm{Su}$ segundo trabajo tuvo que ver con la creación de su propio taller, pensado como la manera de poder conciliar su mundo familiar con el laboral, este aspecto se profundizará en el siguiente capítulo. Lo relevante de mencionarlo ahora tiene que ver con las razones que la llevaron a instalar su taller y las opciones que tenía para poder emplearse sin descuidar a sus 
hijos. Tal como ella percibe sus opciones de empleo, son resumidas con la siguiente frase: "No había otra cosa que trabajar, más que en el deshebrado".

Así fue como le pidieron trabajo a su antiguo patrón, el cual aceptó y desde hace 12 años les lleva los bultos de prendas de exportación y nacionales que deshebran, además trabajan para otras maquilas de la región, que se sumaron con el correr de los años. Desde entonces trabajan en su taller deshebrando junto con otras 25 trabajadoras subcontratadas.

Durante este tiempo, Flora (01) dio continuidad a su trayectoria, manteniéndose en actividades relacionadas a la maquila de confección. Fue su paso por la maquila formal, un aspecto decisivo, fue ahí donde conoció a las personas que después le darían el trabajo y donde aprendió sobre la organización del trabajo que después en su taller pondría en práctica. Recientemente, como se puede ver en el cuadro 4, ha intentado trabajar de manera simultánea en otras actividades como la venta de cosméticos o de trastes, en la cual tuvo como conflictos, la falta del pago por los productos, tal como ella lo narra:

"Ganaba poco, no veía mucha ganancia, a veces la gente no compra porque no hay dinero, no hay trabajo o a veces te dicen -Dámelo y te pago tal díay luego tal día te dicen y no te lo pagan. Como que no te quieren pagar, les dices -Ya vine a cobrar- y te dicen -No tengo, te doy dentro de ocho días." (Flora)

Sus incipientes intentos por tratar de ocuparse en otras actividades para poder complementar su gasto familiar, se ha visto lleno de conflictos, lo que la ha desalentado en ocuparse en otra cosa que no sea su taller de deshebrado.

La trayectoria laboral de Ana (07) está enmarcada por aspectos muy interesantes. Su primera motivación para trabajar fue la de "darse sus gustos" tal como ella lo señala. Ingresó a la maquila a los 14 años, cuenta con 10 años de permanencia en el sector maquilador y ha tenido más entradas y salidas de sus trabajos que Flora. Siempre se ha dedicado al deshebrado, primero en la maquila formal y después en su taller de deshebrado. 
En su segundo empleo permaneció 3 años, el tiempo máximo que alcanzó en una maquila formal. Es ahí donde conoce a su esposo y tiene a su primera hija. El motivo de su salida es que él ya no quiere que siga trabajando, por lo que renuncia y se dedica a las labores domésticas durante un periodo de dos meses aproximadamente.

$\mathrm{Su}$ tercer empleo es en una maquila pequeña, donde trabaja durante 3 meses y a la cual renuncia por los mismos motivos que en la maquila anterior. Este es un claro ejemplo de que las entradas y las salidas del trabajo no tienen que ver solamente con aspectos laborales, sino también con factores personales, que hacen referencia a su mundo familiar. En su cuarto y último trabajo en maquila formal, se enfrentó a las complicaciones de no saber otro paso que no fuera el deshebrado, la pusieron a coser y no pudo llevar a cabo esa actividad porque nunca había hecho otra cosa, así que opto por renunciar. Después decidió incursionar en el comercio y se dedicó a vender tortillas, actividad común en Tehuacán y las comunidades aledañas. En ese tiempo, se enfrentó con la enfermedad de su esposo incapacitado para trabajar, por lo que todas las responsabilidades recayeron en Ana.

Es entonces que decidió poner su taller, comenzó a trabajar para una maquila de manera exclusiva a cambio de que le dieran el seguro social para su esposo, caso inusitado en este tipo de empleo. Esto le fue concedido y ella se dedicó de lleno a su propio taller, el cual duró 6 años, cerró sus puertas debido a que tuvo problemas con los intermediarios y el patrón. Actualmente se encuentran disputando una demanda de indemnización por el despido.

Ana muestra claramente una trayectoria continua en la maquila y particularmente desempeñando el deshebrado a lo largo de toda su trayectoria. Lo que le ayudó a poder llevar su propio taller, en un periodo muy corto de tiempo intenta incursionar en otras actividades, pero al parecer las opciones de empleo son limitadas en Tehuacán para mujeres como Ana.

Lo que nos muestran estos dos ejemplos es la continuidad entre fábrica y talleres, así como las contradicciones entre la vida familiar y de trabajo. En los dos casos se mantiene la idea de que el trabajo a domicilio representa una aparente solución a dichos conflictos. Aunque esta idea será cuestionada en el siguiente capítulo cuando se profundice en la dinámica del taller y en la relación trabajo y familia. 
Dispersión y multiactividad

El resto de las trabajadoras de los talleres que hemos estudiado dan cuenta de la multiactividad y de la volatidad que representa este trabajo, especialmente entre aquellas mujeres que no son las jefas de los talleres, las cuales no tienen la responsabilidad de organizar este tipo de empleo, lo que les permite con mayor libertad buscar otras alternativas, combinándolas con los servicios y el comercio, a veces de manera simultánea y otras veces de manera separada.

En el mismo caso, como lo señalábamos antes, se encuentran las mujeres mayores, aunque fue muy difícil realizarles una entrevista formal, en este caso sí pudimos tener conversaciones, donde por ejemplo Aquilina (06) relata su añoranza por la vida del campo, donde su niñez estaba rodeada de actividades imposibles de realizar ahora en una ciudad como Tehuacán. Donde la pobreza rural se diferencia de la urbana, porque se tiene acceso al alimento con solo cortarlas de un árbol o cazar un conejo.

Aquilina relata una vida de grandes aprendizajes a lo largo de su niñez, donde aprendió a realizar artesanías, actividad heredada de sus padres y abuelos, como la elaboración de petates y sombreros tejidos de palma, que sigue elaborando cuando logra juntar el dinero suficiente para hacerse del material.

Lleva más de 50 años realizando este tipo de artesanías e incursionó en el trabajo a domicilio con la crisis económica del 2001, cuando no tenía para la palma para elaborar sus productos. Ahora trabaja de manera simultánea en ambas actividades. Señala que el deshebrado es una actividad que le ha permitido subsistir los últimos ochos años y que realiza por necesidad, debido a que no puede dedicarse a otra cosa porque lo único que sabe hacer son sus artesanías. 
El caso de Petra (08) y Carmen (03) son muy parecidos, desde muy pequeñas tuvieron que comenzar a trabajar en el trabajo doméstico remunerado para poder contribuir al gasto familiar. Actividad a la que se dedicaron en gran parte de sus vidas. Petra suspendió esta actividad por más de cuarenta años cuando se casó. Mientras que Carmen se mantuvo en él durante más de cincuenta años hasta que por su edad le fue más difícil conseguir que le dieran trabajo.

A finales de los noventa, ambas tuvieron que buscar la manera de sustentar sus gastos cuando quedaron viudas, con más de sesenta años a cuestas y sin experiencia laboral. Encontraron en el trabajo a domicilio un nicho donde emplearse y en el cual se mantienen hasta la actualidad.

En este tipo de trayectoria también se encuentra la mujer más joven de la muestra con 16 años. Se caracteriza por iniciar su trayectoria laboral a los ocho años en el trabajo doméstico y como ayudante en una carnicería, como se puede observar en el cuadro 4. Abandonó estas actividades cuando comenzó a ayudarle a su mamá a deshebrar en el taller de Ana (07), la flexibilidad que representaba esta actividad fue lo que la animo a dedicarse de tiempo completo al deshebrado. Primero supervisada por su madre y después como una trabajadora subcontratada, en el que se mantuvo por cuatro años con una interrupción en el 2000.

Un aspecto interesante de resaltar es que en su relato describe que cuando entra a trabajar en un restaurante de mariscos, se le dificulta cumplir con el horario de trabajo, porque ella estaba acostumbrada a poner sus propios horarios. Por lo que comienza a tener dificultades con su patrón tal como lo señala a continuación:

“A veces entraba tarde y como a las dos apenas estaba acabando de picar todas las cosas, y como a las doce es cuando se amontona [la gente], se me acababa la lechuga y por eso me regañaban. Me decían -Tienes que llegar temprano, por eso te ponemos a las nueve para que te dé tiempo- y siempre era de puro regaño. Por eso ya no me gusto pues no me gusta que me regañen." 
Por este tipo de dificultades decide abandonar este trabajo y reincorporarse al trabajo a domicilio de Ana, en el que se mantuvo hasta que este cerró.

El conjunto de estas trayectorias muestra la diversidad de rutas que llevan a estas mujeres a ocuparse en el trabajo domiciliario, así como las razones que las llevaron a ocuparse en él.

El análisis anterior coincide con lo que Rocío Guadarrama (2008) encuentra en su estudio sobre el tipo de trayectorias que se dan en las trabajadoras de la maquila, donde plantea dos tipos principales: trayectorias continuas y trayectorias itinerantes.

Al igual que en su estudio, lo que podemos observar es que en algunos casos se prefigura una tendencia a mantenerse en la maquila, incluso como primer empleo. Estas trayectorias coinciden con la llegada de la maquila en la región. Es el caso de mujeres que como Flora y Ana se incorporan al mercado de trabajo a través de la maquila y que se mantienen ahí.

Donde después, por distintas razones llegan a los talleres subcontratados a domicilio, entre éstas se encuentran el cierre de maquilas, cuestiones familiares, de salud, etc. Por lo que los talleres constituyen una especie de "refugio" para las mujeres que han trabajado en la maquila y que por diversas circunstancias ven en los talleres una mejor opción que el comercio o los servicios.

\section{Conclusiones}

Durante este capítulo dimos cuenta de las diferentes rutas que siguen estas trabajadoras durante sus vidas. Es a través del relato y algunos datos recabados del cuestionario que reconstruimos las trayectorias laborales de las mujeres que trabajan a domicilio en Tehuacán.

Podemos concluir señalando que los patrones diferenciados de las trayectorias laborales de estas mujeres corresponden a un doble movimiento que expresa la coincidencia y el curso de procesos macro sociales y micro biográficos. Es a partir de esta articulación en el tiempo que podemos explicar la inserción al mercado de trabajo, así como su movilidad posterior. 
Lo que nos revelaron estas trayectorias fueron los cursos que siguieron y que devino en su inserción en los talleres domiciliarios, así también dimos el primer paso en el acercamiento y reconocimiento de algunas características de estas mujeres. Todo ello para conocer a las mujeres que se insertan en el trabajo domiciliario en Tehuacán.

Ahora que conocemos a estas mujeres, nuestro interés se centrará en desentrañar su dinámica laboral y familiar que llevan a cabo al interior de los talleres. Es decir, sus conflictos y contradicciones con sus trabajadoras, los intermediarios y familiares. Así como los aspectos que se resuelven al trabajar desde sus casas y los que se complejizan. 


\section{CAPÍTULO 4}

\section{LA DINÁMICA LABORAL Y FAMILIAR EN LOS TALLERES DE DESHEBRADO}

\section{Introducción}

En este capítulo pretendo reconstruir la dinámica laboral y familiar que desarrollan las trabajadoras de los talleres de deshebrado, debido a que se encuentran íntimamente relacionadas en el tiempo y espacio. Esta reconstrucción es importante en tanto que los talleres son instalados en el espacio doméstico, dándose la invasión no solamente de éste sino también del mundo familiar. El ámbito que antes era privado se modifica y las fronteras entre lo público y lo privado se desvanecen.

También indagaremos la forma en que las trabajadoras intentan conciliar su mundo familiar y laboral a través de diferentes arreglos, algunas veces con éxito y otras veces en conflicto con sus trabajadoras, intermediarios, dueños de la maquila, esposos, hijos, padres, etc.

Parto de la consideración de que uno de los objetivos de esta investigación es indagar, desde la experiencia de las mujeres, la manera en que se construye recrea y en algunas situaciones improvisa la dinámica laboral y familiar, en un trabajo que se encuentra instalado dentro de la casa. Así como las contradicciones, conflictos y arreglos a los que las trabajadoras se enfrentan día a día.

Este capítulo se encuentra organizado por cuatro apartados, en donde primero doy cuenta de la metodología que seguí para la reconstrucción de la experiencia de las trabajadoras. Seguido de la presentación general de éstas y del contexto en que se llevó a cabo cada una de las entrevistas. Por último, el análisis final de las entrevistas, dando cuenta de su dinámica laboral y familiar al interior de los talleres. 


\section{El Relato Biográfico.}

Para desentrañar la experiencia de estas mujeres se partió de la necesidad de tomar al relato biográfico como el método que nos permitirá reconstruir su espacio social. Principalmente aquello que tiene que ver con cómo viven las trabajadoras su dinámica laboral y familiar a partir del taller. Ya que como lo señala Alicia Lindón (1999) una de las características de los relatos biográficos es su carácter "experiencial". Las cuales son narradas, recordadas, interpretadas y conectadas con otros actores.

Asimismo, consideramos que es a partir del relato que lo experiencial puede ser comprendido por el que escucha, en este caso el investigador. Produciéndose lo que Lindón (1999) llama una expresión de lo íntimo de las experiencias vividas a formas compartidas socialmente, por medio del lenguaje. Es decir, se convierte también en "significativo socialmente" debido a que esa experiencia narrada es traducida a un contexto sociocultural, accediendo a un “...discurso en su contexto de significado objetivado en el lenguaje.” (Lindón, 1999: 300)

Para conocer la problemática de estas mujeres y el sentido que le dan a su experiencia es que se retomó al relato como nuestro principal método de investigación. Es a partir de lo subjetivo que nos interesa dar cuenta de lo que han experimentado estas mujeres en su vida cotidiana al interior de los talleres.

Se trata de acceder a un "conjunto de saberes compartidos" a través del individuo, partiendo de la idea de que "El relato de vida es invención, aunque es una construcción permanente gestada en el marco de la praxis social y no en el mundo de la fantasía. De ahí deriva su valor como expresión de un fragmento de lo social y su potencialidad respecto a la acción futura." (Lindón, 1999: 305)

Es bajo estas ideas que colocamos al sujeto como principal protagonista de la aproximación que pretendemos hacer de la realidad social que nos interesa estudiar. Por lo que nuestro interés se centra en profundizar en lo que hace, piensa y dice con la finalidad de "...ensayar interpretaciones de la realidad a partir de la subjetividad individual y colectiva" (Pujadas: 2000: 127) 
Bajo estas consideraciones entendemos por relato biográfico (recit de vie o life story) “...el registro literal de las sesiones de entrevista que el etnógrafo realiza con el sujeto entrevistado." (Pujadas, 2000: 139). Las cuales posteriormente son analizadas y sistematizadas en su conjunto.

A su vez retomamos las ideas expuestas por Joan J. Pujadas (2000) sobre los criterios metodológicos esenciales que requieren las entrevistas de orientación biográfica:

1. Se trata de entrevistas en profundidad abiertas en las que la labor del entrevistador consiste básicamente en estimular al informante para que siga el hilo de su narración, procurando no interrumpirle y manteniendo la atención para orientarle en los momentos de lapsus de memoria.

2. Para apoyar la narración del informante y, a la vez, para garantizar la máxima exhaustividad posible del relato, es imprescindible que el investigador tenga transcritas las entrevistas anteriores y sistematizadas. (Pujadas, 2000: 139)

Para ello utilizamos la entrevista en profundidad, en la que buscamos a través del relato biográfico y a partir de la memoria, tal como lo señala Portelli, “...una interpretación, una lectura de un proceso personal y/o social." (Portelli, 1989:29, en Pujadas, 2000: 148).

La entrevista en profundidad se usó para indagar distintos aspectos de su vida laboral y familiar. En este sentido es que logramos comprender a través de sus narrativas el problema sobre la dinámica que se desarrolla dentro de los talleres desde la experiencia de sus trabajadoras y no como algo impuesto solo por las estructuras del mercado.

Dándole un papel central a nuestros sujetos de estudio y a la profundización de los aspectos biográficos tanto familiares como laborales. Lo que implica describir desde su narrativa sus transformaciones en el transcurso del tiempo. Estos relatos al estar anclados en su experiencia permiten reconstruir las acciones sociales realizadas, es decir, la versión que las mujeres dan acerca de su propia acción pasada. Lo que constituye en una guía que nos acerca al análisis de sus dinámicas laborales y familiares. 
Es importante rescatar su experiencia laboral y familiar de las trabajadoras de los talleres, en tanto que están íntimamente relacionadas, ya que se desarrollan de manera empalmada y simultánea a lo largo del tiempo y el espacio. Es por ello imprescindible dar cuenta de ambas dinámicas, para tener un panorama completo de lo que viven estas trabajadoras en el desarrollo de su trabajo. Asimismo, nos interesa indagar cómo a partir del relato construyen y articulan su mundo familiar y laboral. Tratando de conocer y profundizar estos aspectos a través de la narrativa en el transcurso del tiempo.

\section{Las mujeres del deshebrado a domicilio}

En este apartado pretendo presentar a mis entrevistadas, el contexto de las entrevistas y algunos aspectos relevantes de la observación realizada durante dos semanas en el desarrollo del trabajo de campo.

Tabla 1

\begin{tabular}{|c|c|c|}
\hline Entrevistadas/os & $\begin{array}{c}\text { Situación } \\
\text { laboral } \\
\text { actual }\end{array}$ & $\begin{array}{c}\text { Situación } \\
\text { Familiar }\end{array}$ \\
\hline Flora & Jefa de Taller & $\begin{array}{c}\text { Casada y con 3 } \\
\text { hijos }\end{array}$ \\
\hline Ana & $\begin{array}{c}\text { Jefa de taller por } \\
\text { seis años. En el } \\
\text { momento de la } \\
\text { entrevista } \\
\text { trabajadora } \\
\text { subcontratada }\end{array}$ & $\begin{array}{c}\text { Casada y con 3 } \\
\text { hijas }\end{array}$ \\
\hline Felipa & $\begin{array}{c}\text { Trabajadora } \\
\text { subcontratada }\end{array}$ & $\begin{array}{c}\text { Casada y con 4 } \\
\text { hijos }\end{array}$ \\
\hline Yolanda & $\begin{array}{c}\text { Trabajadora } \\
\text { subcontratada }\end{array}$ & $\begin{array}{c}\text { Soltera, sin hijos. } \\
\text { Vive con sus } \\
\text { padres }\end{array}$ \\
\hline Toño & $\begin{array}{c}\text { Trabajador de la } \\
\text { maquila }\end{array}$ & \begin{tabular}{c} 
Esposo de Ana \\
\hline
\end{tabular} \\
\hline
\end{tabular}




\section{FLORA}

Flora es una mujer casada de 33 años y con 3 hijos, trabajó en la maquila durante 7 años, tiene una amplia experiencia en el manejo de máquinas de coser. Dejó la maquila y se convirtió en jefa de un taller instalado en el patio de la casa de su suegra desde 1995, casa en la que vive desde que se casó y que se encuentra ubicada en una de las colonias marginales de Tehuacán, llamada 3 de mayo. La entrevista fue hecha en su taller mientras ella trabajaba deshebrando pantalones de mezclilla para una de las tantas maquilas con las que trabaja. Nuestro acercamiento tiene su antecedente en la elaboración del trabajo de campo de mi tesis de licenciatura y no tuve problema en reanudar el vínculo. Fue interesante ver que nos reconocíamos del pasado y que las trabajadoras en su mayoría seguían trabajando en el taller, después de dos años.

También observé los cambios hechos en el transcurso de este tiempo, su patio estaba techado, lo percibí inmediatamente porque antes todo estaba más iluminado y ahora con el techo y la obscuridad de la tarde, se obligaron también a instalar alumbrado. Su casa también ahora tiene una fachada de color azul y con protecciones en las ventanas. El taller esta acondicionado con mesas muy largas, algunas sillas y tarimas que sirven para colocar los cerros de bultos que le traen a diario.

La entrevista con Flora me permitió conocer detalles muy interesantes del trabajo a domicilio vinculado a las maquilas de confección, en el transcurso del su relato, que tuvo 3 horas de duración. Ella también me permitió aplicar un cuestionario a las trabajadoras que accedieran. En su taller se encuentran seis trabajadoras de "planta" como ella las llama, otras cinco que van de manera intermitente a trabajar al taller y aproximadamente cinco más que trabajan desde sus propias casas.

Flora rememora con satisfacción su paso por la maquila, en especial en aquélla en la que duro poco más de seis años, donde tenía una buena relación con el supervisor de línea y donde recibía seguro social y estímulos laborales. Narra la dura decisión que fue abandonar la maquila por estar con sus hijos. Durante todo el tiempo insiste en que a ella nunca le gusto deshebrar, es más, rechazó un par de trabajos porque lo que le ponían a hacer era la "tediosa" 
tarea del deshebrado, tarea que paradójicamente se encuentra desempeñando desde hace catorce años.

\section{FELIPA}

Es una mujer que trabaja en el taller de Flora por las tardes, lo prefiere así porque le gusta hacer su quehacer por la mañana e ir a trabajar después, para concentrarse solamente en el trabajo, aunque admite que le gusta mucho platicar mientras lo realiza. Ella es vecina de Flora, su casa se encuentra ubicada casi enfrente del taller en el que trabaja. Tiene 43 años y cuatro hijos, es casada y tiene una de las trayectorias más interesantes, debido a que toda su vida ha trabajado en la maquiladora, pero ello le ha traído como consecuencia fuertes dolores de espalda que la incapacitaron para seguir trabajando en la maquila. El deshebrado le parece una buena opción para seguir trabajando y a partir de esta actividad es que se siente útil.

En su caso se realizó la entrevista en dos partes, en la primera me narro su paso por la maquila y en la segunda toda su dinámica laboral dentro del taller y en su casa con su familia.

Estas dos entrevistas también se realizaron mientras ella trabajaba en el taller de Flora, debido a que había mucho trabajo y urgía entregarlo, tanto, que mientras ella me platicaba yo también deshebraba algunas de las prendas de su bulto, no con la misma agilidad y destreza con la que ella lo hacía, pero sí con la atención suficiente en su relato.

Entre las prisas que ambas experimentábamos, me contaba de la forma en la que convenció a su esposo para no dejar de trabajar mientras sus hijos eran pequeños y de lo importante que es para ella que hayan estudiado y que uno de ellos este terminando su carrera, aquél que promete sacarla de trabajar para que por fin descanse de una vida de duro trabajo y fuertes sacrificios. 
La entrevista concluyó ya entrada la noche, pero con la satisfacción no solamente de haber realizado una buena entrevista, sino también de haber experimentado el duro trabajo al que se enfrentan estas mujeres día con día.

\section{ANA Y TOÑO}

Son un matrimonio de casi diez años, juntos han sufrido un sin fin de sin sabores debido en gran medida a la enfermedad de él, diabetes insípida, extraño mal que los ha llevado al extremo de situaciones emocionales, como la fuerte depresión en la que se sumió Toño debido a que estaba incapacitado para trabajar, sufría de desmayos a causa de la falta del medicamento, el cual es muy caro.

Ana tuvo que afrontar la enfermedad y el sustento económico de su familia. Ella lo hizo poniendo un taller de deshebrado en su casa, en el cual trabajaban para una sola maquila, llegaron a sacar 4000 prendas diarias y había 20 mujeres más trabajando.

Tuvieron que cerrar debido a problemas y mal entendidos con los intermediarios. Ana de 26 años y Toño de 30, tienen 3 hijas y actualmente viven en un par de cuartos herencia que le dejaron a Ana sus padres, a consecuencia de que al quedarse sin el trabajo que les proveía la maquila para la que trabajaban, se endeudaron tanto que tuvieron que vender su casa, la cual les había costado mucho trabajo construir.

La primera vez que fui a buscarlos a su antigua casa donde tenían el taller, fue que me enteré de que no solamente ya no tenían el taller, sino que habían tenido que venderla y que ahora se habían mudado con los padres de ella. La persona que me dio informes me dijo que Toño acababa de entrar a trabajar a una de las maquilas que se encuentran ubicadas en la colonia de "El Riego", nos dio el teléfono de la maquila para que pudiéramos concertar una cita con él.

Durante el resto de la mañana intentamos localizarlo hasta que pudimos acordar una cita para ese mismo día a la salida de su trabajo. Puntualmente estuvimos ahí y nos encaminamos a un parque cercano donde me relató por más de una hora las peripecias por las que pasaron él 
y su esposa a partir del cierre de la maquila, de su enfermedad, la depresión y su problema con el alcohol. Sus ojos se humedecieron en varios momentos de la entrevista. En la cual no tuve que intervenir en ningún momento, ya que de manera muy fluida y como si nos conociéramos de años, fue que me narró toda su historia.

Al final me dijo que Ana se encontraba trabajando actualmente en el taller de deshebrado de su suegra y que él podía intentar hablar con ellos para convencerlos de que me dejaran entrevistarlos, que sería difícil porque ellas no son del tipo de personas que se presta para ser entrevistadas, pero que al menos con su esposa y una trabajadora que trabajaba con ellos seguro estarían dispuestas.

Cuando llegué a casa de los papás de Ana, ella ya se encontraba trabajando, me presentó y reiteró de mi interés por entrevistarlas, ellas no se mostraron muy dispuestas, pero inicié, entrevistando a Ana, ella me relató en el transcurso de dos horas su experiencia en el taller y de su añoranza por el trabajo.

Algunas de las trabajadoras accedieron a que les aplicara el cuestionario, pero no a ser entrevistadas, aunque al permanecer en el taller, entre el trabajo de observación y de también trabajar en el deshebrado, comenzaron a platicarme algunas cosas referentes al taller, al mismo tiempo que pude presenciar parte de la dinámica laboral y familiar.

\section{YOLANDA}

Tiene 16 años, es soltera y sin hijos, vive con su madre, hermanos y padrastro. Ella trabajó en el taller de Ana y Toño, tienen una relación muy estrecha y actualmente también trabaja en el taller de la madre de Ana. Su entrevista fue el mismo día que la de Ana, mientras deshebraba. En ella me narró que no se lleva bien con su madre y que nunca ha ido a la escuela, aunque le gustaría asistir para aprender a leer y escribir. 
También me relató que le oculta a su madre que trabaja con Ana porque no se llevan bien y que se siente más como hija de ellos, hasta ha pensado en irse a vivir a su casa. Le interesa trabajar en un empleo en el que le paguen bien y que no sea tan cansado, le parece que trabajar en el deshebrado es una buena opción. Su entrevista tuvo una duración de más de una hora. En el transcurso se reflejaba la familiaridad con la que convivía con las hijas de Ana y de que le gustaba estar con ellas.

Estas son las mujeres con las que pude convivir durante dos semanas, que me permitieron adentrarme en su mundo laboral y familiar, que me dejaron estar en sus casas observando y en algunas ocasiones trabajando como una más de ellas, intentando llevar el ritmo de su jornada a la vez que intercambiábamos experiencias, en las cuales pretendo profundizar a continuación.

\section{Analizando los relatos}

Los relatos se analizaron siguiendo los principios de la Teoría Fundamentada de Strauss y Corbin (2002). Esta propuesta de análisis consiste en analizar palabras, frases u oraciones, poniendo especial énfasis en aquellas que nos parecen significativas desde una mirada analítica. Es a partir de lo que ellos denominan "codificación abierta", la cual consiste en ir escogiendo trozos o frases de la entrevista asignándole un código descriptivo con la finalidad de crear categorías teóricas, que me van a permitir analizar las relaciones que aparecen como relevantes entre ellas.

Este tipo de análisis cualitativo de los datos nos permite desarrollar conceptualizaciones útiles a partir de éstos. También “...enfatiza el descubrimiento y el desarrollo de teoría y no se basa estrictamente en un razonamiento deductivo apoyado en un marco teórico previo" (De la Cuesta, 2006: 138). En este caso, nos referimos a que, si bien yo parto de conceptos tomados de la teoría, el procedimiento metodológico que seguí me permite reconstruir estos conceptos a partir de lo que observé en la realidad empírica estudiada. En este sentido, es un ejercicio que no se basa estrictamente en un razonamiento deductivo. 
Las características con las que debe de cumplir son las siguientes:

a) La recolección de datos y el análisis transcurren de manera concurrente.

b) Los datos determinan los procesos y productos de la investigación y no marcos teóricos preconcebidos, ya que el procedimiento metodológico permite reconstruir los conceptos a partir de lo que se observa en la realidad empírica estudiada.

c) Los procesos analíticos suscitan el descubrimiento y desarrollo teórico y no la verificación de teorías ya concebidas. (De la Cuesta, 2006: 138)

Lo que esperamos al utilizar la Teoría Fundamentada es una interpretación analítica del mundo de las trabajadoras y de los procesos para construir esos mundos a partir de los relatos biográficos.

Asimismo, la Teoría Fundamentada proporciona comprensiones alternativas a las vigentes a partir de las experiencias, procesos, fenómenos e interacciones sociales de nuestros propios informantes que nos permiten dar una explicación alternativa a lo ya dicho en los estudios anteriores.

Es por ello por lo que retomamos esta propuesta para el análisis de los relatos, la cual consistió en realizar una codificación abierta y una axial, es decir, transformar los trozos de la narrativa en categorías analíticas. Esto con el propósito de disponer de las herramientas analíticas necesarias para ordenar y dar cuenta de los significados que en la narrativa de las entrevistadas nos relatan entre líneas.

En el proceso de leer y escoger trozos o líneas del relato se le van asignando códigos, al igual que con el texto subsecuente que tiene el mismo significado que el anterior o se abre un nuevo código. En este procedimiento de análisis no se trata de reducir los datos a códigos sino de vincular estas ideas con elementos teóricos, formando lo que serán códigos axiales o categorías analíticas, las cuales tienen la función de ordenar e impulsar la interpretación de los datos en su conjunto y de manera relacionada. 
En el caso de los relatos de las mujeres entrevistadas se destacan tres principales líneas indagatorias:

1. La historia del taller

2. La distribución de los ingresos y gastos del taller

3. La relación trabajo y familia

Es a partir de estos ejes temáticos que se hizo el análisis de los datos, los cuales resultaron en las siguientes categorías analíticas.

\section{a) La formación del taller subcontratado a domicilio: el autoempleo precario.}

Esta categoría se refiere a todas aquellas motivaciones, razones y circunstancias que llevaron a estas mujeres a instalar un taller de deshebrado o a emplearse en él. Así como el proceso de formación de los talleres.

Las modificaciones al espacio doméstico, los conflictos, arreglos y las primeras negociaciones con familiares e intermediarios para subcontratarse a domicilio.

En esta categoría también se encuentra reflejado el capital social y de experiencia previa en la maquila, como una expresión de continuidad en un empleo que conocen y en el cual se saben desenvolver. Pero el cual se distingue por ser un trabajo precario, dependiente de la maquila en cuanto a que es quien les provee de la materia prima necesaria, pero independiente en tanto que son las jefas del taller quienes lo conciben como propio, debido a que todas las responsabilidades de organización recaen en ella.

\section{b) El mundo de lo productivo en el espacio doméstico}

Es una categoría que comprende todas las relaciones sociales que tejen las trabajadoras con la jefa del taller. Las cuales tienen que ver con los conflictos y acuerdos, así como la imagen que ésta representa ante ellas. 
También se da cuenta del débil tejido social que se teje a través de las redes de subcontratación con las trabajadoras y los intermediarios con la maquila.

Todos los aspectos del trabajo productivo, es decir, cómo se lleva a cabo la jornada laboral, las características generales del taller, el tipo de organización del trabajo productivo, las condiciones de precariedad y dependencia con respecto a la maquila.

Por último, las representaciones y el significado del trabajo a domicilio para las trabajadoras.

\section{c) La volatidad y vulnerabilidad del trabajo a domicilio.}

En esta categoría se ejemplifican las condiciones de vulnerabilidad y dependencia que viven las y los trabajadores de los talleres subcontratados a domicilio, a partir del caso de Ana y Toño jefes de uno de los talleres. En esta categoría intentamos dar cuenta de una parte muy importante del estudio: el asalariamiento disfrazado, los conflictos y tensiones que viven las organizadoras de los talleres con los intermediarios, así como los aspectos que llevaron al cierre del taller cuando el dueño de la maquila decide no seguir proporcionándoles trabajo. Asimismo, las consecuencias materiales y emocionales que le acarrearon a Ana y Toño organizadores del taller.

La participación de la Comisión de Derechos Humanos y Laborales del Valle de Tehuacán, la cual intervino asesorándolos en una demanda interpuesta al dueño de la maquila y que sigue su curso hasta este momento. Esta demanda fue posible debido a que se les otorgo el seguro social durante 5 años.

\section{d) Simultaneidad del trabajo: el mundo de la familia y del trabajo en un mismo espacio.}

En esta categoría se desarrollan todos los aspectos que tienen que ver con la organización del trabajo productivo y reproductivo en un mismo espacio: el doméstico. Los conflictos de intentar conciliar estos dos mundos que de entrada son irreconciliables. 
Del contexto de violencia y maltrato al que se enfrentan estas mujeres y que forma parte de su vida cotidiana y, bajo el cual tratan de ordenar, entre una estira y afloje, su vida laboral y familiar.

El siguiente esquema resume los conceptos arriba señalados y ejemplifica las características del tipo de dinámica laboral y familiar que llevan a cabo estas mujeres en su vida cotidiana. La importancia de las redes de subcontratación como el mecanismo que permite que este tipo de trabajo se desarrolle, tanto con los intermediarios como con las trabajadoras subcontratadas. El contexto laboral de precariedad, flexibilidad, dependencia y vulnerabilidad en el que se tejen estas relaciones.

También intenta dar cuenta de los conflictos, arreglos, negociaciones y motivaciones que se encuentran en cada uno de estos mundos, sin perder su carácter de interrelación y dinamismo.

PRECARIEDAD

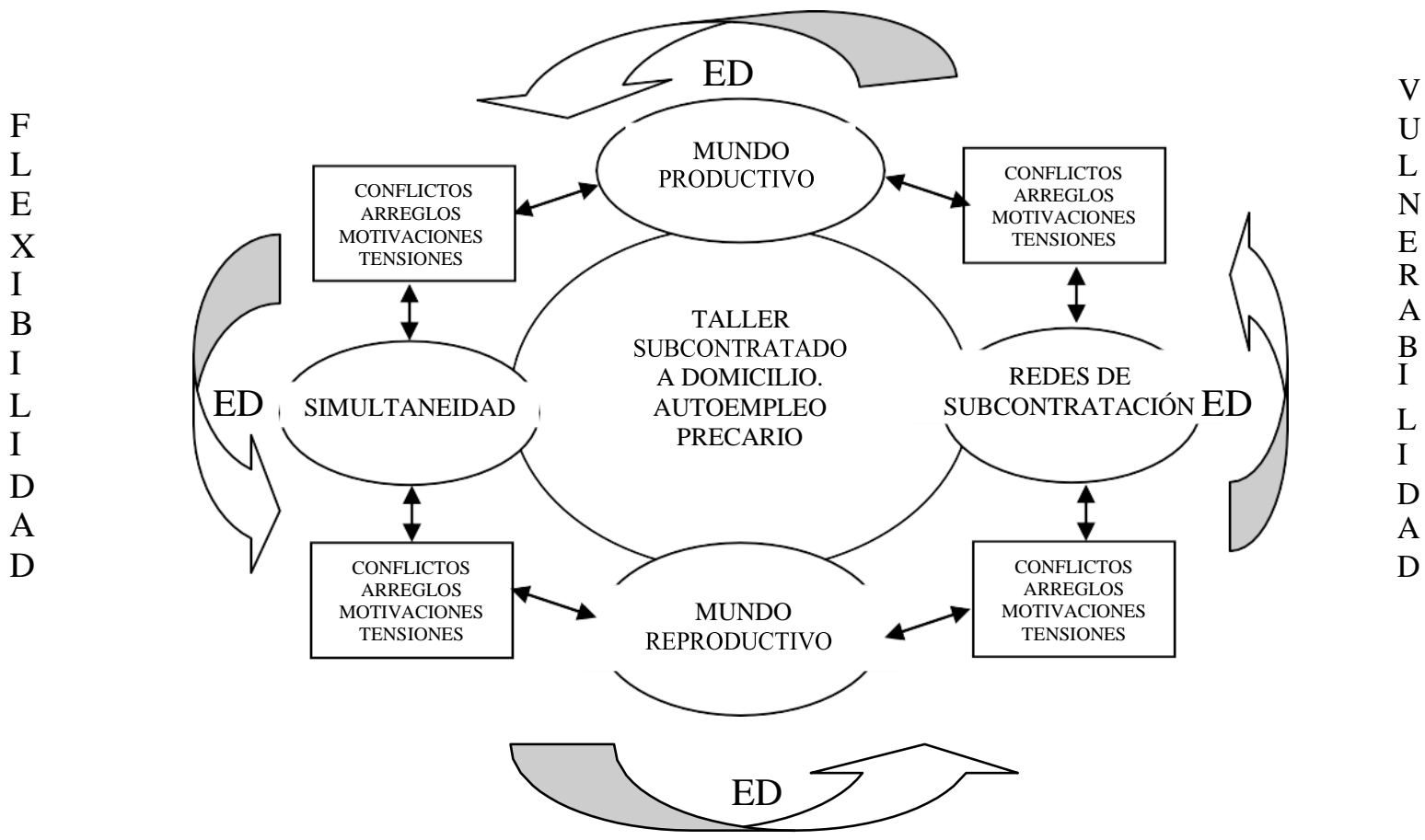

\section{DEPENDENCIA}

ED: Espacio Doméstico 


\section{La formación del taller subcontratado a domicilio: el autoempleo precario.}

En este aparatado hablaré de aquellas circunstancias que llevaron a estas mujeres a subcontratarse a domicilio, ya sean o no jefas del taller. Este proceso es visto como un paso importante en la vida de estas mujeres y explica cómo llegaron a este tipo de trabajo. Sus primeras negociaciones con sus familiares y los intermediarios de la maquila. Asimismo, de las adaptaciones al espacio doméstico para poder instalar el taller en sus casas.

\section{Yo prefiero a mis hijos}

Las mujeres que deciden emprender la idea de poner un taller lo hacen con la convicción de que es la mejor manera de poder estar al pendiente de sus hijos y de no descuidar sus labores domésticas. En muchos de los casos se trata de mujeres que cuentan con una trayectoria amplia en el mundo de la maquila, que conocen el medio y que se encuentran vinculadas de alguna manera con los dueños o intermediarios (proveedores de la materia prima) para que les lleven las prendas que tendrán que deshebrar.

El mundo familiar y en especial los hijos juegan un papel importante en la búsqueda de un trabajo que consideran o que al menos tienen en su imaginario como más compatible con sus actividades domésticas. Imaginan y piensan que debe de ser más fácil organizarse si tienen el trabajo en sus casas. Donde pueden realizarlo y al mismo tiempo atender a sus hijos.

Muchas mujeres que emprenden la idea de poner un taller lo hacen porque mientras trabajaban en la maquila sufren, por no saber cómo estarán sus hijos, por si habrán comido o si los estarán cuidando bien. Tal como lo narra una de ellas a continuación.

"Dije, para qué voy a trabajar si mis hijos lloran. Luego yo también pensaba en ellos y digo "no pues no tiene caso", luego mis hijos quien sabe cómo quedan allá, pensaba en ellos, ya no estaba yo tranquila, ya mejor me salí (de la maquila) definitivamente [...] porque yo prefiero más a mis hijos que a un trabajo, porque pues sí me faltaría, pero a mis hijos les voy a hacer más falta." (Flora) 


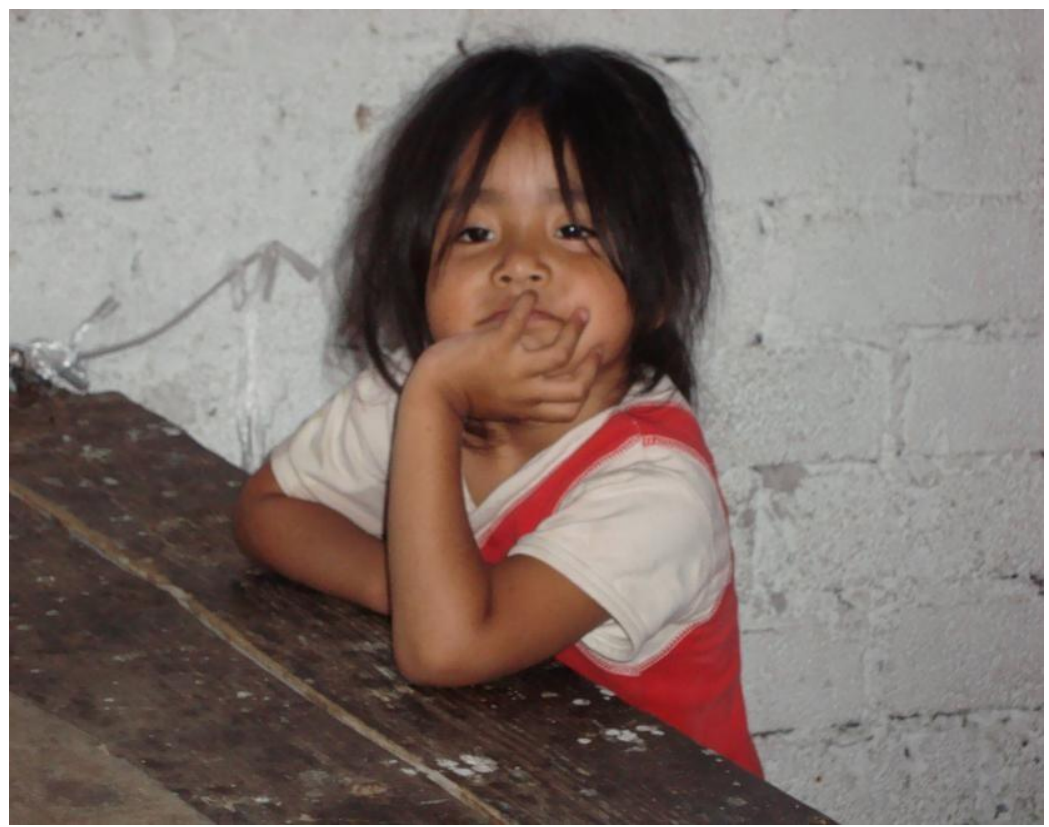

Nancy M. Márquez "Niña posando"

Algunas mujeres no cuentan con redes familiares de apoyo que las ayuden con el cuidado de sus hijos, lo que las orilla a tomar la decisión de abandonar la maquila y buscar otras alternativas de empleo. Como lo narra una de ellas cuando su esposo quería convencerla de regresar a trabajar a la maquila

"Si tuviera a mi mamá pues a lo mejor sí-, pero como ya no vive, quién me los va a cuidar, ya no, le dije [a su esposo]." (Flora)

Pero a veces son también los mismos esposos quienes empujan a las mujeres a dejar la maquila cuando consideran que se está descuidando a los hijos y que son ellas quienes están obligadas a cuidarlos lo mejor posible. Al respecto señala Ana:

"Cuando me junte deje de trabajar [...] porque estaba acá en la casa y ya no quería él que trabajará por mis hijos. Pero después volví a trabajar [...] y ya de ahí me salí, dejé de trabajar otra vez como seis meses, por lo mismo de que Toño me decía "Sí, ve, no vayas", estábamos así de sí, ve, no vayas a trabajar." (Ana)

Aunque también existen casos en los que los esposos no trabajan y ellas se convierten en las principales proveedoras de su familia. En ese caso, buscan un empleo en el que puedan 
estar con sus hijos y que les genere el ingreso que tanto necesitan. Por lo que existen muchas familias que sobreviven con lo que trabajan en el deshebrado. En estos casos las mujeres que toman la iniciativa de instalar un taller reciben un ingreso extra que no tendrían como simples trabajadoras subcontratadas, como se muestra en el relato de Flora:

"Antes, pues ni de comer tenia, porque no trabajaba, ni nada. No, pues no teníamos dinero, porque no trabajábamos. Porque también a mi esposo no le gustaba trabajar, a lo mejor era chamaco todavía. Es un pasado que ya no quiero ni recordar. Él no trabajaba, y tampoco tenía yo en donde, por eso decidimos empezar a deshebrar." (Flora)

Los hijos juegan un papel muy importante para estas mujeres, es por ello que, en muchos casos, con la falta de redes de apoyo y con la presión de los esposos, se ven orilladas a abandonar su trabajo en la maquila. Pero es su deseo seguir trabajando porque necesitan de los ingresos para poder subsistir, lo que las hace buscar otro empleo que les permita mantenerse en sus casas y no "descuidar" a sus hijos.

\section{Inicios en el deshebrado}

Las mujeres que entrevistamos habían trabajado antes en un taller por diferentes motivos. En algunas ocasiones lo hicieron porque sus madres las llevaban para que les ayudaran con algunas piezas de sus bultos, y siendo más grandes para que trabajaran por su cuenta. En la observación que realicé en mi estancia en los talleres, es interesante ver como las niñas pequeñas acompañan a sus mamás y mientras ellas trabajan, las hijas se sientan en el suelo para hacer sus tareas.

Por su parte, las más grandes "ayudan” a deshebrar algunas de las piezas de los bultos de las mamás, sin recibir remuneración alguna. Esto es muy común en los talleres, la presencia de las hijas y en ocasiones de los hijos para que apoyen a sus madres en el trabajo, es parte de este mundo laboral que se invisibiliza con la fachada de "ayuda".

También hay quienes trabajaban en algún taller cuando tienen un periodo de incapacidad en la maquila, porque están embarazadas o enfermas, ya que es un trabajo flexible que se puede adaptar a distintas condiciones familiares y en el que cada uno decide el número de prendas o bultos (con 25 piezas) que deshebra. Para las mujeres embarazadas, constituye 
una posibilidad de ganar un poco de dinero mientras no pueden trabajar en otra cosa que les demande de mayor esfuerzo. Por lo que estas mujeres, no paran, ni dejan de trabajar.

"Cuando a mí me dieron mi incapacidad, no me la agarre que digamos voy a descansar, no, yo seguí agarrando deshebrado con la señora de enfrente porque ella daba el deshebrado. Pero fue poco tiempo porque tenía yo que regresar a la maquila, sí, solamente el tiempo que estuve en mi incapacidad." (Flora)

Aunque representa un trabajo temporal, la jefa del taller les da preferencia a quienes trabajan de manera más continua o regular, y después a quienes lo hacen de manera intermitente.

Su primer acercamiento al deshebrado es muchas veces circunstancial, como una opción que tienen al alcance cuando lo necesitan y que no requiere conocimientos especializados o experiencia previa. No son solamente las mujeres incapacitadas las que en algún momento recurren a este tipo de trabajo, sino también aquellas que nunca han trabajado en la maquila o que son muy grandes o jóvenes para trabajar, en la maquila o en otra cosa. Es a partir del deshebrado, una tarea fácil, aunque laboriosa de realizar, que se insertan en la cadena de producción de ropa. En el eslabón más bajo y vulnerable, pero que para ellas representa una oportunidad de empleo.

La "solicitud" de trabajo.

Existen dos modalidades distintas de solicitar el trabajo domiciliario. La solicitud que hacen por primera vez las mujeres que después se van a convertir en las jefas del taller a los dueños y/o intermediarios de la maquila, y la solicitud que hacen las mujeres que se van a subcontratar en los talleres o desde sus casas. Aunque son dos formas distintas como mencioné antes, en realidad constituyen parte de este continuo de subcontratación.

Algunas mujeres conocen a los intermediarios por su relación previa en la maquila. Por ejemplo, Ana me narró cómo cuando decidió ya no trabajar en la maquila y poner un taller de deshebrado desde su casa, habló con el dueño de la empresa para ver si le podía dar trabajo a domicilio. Tal como lo narra a continuación: 
"Fui a verlo a la maquiladora y le dije que, si nos daban para deshebrar y me dijo que sí, -Sí te llevo, pero ¿cuántos vas a querer? -, le pedí 500, pero hasta eso nada más estaba yo. Ese día le entregue tres paquetes y nada más, no me dijo nada, -No, no se preocupe ya mañana- y al otro día deshebramos toda la noche y así se empezó a llevar.” (Ana)

Muchas veces esto es visto por los dueños como una oportunidad de trabajar con alguien que conocen y que va a redituar en bajar los costos de producción en su maquila.

A veces los dueños de la maquila o los encargados saben que una buena trabajadora va a dejar el trabajo, porque tienen hijos o por otras razones, ellos mismos son los que ofrecen llevarles el trabajo de deshebrado hasta sus casas. Asimismo, también las recomiendan con otros dueños de maquiladoras, que después las buscan para saber si pueden llevar más trabajo de deshebrado, así lo señala Flora:

"Pues donde yo trabajaba el mismo patrón nos ofreció primero el trabajo. Entonces le dije pues sí tráigame, y así fuimos conociendo varias (maquiladoras) y así otros y otras de esa misma empresa les avisaban a otros que aquí deshebrábamos. Entonces así se fueron haciendo más y más maquiladoras." (Flora)

No es de extrañar que cuando el mercado está al alza, los talleres crezcan rápidamente. Al mismo tiempo se va creando una telaraña de redes entre las trabajadoras subcontratadas y los dueños de las maquilas. Sin embargo, se trata de redes que no llegan a consolidarse ya que dependen de la volátil dinámica de los mercados de la industria de confección. Entre los dueños de las plantas y los organizadores de los talleres no existe ningún compromiso más que el de "yo te traigo trabajo, tú lo tienes cuando lo necesito y en ese momento, yo te pago por lo que hayas hecho".

Cuando las jefas de los talleres tienen que incrementar el número de personas porque ellas no pueden realizar todo el trabajo, lo primero que hacen es poner un letrero que dice: "se da deshebrado". Al mismo tiempo le ofrecen el trabajo, principalmente a sus amigas y vecinas. Buscan a otras mujeres para trabajar con ellas. Al menos así es al principio como lo comenta Ana: 
“...pues así fui buscando a las señoras y como hay muchas señoras, luego me decía la mamá de Toño -Pues dile a esa señora haber si no te ayuda-, y las iba a ver a su casa y todas las señoras me apoyaron en ese momento y me dijeron que sí. Y así fui poco a poco y cuando yo vi ya sacaba un montón de trabajo y decía yo - ¿Cómo le hago? quien sabe, ya tengo harto trabajo. (Ana)

También llegan a los talleres mujeres por su cuenta que están buscando trabajo, lo único que tienen que hacer es ir a pedirle el trabajo a la jefa del taller que ha puesto un letrero afuera de su casa. Como señala Yolanda a continuación:

"Porque mi mamá empezó a traer [bultos para deshebrar]. Porque vivíamos nosotros donde vivían ellos [Ana y Toño] en la 30 Poniente y como vimos que tenía el anuncio de deshebrado, me dice mi mamá - Pues, vamos a traer allá- y le dije -Pues vamos- y le íbamos a ayudar. En la noche nos traíamos nuestros 8 paquetes y ya deshebrábamos en la noche.” (Yolanda)

También es común que haya varios talleres en una misma colonia, por lo que cuando se abre uno nuevo, las mujeres que ya se encontraban trabajando en alguno, deciden moverse al que les queda más cerca de sus casas porque es más cómodo para ellas.

Así es que existe mucha movilidad y cierta rotación entre los talleres de una misma colonia, las mujeres entran y salen de ellos, hasta que encuentran el que más les acomoda.

Cuando el taller comienza a crecer y a darse a conocer, los maquileros acuden a él para saber si se les pueden deshebrar sus prendas. Como nos comentó Flora en la entrevista:

"El señor nos ofreció y las maquilas como pasan por la casa, ven que estamos deshebrando ya ellas solitas vienen a ofrecerse." (Flora)

Es así como comienzan los vínculos entre los tres actores más importantes de los talleres de confección: la jefa del taller ${ }^{15}$, el intermediario y/o dueño de la maquila y las trabajadoras subcontratadas.

\footnotetext{
${ }^{15}$ Aunque en esta investigación nos concentramos en las jefas de los talleres, también pueden encontrarse hombres como jefes de los mismos.
} 
En el caso de las mujeres, se trata de aquellas que tienen la necesidad de trabajar en un empleo que les permita permanecer en sus casas, mientras que los intermediarios buscan una forma fácil de ahorrarse no solamente costos en salarios, ya que en los talleres pagan 50 centavos por pieza, en tanto que en la maquila llegan a pagar hasta $\$ 3$ pesos, sino también en seguridad social y organización del trabajo, delegándole esta responsabilidad a la jefa del taller.

Es este conjunto de intereses comunes lo que permite que este tipo de trabajo sea posible.

\section{Los conflictos y arreglos familiares para instalar el taller}

Con las primeras personas que tienen que negociar las organizadoras de los talleres es con sus familiares, principalmente con sus esposos, padres o suegros. Dependiendo de quién sea el propietario de la casa en la que habitan o jefe o jefa de familia. En el caso de las dos jefas de taller que entrevistamos, Flora vive con su suegra, así que tuvo que negociar con ella para poner el taller. En este caso, aunque a su esposo no le gustaba la idea, como dice Flora a quien se tenía que convencer era a su mamá.

"Pues como su mamá es la cabeza de aquí, ella es la que manda. O sea, aunque él sea el hombre es ella la mera mera. A ella es a la que se le tiene que obedecer porque es su casa, vivimos en la casa de ella, no es mi casa. Él paga los gastos, pero no está a nombre de él, está a nombre de ella, por eso ella es la cabeza de la casa, no él, aunque sea el hombre y dé los gastos no es él el que decide...” (Flora)

Aunque han tenido problemas por la instalación del taller de deshebrado, entre ellos han llegado a varios arreglos, ella podía trabajar siempre y cuando no descuidará la casa o a sus hijos. Es importante para reducir tensiones que ella esté disponible para su esposo aun cuando tenga trabajo.

"A veces se molesta y me dice que deje el deshebrado porque quiere que vaya ahí y hacer algo, otras cosas, y por eso ya no agarro en ese tiempo que está molesto. Una vez me dice "Ya, no deshebres cuando hay poco trabajo déjalo para ellas [las trabajadoras subcontratadas], que deshebren, vente a descansar tantito" y ya descansamos tantito y vemos la tele o algo, 
en lo que ellas están deshebrando. Después cuando me aburro pues me vengo, no veo mucha tele, me aburro y me vengo para acá para ver cómo están deshebrando.” (Flora)

En su relato describe las tensiones que existen entre ellos, aspecto con el que tiene que lidiar, agregado a sus presiones en el trabajo.

En el caso de Ana, ella tuvo problemas económicos muy fuertes porque su esposo estaba enfermo, toda la solvencia económica de la familia recaía sobre sus espaldas. En realidad, cuando ella comenzó a trabajar en el taller, no había otra opción para ellos, por lo que su esposo siempre estuvo de acuerdo en que ella trabajara, así que el que lo hiciera en el deshebrado era indistinto para él.

En el caso de las trabajadoras subcontratadas ellas también tienen que negociar con sus familiares, pero es diferente, dependiendo de si se van a llevar los bultos a su casa o de si van a trabajar en el taller. El arreglo más común es que ellas puedan ir a trabar al taller, siempre y cuando ya hayan terminado con sus quehaceres domésticos y estén disponibles para situaciones tales como ir a darle de comer a su esposo e hijos. Razón por la cual ellas siempre prefieren los talleres más cercanos a sus casas como nos comentó Felipa.

Las que trabajan desde sus casas casi siempre son las que tienen hijos pequeños a los cuales hay que cuidar o porque les es más cómodo hacerlo desde el espacio doméstico.

\section{Las modificaciones del espacio doméstico.}

Al instalar el taller en la casa hay cambios primordiales que deben de hacerse, algunos tardan más que otros, sobre todo porque al comienzo del taller no se sabe si realmente va a funcionar, es como cuando se inicia un negocio, puede resultar o no. Es por ello que al principio sólo hacen algunos pequeños ajustes en la casa y en la mayoría de los casos se invade por completo el espacio doméstico: las recamaras, la sala, el comedor, etc., es decir, donde se pueda trabajar. 
"Al principio nosotros trabajamos adentro del cuarto y no teníamos techo, todo estaba descubierto. Entonces como hacía bastante calor pues nos metíamos todos allá adentro, amontonados, y tardamos como cuatro años así..." (Flora)

Pero conforme el taller va comenzando a tomar forma y aumentar el número de trabajadoras, se hace imposible seguir trabajando de esa manera, por ello es que se busca la manera de acondicionar un espacio determinado para trabajar. El cual tiene que ser un lugar espacioso, casi siempre el patio de la casa, ya que es donde se ponen las tarimas para que los bultos de ropa no se ensucien y las mesas, que son muy largas, para que las trabajadoras puedan trabajar en ellas. Es común que esas mesas sean improvisadas por las mismas trabajadoras y que el costo también lo absorban.

"Empezamos a limpiar para abrirnos espacio, para que las señoras trabajaran allí y así fue como las señoras poco a poco empezaron a trabajar. Luego llegaban y decían "No, es que queremos trabajar acá" y fuimos armando mesas, nada más las iba formando y las iba pegando, así las iba armando." (Ana)

Otra modificación que tuvieron que hacer fue techar el patio de la casa, para tratar de cubrirse del sol. Al igual que poner la instalación eléctrica para poder trabajar por las noches. En algunos casos también construyen baños para las trabajadoras.

"Pues ya nos vinimos a deshebrar aquí afuera porque ya había sombra y pues allá adentro no cabíamos." (Flora)

Todos los gastos que representan las adaptaciones a la casa para llevar a cabo el taller son absorbidos por la dueña y en algunas ocasiones los dueños de las fábricas les proporcionan algunas mesas o tarimas, aunque como dice Ana, "después de un año de rogarles". 


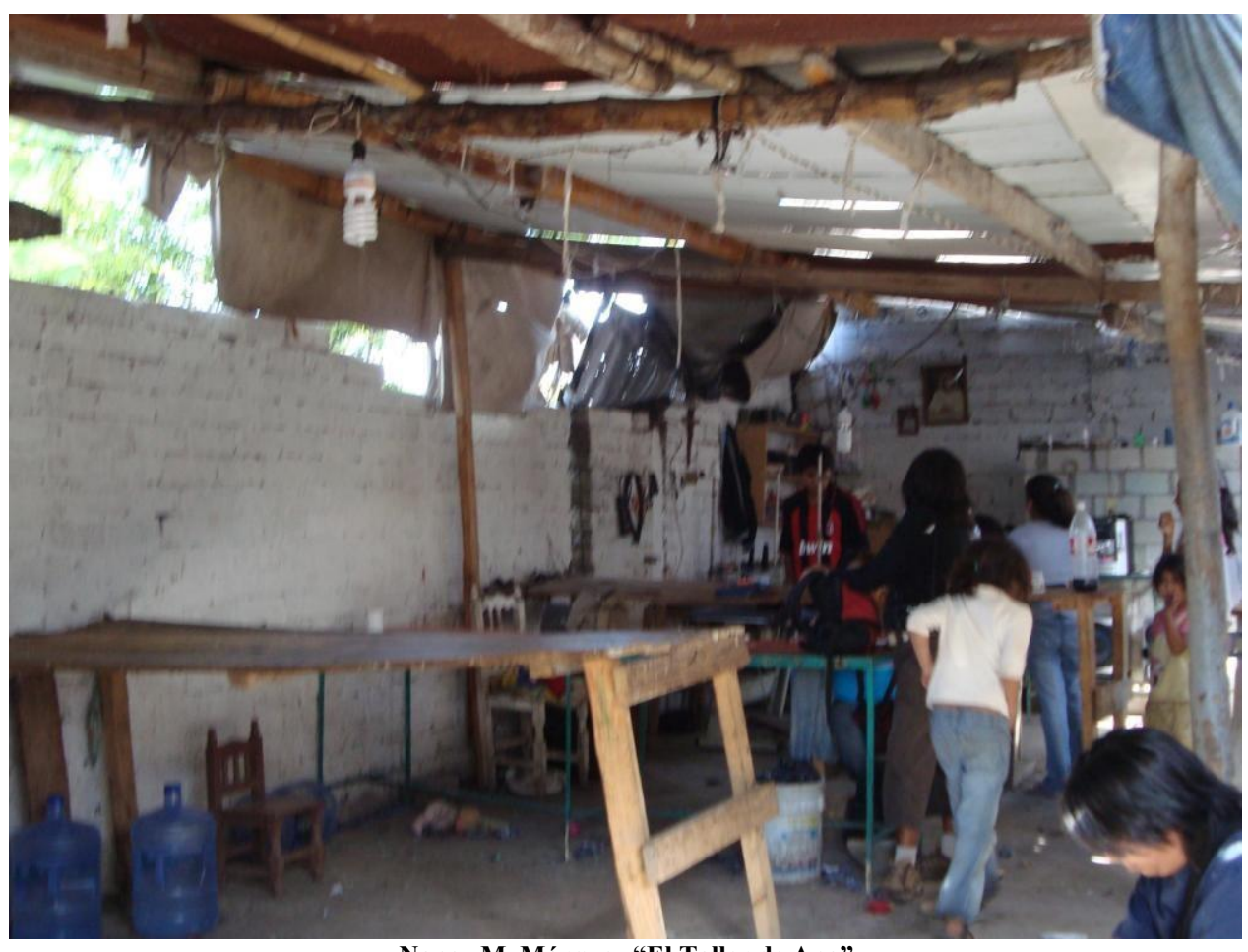

Nancy M. Márquez "El Taller de Ana"

\section{El mundo de lo productivo en el espacio doméstico}

El traslado del trabajo productivo al espacio doméstico altera la dinámica familiar, así como las actividades comunes de su entorno. Recomponiéndose y adaptándose a la jornada de trabajo que se va tejiendo alrededor del trabajo productivo. La casa de la trabajadora se convierte en un brazo productivo de la fábrica y, donde la jefa del taller además de ser madre y esposa, ahora también se convierte en supervisora del trabajo que se realiza desde su casa.

En este aparatado describiré la dinámica del trabajo en la casa, su organización, las relaciones laborales, los pagos, el tipo de jornada laboral, la rutina diaria y el contexto de precariedad en el que se desarrolla. 


\section{La organización del trabajo}

A continuación, relataré la manera en que las jefas del taller organizan el trabajo en un contexto informal y clandestino como en el que se encuentran los talleres de deshebrado. ${ }^{16}$

Los intermediarios son los encargados de llevar los bultos de ropa al taller, la cantidad de éstos depende de la producción que se genere dentro de la maquila. Los trasladan en sus camionetas y casi siempre llevan personas que los ayudan a apilar los cerros de bultos.

La jefa del taller es la responsable de revisar cuántos bultos le dejan, después el intermediario le dice la cantidad, a veces les dan facturas o notas con el número de prendas, acuerdan una fecha para la entrega, la cual también depende de la premura en que la maquila necesite el trabajo realizado. Puede ser para dentro de unas horas, de un día para el otro, en el transcurso de la noche o para dentro de dos días.

Las prendas las llevan regularmente los días martes, debido a que en la maquila se comienza la producción los viernes y para ese día es que terminan de ensamblar las partes que componen las prendas que necesitan del deshebrado, una de las últimas tareas del proceso. Existen maquilas pequeñas que llevan sus prendas durante otros días de la semana, esto tal vez se deba a que se organizan de manera distinta.

En el tiempo que estuve en el taller pude observar distintas maneras en que las trabajadoras subcontratadas toman los bultos de prendas. Esto tiene que ver con la cantidad de prendas que envían las empresas. Si en una semana "escasea" el trabajo, cuando los intermediarios llegan, ni siquiera tienen que molestarse en acomodar los bultos en las tarimas, porque las trabajadoras salen corriendo del taller para apartar sus bultos del día, con la intención de asegurar un pequeño ingreso en la semana.

\footnotetext{
${ }^{16}$ Para ello y debido a todas las dificultades a las que nos enfrentamos, y que ya fueron descritas anteriormente. La observación tomó un papel decisivo en nuestra investigación, es a partir de ella y de las entrevistas en profundidad que la dinámica familiar y laboral se pudo reconstruir, incluidos los aspectos de este apartado. Lo observado se registró en un diario de campo, donde anotábamos todos aquellos aspectos que nos parecían importantes para el estudio. Los que después fueron sistematizados y analizados.
} 
Si la semana corresponde a una en que el trabajo sobrepasa la capacidad del taller, lo que ocurre es que las jefas tienen que ir casa por casa a avisar que ya llego el trabajo y que pueden ir a deshebrar, entonces el trabajo permanece en las tarimas durante períodos más largos de tiempo. Como lo señala Ana:

"Yo les iba a avisar en la bici a su casa. No les decía que vinieran ellas temprano porque a veces me llevaban el trabajo ya tarde." (Ana)

En estos casos, las mujeres que trabajan en el taller tienen más oportunidad de apartar trabajo por sobre las que trabajan desde sus casas. Lo mismo pasa con las que trabajan de manera más "estable" o recurrente, tienen preferencia sobre las que son intermitentes.

Las trabajadoras toman los bultos que saben pueden realizar durante el día. Por lo que no hay una cantidad establecida por trabajadora, cada uno trabaja la cantidad que quiere ganar a la semana. Así lo comenta Flora:

“...aquí [en el taller] agarran el trabajo conforme van acabando, y van agarrando más. Por ejemplo, la que quiere cinco bultos, porque sabe que los va a acabar, pues agarra cinco o seis. La que quiere agarrar un bulto porque sabe que solo eso va a acabar, pues agarra uno y así." (Flora)

El trabajo es tan flexible que hay quienes sólo acuden a los talleres cuando tienen tiempo o quieren, debido a que no se les obliga a nada y tampoco existen acuerdos explícitos. Depende de la necesidad que la trabajadora tenga del ingreso semanal. Como es señalado a continuación:

"Pues si ellas quieren trabajar vienen y piden trabajo y si no quieren trabajar pues no vienen y vienen otras personas. Por ejemplo, piense que una semana no viene una, pues vienen otras, y así. Las que quieren trabajar pues trabajan y las que no, pues no. Si una semana no quieren agarrar trabajo, pues vienen hasta la siguiente semana o vienen dos veces a la semana y ya." (Flora)

Mientras que hay otros talleres que tienen una organización más formal del trabajo, por ejemplo, que tienen un horario de trabajo más establecido, pero eso depende de las propias trabajadoras y sus necesidades tanto económicas como familiares. En el taller de Ana era evidente que había una organización parecida a la maquila para la que trabajaban, debido a que le trabajaban de manera exclusiva y estaban completamente sujetas a sus necesidades de 
producción. Ana describe y hace una analogía muy interesante entre lo que se vive en su taller y lo que ella conoció sobre el funcionamiento de la maquila, mientras trabajó en ella. Lo relata a continuación:

"Había señoras que iban todo el día, lo agarraban como un trabajo, iban a las 9, [después] iban a comer y luego volvían. De hecho, era como si estuvieran en la maquiladora y claro se les pagaba igual, como las de fuera, hay señoras que llegaron a ganar hasta ochocientos pesos a la semana, así deshebrando. No pues sí estaba cómodo.” (Ana)

El mecanismo para saber cuántos bultos deshebra cada trabajadora subcontratada, es que cada quien debe de tener una libreta donde la jefa del taller escriba el número de bultos que toma, ya sea que trabaje dentro o fuera del taller. Asimismo, la jefa tiene su propia libreta donde escribe el nombre y número de bultos que toma cada una. Cuando le traen los pantalones deshebrados hay otra libreta en la que anotan el nombre y número de prendas realizadas.

Este procedimiento les sirve a las jefas para saber cuánto le tienen que pagar a cada una al fin de la semana. Pero no es un control muy estricto y hay a quienes se les olvida la libreta o no quieren llevarla.

Las jefas del taller a veces tienen conflictos y tensiones con las trabajadoras, básicamente radican en que no deshebran correctamente las prendas. Lo que trae como consecuencia que después los intermediarios de la maquila les regresen las prendas o que cuando van a cobrar a la maquila les llamen la atención y les descuenten una cantidad del pago total. Este descuento es absorbido por todas las trabajadoras, incluso las que hicieron correctamente su trabajo. Lo que causa molestias entre las trabajadoras y de éstas con la jefa del taller. Así lo relata Flora:

"Un día la prenda se fue con hilo y todo lo rechazaron. A mí me descontaron y se les descontó [a las trabajadoras], y pues se molestan. Pero yo ¿qué puedo hacer?, todo por no hacer bien el trabajo. A mí no me da tiempo de revisar bulto por bulto, es bastante trabajo y yo también tengo que deshebrar. Unas [trabajadoras] estuvieron de acuerdo y otras se enojaron, es como todo. A mí me regañaron muy feo, la mera mera [en la maquila] me dijo que me iba a descontar 5000 pesos, pero al final sólo me descontó 500 pesos. Pues así también uno se molesta, porque a mí me descuentan y luego ellas ponen su cara y se molestan.” (Flora) 
El segundo punto de conflicto tiene que ver con que no quieren deshebrar ropa de "modelaje", son aquellas prendas que tienen un diseño a la moda, como su nombre lo indica, y se caracterizan por tener muchas bolsas, lo que dificulta y retarda el proceso de deshebrado. Ese tipo de prendas generalmente se pagan más caro, pero aun así resulta muy cansado deshebrar ese tipo de pantalón. Por lo que las jefas tienen que convencer a las trabajadoras de hacer este trabajo, porque muchas de ellas "no lo quieren agarrar” como señala Flora la jefa del taller.

“...Hay veces que sale con hilo, hay veces que no, va variando, entonces, yo no puedo decirle al señor Rubén [dueño de la maquila] que no me traiga eso porque no lo quiero, y es que hay muchas que son así y que dicen que no les gusta y no lo quieren agarrar. Se ponen en un plan que... eso es lo que más me molesta a mí, eso es lo que no me gusta. Trabajo, todo es trabajo y tiene uno que sacarlo venga como venga. (Flora)

Otro aspecto interesante que observé es que hay casos en los que se llevan tantas prendas a su casa a deshebrar, que necesitan de diablitos para poder transportarlas. Son los hijos de las trabajadoras los encargados de llevar y traer las prendas, y de ir al taller a ver si ya llego el trabajo. Ellos tienen una participación en el trabajo de sus madres. También hay ocasiones en que no es solamente la trabajadora subcontratada que deshebra desde su casa, también se involucran los hijos, otras mujeres, ancianos o los mismos esposos, en su conjunto la familia forma parte del proceso.

Es por ello por lo que las redes de subcontratación no tienen límites precisos, se adaptan a las condiciones productivas, familiares y vecinales, el hecho de que se realice desde el ámbito de lo privado es lo que hace que solamente se pueda dar cuenta de las redes más evidentes. En realidad, el número de personas que participan en este trabajo es mucho más grande de lo que se reporta, y al mismo tiempo se invisibiliza el trabajo de los "otros" que casi siempre son los hijos, los ancianos y ocasionalmente los esposos.

Para estas mujeres es algo "normal" que sus hijos ayuden en estas labores o que se encarguen del cuidado de sus hermanos menores mientras las realizan, ya que ellas también crecieron trabajando desde muy pequeñas, colaborando en las obligaciones domésticas o contribuyendo al gasto familiar. Es por ello por lo que consideran que lo más natural es que todos los miembros de la familia cooperen para salir adelante. 
En ese sentido, durante mi estancia en los talleres presencie varías discusiones entre las trabajadoras y sus hijos, donde ellas trataban de ejercer presión en ellos para que las “ayudaran" a deshebrar, mientras que ellos querían jugar. A veces ellas los obligaban y otras veces el llanto de los niños las persuadía.

\section{Los pagos}

Los pagos se realizan los sábados y en los talleres se maneja algo que ellas denominan "salarios caídos"17 que es como lo narra Flora a continuación:

"El trabajo empieza los lunes, martes o miércoles.... Se queda caído jueves, viernes y sábado. Por ejemplo, hoy jueves ya queda caído porque los bultos que hacen ellas para mí ya están caídos, me dan mi nota y lo voy a cobrar, pero hasta la próxima semana. Se paga la siguiente semana junto con lo que se haga lunes y martes." (Flora)

Los dueños de las maquilas imponen los términos de los pagos y las deshebradoras tienen que afrontar que no todas las trabajadoras están de acuerdo con el mecanismo. Hay quienes exigen su pago en la misma semana y la jefa del taller tiene que asumir ese costo con ellas, pagándoles de su bolsa lo que todavía ella no ha podido cobrar.

Existen ocasiones en que las maquilas dejan de producir o cierran y las jefas del taller se quedan endeudadas con sus trabajadoras. En estos casos hay quienes asumen las consecuencias, debido a que son ellas las que consiguen y proveen de trabajo a las demás.

Son las principales responsables del trabajo ante el intermediario y ante las trabajadoras subcontratadas, como lo comenta Flora:

\footnotetext{
${ }^{17}$ Que consiste en esperar el pago de unos días ya trabajados durante una semana. Es decir, se paga lo que se realiza entre lunes y miércoles, mientras lo que se labora entre jueves y sábado se paga hasta la siguiente semana junto con lo del lunes a miércoles de esa semana.
} 
“...había maquilas que tronaban y nos quedaban debiendo. Entonces mi suegra y yo teníamos que conseguir para pagarle a la gente. Poco a poco se le iba devolviendo su dinero [a las trabajadoras]. Por eso ellas siempre han estado aquí, por lo mismo de que nunca se les ha fallado con su dinero, de que se les debiera tantos bultos y nunca se les pagara, no, nunca. Al contrario, si no tiene uno o no nos pagan el sábado, pues conseguimos para pagarles a ellas." (Flora)

Estos problemas con los pagos se deben al carácter informal que tiene el taller, al no existir ningún compromiso formal entre la maquila y éste. Es decir, todo se resume en que es un trabajo a destajo. Es lo que provoca que las trabajadoras no tengan a quién reclamarle si es que cierra, también debido a que ni siquiera saben quién es el dueño de la maquila o dónde está.

Con el paso de los años las jefas de los talleres han aprendido de la experiencia y aprenden a conocer la dinámica del mercado maquilador, saben que el día que les dejen de llevar el trabajo, éste termina, y que cualquier problema con las trabajadoras o con los intermediarios ellas asumen los costos. Esto lo han aprendido a partir de la experiencia.

\section{Condiciones laborales precarias}

Las condiciones en que trabajan las mujeres de los talleres son muy precarias. Las fábricas las someten a ritmos intensivos de trabajo que generan conflictos entre las jefas y las trabajadoras subcontratadas. Por ejemplo, cuando a "los de la maquila" les urge el trabajo, presionan a las jefas del taller y, éstas a su vez presionan y "carrerean" a las trabajadoras subcontratadas. En este sentido, las jefas fungen el papel de capataces, asemejándose a las prácticas en la maquila.

Las jefas del taller tienen que negociar con sus trabajadoras, sobre todo cuando en ocasiones

los intermediarios quieren que deshebren de noche, ese es un tema complicado, porque a muchas de ellas no las dejan sus esposos o simplemente es algo que no están dispuestas a hacer, y es en esas ocasiones cuando las jefas son las que tienen que responder por el trabajo. Tal como lo señala Ana: 
"Es que [las trabajadoras] no se querían quedar tarde, no querían trabajar. Cuando hay trabajo y se carga te lo exigen así de que "Quiero mi trabajo y no me importa si tienes gente o no". Luego lo quieren todo para el mismo día, fuera a las once, doce, una de la mañana allí estaba, y pues las señoras a esa hora ya no me ayudaban, ya era muy noche, tenían que hacer su cena y todo. Siempre me quedaba yo y una de mis sobrinas que trabajaba allá conmigo." (Ana)

Otro aspecto que destaca es la cadena de explotación que se crea entre los intermediarios, las jefas del taller y las trabajadoras subcontratadas. Los intermediarios les pagan a las jefas entre $\$ 25$ y $\$ 60$ el bulto con 25 piezas, mientras que en la fábrica se paga a $\$ 80$. Asimismo, la jefa del taller se queda con una cantidad extra por cada bulto que deshebran sus trabajadoras. En el caso de Ana a ella le pagaban a $\$ 60$ el bulto y se quedaba con $\$ 10$ por cada uno. Ellas justifican este descuento debido a que ellas absorbían otros gastos como el de agua y luz.

El tiempo que tardan en deshebrar un bulto es de aproximadamente entre dos horas y dos horas y media, eso quiere decir que si logran deshebrar cuatro bultos al día ganan alrededor de \$100. Lo que apenas rebasa lo que se gana en la maquila por un bulto deshebrado.

Las trabajadoras en general perciben que su trabajo es muy cansado y agotador, sobre todo porque al ser un trabajo a destajo tienen que trabajar más para ganar lo suficiente y poder juntar el dinero necesario para su semana, lo que hace que su trabajo sea agotador y sienten que su jornada es muy larga. Tal como lo relata Yolanda:

"La sentía muy larga [la jornada], porque pues era todo el día estar ahí. Había muy poco tiempo para descansar, la jornada era muy larga y era todo el día de estar deshebrando." (Yolanda)

El deshebrado comúnmente se hace de pie y con unas tijeras especiales, hay que deshebrar en todas las uniones de las costuras, por el derecho y por el revés. Por lo que pasan mucho tiempo paradas en la misma posición. 


\section{Las trabajadoras de "adentro" y de "afuera"}

Las diferencias entre las trabajadoras de los talleres tienen que ver con que las trabajadoras de "adentro" como las jefas las llaman, son mujeres más disponibles y dispuestas a trabajar. Ellas son las que sacan la producción más rápido y a quienes pueden supervisar. En el caso de Yolanda trabajadora subcontratada de Ana, narra cómo le llamaban la atención cuando le revisaban su trabajo y le decían que tenía que hacerlo bien.

“...si lo hacía mal, me decía "No, tienes que hacerlo así,", y yo pienso que a la vez está bien que me diga para aprender. Pero a la vez si lo tomaba como regaño, yo decía "Que gente tan regañona. Era muy gritona, a veces te regañaba, te apuraba a deshebrar, porque luego urgía." (Yolanda)

Mientras que las trabajadoras de "afuera" son percibidas como personas renuentes a trabajar y que no están disponibles cuando se les requiere. A quienes hay que ir a avisarles hasta su casa que el trabajo "ya llego". En ese sentido Ana sentía que "Las señoras que deshebran afuera eran las más complicadas" ya sea porque no están o porque ya no quieren deshebrar. En su opinión las trabajadoras que lo hacían desde el mismo taller era más fácil organizarlas y estar al pendiente del trabajo que realizaban.

Yolanda que llego a trabajar "adentro" y "afuera" del taller pensaba que la diferencia de trabajar en el taller o desde su casa, radicaba en que no había distracciones y que solamente se dedicaba a deshebrar. Mientras que estando en su casa, se perdía tiempo en ir por los bultos, además de que transportarlos no era algo sencillo, debido a su peso y dimensiones, era fácil distraerse con la televisión o realizando otras tareas domésticas. En su opinión era mejor trabajar en el taller porque trabajabas más y más rápido.

En la reconstrucción fina de la dinámica del taller es interesante presenciar su jornada laboral. Es debido a ella que el patio de la casa se convierte en un lugar donde todo el mundo entra y sale: las trabajadoras, sus familiares, los intermediarios, los cargadores, etc. Es un espacio de múltiples relaciones sociales, donde la dinámica fluye con el transcurrir 
del día. Las trabajadoras que trabajan en el taller conviven mientras deshebran, comparten experiencias y preocupaciones.

Las más viejas cuentan y recrean a las más jóvenes sus vivencias, el taller es un espacio de trabajo, pero también es el escenario de relaciones de amistad y compañerismo.

\section{Percepciones y significados sobre el trabajo}

Las trabajadoras tienen diferentes tipos de percepciones y construyen distintos significados con respecto al trabajo del deshebrado y a la jefa del taller. En las pláticas que tuve con las trabajadoras subcontratadas, ellas me contaban que veían a la jefa del taller como la "patrona", la que les decía cómo tenían que trabajar, cuándo había que entregar y la que les pagaba. Mientras que la jefa del taller a veces se percibe como una trabajadora igual al resto de las que forman el taller. Así se sentía Ana:

“...éramos iguales, ni yo era más ni ellas eran menos, nosotros somos iguales, con todas las señoras me llevaba bien, nos tomábamos un refresco. No, nos hacíamos menos y siempre me decían -No que usted es la patrona, yo les decía -El patrón es el que esta allá, digo porque yo también estoy trabajando mírenme-. Siempre nos llevábamos muy bien, nunca fui mala con ellas, no sé qué digan ellas de mí.” (Ana)

Las mujeres le dan a su trabajo distintos significados. Por un lado, hay quienes piensan en el deshebrado como un "trabajo" que las ayuda a subsistir, pero que al mismo tiempo les facilita las cosas porque trabajan en sus casas. Aspecto de gran relevancia para quienes se subcontratan en los talleres, ya que representa una opción que les permite intentar "conciliar" su trabajo productivo con el reproductivo. Aunque muchas veces esto es muy difícil y hasta imposible, por el tipo de jornada laboral y por las exigencias que de ellas demandan sus familiares, sobre todo en las jefas del taller, que tienen que organizar el trabajo. 
También consideran que han aprendido a ser responsables, porque en el trabajo de la maquila, y del taller como extensión, se necesita que todos trabajen al mismo ritmo, porque todo forma parte de un todo y si alguien falla es mucho más complicado sacar el trabajo.

Cuando Ana puso su taller, relata que se dio cuenta de la importancia de ser responsables, así como de la importancia de que todas como trabajadoras estén comprometidas con su trabajo, que lleven un horario, que no falten, ya que todos estos aspectos afectan el ritmo del trabajo mismo. Eso lo entendió cuando instalo el taller y se enfrentó a que tenía que sacar el trabajo que le pedía la maquiladora.

\section{La volatidad y vulnerabilidad del trabajo a domicilio: El caso de Ana y Toño}

El trabajo subcontratado a domicilio es un trabajo dependiente, inestable y vulnerable a los cambios del mercado. En este aparatado quiero adentrarme en el caso de Ana y Toño porque es un claro ejemplo de lo volátil que puede ser trabajar a domicilio. Su experiencia da cuenta de un contexto de inseguridad, vulnerabilidad y clara dependencia con la maquila.

\section{Contexto familiar}

Ana emprendió la idea de poner un taller en su casa porque vivía una situación familiar muy complicada, tiene tres hijas y su esposo estaba impedido para trabajar porque padecía una enfermedad muy seria y difícil de tratar: diabetes insípida. De un momento a otro ella tuvo que hacerse cargo de brindar el sustento a su familia, y costear los medicamentos que necesita su esposo. Estas circunstancias afectaron a Toño anímicamente, debido que no podía cumplir con el estereotipo de proveedor de su familia, lo que se vio acentuado por las críticas de familiares y amigos. La presión social y la necesidad económica fue lo que orillo a Ana a pensar en conseguir trabajo en el deshebrado. Como lo comenta a continuación:

"Pues de hecho le reprochaban [a Toño] que le compraba medicinas, y le decían que él no hacía nada. Cansada de todo eso fue como empecé, así fue como conseguí el trabajo de deshebrado.” (Ana) 
Toño a consecuencia de su enfermedad, se sumió en una terrible depresión que lo llevo a pensar en el suicidio. Se sentía como una carga para su esposa y un "inútil". A la postre lo llevo a un problema muy fuerte de alcoholismo. Él no trabajaba, al contrario de eso gastaba lo poco que Ana ganaba en el alcohol. Toño también relata a la distancia lo difícil que es para él ahora darse cuenta de que le infundía un terrible miedo a sus hijas debido a los golpes que le propinaba a su esposa.

“...yo tomaba un mantón, tomaba a veces diario, a veces cuatro veces a la semana. Todo el tiempo andaba enojado, todo el tiempo estaba yo bien mal, porque ya me había desesperado. Me entro la depresión bien fea. "Estaba cañón esa vida que yo llevaba, era muy fuerte, en mi cabeza me decía "No, pues ya mátate". Encima se imagina maltratar a mi familia, a los que más quería, que eran mis bebes, mi esposa. Lo que también ella pasó, todo el tiempo enojado y gritando y pues ellos no tienen la culpa, yo no me daba cuenta de todas esas cosas que hacía yo." (Toño)

La violencia doméstica término cuando Toño decidió dejar el alcohol y asistir a unos retiros espirituales para hablar de todos sus problemas. Lo cual tuvo un efecto terapéutico y de reflexión. Actualmente trabaja para una maquiladora que lo aseguro y con lo que puede mantener a su familia y pagar sus gastos médicos.

\section{Conflictos con los intermediarios y el cierre del taller}

El taller que Ana puso en su casa les daba lo necesario para el sustento de sus hijos. Ella trabajaba para una sola maquila perteneciente a Gil Alamán uno de los maquileros de la región. Ella era la encargada de hacer la mayor parte del trabajo de deshebrado para este empresario, llegó a sacar más de 4000 prendas diarias.

Trabajaba incansablemente porque llego al arreglo con el contador de la maquila de que ella trabajaría exclusivamente para ellos y se comprometía a entregar las prendas en tiempo y forma, a cambio de que le otorgaran el seguro a su marido para que pudieran darle el medicamento que es muy costoso. 
El seguro era la razón más poderosa para trabajar para esa maquila de manera exclusiva, fue así durante más de seis años. Hasta que en noviembre del año pasado le dieron a deshebrar un paquete de bultos mucho más barato de lo que acostumbraban a pagarles. Ana no lo tomo porque pensaba que si lo recibía a ese precio significaba que aceptaba que le comenzaran a pagar así. Por lo que los intermediarios y el dueño de la maquila se molestaron mucho y los castigaron quitándoles el trabajo todo el mes de diciembre.

Después Toño habló con el encargado y acordaron que les regresaría el trabajo, pero que ahora estaría a nombre de él y que todos los tratos serían con él y no con Ana. Es de destacar el rol masculino en los tratos con las personas de la maquiladora, donde Ana sufrió de exclusión por ser mujer. También les advirtieron que los bultos se los pagarían más barato, porque la maquiladora en ese momento ya no se los podía pagar al mismo precio, pero acordaron que solamente sería por dos meses.

Ana y Toño esperaron que ese período durara diciembre y enero, no fue así y las tensiones comenzaron a crecer como narra Toño a continuación:

“... empieza enero y pues venia el sobre igual [con la misma cantidad de dinero], y yo decía "Qué onda contigo ya habíamos quedado que empezando enero..." y me dijo "No, pues es que no se puede, no quiere el dueño", y le dije "Es que no, así no sale, nosotros hablamos por teléfono, gastamos más de 100 pesos a la semana, compramos el agua, y realmente así no sale" y me dijo "Dame chance en febrero" y le dije "La neta así no vamos a aguantar." (Toño)

Un día Toño fue al hospital a su consulta habitual y le dijeron que no lo podían recibir porque tenía tres meses que lo habían dado de baja. Ese fue el punto medular por el que comenzaron a acentuarse los problemas con las personas de la maquila. Tal como lo había narrado Ana, la razón más fuerte por la que trabajaban era por el seguro, entonces cuando se lo quitaron a Toño comenzaron las pugnas porque se lo devolvieran y los verdaderos problemas con los intermediarios. Cabe decir que la maquila ya tenía más de siete talleres con los que trabajaban además del de Ana, por lo que podían afrontar el hecho de ya no llevar más trabajo. 
Ana intento hablar con el contador a cargo, para decirle que ella necesitaba el seguro y que, si ella estaba dispuesta a trabajar lo que fuera necesario, era porque realmente lo necesitaba. Al final de la discusión el contador le dijo que ella no tenía derecho al seguro y que si se le había proporcionado era simplemente como un favor, pero que eso ya no podía ser.

Después de un tiempo de haberles quitado el seguro y bajar el precio del deshebrado, tuvieron que pedir préstamos para solventar los gastos de su casa y de los medicamentos de Toño. Se endeudaron tanto, que tuvieron que vender su casa para poder afrontar sus deudas. En menos de tres meses, el trabajo de seis años se había venido abajo.

El último recurso que tuvieron fue el de intentar hablar con el dueño para aclarar los malentendidos y pedirle que les devolvieran el trabajo. Los intermediarios ni siquiera lo dejaron entrar y lo trataron muy mal, ahí se dieron cuenta que no les quedaba más que cerrar el taller al que le habían dedicado años de duro trabajo.

Este es un claro ejemplo de la dependencia que tienen los talleres de deshebrado con las maquilas de la región y que en realidad no se trata de un empleo por cuenta propia, sino de un trabajo dependiente. Es decir, de asalariamiento encubierto, ya que, aunque trabajen para varías maquilas, siguen dependiendo de éstas para poder desempeñar su trabajo y, que el día en que se acabe la maquila en Tehuacán o que simplemente decidan ya no externalizar su producción, ese día los talleres de deshebrado subcontratados a domicilio dejaran de existir.

La vulnerabilidad de los y las trabajadoras es muy fuerte, se trata de personas que viven al día y que desempeñan un trabajo precario, flexible y sumamente inestable. El caso de Ana y Toño ejemplifica el contexto en el que viven las trabajadoras en torno a las maquilas.

\section{Simultaneidad del trabajo: el mundo de la familia y del trabajo en un mismo espacio.}

Fue sobre todo durante mi estancia en los talleres que pude presenciar la forma en que se realiza el trabajo productivo y reproductivo en un mismo espacio. Pude observar las distintas

modalidades en que se organizan y distribuyen sus actividades, algunas veces regidas por la 
lógica del deshebrado y otras por el trabajo reproductivo.

El tema de la "conciliación" es central, es una idea recurrente en el imaginario de las trabajadoras, aun cuando en la práctica pareciera imposible, simplemente porque intentan conciliar actividades de naturaleza opuesta. A continuación, daré cuenta de las expresiones más comunes de estos intentos que encontramos en las trabajadoras.

Cuando el trabajo productivo se realiza desde la casa de las trabajadoras, tal parece que la modalidad más común en que se realizan las actividades productivas y reproductivas es de manera simultánea. Intercalando actividades de acuerdo con cómo se presente el trabajo y los requerimientos familiares. Como lo narra Ana a continuación:

"Me levantaba y luego, luego al trabajo. Después agarraba una hora para hacer la comida. Luego otra vez hacía el trabajo. Cuando no había mucho trabajo, pues ya me agarraba para limpiar la casa y para hacer todo, rápido, para bañar a las niñas. Lo hacía por ratos." (Ana)

La rutina diaria gira en torno a veces de la familia y otras veces al deshebrado, depende de cómo se vaya presentando cada situación. En el caso de las trabajadoras subcontratadas, ellas tienden a desarrollar sus actividades de manera más separada. Por ejemplo, que en las mañanas se dedican a hacer todo su quehacer y por las tardes se dedican exclusivamente al trabajo del deshebrado.

"El tiempo se presta, no tengo que estar a una hora determinada. Termino de hacer mi quehacer, mi comida y me vengo a deshebrar... y a la hora que tengo hambre me voy a comer, luego vengo y ya sigo trabajando." (Felipa)

Las trabajadoras van improvisando sus actividades, de acuerdo con las necesidades que se vayan presentando. Si durante el día no hay mucho trabajo, se dedican más a las actividades domésticas y aprovechan para arreglar la casa y cuidar a sus hijos. Pero si se presenta todo lo contrario, cambian la prioridad de la familia al deshebrado. No es que un mundo rija al otro, sino que más bien se va cambiando la prioridad de acuerdo con cada situación. Lo que trae como consecuencia que cuando se prioriza un ámbito, el otro se descuida, incluidos los hijos y el esposo. Por lo que la idea de que trabajan desde sus casas para estar al pendiente de su familia no es del todo cierta en la práctica cotidiana. 
"Pues todo el día estaba, todo el día estaba ahí (deshebrando), yo solo agarraba una hora para hacer la comida y todo el día estaba en lo del deshebrado." (Ana)

La conciliación del trabajo es más bien una aspiración constante que las mujeres luchan por conseguir día a día. En donde muchas veces, saberse presentes en la casa, basta para sentir que no descuidan a sus hijos, aunque todo el día estén dedicadas al trabajo del deshebrado.

Si bien es cierto que el trabajo subcontratado a domicilio les permite organizar mejor sus horarios y actividades, es decir, jugar con sus tiempos. Conciliar dos actividades contrapuestas y diferentes, a veces es muy difícil y estas mujeres, lo intentan todos los días, a veces lo logran y otras veces no.

Cuando no lo logran, los conflictos y tensiones se desatan, esto sucede con frecuencia particularmente con sus esposos, quienes les demandan atención y cuidados, aun cuando el deshebrado representa un ingreso importante para el gasto familiar. Unas veces considerado como complementario y otras veces como indispensable para el sustento económico familiar.

De acuerdo con lo encontrado, la dinámica laboral y familiar se lleva a cabo a partir de intentar conciliar el trabajo productivo y reproductivo, con todos los bemoles que eso significa, a veces de manera simultánea y en otras ocasiones, con una separación marcada entre las actividades que se realizan en el taller, de las que tienen que ver con su trabajo reproductivo.

Las contradicciones y tensiones son aspectos que las mujeres tienen que librar, algunas ocasiones con sus familiares y otras veces con los intermediarios de la maquila. Resulta casi imposible entender este conjunto de aspectos sin dar cuenta tanto de lo productivo como de lo reproductivo. 


\section{Conclusiones}

La reconstrucción de la dinámica laboral y familiar que se llevó a cabo en los talleres domiciliarios, es vital para entender los vaivenes en que se realiza, y que son expresión de las contradicciones del intento de conciliar el trabajo productivo y reproductivo en un mismo espacio.

Esta reconstrucción implicó dar cuenta de las condiciones laborales en que los talleres se desenvuelven y del tipo de relaciones sociales, tanto laborales como familiares, que se tejen en un espacio de múltiples dimensiones.

La dinámica laboral y familiar que desarrollan responde al anhelo de "conciliar" sus actividades productivas y reproductivas en el tiempo y en el espacio, esta idea siempre está en juego en su vida cotidiana.

El trabajo subcontratado a domicilio es una manera que las mujeres encuentran para seguir manteniéndose en el mercado de trabajo, en su intento de resistirse a abandonar el mundo de lo productivo. Representa un nicho de oportunidad laboral disponible y al alcance de cualquier persona con deseos de trabajar.

El trabajo subcontratado a domicilio es una forma muy extendida en Tehuacán y que provee de trabajo a muchas mujeres de la región. Es posible gracias a las redes de subcontratación que se tejen con los intermediarios y con las trabajadoras subcontratadas, estos vínculos son indispensables para su desarrollo.

Las condiciones de flexibilidad, precariedad y vulnerabilidad de las que dimos cuenta en este capítulo, son parte del contexto en que se desarrolla este tipo de trabajo y las cuales definen sus características y le brindan su sello particular, marcado por la dependencia e inestabilidad que guardan con la maquila. 


\section{CONCLUSIONES}

El presente trabajo, tuvo como propósito analizar el trabajo femenino subcontratado a domicilio, así como la dinámica laboral y familiar que se vive dentro de los talleres de deshebrado. Nos centramos en la riqueza analítica de la observación del trabajo productivo de las mujeres, específicamente cuando éste se desarrolla en constante contradicción con su mundo reproductivo, develando los conflictos a los que se enfrentan en su vida cotidiana cuando estos se desenvuelven en un mismo espacio: el privado y doméstico.

Se adoptó la experiencia de vida y el relato biográfico como principal enfoque de investigación, pues consideramos que es a través de éste que podemos abordar los aspectos considerados significativos tanto para las propias mujeres, como para nuestra investigación, aspecto valioso y central, ya que no se trata de imponer visiones, sino de retomar lo vivido y experimentado por las trabajadoras a través de su propio relato, lo que pone en el centro al sujeto y la construcción de su propia subjetividad como mujeres y trabajadoras.

A través de lo encontrado durante la investigación y del recorrido conceptual que realizamos, podemos concluir que el problema de fondo, en el trabajo femenino subcontratado a domicilio, la imprescindible necesidad de analizar la vida cotidiana de las trabajadoras, para comprender las contradicciones que se tejen entre su mundo productivo y reproductivo en el ámbito privado de la casa y más allá de sus aspectos estructurales.

Es por esto que, como aporte principal, creímos necesario recuperar los planteamientos teóricos sobre vida cotidiana, la simultaneidad del trabajo productivo y reproductivo, así como, los que se refieren a las dificultades de su conciliación. Lo que nos permitió colocar a la subjetividad de las trabajadoras en el centro del análisis, sin demeritar el aspecto estructural. Gracias a estos enfoques, fue posible contribuir al estudio de una forma de trabajo localizado en el espacio doméstico, ya que nos brindaron luz para analizar la interacción que se da entre el mundo productivo y reproductivo, de manera no dicotómica, sino como un continuum, que va de la armonía al conflicto y viceversa. Es a partir de esta consideración que la vida cotidiana es vista como un escenario más amplio, en el que se puede estudiar el mercado laboral y la familia, pero de manera dialéctica. 
A partir de estos aspectos la investigación se llevó a cabo desde un enfoque metodológico cualitativo, que puso en el centro la observación del trabajo domiciliario subcontratado. De esta manera la articulación entre mundo productivo y reproductivo nos permitió conocer, los elementos de la vida cotidiana que ponen en juego estas mujeres en tiempos y espacios empalmados, íntimamente relacionados con la permanente ambivalencia entre las exigencias del mundo doméstico, familiar y trabajo.

Este estudio nos dio la oportunidad de contribuir al conocimiento de una temática poco estudiada, mostrando como experimentan estas mujeres el trabajo subcontratado día a día. Algunos hallazgos y reflexiones que sobresalieron a lo largo de la investigación a partir de los ejes que la fueron guiando: La subcontratación laboral, el trabajo subcontratado a domicilio y la simultaneidad del trabajo productivo y reproductivo en tiempos y espacios compartidos.

A partir de los planteamientos teóricos y metodológicos que hemos apuntado, apuntamos anteriormente se puso al descubierto cómo el espacio doméstico es trasgredido por el trabajo productivo, resultado de estrategias empresariales que promueven la subcontratación laboral. Se trata de un fenómeno producto de una política impulsada desde las fábricas, donde lo que se busca es aprovechar la división sexual del trabajo, que confina a la mujer al espacio doméstico, para brindarles un trabajo a destajo, flexible y precario que se beneficia no solamente de los estereotipos de género sino también de la estructura familiar y las necesidades económicas en las que viven las personas.

La subcontratación, presente en toda la historia del capitalismo, adquiere singularidad debido al actual contexto de mundialización de los mercados, donde la flexibilidad laboral es la principal promotora de estas formas de subcontratación. Lo que busca principalmente, es la reducción de los costos de producción, eludiendo toda responsabilidad en materia de seguridad y dejándosela a un tercero; reconfigurando el modelo de patrón-trabajador, a otro de patrón-intermediario-trabajador, desdibujando la responsabilidad de proporcionar a sus trabajadores y trabajadoras, la seguridad laboral a la que tienen derecho. 
Las mujeres con las que llevamos a cabo esta investigación son un grupo interesante, principalmente por las experiencias de vida por las que han atravesado, vivencias del mundo laboral y familiar que les han permitido actuar, buscando y generando alternativas donde se les permita tratar de conciliar su mundo productivo y reproductivo, a veces con armonía y otras en conflicto.

Al profundizar en su experiencia en estos espacios globalizados, que suponen por un lado explotación y por otro posibilidades de construcción de sus identidades de género, pudimos dar cuenta de que tienen un papel activo e importante, debido no solamente a que son las principales organizadoras del trabajo productivo, sino porque también promueven una alternativa de trabajo para el resto de las mujeres de su comunidad, donde además éstas encuentran un nicho disponible en el cual pueden trabajar.

Es importante hacer hincapié en que, aun cuando el trabajo domiciliario se desarrolla en un contexto precario y de subordinación laboral, éstos coexisten como aspectos contradictorios con el hecho de que al mismo tiempo la mujer encuentra a través del trabajo una forma de reafirmación de su autonomía en la familia, es gracias a los talleres que estas mujeres se vuelven autosuficientes y aprenden a trasgredir los roles de género aprendidos. Es necesario decir que, aunque mantienen el control de algunos aspectos del trabajo, existen límites evidentes cuando se analizan las condiciones laborales, impuestas en su mayoría por los intermediarios de la maquila.

Un eje crucial para nuestra investigación y escasamente estudiado, fue el análisis de las trayectorias laborales, a partir de su exploración es que pudimos articular los planos subjetivo y estructural, pues consideramos que la historia laboral es un instrumento útil para ordenar los eventos de trabajo a lo largo de la vida de las personas, también para conocer las razones y motivaciones que impulsan los cambios y continuidades en esa trayectoria; y finalmente, el significado que le dan las personas a su trabajo a la luz de la reconstrucción que hacen de su propia experiencia. 
A partir de estas ideas las mujeres reconstruyen los factores estructurales que las llevaron a trabajar y mantenerse en este tipo de trabajo, al mismo tiempo que hacen hincapié en cómo vivieron y experimentaron, tanto su vida laboral como familiar. Esta perspectiva hizo posible articular el traslape en la cronología entre las vidas del individuo y las estructuras sociales, ya que al analizar sus trayectorias laborales dimos cuenta de su relación con la economía local y global con respecto a sus itinerarios laborales.

Gracias a ello fue posible descubrir uno de los hallazgos más importantes en la investigación, que tiene que ver con que las mujeres que toman la iniciativa de instalar un taller de deshebrado en su casa son principalmente aquellas con una amplia experiencia previa en la maquila, en la cual iniciaron desde muy pequeñas, y que son principalmente por razones familiares, como la unión o el nacimiento de sus hijos, que muchas veces se ven orilladas a abandonar la maquila formal, presionadas por sus esposos para cumplir con su rol de ama de casa y de madre.

En ese sentido los estereotipos de género se mantienen, pero al mismo tiempo son renegociados, orilladas por las necesidades económicas en que viven. Esta negociación consiste en mantenerse en el ámbito doméstico de la casa y, al mismo tiempo, impulsar la idea de lo beneficioso que es para la economía familiar, la instalación de un taller de deshebrado, el cual es considerado por ellas como la solución a sus problemas de conciliación entre vida laboral y familiar.

Con ello, pasan de ser trabajadoras de la maquila formal a las jefas, organizadoras, supervisoras y en algunos casos capataces de una parte del proceso de acabado de prendas, tarea difícil cuando al mismo tiempo están sujetas a los gerentes de producción. Esta relación encubierta de subordinación entra en contradicción con sus propias aspiraciones de autonomía en el trabajo.

Por otro lado, cuando deciden instalar un taller de deshebrado, ponen en juego su conocimiento acumulado sobre la actividad, lo aprendido por años en la maquila, así como también recurren a las redes sociales construidas a lo largo de su trayectoria, tales como los vínculos que guardan de su experiencia previa con los trabajadores de la maquila, 
supervisores y en ocasiones patrones, que son los que les permiten formar parte de la cadena de subcontratación. Estos factores son los que hacen posible instalar el taller y adquirir la materia prima que será transformada para las medianas y grandes empresas nacionales y de exportación para las cuales trabajan. Es a partir de este capital económico y cultural que es posible que estas mujeres materialicen la idea del taller, aspectos que se encuentran invisibilizados en el mercado de trabajo.

Asimismo, pudimos dar cuenta de que las redes de subcontratación que se tejen en torno a los talleres de deshebrado toman formas variadas, que están íntimamente ligadas al mercado internacional de la industria de confección, ya que en gran medida al incrementar o disminuir la demanda de prendas, las redes se expanden y diversifican o disminuyen y hasta desaparecen.

Se trata de un trabajo que depende de las necesidades de producción de la maquila y al cual se recurre, sobre todo en momentos de crisis, buscando reducir los costos de producción, convirtiendo a los talleres en brazos productores, pero de manera informal, en ocasiones clandestina y, a las trabajadoras, en asalariadas encubiertas, que contribuyen desde la "oscuridad" de los talleres a incrementar las ganancias de las empresas exportadoras. Esto acaba con la idea de talleres independientes, que se mantienen con sus propios recursos. El trabajo a domicilio parecería haber pasado entonces de ser una especie de rémora del desarrollo, a convertirse en parte integrante del mismo, por lo menos en lo que se refiere a ciertas actividades y procesos de trabajo.

Estos talleres desarrollan uno de los últimos pasos del acabado de la prenda, el deshebrado, por lo que no se ocupan de transformar la materia prima, es decir, no cuentan con máquinas de ningún tipo, se trata de un paso muy simple que puede ser externalizado de la fábrica sin mayor problema y realizado o supervisado por estas mujeres. Un aspecto por destacar es que ellas no son las dueñas de los medios de producción, aspecto que es considerado como decisivo en la discusión de si estas mujeres forman microindustrias domésticas. En este caso, se trata de un trabajo a destajo, que forma parte integral de la maquila formal. 
El concepto de "trabajo subcontratado a domicilio" no sólo hace evidente su condición de dependencia y subordinación con la maquila, sino también los efectos que tiene en la vida doméstica y familiar. En otras palabras, este concepto descubre los lazos inequívocos entre la vida productiva y la vida reproductiva en un espacio local globalizado. Además, permite diferenciar este trabajo con el llamado por cuenta propia, ya que el primero tiene como características principales, el suministro de materias primas, a condición de devolver el producto procesado a cambio de un pago. Mientras que el segundo se destaca precisamente por ser el dueño de los medios de producción y comercializar su producto.

Es evidente que la subcontratación es el factor que aprisiona a las trabajadoras y las deja en una situación de vulnerabilidad constante. A tal grado que cuando la maquila deja de funcionar, las trabajadoras se quedan sin trabajo al igual que las de la fábrica. Su único recurso es tratar de conseguir prendas de otras maquilas, aspecto difícil porque las maquilas cuentan con sus propios talleres subcontratados a domicilio.

De acuerdo con lo analizado en estudios previos, la cadena de subcontratación se desarrolla entre maquila, taller y trabajadoras a domicilio. Al respecto, un estudio más fino como el que intentamos demuestra que, en torno a este "último eslabón" se forma un número más complejo de vínculos, con otros talleres, las trabajadoras y las redes sociales a las que pertenecen.

Es importante destacar también el carácter flexible de este trabajo, combinado con la multiactividad de las trabajadoras, quienes comúnmente desarrollan de manera paralela otras actividades no necesariamente vinculadas con la cadena de confección, como la elaboración de otros artículos o la venta de productos cosméticos. Asimismo, las trabajadoras subcontratadas de la confección van cambiando o combinando los distintos talleres en los cuales trabajan, dándose una especie de rotación entre ellos. Así también se observó que cuando los talleres se ven rebasados por la cantidad de producción, otros talleres de la misma comunidad se encargan del trabajo, lo que es indicio de una comunicación fluida, donde los vínculos son lo suficientemente fuertes para generar acuerdos entre las jefas de los talleres, complejizando el proceso de subcontratación en el último eslabón de la cadena. 
El análisis de las redes sociales sobre las que se establece el trabajo a domicilio fue otro hallazgo fundamental. Fue un aspecto difícil de estudiar, debido a que las redes se tejen en el ámbito de lo privado de las personas, invisibilizando a la mayoría de sus participantes, es común encontrar que los familiares, amigos y vecinos, se encuentran imbuidos en las redes de subcontratación no solamente como trabajadoras o trabajadores subcontratados, sino como dueños de pequeñas maquilas o intermediarios de las grandes. Estas relaciones de parentesco y amistad son las que permiten los enlaces necesarios para el desarrollo de este trabajo.

Otro elemento importante es el papel central que juega la jefa del taller en la reordenación de la vida familiar, desde adaptar el espacio de trabajo continuamente, debido a que con la llegada del trabajo productivo el hogar se convierte en un lugar continuamente renegociado, en ocasiones como un espacio privado, otras veces, como un sitio socioeconómico público y dinámico. Lo que significa la convivencia de nuevos y tradicionales roles de género en un mismo contexto social.

Las redes de subcontratación que generan las mujeres a partir de los talleres domiciliarios nos permitieron conocer cuál era la diferencia material y simbólica de ser la jefa de los talleres o una trabajadora subcontratada. Así como la forma en que son vistas por los intermediarios de la maquila, las trabajadoras, su familia y el resto de la comunidad. Observamos de la importancia que guarda el papel de jefa del taller, espacio reconocido por las trabajadoras, con un significado jerárquico, las jefas son vistas como las "patronas". En realidad, existe una confusión entre jefa y compañera del mismo trabajo, frente al verdadero patrón que está fuera del taller.

Existen posturas que plantean que la subcontratación promueve la atomización de las relaciones laborales cuestionando la existencia de relaciones colectivas en un trabajo subcontratado como el domiciliario. Nosotros encontramos que existen condiciones básicas de asociatividad, como compartir el mismo espacio de trabajo dentro de los talleres, lo que promueve la convivencia diaria, la experiencia de trabajar y resolver aspectos de su vida productiva y reproductiva. Existe el compañerismo y la camaradería, expresiones de una realidad compartida. Aunque estos aspectos no sean traducidos en acción colectiva, sí promueven el reconocimiento en el otro y en posibilidades de identificación, y aspecto que 
queda como una línea de indagación abierta para estudiar en el futuro.

Por otra parte, la mayoría de los estudiosos del trabajo a domicilio presentan como perfil de trabajadora a una mujer casada y con hijos. En este estudio dimos cuenta de que además de ellas, existe una amplia diversidad de mano de obra femenina, así como la incorporación de otros miembros de la familia en los talleres. También se insertan mujeres jóvenes, solteras y sin hijos, así como ancianas de más de setenta años que debido a su falta de experiencia y a su avanzada edad trabajan en los talleres realizando tareas simples como el deshebrado, donde no se requiere ningún tipo de experiencia previa. Existe una presencia importante de niñas y niños que comúnmente son los hijos e hijas de las trabajadoras. En este caso se da una doble explotación de las jefas hacia sus trabajadoras y de estas con sus hijas e hijos. Ellos representan fuerza de trabajo que se suma al trabajo de sus madres sin ningún tipo de remuneración ya que ésta es vista como "ayuda". Se trata de una explotación no premeditada, una forma social que adquiere la explotación de las mujeres en los talleres a su vez extendida a su familia. Es debido a esto que en el fondo el taller puede mantenerse, ya que compensan los bajos salarios con trabajo no remunerado, dándose una compleja cadena de explotación sin la cual este trabajo no sería posible.

Las jefas de los talleres son las encargadas de recibir las prendas, llamar a las trabajadoras, repartir el trabajo, supervisarlo llevando un registro minucioso de lo que se deshebra diariamente para poder realizar los pagos al final de la semana. Son también las responsables de las negociaciones de entrega con los intermediarios, así como de cualquier retraso o dificultad, ellas son quienes deben de dar la cara ante la maquila y el resto de las trabajadoras, estos aspectos hablan de su capacidad de gestión. Por otra parte, aun cuando permanecen en el espacio privado, éste se ve resquebrajado por los aspectos del trabajo productivo, donde se mantienen algunos estereotipos de género, al mismo tiempo que se modifican otros. Se trata de mujeres organizadoras de un trabajo informal, dependiente, inestable y precario. Su precariedad y vulnerabilidad radica en varios aspectos, por un lado, la merma de su seguridad social les da una sensación de pérdida, de retroceso en sus condiciones de trabajo. Saben que ganan salarios más bajos, trabajan más horas y que en el momento en que las maquilas dejen de existir ellas pierden su trabajo. El haber trabajado antes en la maquila es su referente diario con su situación actual, por lo que son conscientes de su vulnerabilidad, misma que se 
refrenda cuando una maquila cierra y se va sin pagarles lo que ellas han trabajado o cuando el nivel de producción de la maquila se reduce afectando el trabajo que se realiza en los talleres. Estos aspectos son descubiertos en la experiencia de la vida cotidiana que contradice sus aspiraciones iniciales de mejoría en su trabajo y de conciliación de éste con sus obligaciones familiares.

El trabajo a domicilio sigue manteniendo características del pasado, pero debe ser entendido en un contexto de creciente flexibilidad, revitalizado a partir de empresas globalizadas que forman parte de las cadenas de producción de ropa. Se trata de un nuevo contexto de explotación, donde los talleres domiciliarios son los más vulnerables a los cambios del mercado. Es así que compartimos la idea de que la subcontratación se caracteriza más por las condiciones de precariedad que por sus efectos positivos como la transferencia de tecnología. En este tipo de trabajo responde a da es un mercado voraz que busca la reducción de costos.

En este sentido habría que decir que si bien el trabajo domiciliario es el resultado de estrategias empresariales que buscan reducir costos de producción, estos espacios son redefinidos por los propios sujetos sociales, en particular por las mujeres, que se convierten en sus "promotoras" y al mismo tiempo en sus "víctimas", donde creemos que son también las jefas de los talleres quienes juegan un papel crucial en la búsqueda de alternativas que respondan a sus necesidades cotidianas y como respuesta a la lógica del mercado global agudizada por la crisis.

Las mujeres son a su vez sujetas activas que ponen en práctica sus capacidades para el trabajo y actúan aún dentro de estos contextos de pobreza, ya que consideramos que siempre hay un espacio para la acción de los sujetos y sus capacidades. Éstas se expresan en la capacidad de poner en práctica lo aprendido en la maquila, pero en sus propias casas, como organizadoras de un trabajo que llevan a cabo, con las dificultades que ello representa, todos los días. A veces modificando algunos patrones culturales y otras conviviendo con ellos, pero en constante conflicto y tensión. Un ejemplo de ello son los conflictos familiares por el proceso de negociación de los talleres en el espacio doméstico y los efectos que tienen en el cambio y reforzamiento de los roles de género, donde defienden no solamente su necesidad por el trabajo, sino también la idea de sentirse útiles. 
Aunque muchas de ellas creen que los talleres son la forma ideal de "conciliar" sus mundos productivo y reproductivo, con el paso del tiempo se convencen de que el aspecto espacial no resuelve los conflictos y tensiones, sino que, en algunas ocasiones los acentúa y modifica. Tal como lo señalan las perspectivas que tratan este tema, la mayoría de los casos no se reduce o facilita la jornada de trabajo, sino que se redistribuye de acuerdo con las necesidades de la empresa lo que normalmente significa una organización del tiempo que repercute negativamente en la vida de las personas, especialmente de las mujeres.

El análisis de los relatos de las trabajadoras nos permitió identificar varios aspectos significativos de la vida laboral y familiar de estas mujeres, asimismo se acuñaron proto conceptos que dejo apuntados y que podrían ser trabajados y profundizados en una investigación posterior. Éstos nos facilitaron nombrar dichos eventos señalando sus propiedades dimensiones, acciones, percepciones, características, interacciones y consecuencias. Algunos aspectos que encontramos al analizar la información nos llevaron a organizar los resultados en cuatro claves analíticas: la formación del taller subcontratado a domicilio: el autoempleo precario, el mundo de lo productivo en el espacio doméstico, la volatidad y vulnerabilidad del trabajo a domicilio y la simultaneidad del trabajo: el mundo de la familia y del trabajo en un mismo espacio. Consideramos que podrían ser la base para iniciar una discusión más amplia sobre la vida cotidiana de las mujeres en los nuevos espacios globalizados.

A partir de la lectura de estos proto conceptos, señalamos las razones para formar los talleres de deshebrado, así como las redes de subcontratación que se tejen en torno a él, las dinámicas laboral y familiar de estas mujeres, están relacionadas entre sí en su vida cotidiana, esto implicó entender la relación de mutua reciprocidad de estas claves.

También se puso al descubierto que en la búsqueda de conciliar trabajo y familia, tratan de incorporar su trabajo productivo en su espacio doméstico, pero el malestar no desaparece, sin embargo, comprenden que las exigencias no dejaran de existir trabajen en la maquila o desde sus casas. Se dan cuenta de que algunos aspectos son más fáciles de resolver desde su espacio doméstico ya que pueden construir y reconstruir a veces con éxito y otras en conflicto su dinámica laboral y familiar, donde en ocasiones la primera se impone la segunda y viceversa. 
Es un contexto que forma parte de la complejidad de la problemática que encaran las mujeres, sin importar si son profesionales, trabajadoras independientes u obreras. La diferencia con las trabajadoras subcontratadas a domicilio tiene que ver con sus condiciones laborales más precarias y sus necesidades mayores económicas. Lo que no impide la búsqueda constante de alternativas que ayuden a enfrentar su realidad de mujeres trabajadoras, madres y esposas con el valor que ellas mismas le confieren. 


\section{BIBLIOGRAFÍA}

Albizu, E. (1997), Flexibilidad Laboral y gestión de los recursos humanos, Barcelona, Ariel.

Alonso, Herrero, José Antonio, (1988a) "Crisis, sismos e industria doméstica", en Luisa Gabayet et al. (comps.), Mujeres y Sociedad. Salario, Hogar y Acción Social en el Occidente de México. México, El Colegio de Jalisco y CIESAS de Occidente, pp. 107-123.

-(1988b) "La maquila industrial domiciliaria en la metrópoli mexicana", en Estudios Sociológicos, México, El Colegio de México, vol. VI, n. 18, (septiembrediciembre), pp. 517-533.

- (1991a) "La industria domiciliaria del vestido en Tlaxcala. Una investigación exploratoria", en Acta Sociológica, México, UNAM, vol. IV, n.1 (enero-abril), pp. 47-61.

-(1991b) Mujeres maquiladoras y microindustria doméstica. México, D.F., Fontamara, Pp.180.

-(2002) Maquila domiciliaria y subcontratación en México en la era de la globalización neoliberal, México, D.F., Plaza y Valdés, Pp. 167.

-(2004) “El sistema dual ante la maquila en México ante la reciente globalización”, en Bajo el Volcán, año/vol. 4, núm. 007, BUAP, Puebla, México, Pp. 13-25.

Arias, Patricia (1998) “El trabajo femenino a domicilio ayer y hoy", en Sociológica, n. 37, año 13, (mayo-agosto), Pp. 77-97.

Arias, Patricia y Wilson Fiona (1997) La aguja y el surco: cambio regional, consumo y relaciones de género en la industria de la ropa en México. Universidad de Guadalajara, Pp. 297.

Balbo, Laura (1994) "La doble presencia", en Las mujeres y el trabajo. Rupturas conceptuales, Cristina Borderias, Cristina Carrasco y Carmen Alemany (Comp.), Barcelona, España, Edit. ICARIA, Pp. 503-513.

Barrios, Hernández Martín y Hernández, Santiago Rodrigo (2004) Tehuacán: del calzón de manta a los blue jeans, Comisión de Derechos Humanos y Laborales del Valle de Tehuacán, Red de Solidaridad de la Maquila (Canadá)

Benería, Lourdes y Roldán, Martha (1992). Las encrucijadas de clase y género. Trabajo a domicilio, subcontratación y dinámica de la unidad doméstica en la ciudad de México. D.F., México, El Colegio de México y el Fondo de Cultura Económica. Pp.222. 
Borderías, C., C. Carrasco, et al. (1994) “Las mujeres y el trabajo. Rupturas Conceptuales. Barcelona, España, ICARIA, Pp.556.

-(2003). La feminización de los estudios sobre el trabajo de las mujeres: España en el contexto internacional (1969-2002). Sociología del Trabajo, núm. 48, págs. 57124.

Bronstein, Arturo S. (1999) “La subcontratación laboral”, Costa Rica, OIT. Pp.24.

Carresquer, Pilar, Torns, Teresa, Tejero, Elisabet y Romero, Alfonso (1998) "El trabajo reproductivo" en Papers, Universidad autónoma de Barcelona, 55, Pp.95-114.

Cerrutti, Marcela (2002). "Trabajo, organización familiar y relaciones de género en Buenos Aires"., en Catalina Wainerman (comp.), Familia, trabajo y género. Un mundo de nuevas relaciones. Buenos Aires, Argentina, Fondo de Cultura Económica, pp. $105-225$.

De la Cuesta, Benjumea Carmen (2006) "La Teoría Fundamentada como herramienta de análisis”, en Teoría y Método, $2^{\circ}$ Semestre, Año X, No. 20. Pp. 136-140.

De la Garza, Enrique, et al (2005a) "La industria maquiladora de exportación en México, mitos, realidades y crisis”, Estudios Sociológicos, COLMEX, Pp.1-38.

De la Garza, Enrique (2005b) "Modelos de Producción en la Maquila de Exportación: La Crisis del Toyotismo Precario", en La Situación del Trabajo en México, 2006. Enrique De la Garza y Carlos Salas (Coord.), México, UAMI-Plaza y Valdés, Pp. 55-87.

De la O, María Eugenia (2006) “Transnacionales, trabajo y género” en México en Desacatos. Revista de Antropología Social CIESAS. Mujeres, trabajo y sindicatos en la globalización, mayo-agosto.

De la O, María Eugenia (2001) “Ciudad Juárez: un polo de crecimiento maquilador” en Quintero Cirila y De la O María Eugenia (Coord.) Globalización trabajo y maquilas: Las nuevas y viejas fronteras en México, México Friedrich Ebert Stiftung, CIESAS Plaza y Valdez Editores.

De Oliveira, Orlandina, Marcela Eternod y María de la Paz López (1999). "Familia y Género en el Análisis Sociodemográfico", en Brígida García (coord.), Mujer, género y población en México, México, El Colegio de México, Sociedad Mexicana de Demografía. pp. 211-271.

Díaz, Ximena y Yánez Sonia (1998). La proliferación del sistema de subcontrataciones en la industria del vestuario en Chile como fuente de la precarización del empleo femenino. Santiago de Chile, Centro de Estudios de la Mujer, Pp. 65. 
Echeverría, M.; V. Solís y V. Uribe-Echeverría (1998), El otro trabajo. El suministro de personas en las empresas, Santiago, chile, Dirección del Trabajo.

Echeverría Magdalena y Verónica Uribe (1998) “Condiciones de trabajo en sistema de subcontratación" (Chile: OIT)

García, Brígida, Mercedes Blanco y Edith Pacheco (1999). "Género y Trabajo”, en Brígida García (coord.), Mujer, género y población en México, México, El Colegio de México, Sociedad Mexicana de Demografía. pp. 273-316.

García, Brígida y De Oliveira Orlandina (2006). Las familias en el México metropolitano. Visiones femeninas y masculinas. El Colegio de México, Centro de Estudios Demográficos, Urbanos y Ambientales, Centro de Estudios Sociológicos. Cap. I, pp. 27-49.

Gereffi, Gary (2000) El tratado de libre comercio de América del Norte en la transformación de la industria del vestido: ¿bendición o castigo? Santiago, Chile: Naciones Unidas, CEPAL y División de Desarrollo Productivo y Empresarial, Pp. 1-55.

Guzmán, Virginia, et al (1999) Trayectorias Laborales de Mujeres. Cambios generacionales en el mercado de trabajo, Chile, Centro de Estudios de la Mujer.

Henríquez, Riquelme Helia (2005) “El Trabajo a Domicilio: una transformación que requiere afinar el diagnóstico" en Trabajo a Domicilio en el Siglo XXI. Tres miradas sobre el teletrabajo en Cuaderno de Investigación, No 26, Gobierno de Chile, Dirección del Trabajo y el Departamento de Estudios, Santiago, Chile, Pp. 5-30.

Hernández, De la Cruz Luis Alberto (2007) “La vida detrás de la fibra. Las Mujeres de la Maquila de confección del Valle de Tehuacán, Puebla. Hilvanando identidades” , UAM.

Iranzo, Consuelo y Leite, Marcia De Paula (2006) La subcontratación laboral en América Latina, en Teorías Sociales y Estudios del Trabajo: Nuevos Enfoques, Coord. Enrique de la Garza Toledo, Edit. Anthropos y UAM-I, México, D.F., Pp.268288.

Jelin, Elizabeth (1994). "Las familias en América Latina", en Familias. Siglo XXI, Santiago de Chile, Isis Internacional, pp. 75-106.

Juárez, Huberto (2004) “Allá...donde viven los más pobres”, México, BUAP, Universidad de Guadalajara, Universidad Obrera de México, Universidad Michoacana de San Nicolás de Hidalgo. 
Lindón, Alicia (1999) "Narrativas autobiográficas, memoria y mitos: una aproximación a la acción social”, Economía, Sociedad y Territorio, vol. II, num. 6, Pp. 295-310.

López, Estrada Silvia (2006) Trabajo, espacio y género. El trabajo femenino por cuenta propia a domicilio en Tijuana, en Camilo Contreras Delgado y Adolfo Benito Narváez Tijerina (Coord.), La experiencia de la ciudad y el trabajo como espacios de vida, México, COLEF, Plaza y Valdés y la Universidad Autónoma de Nuevo León, Pp.77-112.

Martínez de Ita, María (1993) El comportamiento de la industria textil en Puebla, en El proceso de reestructuración en México. Análisis de Ramas, BUAP.

Morales, Josefina (2000) "Maquila 2000”. El eslabón industrial. Cuatro imágenes de la maquila en México. Josefina Morales (Coord.), México, D.F. Nuestro Tiempo. Pp. 17-102

Neffa, J. C. (1985), “Condiciones y medio ambiente de trabajo y remuneraciones de los trabajadores precarios", en Reunión técnica sobre administración del trabajo precarizado del empleo, CIAT/OIT, Buenos Aires.

Partida, Rocha Raquel (2001) "Empleo flexible: El trabajo subcontratado en las agencias de colocación en Jalisco” en Región y Sociedad, julio-diciembre, Vol. XIII, núm. 22, Sonora, México, El Colegio de Sonora, Pp. 99-127.

Pedrero, Nieto Mercedes (2000) La clasificación de la situación en el trabajo y los estudios de mercados de trabajo: el caso de los trabajadores a domicilio. en Estudios Demográficos y Urbanos, n.3, Vol. 15, (septiembre-diciembre), Pp. 583-612.

Pujadas J. Joan (2000) "El método biográfico y los géneros de la memoria" Revista de Antropología Social, No. 9, España, Pp. 127-158.

Quintero, Cirila y De la O, María Eugenia (2001) Globalización, trabajo y maquilas: Las nuevas y viejas fronteras en México, México Friedrich Ebert Stiftung, CIESAS Plaza y Valdez Editores.

Rivas, Ana María (2006) "El empleo o la vida: Perder el empleo para conservar la vida o renunciar a la vida para conservar el empleo ¿De qué conciliación hablamos?” en Revista Antropológica Iberoamericana, Ed. Electrónica, Madrid, España, Vol. 1, No. 3, Agosto-Diciembre, Pp.367-374.

Rossignotti, Giovanna (2001) "Género, Trabajo a domicilio y Acción Sindical en América Latina. OIT, Pp.19. 
Strauss, Anselm y Corbin, Juliet (2002) "Bases de la Investigación Cualitativa. Técnicas y procedimientos para desarrollar la teoría fundamentada", Universidad de Antioquia, Facultad de Enfermería, Medellín, Colombia. P. 341.

Torns, Martín Teresa (2005) “De la imposible conciliación a los permanentes malos arreglos” en Cuadernos de relaciones laborales, Universidad Autónoma de Barcelona, 23, No. 1, Pp.15-33.

Treviño, Siller Sandra (1988), "Reflexiones sobre el trabajo a domicilio en la zona noreste de Guanajuato", en Estudios Sociológicos, vol. VI, n. 18 (septiembre- diciembre), pp.583-602. 


\section{$\underline{\text { ANEXO } 1}$}

Cuestionario para jefas y jefes de taller domiciliario Cuestionario para trabajadoras subcontratadas

Tarjeta de períodos de inactividad

Guía de entrevista para jefas de taller domiciliario

Guía de entrevista para trabajadoras subcontratadas 


\title{
Universidad Autónoma Metropolitana Unidad Iztapalapa
}

No. De Cuestionario

\begin{abstract}
Cuestionario de datos sociodemográficos, datos socioeconómicos, trayectoria laboral y redes de subcontratación, para jefas/jefes de taller domiciliario de la industria maquiladora de confección de ropa en Tehuacán, Puebla.
\end{abstract}

\section{DATOS GENERALES}

01. Nombre

02. Domicilio completo

Municipio Ciudad Barrio

03. Fecha de la entrevista (d/m/a)

\section{ANTECEDENTES FAMILIARES}

04. Quisiera hacerle algunas preguntas sobre sus padres. Vamos a empezar con su madre. ¿Qué estudios tiene o tenía su madre? (Señale el último grado que aprobó en la opción correspondiente).

1. Sin instrucción 2. Primaria 3. Secundaria 4. Estudios técnicos

5. Otros estudios (especificar) 6. NS/NA NS:especificar porque no sabe la información NA: madre ausente o desconocida

05. A qué se dedicaba su madre cuando ud. Tenía 12 años aproximadamente (permitir que el entrevistado de la respuesta sin leerle las opciones)

1. Trabajaba (especificar en qué)

2. actividades del hogar

2. Otro tipo de actividades 4. Otro tipo de actividades

06. Ahora le voy a preguntar los mismos datos sobre su papá.

¿Qué estudios tiene o tenía su padre? (Señale el último grado que aprobó en la opción correspondiente).

2. Sin instrucción 2. Primaria 3. Secundaria

6. Otros estudios (especificar) 6. NS/NA 4. Estudios técnicos NS:especificar porque no sabe la información NA: madre ausente o desconocida

07. A qué se dedicaba su padre cuando ud. tenía 12 años aproximadamente (permitir que el entrevistado de la respuesta sin leerle las opciones)

3. Trabajaba (especificar en qué)

2. actividades del hogar

4. Otro tipo de actividades 4. Otro tipo de actividades

\section{DATOS SOCIODEMOGRÁFICOS}

08. Fecha de nacimiento (mes/año)

09. Lugar de nacimiento País Ciudad Localidad

10. Escolaridad:

Sin estudios

Primaria completa

Primaria incompleta

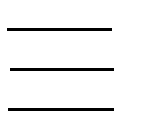

011. ¿Actualmente cuál es su estado civil? Soltera

Unida

Casada 
Secundaria completa Secundaria incompleta Técnicos

Otros

Separada

Divorciada

Viuda

12. ¿Cuál es la escolaridad de su esposo o pareja actual?

Sin estudios

Primaria completa

Primaria incompleta

Secundaria completa

Secundaria incompleta

Técnicos

Otros

13. Ha tenido hijos nacidos vivos Sí

No

¿Cuántos?

14. ¿Dígame las edades de cada uno de sus hijos del más chico al más grande?
a)
b)
d)
c)
e)
f)

15. ¿Actualmente cuántos hijos viven con usted?

16. ¿Además de sus hijos quién más vive en la familia?

a) Esposo/pareja

b) Padres

c) Hermanas/ Hermanos

d) Otros familiares

e) Otros no familiares

17. En su actual hogar usted es:

Hija de familia___Esposa/compañera Esposa-madre Otro, especifique

\section{DATOS ECONÓMICOS}

18. ¿A cuánto ascienden sus ingresos mensuales?

19. ¿Otros miembros de la familia contribuyen al ingreso familiar? Sí ¿ No

20. ¿Quiénes son? $\quad$ 021. ¿Cuánto aporta cada uno? $\quad 022$. ¿Cuál es su ocupación?

\section{HISTORIA LABORAL}

023. Las siguientes preguntas se refieren a los diferentes trabajos remunerados de la entrevistada, desde que empezó a laborar hasta el trabajo actual o el último trabajo en el caso de estar desempleada actualmente. Empecemos por su primer trabajo: 
1. En qué trabajó de manera remunerada por primera vez en su vida.

Dígame cuáles son sus siguientes trabajos... repetir hasta llegar al actual.

2. Describa la actividad que realizaba

3. Durante cuánto tiempo trabajó en esta actividad.

4. Realizaba y realiza otro tipo de trabajo o actividad actualmente.

Los datos correspondientes a cada trabajo deberán ser puestos en el cuadro siguiente:

PRIMERA VUELTA

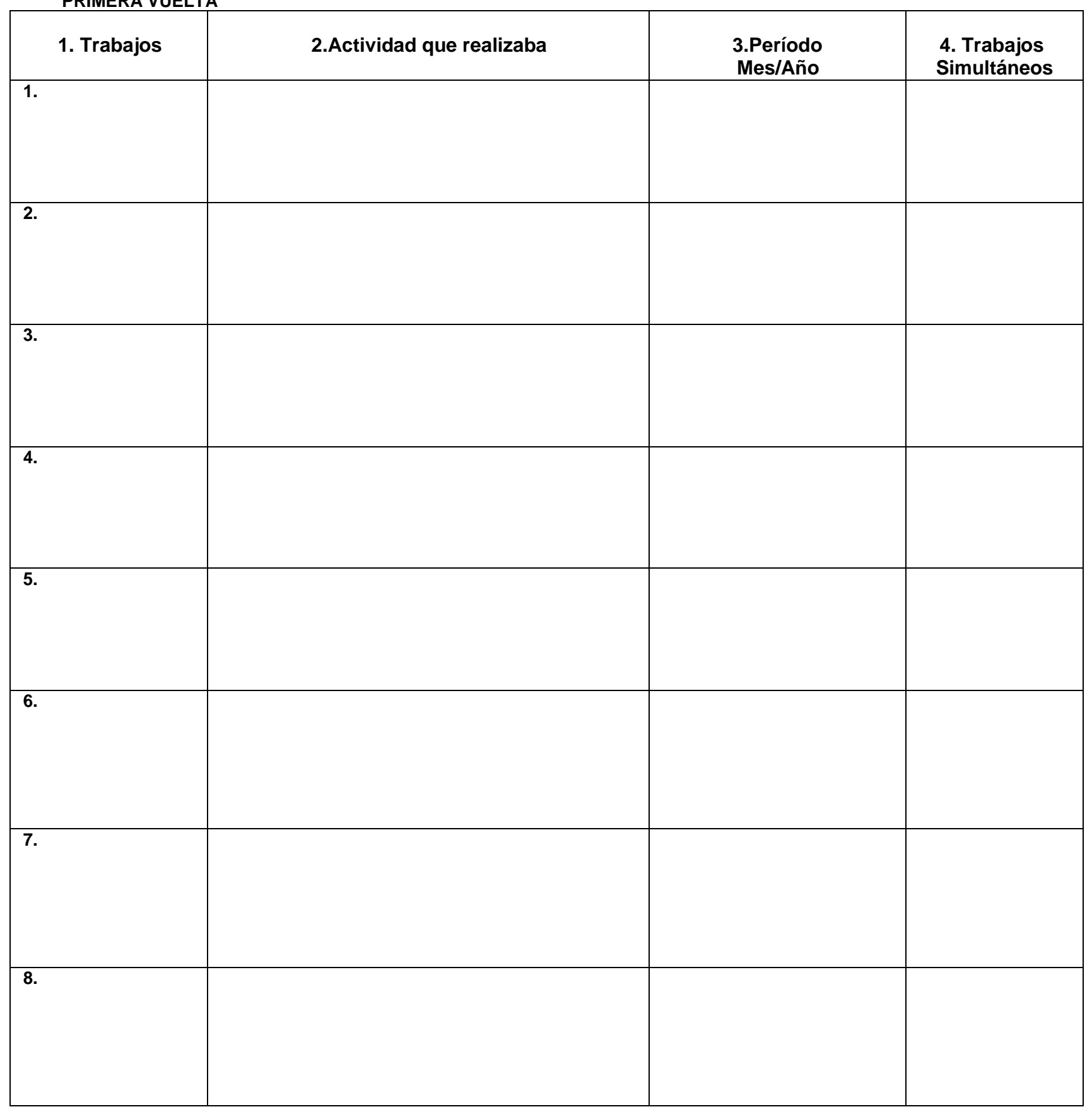




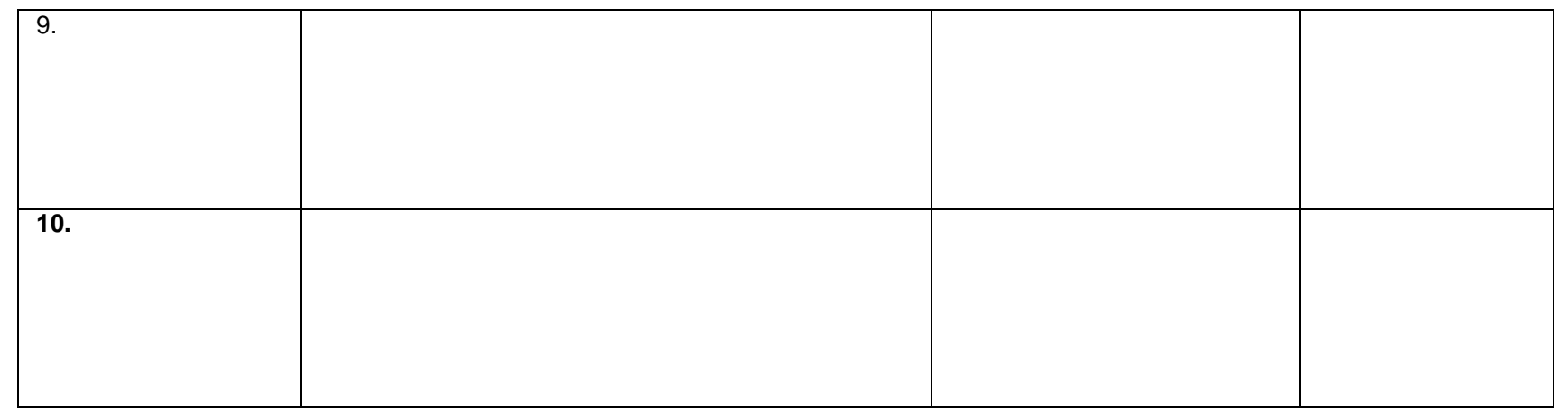

SEGUNDA VUELTA

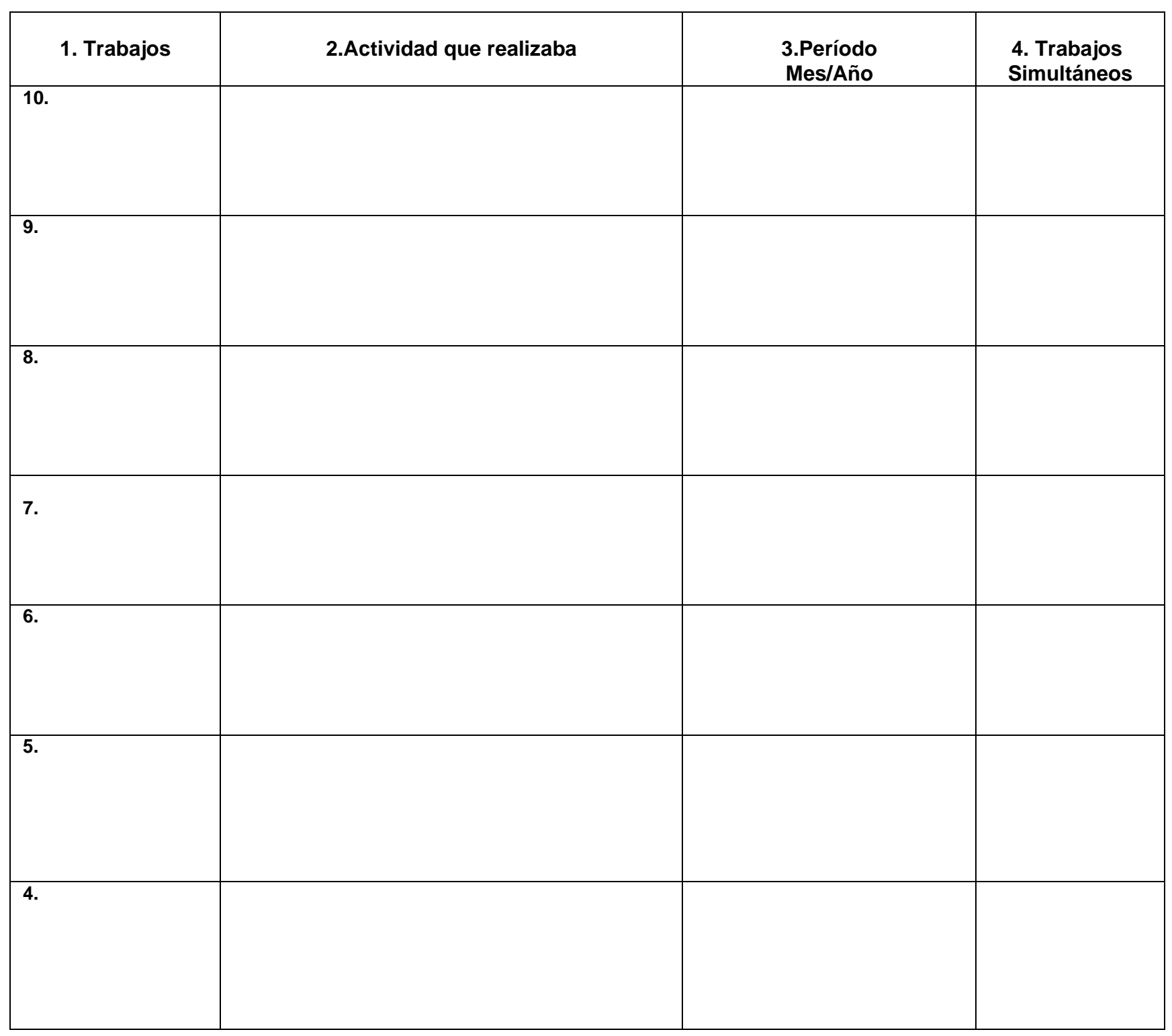




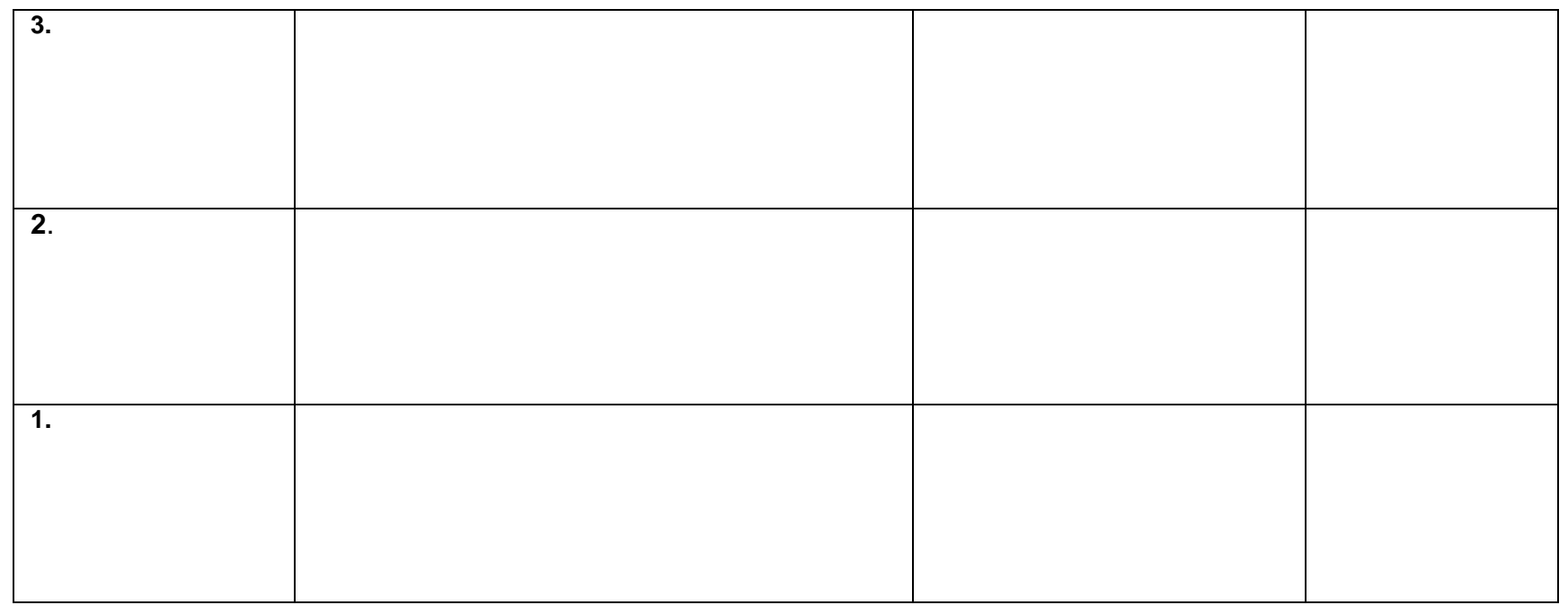

24. Le pediría que me proporcionara la siguiente información sobre sus tres últimos trabajos, empezando por su último trabajo

1. Nombre de la empresa

2. Cómo logró entrar a este trabajo (amigos, parientes, solicitud directa, etc.)

3. Porque eligió este trabajo

4. Porqué cambió de trabajo o le gustaría cambiar su actual trabajo

Los datos correspondientes a cada trabajo deberán ser puestos en el cuadro siguiente:

Historia Laboral 2

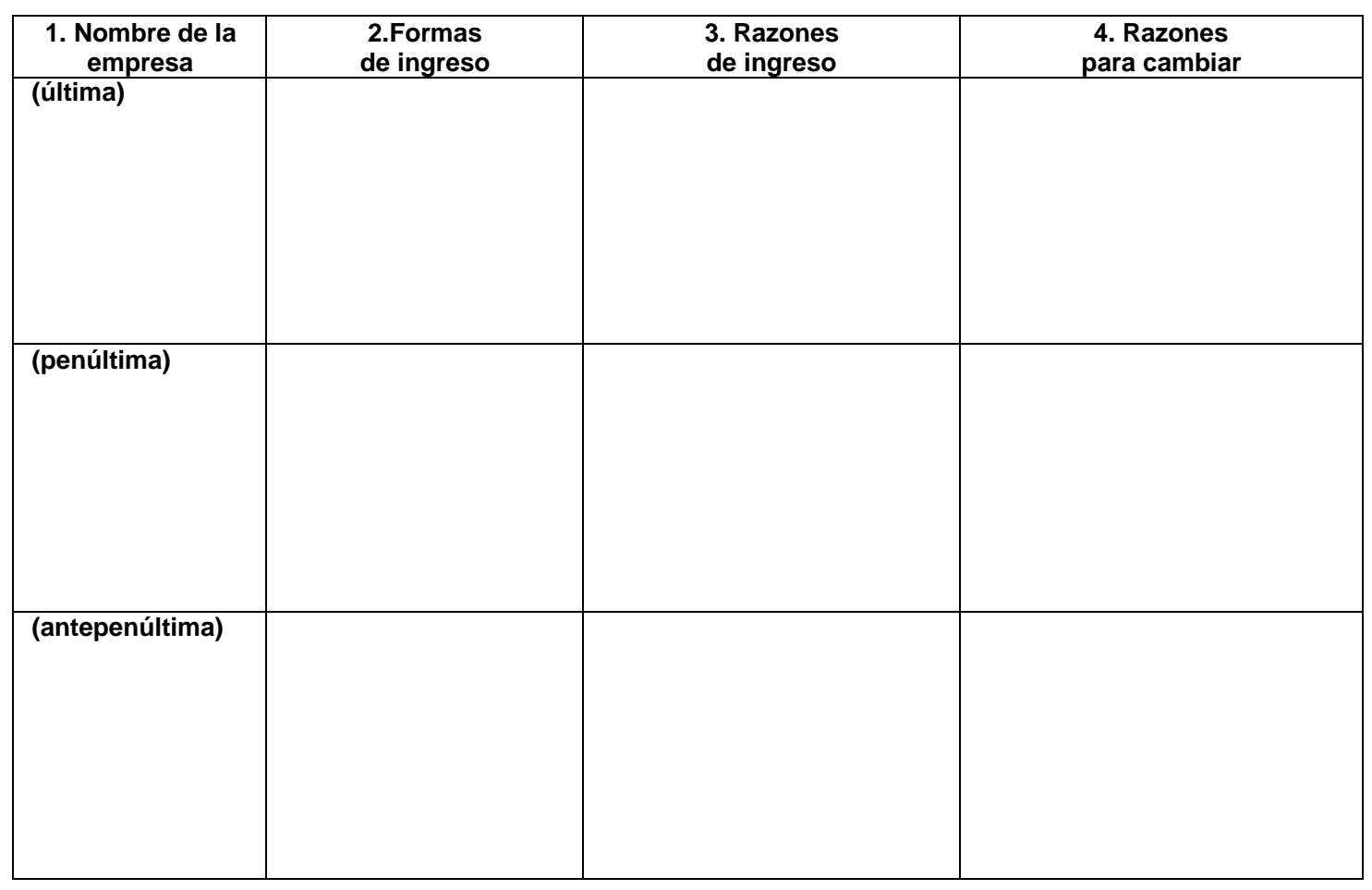




\section{REDES DE SUBCONTRATACIÓN}

25. Le pido que me proporcione la siguiente información con respecto a su actual trabajo.

\section{TALLER (JEFA)}

1. ¿Número de personas que trabajan en el taller?

2. ¿De estos cuántos son sus parientes? y ¿qué tipo de parentesco tienen con usted?

3. ¿Quiénes de ellos viven en su casa?

4. ¿Cuántas personas trabajan en el mismo espacio de su taller?

5. ¿Cuántas personas trabajan desde su propia casa?

6. ¿Por qué empresa ha sido contratada o subcontratada en los últimos tres años?

7. ¿Qué productos trabaja?

8. ¿Qué actividades realizaba?

Los datos correspondientes deberán ser puestos en el cuadro siguiente:

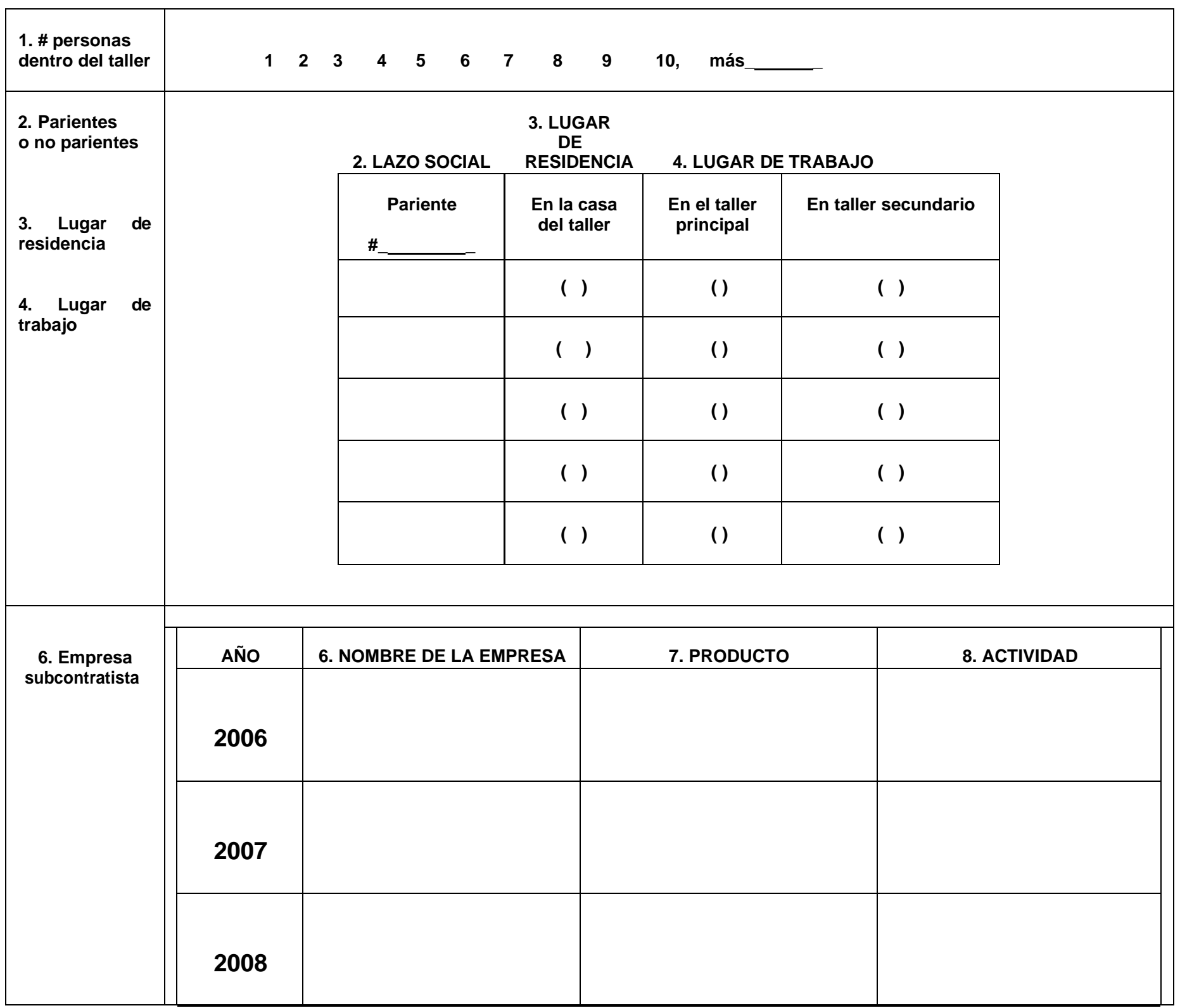




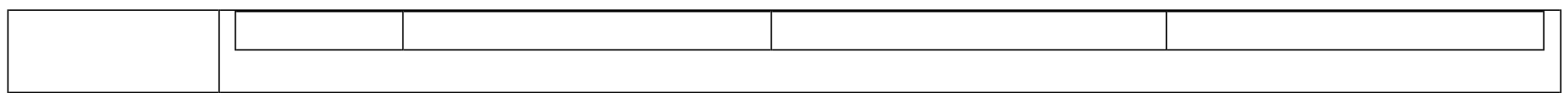

VII. HISTORIA MIGRATORIA

26. Enseguida le voy a solicitar información sobre los lugares y hogares en donde ha vivido.

Por favor dígame los lugares (ciudades) donde vivió desde su nacimiento y en los que haya permanecido por más de tres meses.

1. En qué localidad nació. En cuál vivió después (preguntar así sucesivamente).

2. Desde cuándo y hasta cuando vivió allí

3. Cuáles fueron las razones o motivos para cambiarse de esta localidad

\begin{tabular}{|l|l|l|}
\hline 1. Localidad & \multicolumn{1}{|c|}{$\begin{array}{c}\text { 2. Tiempo vivido allí } \\
\text { (mes y año) }\end{array}$} & $\begin{array}{c}\text { 3. Razones o motivos } \\
\text { del } \\
\text { cambio }\end{array}$ \\
\hline & $\begin{array}{l}\text { desde } \\
\text { hasta }\end{array}$ & \\
\hline & desde \\
hasta & desde \\
hasta & \\
\hline & desde & \\
hasta & \\
\hline & desde & \\
\hline hasta & \\
\hline
\end{tabular}

\section{APARTADO PARA TRABAJADORAS SUBCONTRATADAS}

\section{VI.I REDES DE SUBCONTRATACIÓN}

25. Le pido que me proporcione la siguiente información con respecto a su actual trabajo.

\section{TRABAJADORA SUBCONTRATADA}

1. ¿Tiene alguna relación de parentesco con la dueña del taller?

2. ¿Cuál?

3. ¿Quién la contacto o recomendó con la dueña del taller?

4. ¿Cuántas horas trabaja en el taller?

5. ¿Además de este realiza otros trabajos remunerados?

6. ¿Cuáles son?

7. Describa su actividad.

8. En promedio ¿cuánto gana en ese otro trabajo?

9. ¿Cuántas horas trabaja en promedio al día?

10. ¿Cuánto le pagan por pieza deshebrada? 
Los datos correspondientes deberán ser puestos en el cuadro siguiente:

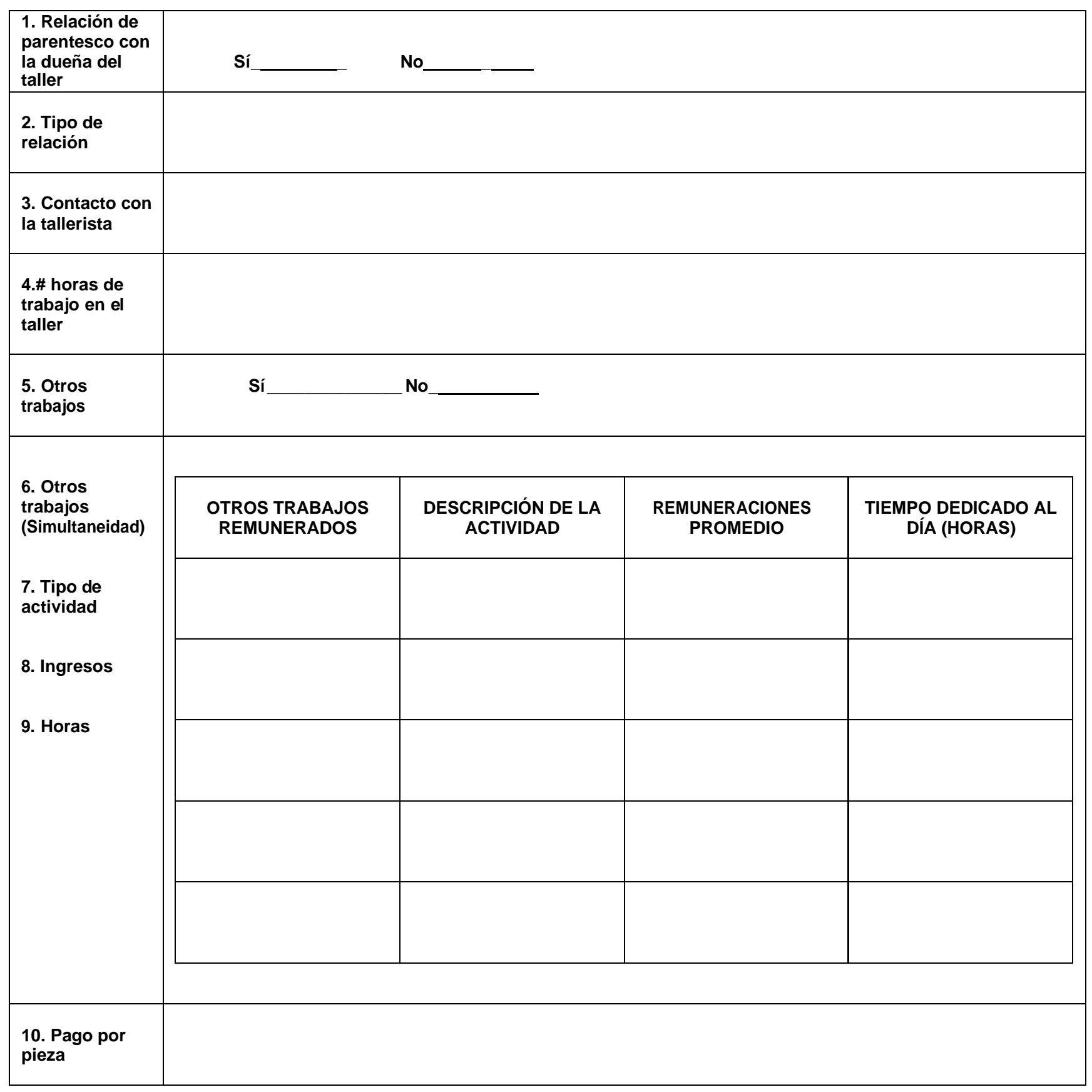


No. de entrevista

TARJETA DE PERÍODOS DE INACTIVIDAD

1. Tuvo períodos de inactividad desde su primer empleo, en qué momentos.

2. Cuáles fueron las razones o causas de la inactividad

\section{PERIODOS DE INACTIVIDAD}

2. CAUSAS Y RAZONES DE LA INACTIVIDAD

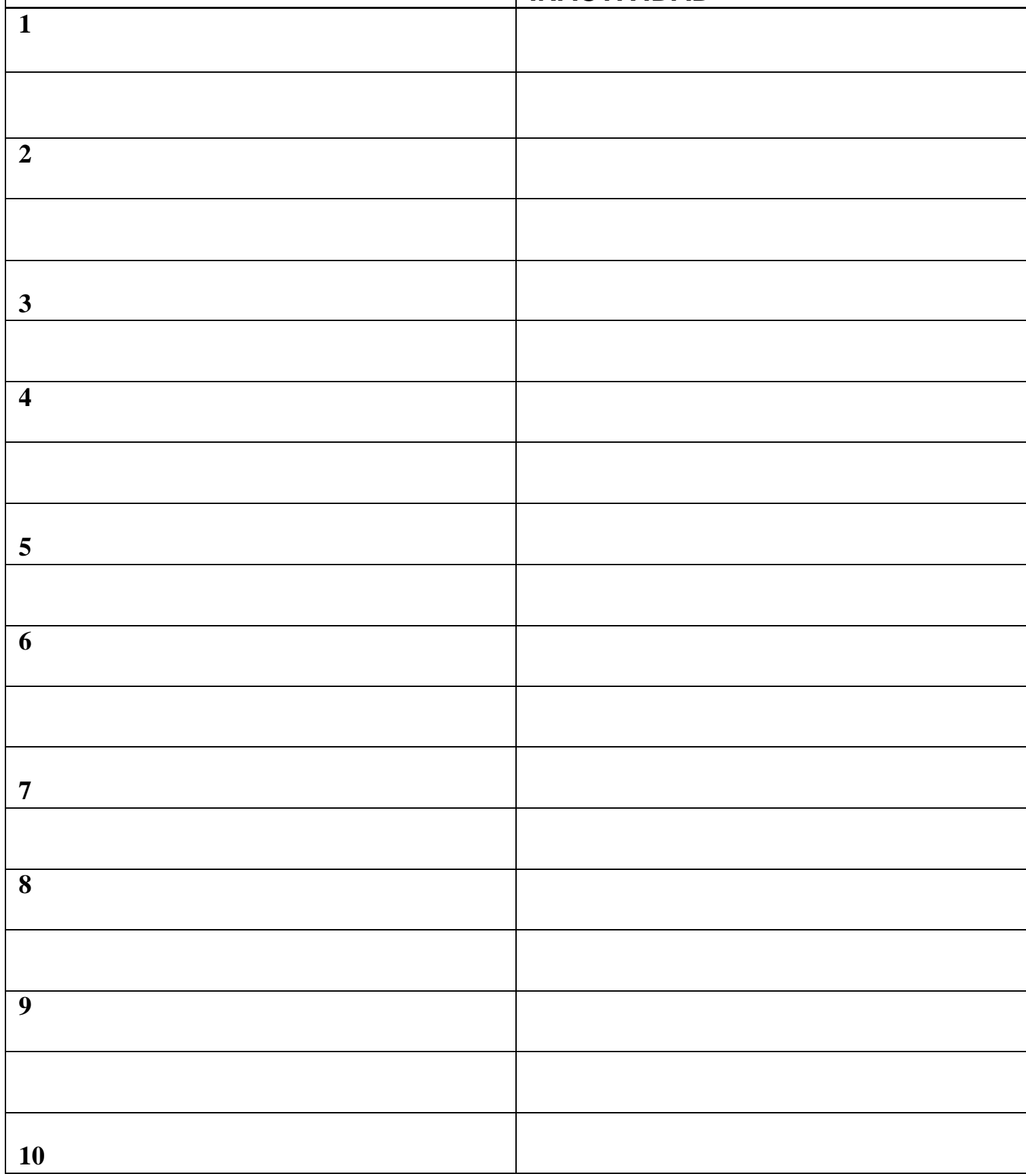




\section{GUIA DE ENTREVISTA A JEFAS DE TALLERES DOMICILIARIOS}

EL OBJETIVO DE ESTA ENTREVISTA ES OBTENER INFORMACIÓN SOBRE LA TRAYECTORIA LABORAL, SU DINÁMIFA FAMILIAR Y LABORAL, LAS REDES DE SUBCONTRATACIÓN Y SUS CONDICIONES LABORALES DE LAS JEFAS DE TALLERES A DOMICILIO DE LA INDUSTRIA MAQUILADORA DE CONFECCIÓN DE ROPA EN TEHUACÁN, PUEBLA. LA INFORMACIÓN QUE NOS PROPORCIONE SERÁ ESTRICTAMENTE CONFIDENCIAL Y ANÓNIMA, Y SERA UTILIZADA EXCLUSIVAMENTE PARA FINES ACADÉMICOS.

FECHA ENTREVISTA:

INICIO ENTREVISTA:

FIN ENTREVISTA:

NOMBRE

DOMICILIO

\section{HISTORIA LABORAL}

\begin{tabular}{|c|c|c|c|}
\hline TEMA & PREGUNTAS BÁSICAS & COMPLEMENTARIAS & OBSERVACIONES \\
\hline $\begin{array}{l}\text { 1. Entradas y } \\
\text { salidas del } \\
\text { mercado de } \\
\text { trabajo }\end{array}$ & $\begin{array}{l}\text { Antes de trabajar en el deshebrado ¿realizó otro tipo de } \\
\text { trabajo?, ¿A qué edad comenzó a trabajar?, ¿Cuáles } \\
\text { fueron sus primeros trabajos?, ¿Cómo fueron sus } \\
\text { primeros trabajos?, ¿Cuál fue la primera actividad que } \\
\text { realizo?, ¿Cuánto duro? ¿Cuál fue su primer trabajo } \\
\text { formal o remunerado? ¿En qué año?, ¿Qué tareas } \\
\text { desempeñaba en ellos? (empleada, obrera, trabajadora } \\
\text { por cuenta propia o ayudante familiar) ¿Cómo los } \\
\text { consiguió? ¿Por qué los dejó? }\end{array}$ & $\begin{array}{l}\text { ¿Por qué ingreso? Y ¿Por } \\
\text { qué salio? (Repetir las } \\
\text { preguntas durante la } \\
\text { narración de su historia } \\
\text { laboral a cada uno de sus } \\
\text { trabajos) }\end{array}$ & Indagar la trayectoria laboral \\
\hline $\begin{array}{l}2 . \text { Otras } \\
\text { actividades } \\
\text { remuneradas } \\
\text { actuales }\end{array}$ & $\begin{array}{l}\text { Además de trabajar en el deshebrado, actualmente ¿ha } \\
\text { tenido otra ocupación por las que recibe ingresos? ¿Qué } \\
\text { tipo de actividades son?, ¿Están relacionadas de alguna } \\
\text { manera con la maquila? ¿Por qué se dedica a estas } \\
\text { actividades?, ¿El hecho de dedicarse a estas actividades }\end{array}$ & $\begin{array}{l}\text { ¿Quién la impulsó a } \\
\text { dedicarse } \quad \text { a } \quad \text { estas } \\
\text { actividades? } \\
\text { cuándo las realiza? }\end{array}$ & $\begin{array}{l}\text { Indagar sobre doble jornada } \\
\text { Simultaneidad de trabajo }\end{array}$ \\
\hline
\end{tabular}




\begin{tabular}{|c|c|c|c|}
\hline TEMA & PREGUNTAS BÁSICAS & COMPLEMENTARIAS & OBSERVACIONES \\
\hline & $\begin{array}{l}\text { le ha credo conflictos en su casa? ¿Qué tipo de conflictos? } \\
\text { ¿Cuánto tiempo les dedica a estas actividades? ¿Su } \\
\text { trabajo en el deshebrado le ha creado problemas? } \\
\text { ¿Cuáles? ¿Qué le gusta más: su trabajo en el deshebrado } \\
\text { o estas otras actividades? ¿Por qué? }\end{array}$ & ¿En dónde las realiza? & \\
\hline $\begin{array}{l}\text { 3. Razones } \\
\text { para trabajar } \\
\text { o dejar de } \\
\text { trabajar }\end{array}$ & $\begin{array}{l}\text { ¿A usted le gustaría trabajar fuera de casa?, ¿Por qué } \\
\text { quiso trabajar en su casa?, ¿Cuáles fueron las razones } \\
\text { más importantes que la hicieron decidir trabajar dentro } \\
\text { de su casa y no fuera de ella?, ¿Por qué eligió este } \\
\text { trabajo?, Si ha dejado de trabajar, ¿por qué lo hizo?, } \\
\text { ¿Preferiría no trabajar y ser "ama de casa" de tiempo } \\
\text { completo? ¿Por qué? }\end{array}$ & $\begin{array}{l}\text { ¿Quién le ayudó a } \\
\text { conseguir trabajo? ¿Le } \\
\text { gusta o le disgusta el tipo } \\
\text { de trabajos que realiza o ha } \\
\text { realizado? }\end{array}$ & $\begin{array}{l}\text { Indagar sobre las preferencias } \\
\text { ocupacionales de ellas. }\end{array}$ \\
\hline
\end{tabular}

\section{HISTORIA DEL TALLER}

\begin{tabular}{|c|c|c|c|}
\hline TEMA & PREGUNTAS BASICAS & COMPLEMENTARIAS & OBERVACIONES \\
\hline $\begin{array}{l}\text { 1) MOTIVACIONES } \\
\text { PARA LA } \\
\text { CREACIÓN DEL } \\
\text { TALLER } \\
\text { DOMICILIARIO }\end{array}$ & $\begin{array}{l}\text { ¿Cómo surge la idea de poner un taller?, ¿Qué la } \\
\text { motivo?, ¿Quién le ayudo?, ¿Entre quiénes lo } \\
\text { organizaron?, ¿Con cuánto comenzó su producción y } \\
\text { cuánto tardo en convertirse en lo que actualmente es?, } \\
\text { ¿Han participado familiares?, ¿Qué tipo de personas han } \\
\text { participado en el taller? }\end{array}$ & $\begin{array}{l}\text { ¿Cuál fue la razón } \\
\text { principal para poner el } \\
\text { taller?, ¿Se asocio con } \\
\text { alguien?, }\end{array}$ & \\
\hline $\begin{array}{l}\text { 2)TRABAJADORAS } \\
\text { SUBCONTRATADAS }\end{array}$ & $\begin{array}{l}\text { ¿Cuándo comenzaron a darle trabajo a otras personas?, } \\
\text { ¿las ve como a sus colaboradoras, como sus empleadas } \\
\text { o ayudantes?, ¿qué son para ella?, } \\
\text { ¿cómo organiza su trabajo con las personas que le } \\
\text { ayudan?, ¿cómo se establecen las relaciones y que la } \\
\text { gente venga cuando tiene más trabajo?, ¿cómo } \\
\text { empezaron a establecer la relación con las personas } \\
\text { que le ayudan al deshebrado?, ¿qué tipo de acuerdos }\end{array}$ & $\begin{array}{l}\text { ¿Con cuántas personas } \\
\text { empezó? } \\
\text { Por lo común ¿qué tipo de } \\
\text { personas se emplean con } \\
\text { usted? }\end{array}$ & $\begin{array}{l}\text { Profundizar en las redes de } \\
\text { subcontratación. }\end{array}$ \\
\hline
\end{tabular}




\begin{tabular}{|c|c|c|c|}
\hline & $\begin{array}{l}\text { tienen?, ¿pueden venir y trabajar cuando quieran?, si } \\
\text { no vienen cuando usted las llama ¿qué es lo que hace?, } \\
\text { ¿hay muchas personas disponibles?, ¿Con cuántas } \\
\text { trabajadoras cuenta actualmente dentro y fuera del } \\
\text { taller?, ¿Cómo se reparten el trabajo?, ¿De qué manera } \\
\text { desempeñan su trabajo?, ¿Cómo están organizadas?, } \\
\text { ¿Cuáles son los problemas en la organización del trabajo } \\
\text { con sus trabajadoras?, ¿Cómo lo resuelve?, ¿Qué tipo } \\
\text { de relación tiene con sus empleadas?, ¿Son familiares, } \\
\text { vecinas o amigas?, ¿Su relación con sus trabajadoras es } \\
\text { exclusivamente laboral?, ¿De qué otro tipo?, ¿sus } \\
\text { trabajadoras le ayudan de alguna otra manera, por } \\
\text { ejemplo en el } \\
\text { trabajo doméstico del taller?, ¿Ha tenido algún tipo de } \\
\text { conflicto con ellas?, ¿Cómo lo soluciono? }\end{array}$ & & \\
\hline $\begin{array}{l}\text { 3) } \\
\text { CARACTERISTICAS } \\
\text { DEL TRABAJO } \\
\text { PRODUCTIVO }\end{array}$ & $\begin{array}{l}\text { ¿Considera su trabajo como pesado?, ¿Cree que es muy } \\
\text { laborioso? ¿La cansa?, ¿De qué manera?, ¿De qué } \\
\text { depende el tiempo que le dedica a su trabajo? ¿Tiene } \\
\text { algún horario? ¿Siempre es igual o varía? Siente que } \\
\text { trabaja jornadas muy largas y agotadoras o que el } \\
\text { tiempo se le va muy rápido y sin demasiado esfuerzo, } \\
\text { ¿En dónde aprendió el trabajo que realiza? Hábleme de } \\
\text { las actividades que realiza en su trabajo, ¿Con qué tipo } \\
\text { de herramientas o máquinas cuenta?, Considera que su } \\
\text { pago es justo o inferior al que debería recibir, } \\
\text { ¿Por qué?, ¿Para quién trabaja? ¿Tiene una buena } \\
\text { relación? ¿Tiene problemas a la hora de la paga?, } \\
\text { ¿Recibe algún tipo de ayuda por parte de los miembros } \\
\text { de su familia? ¿Quiénes le ayudan en su trabajo? }\end{array}$ & & $\begin{array}{l}\text { Indagar sobre los aspectos } \\
\text { más relevantes de su trabajo } \\
\text { productivo, haciendo énfasis } \\
\text { en las condiciones y la } \\
\text { percepción que tiene del } \\
\text { trabajo que realiza. }\end{array}$ \\
\hline $\begin{array}{c}\text { 4)LOS } \\
\text { INTERMEDIARIOS }\end{array}$ & $\begin{array}{l}\text { ¿Cómo comenzó su relación con los intermediarios o con } \\
\text { los maquileros que le dan el trabajo del deshebrado?, } \\
\text { ¿Cómo es esa relación?, ¿Se lleva bien con ellos?, } \\
\text { ¿Con cuántos intermediarios tiene } \\
\text { contacto?, ¿Para quiénes trabaja?, ¿la producción es }\end{array}$ & $\begin{array}{l}\text { ¿Para quiénes ha } \\
\text { trabajado a lo largo de la } \\
\text { historia del taller? } \\
\text { ¿Alguien le ofreció el }\end{array}$ & \\
\hline
\end{tabular}




\begin{tabular}{|c|c|c|c|}
\hline $\begin{array}{l}\text { 4.1) RELACIÓN } \\
\text { CON LOS } \\
\text { SUPERVISORES DE } \\
\text { LA MAQUILA }\end{array}$ & $\begin{array}{l}\text { nacional o de exportación? } \\
\text { ¿Ha tenido algún tipo de problema como de pagos?, } \\
\text { ¿Quiénes son?, ¿cómo es su relación?, ¿qué conflictos } \\
\text { tiene con esa persona?, ¿si el trabajo lo revisan enfrente } \\
\text { de ella?, ¿si se lo devuelven o se lo cobran cuando no } \\
\text { está bien deshebrado? }\end{array}$ & $\begin{array}{l}\text { trabajo?, } \\
\text { ¿Cómo lo soluciono? }\end{array}$ & \\
\hline $\begin{array}{l}\text { 5) HACINAMIENTO } \\
\text { Y DISTRIBUCIÓN } \\
\text { DOMÉSTICA }\end{array}$ & $\begin{array}{l}\text { Cuando comenzó a trabajar ¿cómo distribuyo el espacio } \\
\text { de su casa para poder hacerlo? y ¿Cómo lo hace } \\
\text { actualmente? ¿Le ha causado problemas la distribución } \\
\text { del material con sus muebles domésticos? } \\
\text { ¿De qué tipo? ¿El material es estorboso? ¿Cómo realiza } \\
\text { las labores domésticas desde que comenzó a trabajar? } \\
\text { ¿Cambio de alguna manera? ¿Cómo es el lugar en el que } \\
\text { realiza sus actividades? ¿Lo acondiciono de alguna } \\
\text { manera? }\end{array}$ & & $\begin{array}{l}\text { Indagar sobre como esta } \\
\text { repartido el espacio, buscando } \\
\text { encontrar de qué formas } \\
\text { espaciales se puede estudiar } \\
\text { el empalme que existe entre } \\
\text { el trabajo doméstico y el } \\
\text { deshebrado. Tienen un lugar } \\
\text { determinado para cada cosa o } \\
\text { cómo se encuentran } \\
\text { repartidos los } \\
\text { muebles. }\end{array}$ \\
\hline
\end{tabular}

\section{II.I DISTRIBUCIÓN DE LOS INGRESOS Y GASTOS DEL TALLER.}

\begin{tabular}{|c|c|c|c|}
\hline TEMA & PREGUNTAS BÁSICAS & COMPLEMENTARIAS & OBSERVACIONES \\
\hline $\begin{array}{c}\text { 1) } \\
\text { Distribución } \\
\text { de los } \\
\text { ingresos }\end{array}$ & $\begin{array}{l}\text { ¿Con cuánto contribuye usted a la manutención de su } \\
\text { casa? ¿Considera que su ingreso es sólo } \\
\text { complementario?, ¿Quiénes más y con cuánto } \\
\text { contribuyen para la manutención de la casa? ¿Considera } \\
\text { que es suficiente?, ¿Usted sabe cuánto ganan los otros?, } \\
\text { ¿Los demás saben cuánto gana usted?, ¿Cómo utiliza } \\
\text { usted sus ingresos?, ¿Quién decide como gastarlo o } \\
\text { ahorrarlo?, ¿Qué dificultades le ha traído el manejo del } \\
\text { dinero en la casa? ¿Cómo las ha resuelto?, ¿Se reparten } \\
\text { el ingreso entre sus familiares?, ¿Tiene algún problema } \\
\text { para que le paguen a tiempo? }\end{array}$ & $\begin{array}{l}\text { ¿Qué necesidades } \\
\text { familiares cubre con el } \\
\text { dinero que le da su pareja? } \\
\text { ¿Usted sabe qué hace él } \\
\text { con el dinero que gana? } \\
\text { ¿Cada cuándo le da usted } \\
\text { para el gasto? Si ha tenido } \\
\text { dificultades con el dinero } \\
\text { ¿Cómo las ha resuelto? }\end{array}$ & $\begin{array}{l}\text { Indagar sobre las formas de } \\
\text { distribución de los aportes al } \\
\text { ingreso de los diferentes } \\
\text { miembros del hogar. En caso de } \\
\text { las no unidas hacer referencia a } \\
\text { los otros miembros que aportan } \\
\text { (hijos, padres, otros familiares, } \\
\text { otros no familiares). }\end{array}$ \\
\hline
\end{tabular}




\begin{tabular}{|c|l|l|l|}
\hline TEMA & \multicolumn{1}{|c|}{ PREGUNTAS BÁSICAS } & \multicolumn{1}{|c|}{ COMPLEMENTARIAS } & OBSERVACIONES \\
\hline 2) GASTOS & $\begin{array}{l}\text { ¿Cuánto gasta en luz y agua de su casa y del taller? } \\
\text { DEL TALLER casa es propia o rentada? ¿Reinvierte sus } \\
\text { ¿Sunancias en el taller? }\end{array}$ & $\begin{array}{l}\text { ¿Cuánto paga por la renta } \\
\text { de su casa? }\end{array}$ & \\
\hline
\end{tabular}

\section{LA RELACIÓN TRABAJO Y FAMILIA}

\section{DINÁMICA FAMILIAR Y LABORAL}

TEMA

1. Dinámica familiar antes del deshebrado

\section{Negociación con los}

3. Dinámica familiar y

laboral actualmente familiares

\section{PREGUNTAS BÁSICAS}

\section{COMPLEMENTARIAS}

¿Como era la dinámica familiar antes de que el ¿Qué hacía deshebrado se instalara dentro de su casa?, ¿qué hacía ¿cómo lo hacía? antes que ya no hace ahora?, ¿En qué aspectos cambio su dinámica familiar o la manera en que organizaba su vida familiar y laboral?

¿A qué conflictos se enfrentó para poder instalar el deshebrado en su casa?, ¿De qué tipo?, ¿Con quiénes? ¿Cómo fue la negociación con sus familiares?

¿Cuénteme cómo es un día de trabajo?, ¿Desarrolla algún ¿Platíqueme cómo es un tipo de rutina?, ¿Cómo desempeña sus actividades día de trabajo laborales y familiares?, ¿Quién o quiénes colaboran con actualmente? el trabajo doméstico y lo concerniente al trabajo del deshebrado?, ¿Cómo se dividen el trabajo entre sus familiares?, ¿Qué hacen su esposo e hijos en el taller?, ¿Qué hacen en la casa?, ¿Quién o quiénes lo deciden?, ¿Cuáles son los conflictos que esto le genera con su esposo e hijos?, ¿Cómo los resuelve?

¿Cuáles son los conflictos que esto le genera con otros familiares?

4. Impacto del ¿Qué problemas ha tenido en su hogar por trabajar en el Si vive con otros familiares trabajo en la dinámica deshebrado?, ¿Considera que al comenzar a trabajar en ¿qué opinan ellos de que su casa se intensifico de alguna manera el trabajo usted trabaje?

familiar doméstico? ¿Por qué?

Si tiene hijos ¿Usted cree que no atiende lo ¿Ha tenido problemas con suficientemente a sus hijos por dedicarse al trabajo del sus hijos por trabajar?

\section{OBSERVACIONES}

Indagar el impacto de la instalación del deshebrado en la dinámica familiar.

Indagar sobre las percepciones que tienen los miembros de su familia sobre su trabajo y las situaciones de conflicto que le ha generado al interior del hogar por dedicarse a esta 


\begin{tabular}{|c|c|c|c|}
\hline TEMA & PREGUNTAS BÁSICAS & COMPLEMENTARIAS & OBSERVACIONES \\
\hline & $\begin{array}{l}\text { taller?, ¿Por qué?, ¿Cree que este trabajo le ha ayudado } \\
\text { a resolver los problemas que enfrentaría si trabajara } \\
\text { fuera de casa?, ¿En qué aspectos?, ¿Preferiría dejarlo? } \\
\text { ¿Sus hijos qué opinan de su trabajo en el deshebrado? }\end{array}$ & ¿Cuáles? & ocupación. \\
\hline $\begin{array}{l}\text { 5. Conflictos en } \\
\text { la dinámica } \\
\text { familiar y } \\
\text { laboral }\end{array}$ & $\begin{array}{l}\text { ¿Es difícil compaginar su vida familiar y laboral?, ¿Por } \\
\text { qué?, ¿Cuáles son las dificultades o problemas de } \\
\text { trabajar en el deshebrado y de ser la dueña del taller?, } \\
\text { ¿Con quiénes son esos problemas?, ¿cómo los resuelve?, } \\
\text { ¿Cuáles son los beneficios de trabajar en el deshebrado?, } \\
\text { ¿Cuáles son los problemas?, Usted considera que cumple } \\
\text { con su papel de madre trabajadora, ¿Por qué?, ¿Usted } \\
\text { preferiría regresar a su } \\
\text { trabajo en la maquila o cambiar de trabajo? }\end{array}$ & & \\
\hline $\begin{array}{l}\text { 6. Ejercicio de } \\
\text { autoridad en la } \\
\text { familia. }\end{array}$ & $\begin{array}{l}\text { En su casa ¿cómo se toman las decisiones importantes? } \\
\text { ¿Quién decide qué? ¿Toma en cuenta la opinión de su } \\
\text { pareja? } \\
\text { ¿Él toma en cuenta la opinión de usted? }\end{array}$ & $\begin{array}{l}\text { ¿Quién es el (la) jefe (a) de } \\
\text { familia? ¿Sobre qué } \\
\text { aspectos de la vida en } \\
\text { familia decide usted? }\end{array}$ & $\begin{array}{l}\text { Las preguntas básicas se aplican } \\
\text { a los que están unidas, las } \\
\text { complementarias se aplican } \\
\text { a todos. }\end{array}$ \\
\hline $\begin{array}{l}\text { 7. Valoración } \\
\text { del trabajo } \\
\text { productivo }\end{array}$ & $\begin{array}{l}\text { En general ¿qué es para usted o qué representa el } \\
\text { trabajo del deshebrado en su vida? } \\
\text { ¿Qué ha logrado con su trabajo como deshebradora? } \\
\text { (Independencia, dinero, realización) } \\
\text { ¿Ha sido buena o mala su experiencia en el trabajo? } \\
\text { ¿Por qué? } \\
\text { Si se lo pidieran ¿Usted dedicaría más tiempo a su } \\
\text { trabajo que el que actualmente le dedica? ¿Por qué? }\end{array}$ & $\begin{array}{l}\text { ¿Qué le da su trabajo? ¿Le } \\
\text { permite comprarse las } \\
\text { cosas que usted necesita o } \\
\text { quiere? ¿Le permite ser } \\
\text { independiente de su marido } \\
\text { (compañero)? } \\
\text { ¿Trabaja porque le } \\
\text { satisface, porque le permite } \\
\text { ser útil? }\end{array}$ & $\begin{array}{l}\text { Indagar sobre la parte práctica } \\
\text { del trabajo en términos de } \\
\text { utilidad y satisfacción personal } \\
\text { con el trabajo, así como la } \\
\text { aceptación de malas condiciones } \\
\text { de trabajo. }\end{array}$ \\
\hline $\begin{array}{l}\text { 8. Significado } \\
\text { del trabajo en el } \\
\text { deshebrado }\end{array}$ & $\begin{array}{l}\text { ¿Qué cosas son las que le gustan más de su ocupación } \\
\text { y por qué le gustan? } \\
\text { ¿Qué cosas le disgustan más de su ocupación y por qué } \\
\text { no le gustan? } \\
\text { Si pudiera ¿cambiaría de ocupación? ¿Por qué? } \\
\text { ¿A qué le gustaría dedicarse? }\end{array}$ & & $\begin{array}{l}\text { Indagar sobre los distintos } \\
\text { significados que le dan a su } \\
\text { trabajo en el deshebrado. }\end{array}$ \\
\hline
\end{tabular}




\begin{tabular}{|l|l|c|c|}
\hline TEMA & \multicolumn{1}{|c|}{ PREGUNTAS BÁSICAS } & COMPLEMENTARIAS & OBSERVACIONES \\
\hline & $\begin{array}{l}\text { ¿Qué satisfacciones le ha proporcionado el trabajar en } \\
\text { el deshebrado? } \\
\text { ¿Se encuentra satisfecha con este trabajo?, ¿Piensa } \\
\text { seguir en este taller? }\end{array}$ & & \\
\hline
\end{tabular}

\section{GUIA DE ENTREVISTA A TRABAJADORAS SUBCONTRATADAS DE TALLERES DOMICILIARIOS}

EL OBJETIVO DE ESTA ENTREVISTA ES OBTENER INFORMACIÓN SOBRE LA TRAYECTORIA LABORAL, SU DINÁMIFA FAMILIAR Y LABORAL, LAS REDES DE SUBCONTRATACIÓN Y SUS CONDICIONES LABORALES DE LAS TRABAJADORAS SUBCONTRATADAS DE TALLERES A DOMICILIO DE LA INDUSTRIA MAQUILADORA DE CONFECCIÓN DE ROPA EN TEHUACÁN, PUEBLA. LA INFORMACIÓN QUE NOS PROPORCIONE SERÁ ESTRICTAMENTE CONFIDENCIAL Y ANÓNIMA, Y SERA UTILIZADA EXCLUSIVAMENTE PARA FINES ACADÉMICOS.

FECHA ENTREVISTA:

INICIO ENTREVISTA:

FIN ENTREVISTA:

NOMBRE

DOMICILIO

\section{HISTORIA LABORAL}


TEMA

\section{Entradas y salidas del \\ mercado de \\ trabajo}

2. Otras actividades

remuneradas actuales

3. Razones para trabajar

o dejar de trabajar

\section{PREGUNTAS BASICAS}

Antes de trabajar en el deshebrado ¿realizó otro tipo de trabajo?, ¿A qué edad comenzó a trabajar?, ¿Cuáles fueron sus primeros trabajos?, ¿Cómo fueron sus primeros trabajos?, ¿Cuál fue la primera actividad que realizo?, ¿Cuánto duro? ¿Cuál fue su primer trabajo formal o remunerado? ¿En qué año?, ¿Qué tareas desempeñaba en ellos? (empleada, obrera, trabajadora por cuenta propia o ayudante familiar) ¿Cómo los consiguió? ¿Por qué los dejó?

Además de trabajar en el deshebrado, actualmente

¿tiene otra ocupación por la que recibe ingresos? ¿Qué

tipo de actividades son?, ¿Están relacionadas de alguna manera con la maquila? ¿Por qué se dedica a estas actividades?, ¿El hecho de dedicarse a estas actividades le ha credo conflictos en su casa? ¿Qué tipo de conflictos? ¿Cuánto tiempo le dedica a estas actividades? ¿Su trabajo en el deshebrado le ha creado problemas? ¿Cuáles? ¿Qué le gusta más: su trabajo en el deshebrado o estas otras actividades? ¿Por qué?

¿Cuáles fueron las razones más importantes que la hicieron decidir trabajar en el deshebrado?, ¿Por qué trabaja en este taller y no en otros?, Si ha dejado de trabajar, ¿por qué lo hizo?, ¿Preferiría no trabajar y ser "ama de casa" de tiempo completo? ¿Por qué?

qué salió? (Repetir las

preguntas durante la

narración de su historia

laboral a cada uno de sus

trabajos)

\begin{tabular}{|c|c|}
\hline 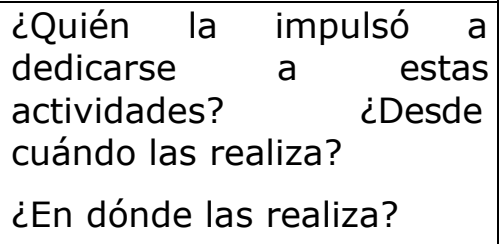 & $\begin{array}{l}\text { Indagar sobre doble jornada } \\
\text { Simultaneidad de trabajo }\end{array}$ \\
\hline $\begin{array}{l}\text { ¿Quién le ayudó a } \\
\text { conseguir este trabajo? } \\
\text { ¿Le gusta o le disgusta el } \\
\text { tipo de trabajos que } \\
\text { realiza o ha realizado? }\end{array}$ & $\begin{array}{l}\text { Indagar sobre las preferencias } \\
\text { ocupacionales de ellas. } \\
\text { (Identificar modelos } \\
\text { ocupacionales preferidos) }\end{array}$ \\
\hline
\end{tabular}

\section{EL TRABAJO DENTRO DEL TALLER}

\begin{tabular}{|c|c|c|c|}
\hline TEMA & PREGUNTAS BASICAS & COMPLEMENTARIAS & OBERVACIONES \\
\hline $\begin{array}{l}\text { 1. Características } \\
\text { del trabajo }\end{array}$ & $\begin{array}{l}\text { ¿Considera su trabajo como pesado?, ¿Cree que es } \\
\text { muy laborioso? ¿La cansa?, ¿De qué manera?, ¿De qué }\end{array}$ & & $\begin{array}{l}\text { Indagar sobre los aspectos } \\
\text { más relevantes de su trabajo }\end{array}$ \\
\hline
\end{tabular}




\begin{tabular}{|c|c|c|c|}
\hline productivo & $\begin{array}{l}\text { depende el tiempo que le dedica a su trabajo? ¿Tiene } \\
\text { algún horario? ¿Siempre es igual o varía? Siente que } \\
\text { trabaja jornadas muy largas y agotadoras o que el } \\
\text { tiempo se le va muy rápido y sin demasiado esfuerzo, } \\
\text { ¿En dónde aprendió el trabajo que realiza? Hábleme de } \\
\text { las actividades que realiza en su trabajo, ¿Considera que } \\
\text { su pago es justo o inferior al que debería recibir?, } \\
\text { ¿Por qué?, ¿Para quién trabaja?, ¿Recibe algún tipo de } \\
\text { ayuda por parte de los miembros de su familia? } \\
\text { ¿Quiénes le ayudan en su trabajo? }\end{array}$ & & $\begin{array}{l}\text { productivo, haciendo énfasis } \\
\text { en las condiciones y la } \\
\text { percepción que tiene del } \\
\text { trabajo que realiza. }\end{array}$ \\
\hline $\begin{array}{l}\text { 3. Distribución de } \\
\text { los ingresos }\end{array}$ & $\begin{array}{l}\text { ¿Con cuánto contribuye usted a la manutención de su } \\
\text { casa? ¿Considera que su ingreso es sólo } \\
\text { complementario?, ¿Quiénes más y con cuánto } \\
\text { contribuyen para la manutención de la casa? } \\
\text { ¿Considera que es suficiente?, ¿Cuánto le queda al final } \\
\text { de sus ingresos para sus gastos personales y } \\
\text { familiares?, ¿Usted sabe cuánto ganan los otros?, ¿Los } \\
\text { demás saben cuánto gana usted?, ¿Cómo utiliza usted } \\
\text { sus ingresos?, ¿Quién decide como gastarlo o } \\
\text { ahorrarlo?, ¿Qué dificultades le ha traído el manejo del } \\
\text { dinero en la casa? ¿Cómo las ha resuelto?, ¿Se } \\
\text { reparten el ingreso entre sus familiares?, ¿Tiene algún } \\
\text { problema para que le paguen a tiempo? }\end{array}$ & $\begin{array}{l}\text { ¿Qué necesidades } \\
\text { familiares cubre con el } \\
\text { dinero que le da su pareja? } \\
\text { ¿Usted sabe qué hace él } \\
\text { con el dinero que gana? } \\
\text { ¿Cada cuándo le da usted } \\
\text { para el gasto? Si ha tenido } \\
\text { dificultades con el dinero } \\
\text { ¿Cómo las ha resuelto? }\end{array}$ & $\begin{array}{l}\text { Indagar sobre las formas de } \\
\text { distribución de los aportes al } \\
\text { ingreso de los diferentes } \\
\text { miembros del hogar. En caso } \\
\text { de las no unidas hacer } \\
\text { referencia a los otros } \\
\text { miembros que aportan (hijos, } \\
\text { padres, otros familiares, otros } \\
\text { no familiares). }\end{array}$ \\
\hline
\end{tabular}




\section{LA RELACIÓN TRABAJO Y FAMILIA}

\section{DINÁMICA FAMILIAR Y LABORAL}

\begin{tabular}{|c|c|c|c|}
\hline TEMA & PREGUNTAS BÁSICAS & COMPLEMENTARIAS & OBSERVACIONES \\
\hline $\begin{array}{l}\text { 1. Dinámica } \\
\text { familiar antes } \\
\text { del deshebrado }\end{array}$ & $\begin{array}{l}\text { ¿Cómo era la dinámica familiar antes de que usted } \\
\text { trabajara en el deshebrado?, ¿qué hacía antes que ya no } \\
\text { hace ahora?, ¿En qué aspectos cambio su dinámica } \\
\text { familiar o la manera en que organizaba su vida familiar } \\
\text { y laboral? }\end{array}$ & $\begin{array}{l}\text { ¿Qué hacía antes? y } \\
\text { ¿cómo lo hacía? }\end{array}$ & $\begin{array}{l}\text { Indagar el impacto de la } \\
\text { instalación del deshebrado en la } \\
\text { dinámica familiar. }\end{array}$ \\
\hline $\begin{array}{l}\text { 2. Dinámica } \\
\text { familiar y } \\
\text { laboral } \\
\text { actualmente }\end{array}$ & $\begin{array}{l}\text { ¿Cuénteme cómo es un día de trabajo?, ¿Desarrolla algún } \\
\text { tipo de rutina?, ¿Cómo desempeña sus actividades } \\
\text { laborales y familiares?, ¿Quién o quiénes colaboran con } \\
\text { el trabajo doméstico y lo concerniente al trabajo del } \\
\text { deshebrado?, ¿Cómo se dividen el trabajo entre sus } \\
\text { familiares?, ¿Qué hacen su esposo e hijos en el taller?, } \\
\text { ¿Qué hacen en la casa?, ¿Quién o quiénes lo deciden?, } \\
\text { ¿Cuáles son los conflictos que esto le genera con su } \\
\text { esposo e hijos?, ¿Cómo los resuelve? }\end{array}$ & $\begin{array}{l}\text { ¿Platíqueme cómo es un } \\
\text { día de trabajo } \\
\text { actualmente? } \\
\text { ¿Cuáles son los conflictos } \\
\text { que esto le genera con } \\
\text { otros familiares? }\end{array}$ & \\
\hline $\begin{array}{l}\text { 3. Impacto del } \\
\text { trabajo en la } \\
\text { dinámica } \\
\text { familiar }\end{array}$ & $\begin{array}{l}\text { ¿Qué problemas ha tenido en su hogar por trabajar en el } \\
\text { deshebrado?, ¿Considera que al comenzar a trabajar en } \\
\text { su casa se intensifico de alguna manera el trabajo } \\
\text { doméstico? ¿Por qué? } \\
\text { Si tiene hijos ¿Usted cree que no atiende lo } \\
\text { suficientemente a sus hijos por dedicarse al trabajo del } \\
\text { taller?, ¿Por qué?, ¿Cree que este trabajo le ha ayudado } \\
\text { a resolver los problemas que enfrentaría si trabajara en } \\
\text { otra cosa, como en la maquila?, ¿En qué aspectos?, } \\
\text { ¿Preferiría dejarlo? ¿Sus hijos qué opinan de su trabajo } \\
\text { en el deshebrado? }\end{array}$ & $\begin{array}{l}\text { Si vive con otros familiares } \\
\text { ¿qué opinan ellos de que } \\
\text { usted trabaje? } \\
\text { ¿Ha tenido problemas con } \\
\text { sus hijos por trabajar? } \\
\text { ¿Cuáles? }\end{array}$ & $\begin{array}{l}\text { Indagar sobre las percepciones } \\
\text { que tienen los miembros de su } \\
\text { familia sobre su trabajo y las } \\
\text { situaciones de conflicto que le ha } \\
\text { generado al interior del hogar } \\
\text { por dedicarse a esta ocupación. }\end{array}$ \\
\hline $\begin{array}{l}\text { 4. Conflictos en } \\
\text { la dinámica } \\
\text { familiar y } \\
\text { laboral }\end{array}$ & $\begin{array}{l}\text { ¿Es difícil compaginar su vida familiar y laboral?, ¿Por } \\
\text { qué?, ¿Cuáles son las dificultades o problemas de } \\
\text { trabajar en el deshebrado?, ¿Con quiénes son esos } \\
\text { problemas?, ¿Cómo los resuelve?, ¿Cuáles son los }\end{array}$ & & \\
\hline
\end{tabular}




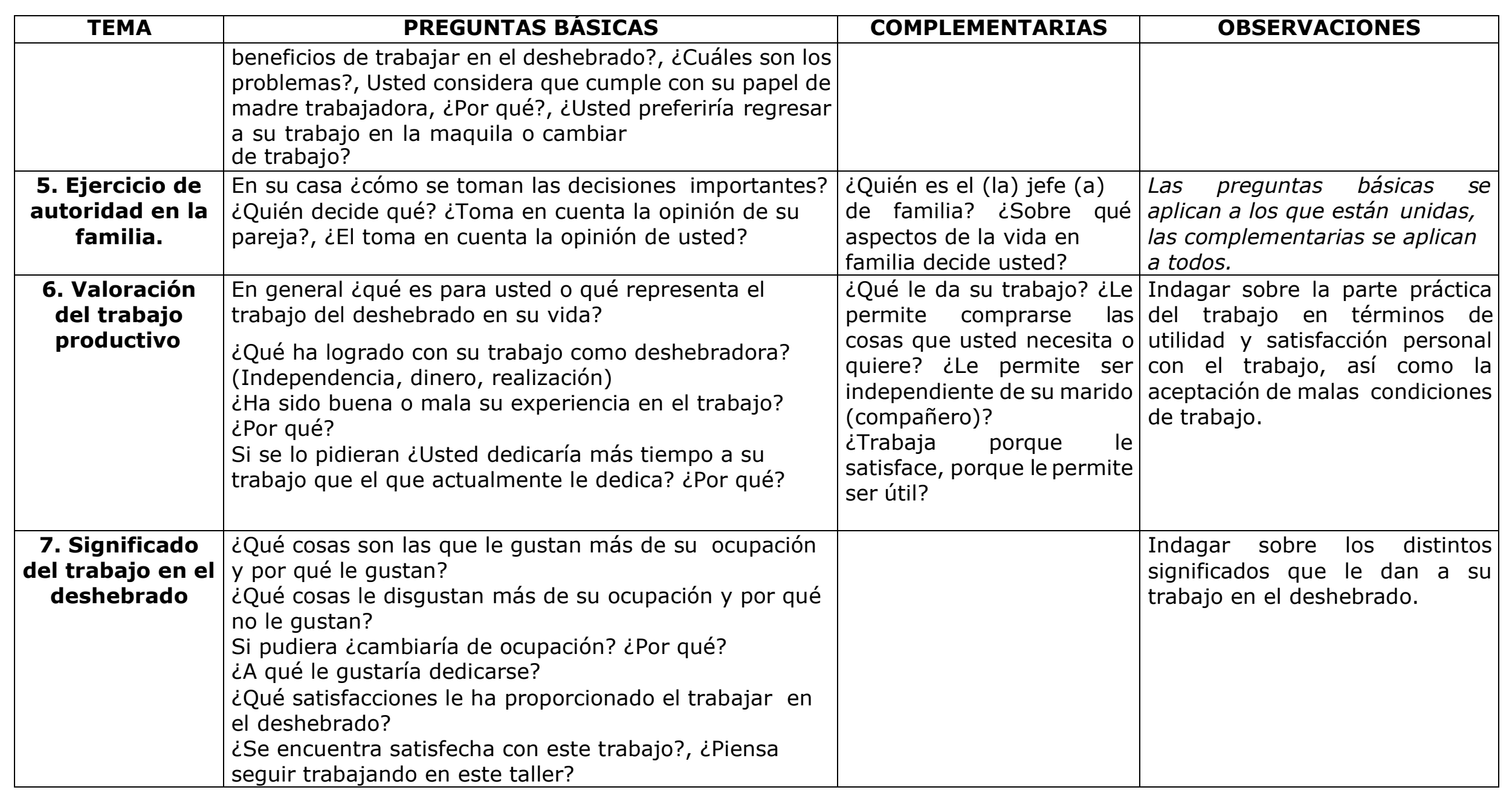


ANEXO 2 CUADROS DE ANÁLISIS DEL CAPÍTULO 3.

\section{Cuadro 1}

Características sociodemográficas

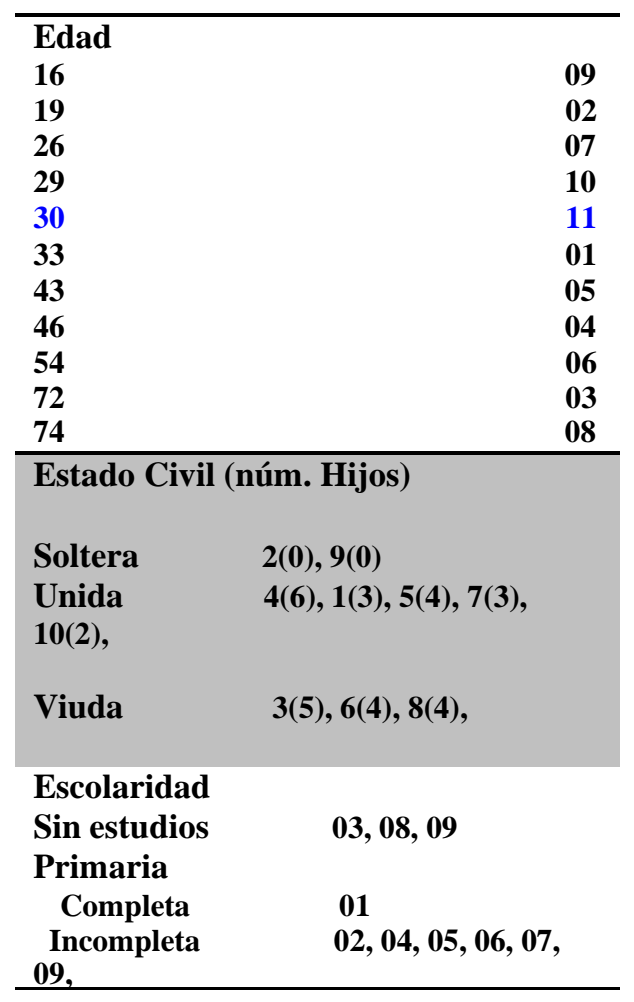

\begin{tabular}{|l|c|}
\hline NOMBRE & CÓDIGO \\
\hline Flora & 01 \\
\hline Eugenia & 02 \\
\hline Carmen & 03 \\
\hline Asunción & 04 \\
\hline Felipa & 05 \\
\hline Aquilina & 06 \\
\hline Ana & 07 \\
\hline Petra & 08 \\
\hline Yolanda & 09 \\
\hline Agustina & 10 \\
\hline Antonio & 11 \\
\hline
\end{tabular}

NOTA: El caso de Antonio solamente fue tomado en cuenta en el cuadro de edad y las trayectorias laborales. 
Cuadro 2

Socialización durante la infancia

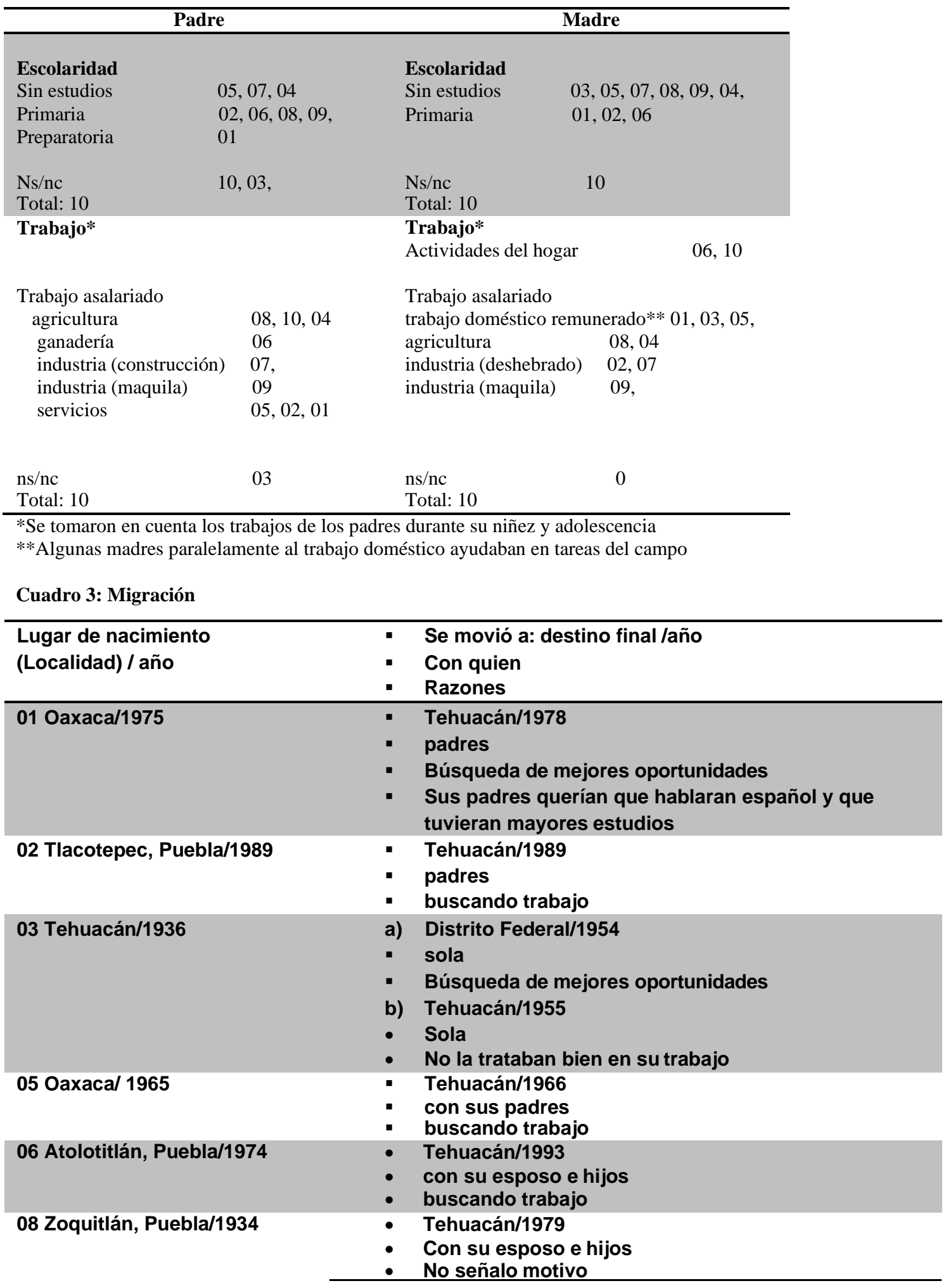


Cuadro 4

Trayectoria laboral por edad, número de empleos y ocupación

\begin{tabular}{|c|c|c|c|c|c|c|c|c|c|c|c|c|}
\hline \multirow[b]{2}{*}{$\begin{array}{c}\text { CÓDIGO/ } \\
\text { Edad }\end{array}$} & \multirow{2}{*}{$\begin{array}{c}\text { Edad } \\
\text { 1er } \\
\text { empleo }\end{array}$} & \multicolumn{11}{|c|}{ Empleos por sector de ocupación } \\
\hline & & $\mathbf{1}^{\mathbf{0}}$ & $\mathbf{2}^{\mathbf{0}}$ & $\mathbf{3}^{\mathbf{0}}$ & $4^{\circ}$ & $\mathbf{5}^{\mathbf{0}}$ & $\mathbf{6}^{\mathbf{0}}$ & $7^{\circ}$ & $\mathbf{8}^{\mathbf{0}}$ & $9^{\circ}$ & $\mathbf{1 0}^{\circ}$ & $\begin{array}{c}\text { Duración } \\
\text { en años }\end{array}$ \\
\hline \multirow[t]{2}{*}{$09 / \mathbf{1 6}$} & \multirow[t]{2}{*}{8} & $\begin{array}{c}3 \\
2000 \\
\end{array}$ & \multirow[t]{2}{*}{$\begin{array}{c}5 \\
2000\end{array}$} & \multirow{2}{*}{$\begin{array}{c}5 \\
2004- \\
2006\end{array}$} & \multirow{2}{*}{$\begin{array}{c}3 \\
2006- \\
2007\end{array}$} & \multirow{2}{*}{$\begin{array}{c}5 \\
2007- \\
2008\end{array}$} & & & & & & \multirow[t]{2}{*}{5} \\
\hline & & $\begin{array}{c}4 \\
2000\end{array}$ & & & & & & & & & & \\
\hline $02 / 19$ & 14 & $\begin{array}{c}1 \\
2003- \\
2004\end{array}$ & $\begin{array}{c}5 \\
2008\end{array}$ & & & & & & & & & 2 \\
\hline \multirow[t]{2}{*}{ (JTM) } & \multirow[t]{2}{*}{14} & \multirow[t]{2}{*}{$\begin{array}{c}1 \\
1996 \\
(1 \mathrm{mes})\end{array}$} & \multirow[t]{2}{*}{$\begin{array}{c}1 \\
1996- \\
1999\end{array}$} & \multirow[t]{2}{*}{$\begin{array}{c}1 \\
1999 \\
(3 \text { meses })\end{array}$} & $\begin{array}{c}1 \\
2001 \\
(8 \text { meses })\end{array}$ & \multirow[t]{2}{*}{$\begin{array}{c}1 \\
2002 \\
(1 \text { mes })\end{array}$} & \multirow[t]{2}{*}{$\begin{array}{c}5 \\
2002\end{array}$} & \multirow[t]{2}{*}{$\begin{array}{c}2 \\
2002- \\
2008\end{array}$} & \multirow[t]{2}{*}{$\begin{array}{c}5 \\
2008\end{array}$} & & & \multirow[t]{2}{*}{10} \\
\hline & & & & & $\begin{array}{c}3 \\
2001 \\
\text { (3 meses) }\end{array}$ & & & & & & & \\
\hline $\begin{array}{l}\text { 10/29 } \\
\text { (JTM) }\end{array}$ & 13 & $\begin{array}{c}4 \\
1992- \\
1996\end{array}$ & $\begin{array}{c}2 \\
2002- \\
2008\end{array}$ & & & & & & & & & 10 \\
\hline $\begin{array}{l}11 / 30 \\
(\mathbf{J T H})\end{array}$ & 11 & $\begin{array}{c}1 \\
1989- \\
1990\end{array}$ & $\begin{array}{c}1 * \\
1990 \\
(20 \text { días })\end{array}$ & $\begin{array}{c}1 \\
1990- \\
1991\end{array}$ & $\begin{array}{c}1 * \\
1991-1993\end{array}$ & $\begin{array}{c}1 \\
1993- \\
2000\end{array}$ & $\begin{array}{c}1 \\
2000 \\
(8 \\
\text { meses })\end{array}$ & $\begin{array}{c}2 \\
2001- \\
2008\end{array}$ & $\begin{array}{c}1 \\
2008\end{array}$ & & & 19 \\
\hline \multirow[t]{2}{*}{$\begin{array}{l}01 / 33 \\
(\text { JTM) }\end{array}$} & \multirow[t]{2}{*}{13} & \multirow[t]{2}{*}{$\begin{array}{c}1 \\
1988- \\
1995\end{array}$} & \multirow[t]{2}{*}{$\begin{array}{c}5 \\
1995 \\
(6 \text { meses })\end{array}$} & $\begin{array}{c}2 \\
1995- \\
2008\end{array}$ & & & & & & & & \multirow{2}{*}{20} \\
\hline & & & & $\begin{array}{c}3 \\
2007= \\
2008\end{array}$ & & & & & & & & \\
\hline $05 / 43$ & 11 & $\begin{array}{c}1 \\
1976- \\
1979\end{array}$ & $\begin{array}{c}1 \\
1979 . \\
1980\end{array}$ & $\begin{array}{c}1 \\
1980- \\
1981\end{array}$ & $\begin{array}{c}1 \\
1981- \\
1982\end{array}$ & $\begin{array}{c}1 \\
1984- \\
1985\end{array}$ & $\begin{array}{c}1 \\
1988 \\
(8 \\
\text { meses })\end{array}$ & $\begin{array}{c}1 \\
1990- \\
1996\end{array}$ & $\begin{array}{c}1 \\
1996\end{array}$ & $\begin{array}{c}1 \\
1996- \\
1997\end{array}$ & $\begin{array}{c}5 \\
1997= \\
2008\end{array}$ & 26 \\
\hline
\end{tabular}




\begin{tabular}{|c|c|c|c|c|c|c|c|c|c|}
\hline \multirow[t]{2}{*}{$04 / 46$} & \multirow[t]{2}{*}{12} & $\begin{array}{c}4 \\
1974- \\
1977\end{array}$ & $\begin{array}{c}4 \\
1977- \\
1978\end{array}$ & $\begin{array}{c}5 \\
1992- \\
1994\end{array}$ & $\begin{array}{c}5 \\
1994- \\
1995\end{array}$ & $\begin{array}{c}5 \\
1995- \\
2005 \\
\text { (Combina } \\
4 \text { talleres) }\end{array}$ & $\begin{array}{c}5 \\
2005- \\
2008\end{array}$ & & \multirow[t]{2}{*}{20} \\
\hline & & \multicolumn{6}{|c|}{$\begin{array}{c}6 \\
1974-2008\end{array}$} & & \\
\hline $06 / 54$ & 7 & \multicolumn{7}{|c|}{$\begin{array}{c}7 \\
1961-2008\end{array}$} & 27 \\
\hline $03 / 72$ & 7 & $\begin{array}{c}4 \\
1943= \\
1954\end{array}$ & $\begin{array}{c}4 \\
1954- \\
1955\end{array}$ & $\begin{array}{c}4 \\
1955- \\
2000\end{array}$ & $\begin{array}{c}5 \\
2000- \\
2008\end{array}$ & & & & 65 \\
\hline $08 / 74$ & 12 & $\begin{array}{c}4 \\
1946= \\
1951\end{array}$ & $\begin{array}{c}4 \\
1951\end{array}$ & $\begin{array}{c}5 \\
1998- \\
2008\end{array}$ & & & & & 15 \\
\hline
\end{tabular}

1 Maquila de confección de ropa 2 Taller de deshebrado propio 3 Comercio y servicios 4Trabajo doméstico 5 Talleres de deshebrado 6 Lavar ropa ajena 7 Petates/sombreros tejidos de palma

*Cierre de maquila

JTH: Jefe de taller -hombre

JTM: Jefa de taller-mujer

Las líneas dobles se refieren a las interrupciones.

Cuando en una celda se encuentran dos trabajos, nos referimos a la simultaneidad. 
LA DINAMICA LABORAL $Y$

PAMILIAR DE LAS TRABAJADORAS

SUBCONTRATADAS A DOMICILIO

EN TEHUACAN, PUEBLA
En México, D.F. se presentaron a las 11:00 horas del día 10 del mes de diciembre del año 2009 en la Unidad Iztapalapa de la Universidad Autónoma Metropolitana, los suscritos miembros del jurado:

DR. IGNACIO GATICA LARA

DRA. MA.ELIZABETH ROSA ZAMORA RAMTREZ

DR. JOSE LUIS TORRES FRANCO

Bajo la presidencia del primero $y$ con carácter de Secretario el altimo, se reunieron para proceder al Examen de Grado cuya denominacion aparece al margen, para la obtención del grado de

MAESTRA EN ESTUDIOS SOCIALES (ESTUDIOS LABORALES)

DE: LOURDES NANCY MARTINEZ MARQUEZ

$\%$ de acuerdo con el artículo 78 fracción III del Reglamento de Estudios Superiores de la Universidad Autonoma Metropolitana, los miembros del jurado resolvieron:

\section{Cerrobar}

Acto continuo, el presidente del Jurado comunico a la interesada el resultado de la evaluación $y$, en caso aprobatorio, le fue tomada la protesta.
UIC. JUUOO CESARDE LARU ISASSI DIRECTOR DE SISTEH ES ESCOLARES
LOURDES NANCY MARTINEZ MARQUEZ ALUMNA

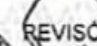

15

$1 \mathrm{~h}$ DIRECTOR DE SISTEKAS ESCOLARES
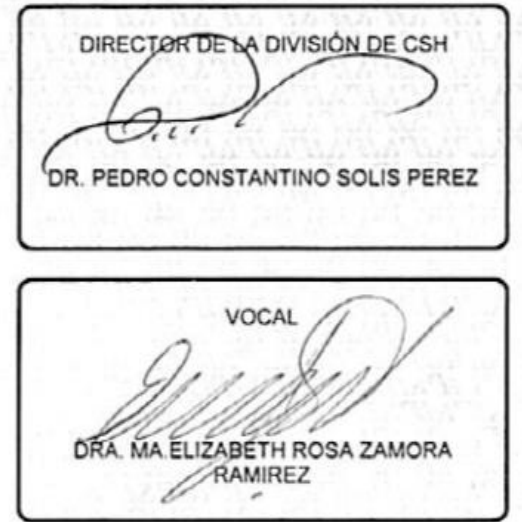

PRESIDENTE

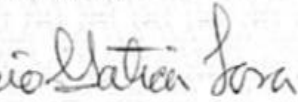

DR. IGNACIO GATICA LARA

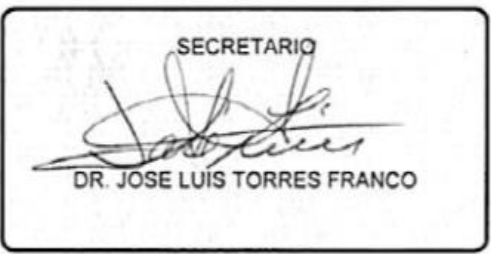

